\title{
STRENGTHENING METHODOLOGY FOR LIGHTLY REINFORCED CONCRETE FRAMES-I
}

\author{
L.T. Phan \\ D.R. Todd \\ H.S. Lew
}

Building and Fire Research Laboratory

Gaithersburg, Maryland 20899

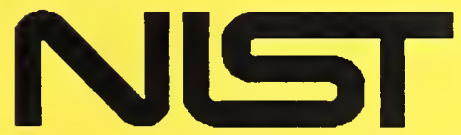

United States Department of Commerce Technology Administration National Institute of Standards and Technology 



\title{
STRENGTHENING METHODOLOGY FOR LIGHTLY REINFORCED CONCRETE FRAMES-I
}

\author{
L.T. Phan \\ D.R. Todd \\ H.S. Lew
}

February 1993

Building and Fire Research Laboratory

National Institute of Standards and Technology

Gaithersburg, MD 20899

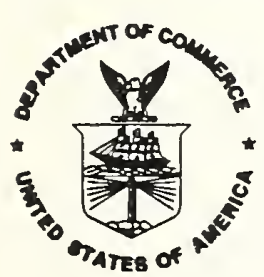

U.S. Department of Commerce

Ronald H. Brown, Secretary

National Institute of Standards and Technology

Raymond G. Kammer, Acting Director 



\section{ABSTRACT}

An analytical method for evaluating the inelastic dynamic structural response of lightly reinforced concrete $(\mathrm{RC})$ frames strengthened by infilled shear walls was developed. This method consists of the development of hysteresis failure models for existing and strengthened RC frames and the incorporation of the models into computer program IDARC for use in analytical study. The hysteresis models were developed by, first, using the system identification techniques to characterize the load-deformation histories of fifty-five RC frame tests in terms of the stiffness degradation parameter $\alpha$, the strength degradation parameter $\beta$, and the pinching parameter $\gamma$. Next, multi-variable regressions were performed to relate $\alpha, \beta, \gamma$ as functions of the specimen's material and geometric properties and reinforcement parameters. The empirical expressions resulted from these regressions are the hysteresis failure models. The models were validated by analyzing a one-story, one-bay infilled frame, tested by Aoyama et al., and a three-story, one-bay infilled frame tested by Higashi et al. The results of the analyses showed that (1) hysteresis models developed using one-story, one-bay frames can be incorporated into IDARC for the analysis of frames with more than one-story height, and (2) reasonable predictions of structural behavior, both in terms of ultimate load capacity and in absorbed energy on the per cycle basis, can be achieved using the hysteresis models. Thus, in the present form, the hysteresis models can be used in parameter study to assist in the design of strengthening of RC frame structures.

Keywords: Analytical; reinforced concrete; dynamic analysis; experimental; frames; hysteresis models; infilled walls; system identification; multi-variable regression. 


\section{TABLE OF CONTENTS}

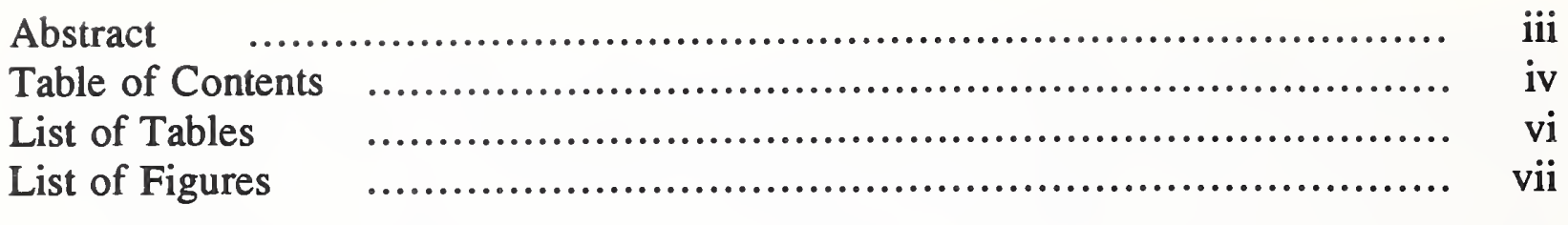

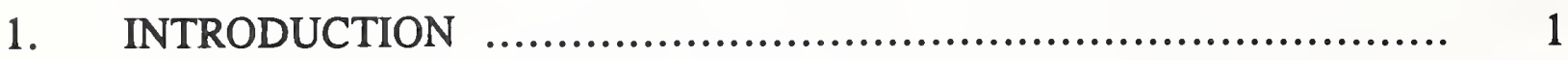

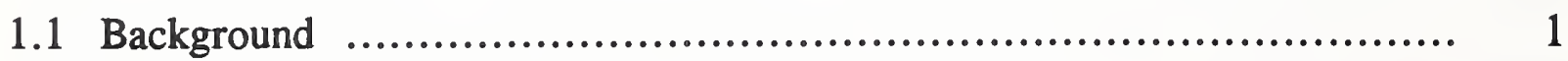

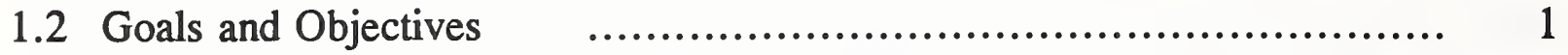

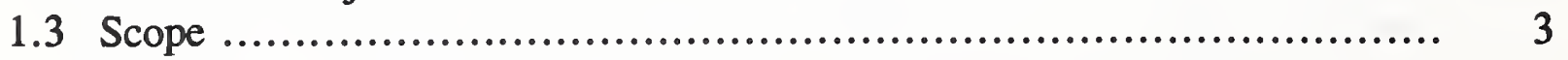

2. DISCUSSION OF REHABILITATION SCHEMES $\quad \ldots . \ldots \ldots \ldots \ldots \ldots \ldots . . . . . . . .4$

2.1 Infill Walls ............................................................... 6

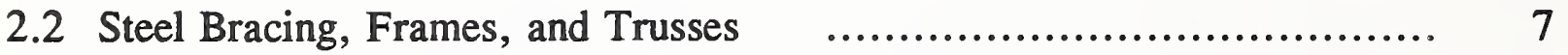

2.3 Column Strengthening $\quad$.................................................. 8

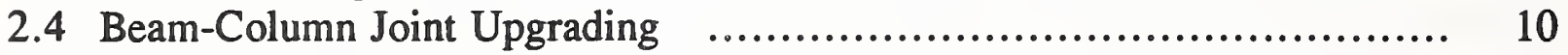

2.5 Collection of Data ......................................................... 11

3. INELASTIC ANALYSIS OF REINFORCED CONCRETE

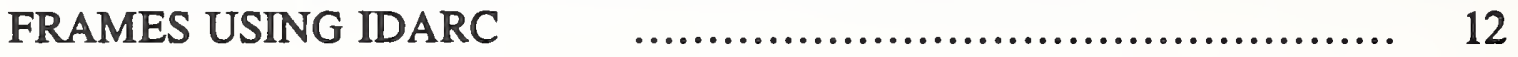

3.1 Introduction to Program IDARC ......................................... 12

3.2 Three-Parameter Hysteresis Model $\quad$................................... 13

4. DEVELOPMENT OF HYSTERESIS MODELS FOR R/C FRAMES .... 16

4.1 Relevant Experimental Programs $\quad$................................... 16

4.1.1 Aoyama et al. $\quad$............................................... 17

4.1.2 Kahn ................................................................ 20

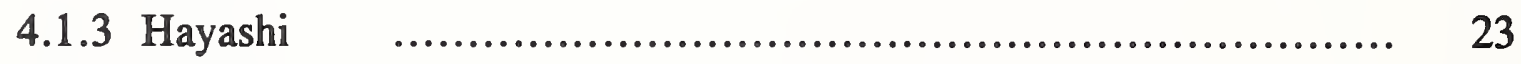

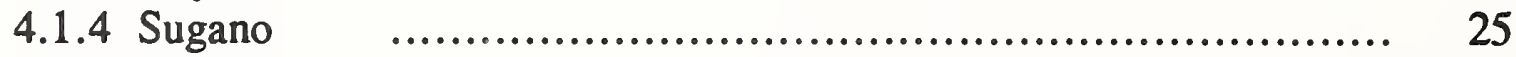

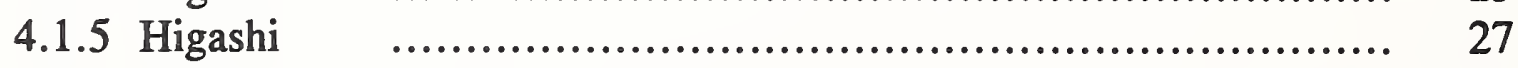

4.1.6 Corley $\quad$........................................................ 29

4.1.7 Ogata et al. ...................................................... 31

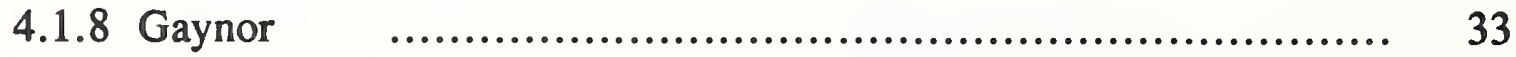

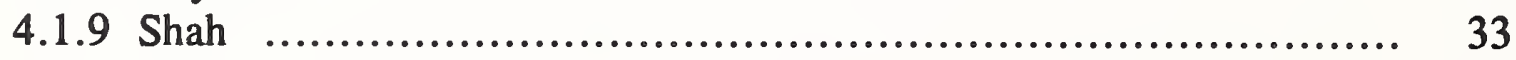

4.2 Development of Three-Parameter Hysteresis Models ...................... 36

4.2.1 System Identification of Hysteresis Parameters $\quad$............. 36 
4.2.2 Empirical Expressions for Hysteresis Parameters $\quad$............... 37

4.2.2.1 Hysteresis Model for Existing Frame ............... 42

4.2.2.2 Hysteresis Model for Frames with CIP Infilled

Walls ................................................... 44

4.2.2.3 Hysteresis Model for Frame Infilled

by Precast Panels .................................... 46

4.2.2.4 Hysteresis Model for Monolithic

Wall-Frame Construction ............................... 48

4.2.3 Comparison between the Predicted and Experimental Hysteresis

Parameters

5. VALIDATION OF HYSTERETIC MODELS FOR USE WITH IDARC .. 52

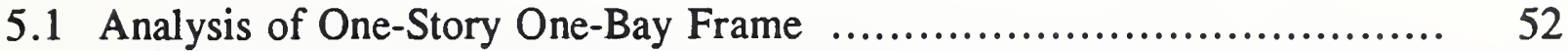

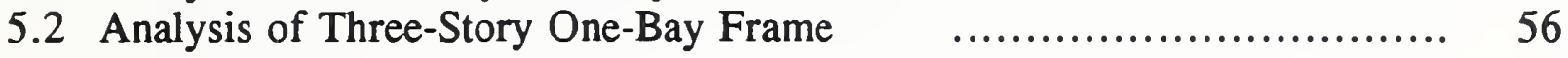

6. SUMMARY, CONCLUSIONS, AND RECOMMENDATION ........... 59

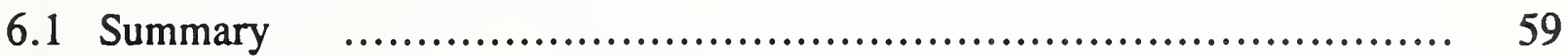

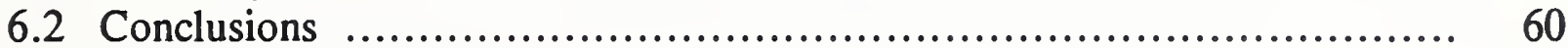

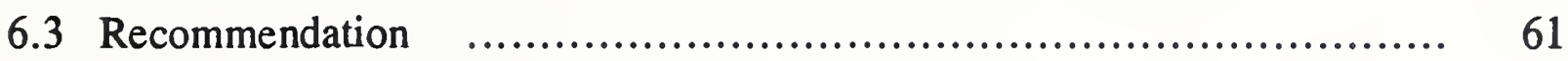

7. REFERENCES

Appendix A. Definitions of Variables Used in Regression Analysis $\quad$........ 68

Appendix B. Test Specimen's Parameters $\quad$..................................... 75

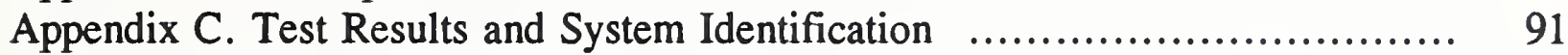




\section{LIST OF TABLES}

Table No.

Page

4.1 Summary of Aoyama's Test Specimens.................................. 20

4.2 Summary of Kahn's Test Specimens....................................... 21

4.3 Summary of Hayashi's Test Specimens................................. 23

4.4 Summary of Sugano's Test Specimens................................. 25

4.5 Summary of Higashi's Test Specimens.................................. 27

4.6 Summary of Corley's Test Specimens.................................... 29

4.7 Summary of Ogata's Test Specimens................................... 31

4.8 Summary of Gaynor's Test Specimens................................ 33

4.9 Summary of Shah's Test Specimen.................................... 34

4.10 Estimated Hysteresis Parameters from System Identification............... 41

4.11 Regression Coefficients for Hysteresis Model for Existing Frame.......... 43

4.12 Regression Coefficients for Hysteresis Model for Cast-In-Place Infilled Frame................................................................... 45

4.13 Regression Coefficients for Hysteresis Model for Precast Panel Infilled Frame.

4.14 Regression Coefficients for Hysteresis Model for Monolithic Wall-Frame Construction. 


\section{LIST OF FIGURES}

Figure No.

2.1 Relative Shear Capacities of RC Frame Strengthened by Different Techniques (After Sugano et al. ${ }^{2}$ ).

3.1 Three-Parameter Hysteresis Models (After Park, Reinhorn and Kunnath)..

4.1 Geometry, Dimensions, and Reinforcement Pattern of Aoyama's Test Specimens

4.2 Hysteresis Behavior of Aoyama's Test Specimens

(a) CIP Infilled Frame C2005-III............................................ 19

(b) CIP Infilled Frame C2015-A....................................... 19

(c) Monolithic Wall-Frame P2005-A................................... 19

(d) CIP Infilled Frame M2005........................................ 19

4.3 Geometry, Dimensions and Reinforcement Patterns of Kahn's Test Specimen................................................... 22

4.4 Hysteresis Behavior of Kahn's Test Specimens

(a) CIP Infilled Frame SP3.............................................. 22

(b) Frame Infilled by Precast Panels SP5................................. 22

4.5 Geometry, Dimensions, and Reinforcement Patterns of Hayashi's Test Specimen..................................................... 24

4.6 Hysteresis Behavior of Hayashi's Test Specimens

(a) CIP Infilled Frame W-5........................................... 24

(b) CIP Infilled Frame W-6............................................ 24

4.7 Geometry, Dimensions, and Reinforcement Patterns of Sugano's Test Specimen.

4.8 Hysteresis Behavior of Sugano's Test Specimens

(a) Monolithic Wall-Frame Construction W-40W........................ 26

(b) CIP Infilled Frame W-HA........................................ 26

4.9 Geometry, Dimensions, and Reinforcement Patterns of Higashi's Test Specimen. 
4.10 Hysteresis Behavior of Higashi's Test Specimens

(a) CIP Infilled Frame 2-PW ........................................... 28

(b) Multiple Precast Panel Infilled Frame 4-C3C....................... 28

4.11 Geometry, Dimensions, and Reinforcement Patterns

of Corley's Test Specimen................................................... 30

4.12 Hysteresis Behavior of Corley's Test Specimens

(a) Monolithic Wall-Frame Specimen B5.............................. 30

(b) Monolithic Wall-Frame Specimen B8............................ 30

4.13 Geometry, Dimensions, and Reinforcement Patterns of Ogata's Test Specimen

4.14 Hysteresis Behavior of Ogata's Test Specimens

(a) Monolithic Wall-Frame Specimen K2 ............................. 32

(b) Monolithic Wall-Frame Specimen K5........................... 32

4.15 Geometry, Dimensions, and Reinforcement Patterns of Gaynor and Shah's Test Specimen.

4.16 Hysteresis Behavior of Gaynor's Test Specimens

(a) Shotcrete Infilled Frame with Window Opening W..................... 35

(b) Shotcrete Infilled Frame with Door Opening D....................... 35

4.17 Hysteresis Behavior of Shah's Specimen SP1........................... 35

4.18 System Identification of Experimental Results

(a) Load-Deformation Characteristics of Specimen C2005-III.............. 39

(b) Absorbed Energy Histograms for Specimen C2005-III................... 39

(c) Load-Deformation Characteristics of Specimen K3..................... 39

(d) Absorbed Energy Histograms for Specimen K3........................ 39

(e) Load-Deformation Characteristics of Specimen 5-F2 .................. 40

(f) Absorbed Energy Histograms for Specimen 5-F2.................... 40

(g) Load-Deformation Characteristics of Specimen W...................... 40

(h) Absorbed Energy Histograms for Specimen W........................... 40

4.19 Comparisons of Predicted versus Experimental Hysteresis Parameters

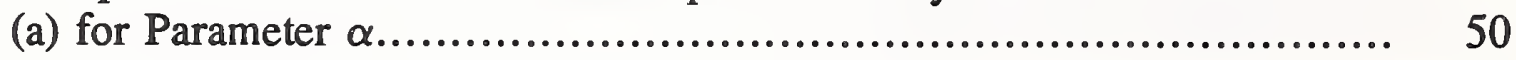

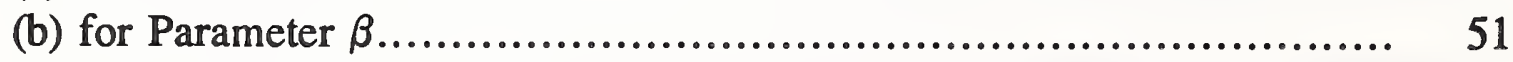

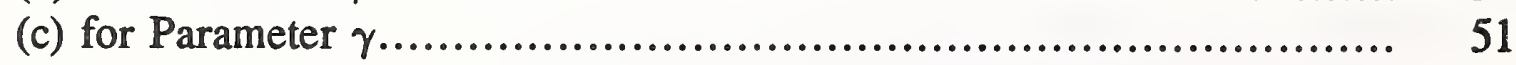


5.1 Comparisons of Experimental and Analytical Hysteresis

Behavior for Aoyama's One-Story, One-Bay Frame C2005-I

(a) Experimental......................................................... 54

(b) IDARC's Prediction Using Default Hysteresis Parameters.............. 54

(c) IDARC's Prediction Using Hysteresis Parameters from Models Developed in This Study.............................................. 54

5.2 Comparisons of Experimental and Analytical Absorbed Energy on the Per Cycle Basis for Aoyama's Frame C2005-I...................... 55

5.3 Comparisons of Experimental and Analytical Hysteresis Behavior for Higashi's Three-Story, One-Bay Frame 79-3PW

(a) Experimental....................................................... 57

(b) IDARC's Prediction Using Default Hysteresis Parameters............... 57

(c) IDARC's Prediction Using Hysteresis Parameters from Models Developed in This Study............................................... 57

5.4 Comparisons of Experimental and Analytical Absorbed Energy on the Per Cycle Basis for Higashi's Frame 79-3PW 



\section{STRENGTHENING METHODOLOGY \\ FOR LIGHTLY REINFORCED CONCRETE FRAMES}

\section{INTRODUCTION}

\subsection{Background}

Forty-six of the fifty United States are vulnerable to the effects of strong earthquakes. A primary focus of earthquake engineering research in past decades has been on developing standards for seismic-resistant design and construction of new buildings. Much progress has been made in this area; by late 1991 all three major model building codes had adopted up-to-date seismic design requirements.

Efforts are now underway to develop similar standards for the seismic rehabilitation of existing buildings. The population of buildings that were designed and built without adequate consideration of seismic safety far exceeds that of buildings constructed with the benefit of a modern understanding of earthquake resistance. In areas where earthquakes occur infrequently, the building stock is especially vulnerable because technological advances that were adopted in high seismic regions often were not recognized as being necessary in seismically less active areas.

Unless properly designed and detailed, reinforced concrete (RC) buildings are vulnerable to earthquake ground shaking. The relatively large mass of concrete buildings creates high inertial forces. Catastrophic failures that occurred in the 1971 San Fernando, 1985 Mexico City, and 1988 Armenia earthquakes, among others, illustrate the vulnerability and potential for large loss of life in older or poorly designed and built RC buildings.

NIST has initiated a multiyear effort to develop rehabilitation guidelines for RC buildings. In previous years, in cooperation with researchers at Cornell University, a nonlinear dynamic analysis program for reinforced concrete frames (IDARC) was improved, and experimental tests of beam-column joint strengthening techniques were performed.

\subsection{Goals and Objectives}

In order to reduce the risk associated with $\mathrm{RC}$ structures that were designed and built without adequate consideration of seismic safety, an accurate understanding of the behavior of such structures under seismic loads must be developed. Similarly, the effectiveness of proposed strengthening schemes must be assessed. Information collected after actual earthquakes can provide preliminary insights. Experimental studies provide additional valuable information. However, analytical and computational methods are the 
most time and cost effective methods for assessing large numbers of structures and strengthening schemes. The goals of the NIST existing buildings research project is to develop reliable tools that can be used to:

- accurately evaluate the performance of existing RC buildings under credible earthquake excitation,

- identify the critical weaknesses in the existing structures,

- reliably model strengthening schemes, and assess the effectiveness of different strengthening schemes.

- develop guidelines for strengthening RC buildings.

Increasingly sophisticated nonlinear dynamic analysis programs capable of analyzing the performance of RC structures under seismic loads are being developed. To obtain sufficiently accurate analyses of actual behavior, the hysteresis rules which characterize the behavior of RC structures under cyclic loads must be identified and incorporated into the analysis programs. The hysteretic behavior of strengthened elements must be similarly determined and incorporated.

Once reliable analytical techniques have been developed, the functional relationships between experimental load-displacement relationships and the physical characteristics of structural elements (such as geometric dimensions, material properties, and reinforcement patterns) can be determined through sensitivity analysis of critical parameters. Establishing sufficient functional relationships will make it possible to analyze the cyclic behavior of any RC structure, strengthened or unstrengthened.

Ultimately, these analysis techniques can be used to develop a reliable body of information about the efficacy of various retrofit techniques for common building types and structural systems. This information can be consolidated into guidelines for use by design engineers nationwide.

The objectives of this phase of the research were:

- to develop accurate hysteretic models using existing experimental data to describe the actual behavior under cyclic loads of existing RC frames with and without strengthening elements.

- to validate the accuracy of the hysteretic models by comparing predicted responses to existing experimental data.

- to develop tentative recommendations for effective applications of strengthening techniques. 


\subsection{Scope}

The scope of this report is limited to the development of analytical methods for evaluating the structural performance of lightly reinforced concrete frames strengthened with infilled shear walls. The report is organized as follows:

- Chapter 2 describes commonly used and experimentally documented retrofit techniques.

- Chapter 3 presents information on the analysis program IDARC.

- Chapter 4 describes the selection of the experimental data sets for use in this study from among those amassed in a literature search of sources worldwide, the techniques used to identify hysteresis parameters for use with IDARC that accurately describe the experimental data, and the development of generally applicable hysteresis models using statistically based regression analysis techniques.

- Chapter 5 describes the validation of the models and their incorporation into IDARC.

- Chapter 6 summarizes the study and presents conclusions and recommendations.

- Chapter 7 lists the references used in this study.

Types of infilled shear walls considered include cast-in-place concrete and Multiple Precast concrete panels. 


\section{DISCUSSION OF REHABILITATION SCHEMES}

Existing literature on seismic strengthening of $\mathrm{RC}$ frame structures was reviewed to identify common retrofit techniques and to locate available experimental data. This chapter presents general information about retrofit issues and techniques, and describes the assessment of available data which led to the selection of specific strengthening schemes for investigation in this project.

Seismic retrofit of existing buildings is particularly challenging because of the interrelated effects of any change to a structural system. For example, increasing strength generally results in a corresponding increase in stiffness, reducing the fundamental period of the building, which in turn results in an increase in the seismically-induced lateral forces. If new elements have significant mass, earthquake induced forces will be increased proportionally. Existing foundations may be insufficient to support massive new elements or resist overturning forces induced by new structural systems. For example, attempts to enhance the shear capacity of columns must be carefully designed to avoid increasing their flexural stiffness, which would increase the shear forces on the column. Therefore, "cookbook" solutions to rehabilitation problems would not be realistic. However, general recommendations and rehabilitation guidance can be developed based on research and experience, with the caveat that the appropriateness of the guidelines must always be assessed in the context of the specific building being retrofit.

The seismic capacity of existing $\mathrm{RC}$ frame buildings can be improved by

- increasing the lateral strength,

- improving the ductility, or

- using a combination of strength and ductility enhancements.

Figure 2.1, after Sugano and Fujimura ${ }^{2}$, generically illustrates how these approaches affect a structure's force-displacement curve. The trends illustrated in Figure 2.1 are supported by experimental results obtained by Sugano and by other researchers. In general, strength is increased by adding new elements; ductility is enhanced by reinforcing existing elements. ${ }^{28}$ Rehabilitation schemes for concrete frame buildings include:

- adding infilled walls or steel cross-bracing in frame openings

- adding new continuous shear walls or braces through existing floor slabs between existing column lines

- adding buttresses or frames at the building exterior

- increasing the thickness of existing walls or infilled walls

- adding wing walls to columns

- jacketing existing columns and/or beams 
- strengthening existing joints

The success of any rehabilitation project depends, of course, on adequate detailing of connections between the new and existing elements.

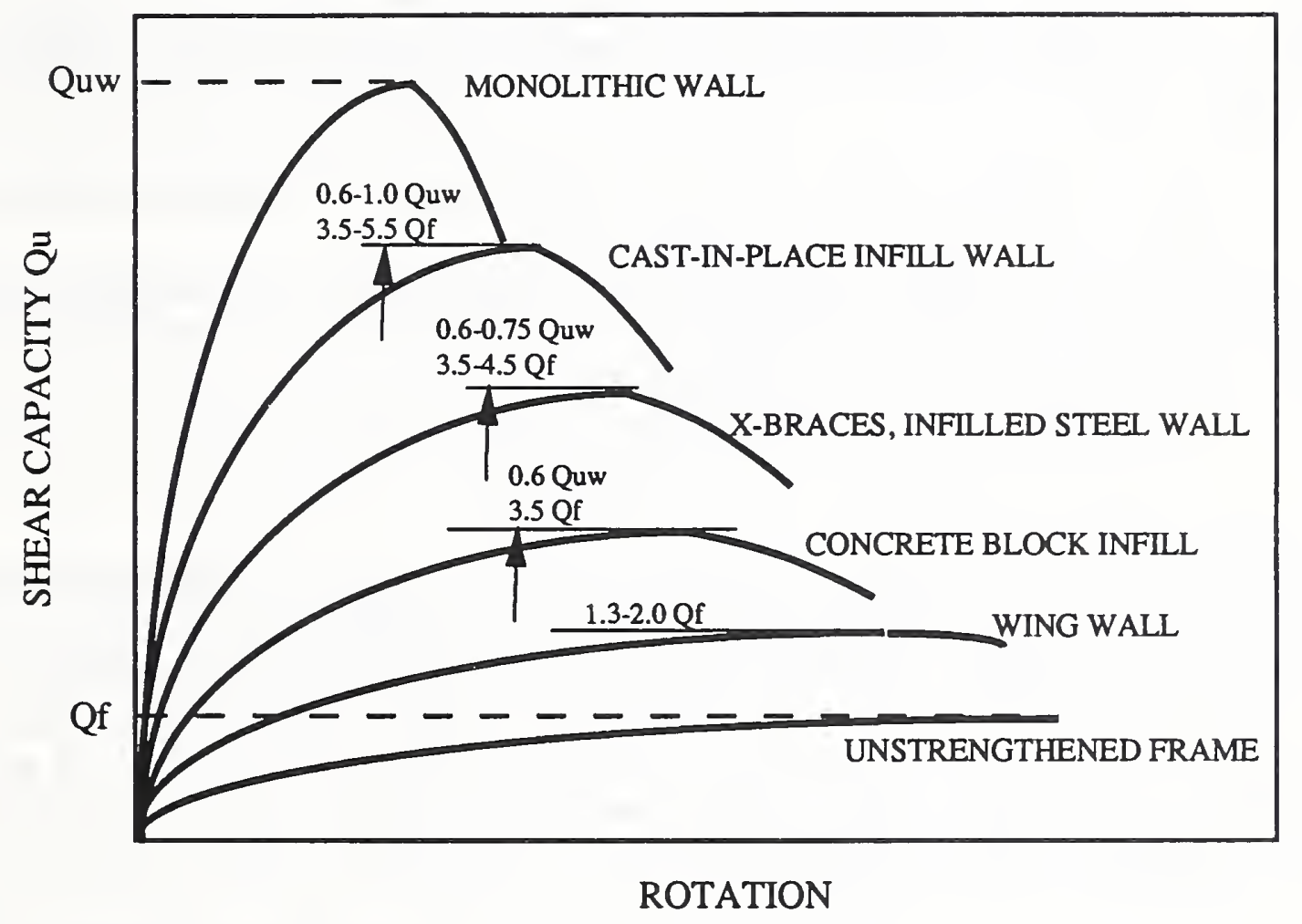

Quw: Ultimate Shear Capacity of Monolithic Wall-Frame Construction Qf : Ultimate Shear Capacity of Unstrengthened Frame.

Figure 2.1 Relative Shear Capacities of RC Frame Strengthened By Different Techniques (After Sugano et al. ${ }^{2}$ ) 
Four experimentally-proven techniques for seismic strengthening of RC structures are described below. Most experimental test programs evaluate the behavior of single frame units or single bays to assess the potential effectiveness of various proposed retrofit schemes. Very little data are available on the effectiveness of these schemes in complete structures, and almost no specific design guidance has been proposed. The intent of the NIST research effort is to make use of the available experimental data, or if necessary to conduct experimental study, to develop valid analytical models which can assess the effectiveness of retrofit schemes in prototypical and actual buildings. Ultimately, design guidelines can be developed using the results of sufficient analytical studies.

\subsection{Infilled Walls}

Adding wall elements to RC frames by infilling the frame cells can add strength and stiffness to a building. Infilled walls that have been experimentally tested have been constructed using:

- cast-in-place concrete, connected to the original construction with dowels, epoxy, or wedge anchors; or shear keys,

- precast concrete, using either single or multiple panels, connected by welding to new steel anchors in the original construction,

- masonry, either brick or concrete block,

- steel panels, connected by welding to new anchors, or

- pneumatically applied concrete (shotcrete).

Rigid infilled walls act primarily as shear walls. Because of the relative rigidity of the infilled bays, the demand on the existing frame is substantially reduced. This is especially true for buildings with rigid diaphragms. ${ }^{33}$ Frames with less rigid infill, such as unreinforced masonry often used to form exterior walls in original construction, will behave like braced frames with the infill acting as a compression strut. ${ }^{33} \mathrm{~A}$ test of unreinforced brick masonry infill by Krause and Wight suggests that this method of infill can lead to unstable hysteretic behavior. ${ }^{14}$

Tests of solid CIP concrete infilled walls demonstrate that the strength and stiffness of the retrofit structure approaches that of a monolithically cast wall (see Figure 2.1). For CIP infilled walls, once maximum strength is reached, strength degradation is moderate, but not abrupt. The method of anchoring the infilled wall to the existing frame has some effect on behavior, but in general, all tests reviewed in the present literature search showed substantial increases in strength and stiffness, regardless of anchoring technique used. Tests of frames infilled with precast concrete panels show that with this technique the retrofit frame attains slightly less than half the strength of the monolithic wall. As strength levels decrease, the rate of strength degradation after the maximum load is reached also decreases, i.e. the ductility increases. In tests by Sugano and Fujimura ${ }^{2}$, a frame retrofit with reinforced concrete block masonry infill (using a Japanese butterfly 
shape not commonly available in this country) acquired over half the strength of a monolithically cast wall. A study of the effects of concrete masonry infill by Zarnic and Tomazevic, ${ }^{44,45}$ as part of a US-Yugoslav joint research effort, reported significant increases in lateral resistance and stiffness over the bare frame response. Studies in this country by Klingner and Bertero ${ }^{20}$, and Brokken and Bertero ${ }^{27}$, have produced similar results. A very limited amount of information on pneumatically applied infill exists. Tests by Gaynor ${ }^{18}$ showed that shotcrete infill did increase strength, but no comparisons to monolithically cast walls were made.

Openings for doors, windows, mechanical/electrical conduits, or other needs can reduce the effectiveness of infilled walls. A small number of experiments have examined the effect of openings in infilled walls. ${ }^{4,16,18}$

Partial walls added adjacent to the column lines are known as wing walls. This rehabilitation method is intermediate between full infill and column strengthening. The relative levels of ductility and strength increases are dependent on the proportions and detailing of the original and strengthened elements.

Among the practical problems associated with designing effective infilled walls is providing sufficient anchorage to ensure good vertical continuity in multi-story buildings. Some engineers have proposed schemes which add continuous multi-story CIP walls through holes cut in the floor slabs on lines adjacent to, rather than directly on, the column lines in an attempt to avoid this problem. ${ }^{41}$

Designers using infilled walls must consider uplift that may be created in the infilled bays. Foundations may require re-examination and strengthening due to the newly created overturning forces and the added weight of the infill. Drag struts or collectors may be needed to transfer diaphragm forces to the new shear wall elements.

Adding infilled walls can create significant functional changes which must be considered when evaluating potential rehabilitation schemes. Loss of windows, interrupted travel paths, and aesthetic changes to the building interior and exterior are common problems with most rehabilitation schemes.

\subsection{Steel Bracing, Frames, and Trusses}

Steel bracing, frames, or trusses can be added to existing $\mathrm{RC}$ frame buildings to supplement the existing lateral force resisting system. Steel members can be inserted in frame openings to enhance the ductility and strength of the existing concrete frame. Complete steel structural systems which are continuous through the floor slabs or attached to the building exterior can be designed to essentially replace the existing lateral force resisting system. These schemes typically require the addition of collectors to transfer the load from floor slabs to the new frame. 
Sugano and Fujimura ${ }^{2}$ strengthened and tested identical frames using a variety of infilling and bracing techniques. They found that steel bracing provided a moderate increase in strength compared to the increases provided by CIP solid infill. However, the steel system did provide substantial ductility and energy absorption capacity. For simple cross bracing, Sugano found that connections to the concrete were the vulnerable link in the system. Goel and Lee ${ }^{15}$ tested a rehabilitation technique utilizing a complete steel truss inserted into the frame opening. They found that the horizontal and vertical steel members acted as both truss members and as supplements to the moment resistance of the concrete frame, this despite the fact that no shear connectors were used on the vertical members. Apparently by using truss inserts the connection problems associated with cross bracing are minimized. Higashi et al. ${ }^{4}$ tested steel bracing, trusses, and moment frames inserted in the frame opening and had similar results.

Jones and Jirsa ${ }^{22}$ tested a two-thirds scale model of a concrete frame building retrofit with a concentrically braced steel frame attached to the exterior of the building and designed to carry the entire seismic load. They found that the system greatly improved the performance of the building and protected the concrete columns from shear failure, even after buckling of the steel frame. However, weld failures and construction problems pointed out the need for high quality workmanship and careful consideration of constructability as details are developed.

Functional changes created by steel braces and frames (loss of windows, alteration of traffic patterns, etc.) are similar to those caused by infilling. Diagonal elements can be challenging to incorporate into an existing building in a visually pleasing manner. If elements are added to the building exterior, disruption to building occupants during construction can be minimal.

\subsection{Column Strengthening}

Inadequate ductility of the columns is frequently found to be the weak link in the seismic resistance of a RC frame building. Column deterioration, due to insufficient shear strength and lack of core confinement, can cause abrupt, catastrophic failures of entire stories or entire buildings. Building configurations that can exacerbate the problem include soft and weak story designs; short and "captured" columns; and weak columnstrong beam configuration.

Detailing requirements for new structures call for closely spaced transverse reinforcement in the regions of plastic hinging in order to provide ductile rather than brittle behavior under lateral loads. Most column strengthening techniques add transverse reinforcement in an attempt to improve ductility. Column strengthening techniques that have been experimentally studied include:

- encasing the column in steel plates or pipes and filling the gap with grout, 
- attaching tightly fitted steel bands or straps around the column,

- enlarging the column with additional reinforced concrete, using either welded wire fabric or closely spaced ties for transverse reinforcement, and either pneumatically applied or CIP concrete.

These techniques are often generically termed "jacketing". Where the flexural capacity of the column is adequate, gaps are left at top and bottom of the jacketing to avoid increasing the flexural capacity and related induced shear forces. Testing programs by Hayashi et al. ${ }^{3}$ Nene, ${ }^{47}$ and Bett et al ${ }^{24}$ have verified the ability of these techniques to strengthen and stiffen columns.

Jacketing columns creates many of the same construction and occupant dislocation problems as does infilling frames. However, permanent disruption of traffic flow, loss of window space, and other major changes in building function will not occur.

Anticipating public demand for immediate strengthening of structures following earthquake forecasts, $\mathrm{Kahn}^{46}$ investigated three quick and simple jacketing techniques: strapping the column with steel packaging bands, bolting on steel U-clamps, and hammering a plain steel rod spirally around the column. Testing showed that all three techniques greatly increased the ductility. of the columns. Because the steel is not enclosed in concrete, these easy to install schemes are aesthetically unpleasing. Architectural coverings could solve this problem.

A rehabilitation scheme investigated by Roach and $\mathrm{Jirsa}^{23}$ consisted of casting new reinforced concrete piers around three sides of the columns at the exterior of a building. The prototype tested was typical of an architectural style widely used in the 1950's and 1960's: a reinforced concrete frame with deep spandrel beams and windows filling the remaining openings. With this retrofit scheme, the new piers partially filled the window openings. Dowels were anchored into the existing concrete using epoxy to achieve monolithic behavior of the old and new concrete. This technique is intended to increase both flexural and shear strength of the columns, and provide continuity in the new elements over the entire height of the building. Testing showed that the scheme was successful in shifting the mode of failure in the frame from shear in the columns to flexure in the beams. The new piers are aesthetically acceptable even though they change the visual impact of the building. Because the new elements are on the exterior of the building, disruption during construction may be minimal, depending on whether the existing windows can be left in place.

Adding wing walls adjacent to columns, discussed in the section on infilled walls, can provide benefits similar to the piers described above. 


\subsection{Beam-Column Joint Upgrading}

In theory, improving the strength and/or toughness of the beam-column joints in a concrete frame will improve the overall ductility of the building. Although many experimental studies of the behavior of typical interior and exterior joints under cyclic loads have been done, there has been very little experimental testing of joint strengthening techniques. In an attempt to partially fill this gap, NIST, in an earlier phase of this multi-year existing concrete buildings research program, carried out a joint study at Cornell University to design, construct, and test several joint strengthening techniques.

Following the 1985 Mexico earthquake, Alcocer and Jirsa ${ }^{42}$ tested joint strengthening. The scheme they used required perforating the slab in order to construct a steel and concrete jacket around the joint, columns, and in some cases, beams. In addition to longitudinal bars and transverse steel around the jacketed columns and beams, the retrofit scheme included a welded steel frame of angles and straps intended to confine the concrete in the joint. They found that the technique enabled them to change the behavior of the specimens from weak column-strong beam to strong column-weak beam. They state that the placement of forms and concrete was not difficult, but it did require "intensive labor and artful detailing that might be uneconomical for U.S. practice."

The NIST-Cornell study, reported by Beres et al. ${ }^{43}$ investigated the behavior of two simple, inexpensive, easy to implement rehabilitation schemes. For interior joints, the retrofit was designed to prevent the pullout of discontinuous bottom beam reinforcement. Steel channel sections were bolted into the bottom surfaces of beams on each side of the joint, and connected by steel bars welded to the channels. Testing under cyclic loads showed the scheme to be successful in preventing pullout, increasing shear strength, and reducing the rate of strength deterioration. The stiffness and energy dissipation characteristics were essentially unchanged. For exterior joints, the retrofit was designed to reduce vertical cracks propagating in the column lap splice zone above the joint by eliminating loss of cover due to prying at the outside (non-beam side) of the joint. Steel plates above and below the beam were through-bolted to a continuous steel plate on the outside of the joint. Testing showed significant improvements in the behavior of the specimen: cover was protected, and peak strength, initial stiffness, and energy dissipation capacity were increased. However, strength deterioration after peak strength was achieved was more rapid than for the unstrengthened specimen.

The retrofit schemes investigated at Cornell show great promise, particularly in light of the fact that they are relatively inexpensive and non-disruptive both aesthetically and during construction. It may be possible to implement schemes of this type building-wide without requiring long term relocations of people and contents. However, these schemes are specifically designed to rectify problems common to concrete construction of the 1950 's and 1960's (which typically have 1) little or no transverse reinforcement within the beam-column joint region, 2) widely spaced column ties, and 3) discontinuous 
negative and positive beam reinforcement with approximately $150 \mathrm{~mm}$ (6 inches) embedment length into the column), subject to moderate $(0.2 \mathrm{~g})$ earthquake loads, and they may not be useful for buildings which were constructed with different details or that are sited in areas of greater expected accelerations.

\subsection{Collection of Data}

Existing experimental data were obtained for use in developing and validating analytical models. Data sets for existing and strengthened conditions were collected for frames, beam-column joints, and columns. Seventy sets of data were collected on frames and infilled walls. More than half of the data were on behavior of various retrofit schemes. In contrast, over one hundred sets of data were collected on the behavior of beam-column joints, but only five of the tests were on strengthened joints. Twenty-three data sets were obtained on columns that had been experimentally tested; only nine had been strengthened, and those nine included a wide variety of dissimilar strengthening schemes.

The amount of data available led to the decision to investigate variations on infilled walls in this phase of the research program. The seventy available data sets on existing and strengthened frames were culled to identify specific cases for further use. The selected specimens shared common physical and geometric characteristics, were tested using similar quasi-static cyclic loads, and produced results that were published as readable hysteresis loops. The specimens selected for study are described in greater detail in Section 4.1. 


\section{INELASTIC ANALYSIS OF REINFORCED CONCRETE FRAMES USING IDARC}

\subsection{Introduction to Program IDARC}

The program IDARC (Inelastic Damage Analysis of Reinforced Concrete Frame-Shear Wall Structures) was developed from 1985 to 1987 at the State University of New York at Buffalo by Park, Reinhorn, and Kunnath ${ }^{35}$. The program, developed for use as a research tool, was designed to overcome several limitations typical of previous analytical programs. Park et al. describe three major drawbacks in extant inelastic analysis programs that were overcome by IDARC:

- the analysis was carried out using equivalent properties of damaged or cracked sections of elastic models,

- the general hysteresis models used for inelastic analysis did not always fit actual behavior (shear and flexure) of reinforced concrete elements, and

- strength limits, which had to be precomputed off-line, remained unchanged throughout the analysis.

IDARC performs in the first phase a static analysis which determines component properties, inelastic behavior and failure mode under monotonic loading, and natural period. In the second phase, a step-by-step inelastic dynamic response analysis using the Newmark- $\beta$ method, is performed. A hysteresis model that accounts for shear and flexure was developed for use in this part of the program. The program also computes and updates strength levels of components. In the third phase, the program performs a damage analysis, calculating damage indices for individual members, specified subsections, and the entire building. A detailed description of the program as originally released can be found in Park et al..$^{35}$

NIST sponsored additional development of the program at Cornell University in the early 1990's. A description of the improvement of the hysteresis model and development of a System Identification Method can be found in El-Borgi et al. ${ }^{36}$ Researchers at NIST have developed further refinements and modifications for use in specific projects.

IDARC uses two-dimensional analysis to evaluate the behavior of three-dimensional structures; transverse beam elements are used to model the effects of slabs and beams connecting parallel frames. Identical frames can be lumped together. Other elements available for modeling structures include beams, columns, shear walls, and edge columns.

In beam and column elements, rigid panel zones and flexibility distribution are accounted for using non-linear springs. Edge columns are modeled using inelastic axial springs. Transverse beams are modeled with elastic linear and rotational springs. Shear wall 
elements are modeled using flexure and shear springs connected in series, each with independent inelasticity. This allows shear hysteresis to be modeled independently of the flexural hysteresis in these elements.

For this IDARC-based study of frames strengthened with infilled walls, each frame unit (one-story one-bay), whether strengthened or bare frame, is modeled using a single shear wall element rather than a combination of beam, column, and wall elements. Chapter 4 describes the development of hysteresis models for use with IDARC shear wall elements that describe the behavior of unstrengthened and strengthened single-story single-bay frames. Chapter 5 describes the validation of these models, including an assessment of the effectiveness of modeling multi-story multi-bay frames using stacks of these singlestory single-bay units.

\subsection{Three-Parameter Hysteresis Model}

The accuracy of any dynamic inelastic response analysis is heavily dependent on the validity of the model used to describe the hysteretic behavior of the components. For analysis of reinforced concrete, the model must be sophisticated enough to describe stiffness degradation, strength deterioration, pinching behavior, and unsymmetric hysteresis. However, simplicity of the model is also at a premium, since a large number of inelastic springs are needed to model any given structure, and every additional parameter used to refine complex hysteresis loop shape adds to computational time and complexity.

The programmers of IDARC assessed many available hysteretic models and found that most of them were specifically aimed at a particular type of component such as beams, columns, or shear walls. Thus, most lacked the versatility needed to accurately describe the behavior of actual buildings. The IDARC designers developed a three-parameter model that can be used to describe the behavior of all types of structural elements. The parameters $\alpha, \beta$, and $\gamma$ determine the stiffness degradation, strength deterioration, and pinching behavior, respectively. Figure 3.1 and the descriptions below, taken from Park et al., ${ }^{35}$ describe the effects of the three parameters on a trilinear skeleton curve.

$\alpha$ - "The stiffness degradation is introduced by setting a common point on the extrapolated initial skeleton curve line, and assumes that the unloading lines aim at this point until they reach the $\mathrm{x}$-axis. The parameter $\alpha$ specifies the degree of stiffness degradation, and, more importantly, the area enclosed by the hysteresis loops."

$\beta$ - "The parameter $\beta$ specifies the rate of strength degradation." 
$\gamma$ - "The pinching behavior is introduced by lowering the target maximum point (A in Figure 3.1) to a straight level of $\gamma \mathrm{P}_{\mathrm{y}}$ (B in Figure 3.1) along the previous unloading line. Reloading points aim this new target point ' $B$ ' until they reach the crack closing deformation. The stiffness of reloading paths is changed at this point to aim the previous target maximum point ' $A$ '. The introduction of such a pinching behavior also leads to a reduction of hysteresis loop areas and indirectly, the amount of dissipated energy."
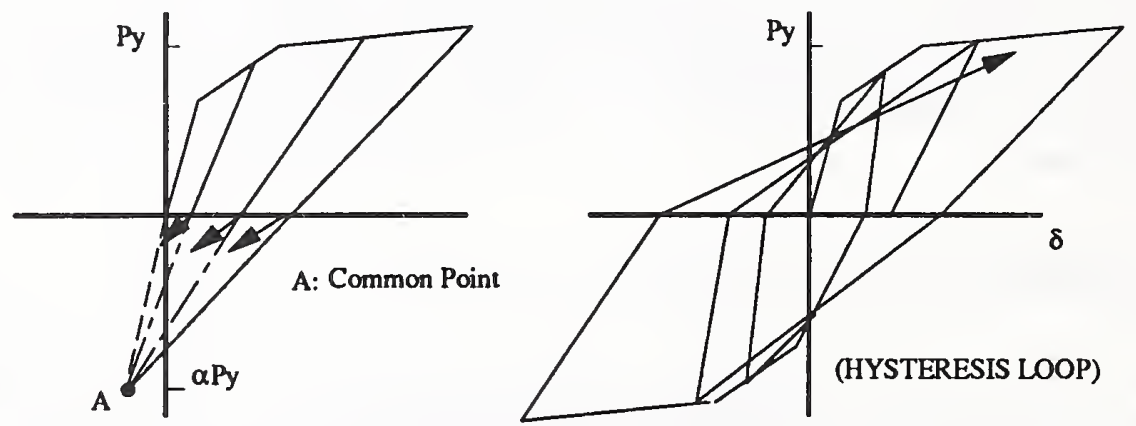

(a) STIFFNESS DEGRADATION
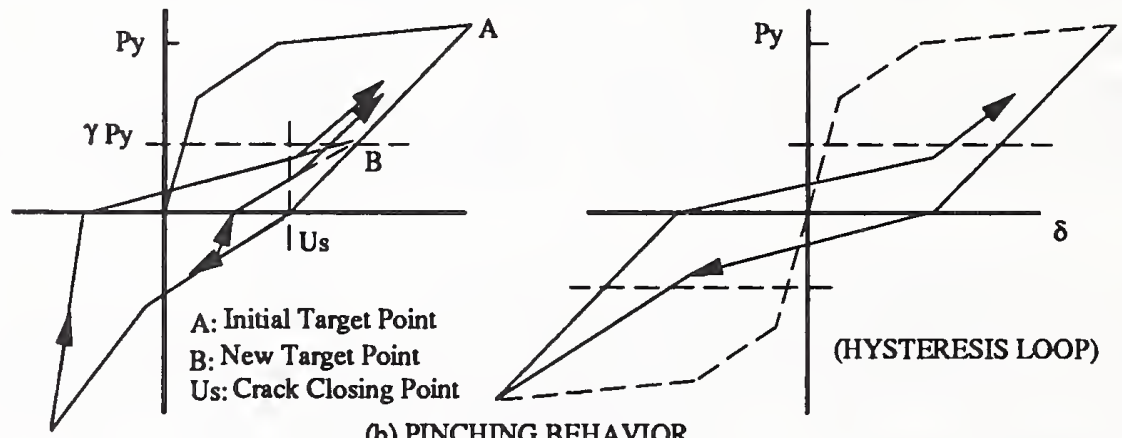

(b) PINCHING BEHAVIOR
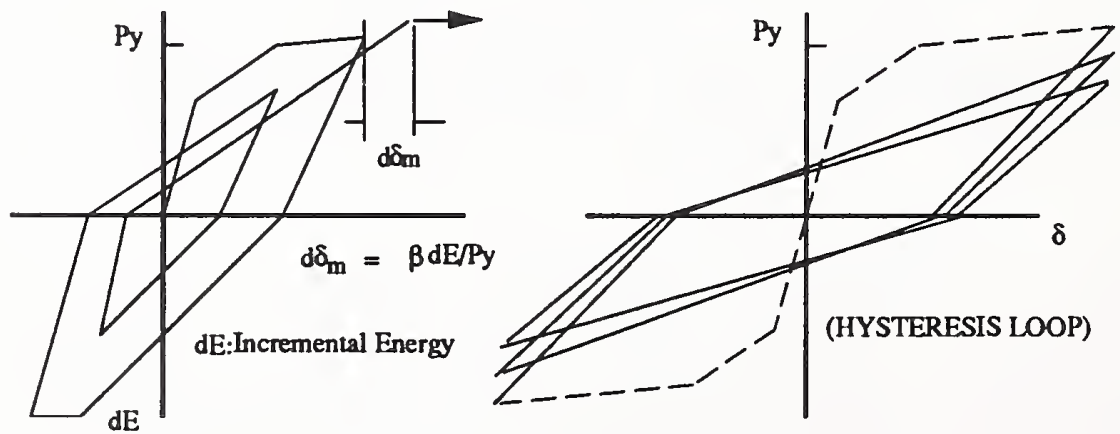

(c) STRENGTH DETERIORATION

Figure 3.1 Three-Parameter Hysteresis Models (After Park, Reinhorn and Kunnath ${ }^{35}$ ) 
NIST, in an earlier phase of this multi-year research project, supported a Cornell University effort to improve IDARC's basic hysteresis model. The results of that study are reported by El-Borgi et al. ${ }^{36}$ The three-parameter model was refined to use smooth continuous curves to model hysteresis loops. Several problems associated with the hysteresis model of the original program were eliminated, including error accumulation due to overshooting during unloading.

The refined model requires that the $\alpha, \beta$, and $\gamma$ parameters be calibrated against experimental test records prior to use. El-Borgi et al ${ }^{36}$ refer to this task as the System Identification Method, and describe the procedure in their report. NIST researchers Stone and Taylor have incorporated the System Identification Method into an InteractiveGraphics based system identification software called NIDENT. ${ }^{40}$ The calibration of the three-parameter model for this investigation is discussed in Chapter 4. 


\section{DEVELOPMENT OF HYSTERESIS MODELS FOR R/C FRAMES}

As discussed in Chapter 3, the current program IDARC ${ }^{35}$ requires pre-characterization of the hysteresis behavior of the structural components by means of the three parameters: stiffness degradation parameter $\alpha$, strength degradation parameter $\beta$, and pinching parameter $\gamma$. Even though IDARC offers default values for $\alpha, \beta$, and $\gamma$ based on a frame identification study by $\mathrm{Yeh}^{38}(1988)$, these default values are judged to be too simplistic to correctly characterize the hysteretic response of reinforced concrete frame structures given the complexity and the innumerable factors which influence this behavior. This is especially true for structures which are strengthened by adding new structural elements, since the current default values of the three parameters were not calibrated by experimental results of strengthened structures. Thus, in order to accurately analyze existing or strengthened reinforced concrete frame structures using the program IDARC, it is crucial to obtain parameters $(\alpha, \beta, \gamma)$ which have been calibrated by the results of experiments on both existing and strengthened frames.

The hysteresis models developed in this study, which are empirical expressions relating the three parameters $\alpha, \beta, \gamma$ to the geometric and material properties of the structural frames, were calibrated using actual test results of the selected experiments described in section 4.1. The procedure used in developing the models, and the hysteresis models for various constructions indicated above, are described in section 4.2. Models have been developed which may be used to predict the hysteresis parameters of the following types of construction:

- bare frames

- monolithic wall-frame constructions

- frames strengthened by CIP infilled walls, with and without wall openings

- frames strengthened by multiple precast concrete panels, with and without wall openings

\subsection{Relevant Experimental Programs}

Experimental programs on seismic strengthening of RC frames conducted by Aoyama et al $^{8,9,10,11,12}$, Kahn $^{1}$, Hayashi et al. ${ }^{3}$, Sugano et al. ${ }^{2}$, Higashi et al ${ }^{4}$, Corley et al ${ }^{5,6,7}$, Ogata et al. ${ }^{13}$, Gaynor ${ }^{18}$, and $\underline{\text { Shah }}^{16}$ were selected for use in developing the hysteresis models in this study. These programs were selected based on the following criteria:

- The test specimens are one-bay one-story frames.

- The loading program is quasi-static reversed cyclic.

- Strengthening is accomplished by reinforced concrete infilled wall. 
- Reinforcement details in the existing frame are typical of construction in the 1950's or 1960's.

The use of one-bay one-story frame tests limits the number of variables that need to be considered and permits direct comparison of test results between the various test programs. It also allows the most efficient utilization of existing test data relevant to seismic strengthening since the majority of seismic strengthening tests on RC frames are one-bay one-story. Further, the hysteresis models developed for RC frames based on one-bay one-story tests are versatile and may easily be incorporated into such programs as IDARC for use in the analysis of RC structures being strengthened by different schemes.

A total of fifty-five specimens were selected from these experimental programs. These consisted of five bare frames, twenty-one monolithic wall-frame constructions, twenty-one frames strengthened by CIP infilled wall (with and without wall opening), and eight frames strengthened by multiple precast concrete panels used as infilled wall. In most cases, the specimens were deliberately designed to have reinforcement details that are typical of lightly reinforced construction ${ }^{1,2,3,4,8,9,10,11,12,13}$ - i.e., low longitudinal reinforcement ratio for columns, little or no transverse reinforcement within the beamcolumn joint regions, and large spacing between column transverse reinforcement which results in little confinement of the concrete core. The ranges of some typical parameters of the specimens included in this study are as follow:

- Flexural Reinforcement ratio of column (\%)

- Shear Reinforcement ratio of column (\%)

- Ratio of beam clear span/column height

- Frame concrete compressive strength $\left(\mathrm{kgf} / \mathrm{cm}^{2}\right)$

- Column axial stress $\left(\mathrm{kgf} / \mathrm{cm}^{2}\right)$

$\begin{array}{ll}: & 0.71 \text { to } 5.35 \\ : & 0.068 \text { to } 1.92 \\ : & 0.40 \text { to } 1.90 \\ : & 183.0 \text { to } 548.2 \\ 0.0 \text { to } 38.3\end{array}$

As indicated in Chapter 2, many other experimental programs dealing with seismic strengthening of existing RC buildings beside those mentioned above have been performed. Those tests were not utilized in the hysteresis model development in this study because they do not meet the criteria indicated above. However, the results of these tests will provide useful data for validating this and future analytical developments. Brief summaries of the selected experimental programs are given below.

\subsubsection{Aoyama et al..$^{8,9,10,11,12}$}

A total of fourteen one-third scale specimens were selected from Aoyama's test program for use in this study. These included three monolithic wall-frame constructions and eleven frames strengthened by CIP infilled wall. The specimens had non-ductile columns and were intended to represent buildings designed in accordance with the Japanese building code of the 1960's. The variables studied included column sizes, column 
reinforcement ratio, method of anchoring infilled wall to frame (monolithic vs. mechanical wedge anchors vs. epoxy anchors), test variability, and wall opening. Typical parameters and material properties of the selected specimens are listed in Table 4.1. Figure 4.1 shows the geometry, dimensions, and reinforcement pattern of a typical specimen. Figure 4.2 shows the hysteresis behavior, as digitized from published reports $^{8,9,10,11,12}$, of four specimens tested in this test program. Two of the specimens are frames strengthened by CIP infilled walls with epoxy anchors (specimens C2005-III and C2015-A), one is a monolithic wall-frame construction (specimen P2005-A), and one is a frame strengthened by CIP infilled wall with wedge anchors (specimen M2005).

Among the findings of this experimental program are:

- Ultimate shear strengths of frames strengthened by CIP infilled wall are about 70 80 percent of the corresponding monolithic frame-wall constructions.

- Ultimate shear strengths of frames strengthened by infilled walls increase with increasing column stiffness and column flexural reinforcement.

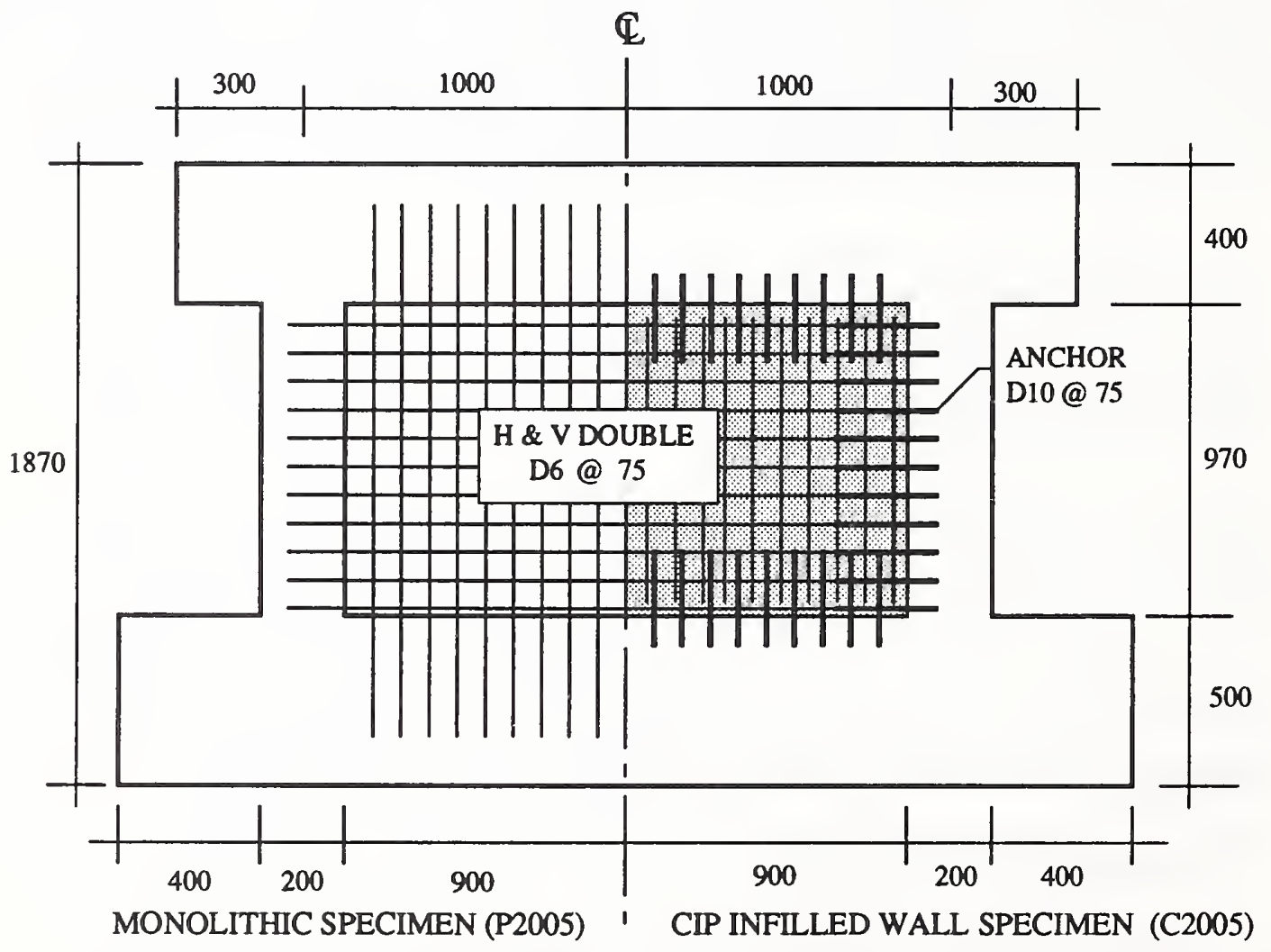

Figure 4.1 Geometry, Dimensions, and Reinforcement Pattern of Aoyama's Test Specimens 


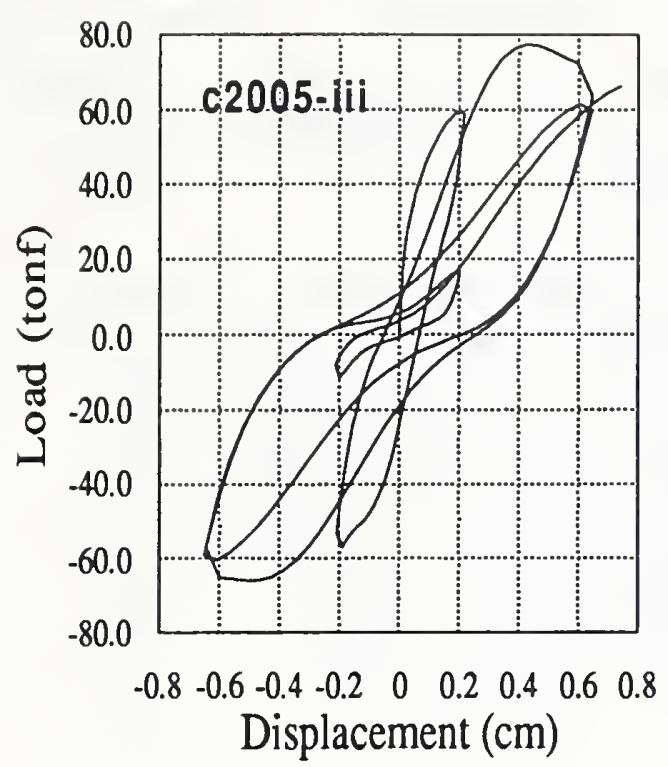

(a)

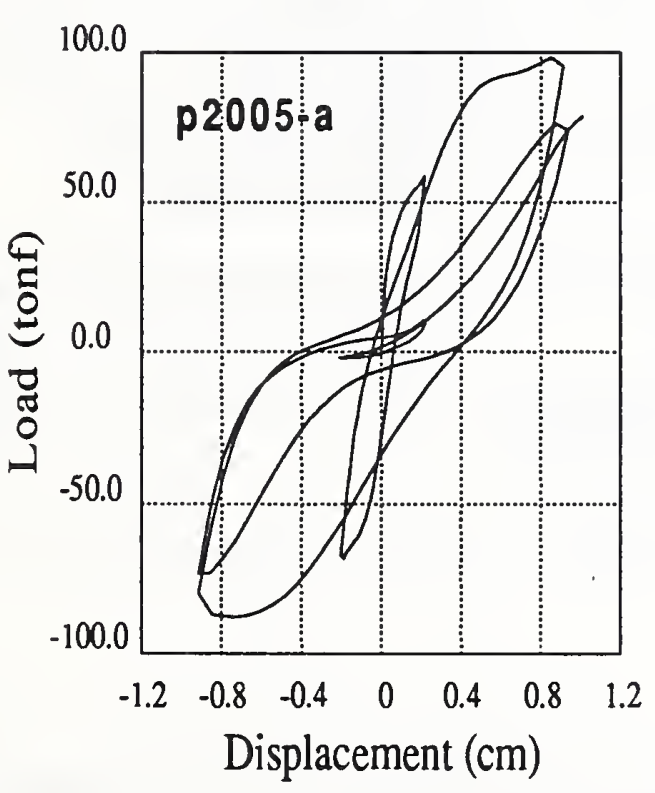

(c)

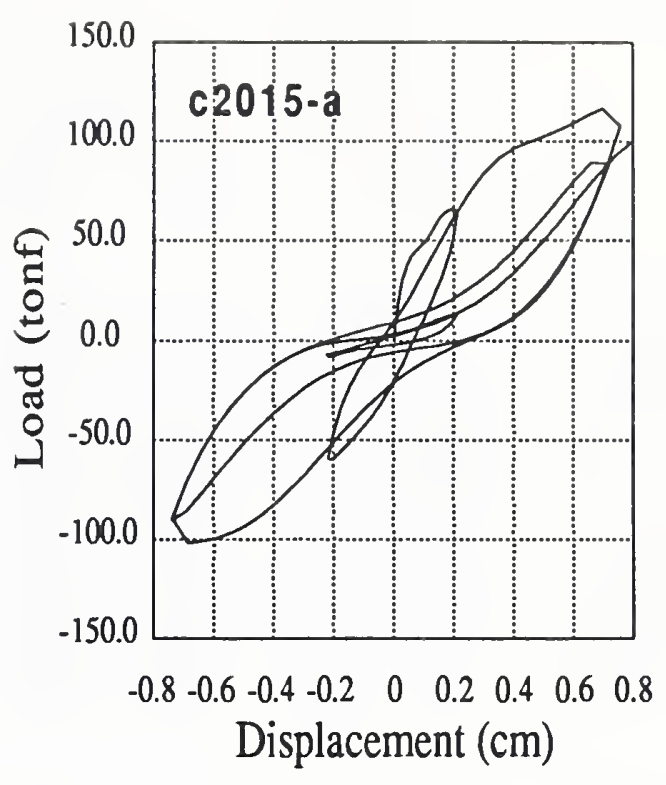

(b)

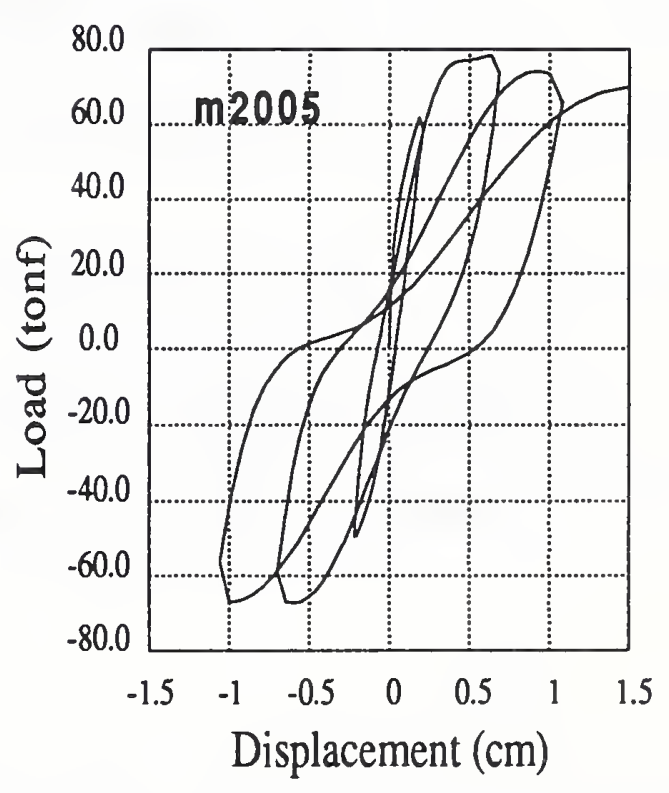

(d)

Figure 4.2 Hysteresis Behavior of Aoyama's Test Specimens
(a) CIP Infilled Frame C2005-III
(b) CIP Infilled Frame C2015-A
(c) Monolithic Wall-Frame P2005-A
(d) CIP Infilled Frame M2005 
Table 4.1 SUMMARY OF AOYAMA'S TEST SPECIMENS

\begin{tabular}{|c|c|c|c|c|c|c|c|c|}
\hline & $\begin{array}{l}\text { Coll } \\
\text { bxD } \\
\text { (cm) }\end{array}$ & $\begin{array}{l}\mathrm{umn} \\
\mathrm{A}_{\mathrm{g}} \\
\left(\mathrm{cm}^{2}\right)\end{array}$ & $\begin{array}{l}\text { Concre } \\
\text { (kgf/c } \\
\text { Frame }\end{array}$ & $\begin{array}{l}\text { te } f_{c} \\
\left.m^{2}\right) \\
\text { Wall }\end{array}$ & $\begin{array}{l}\mathrm{P}_{\mathrm{x}} / \mathrm{A}_{\mathrm{cg}} \\
(\mathrm{kgf} / \mathrm{cm}\end{array}$ & $\begin{array}{l}\mathrm{L}_{\mathrm{b}} / \mathrm{H}_{\mathrm{c}} \\
\left.\mathrm{n}^{2}\right)\end{array}$ & $\begin{array}{c}\text { Construction } \\
\text { and Anchor } \\
\text { Type }\end{array}$ & $\begin{array}{l}\text { Max. } \\
\text { Load } \\
\text { (ton) }\end{array}$ \\
\hline C2005-I & $20 \times 20$ & 5.08 & 236.0 & 205.0 & 30.0 & 1.86 & CIP Infill/Epoxy & 84.2 \\
\hline C2005-II & $20 \times 20$ & 5.08 & 236.0 & 205.0 & 30.0 & 1.86 & CIP Infill/Epoxy & 81.2 \\
\hline C2005-III & $20 \times 20$ & 5.08 & 226.0 & 220.0 & 30.0 & 1.86 & CIP Infill/Epoxy & 75.8 \\
\hline C2015-A & $20 \times 20$ & 15.2 & 223.0 & 150.0 & 30.0 & 1.86 & CIP Infill/Epoxy & 116.2 \\
\hline C2015-B & $20 \times 20$ & 15.2 & 198.0 & 150.0 & 30.0 & 1.86 & CIP Infill/Epoxy & 112.2 \\
\hline C2015-C & $20 \times 20$ & 15.2 & 403.0 & 394.0 & 30.0 & 1.86 & CIP Infill/Epoxy & 159.7 \\
\hline P2005 & $20 \times 20$ & 5.08 & 220.0 & 220.0 & 30.0 & 1.86 & Monolithic & 97.8 \\
\hline P2015 & $20 \times 20$ & 15.2 & 394.0 & 394.0 & 30.0 & 1.86 & Monolithic & 171.1 \\
\hline C4015 & $20 \times 40$ & 15.2 & 234.0 & 297.0 & 15.0 & 1.65 & CIP Infill/Epoxy & 126.0 \\
\hline P4015 & $20 \times 40$ & 15.2 & 297.0 & 297.0 & 15.0 & 1.65 & Monolithic & 165.0 \\
\hline M2005 & $20 \times 20$ & 5.08 & 301.0 & 287.0 & 30.0 & 1.86 & CIP Infill/Wedge & 77.0 \\
\hline $\mathrm{CH} 2015$ & $20 \times 20$ & 15.2 & 289.0 & 222.0 & 30.0 & 1.86 & $\begin{array}{l}\text { Expansive CIP } \\
\text { Infill/Epoxy }\end{array}$ & 122.0 \\
\hline $\mathrm{CH} 2018$ & $20 \times 20$ & 18.1 & 261.0 & 222.0 & 30.0 & 1.86 & $\begin{array}{l}\text { Expansive CIP } \\
\text { Infill/Epoxy }\end{array}$ & 119.0 \\
\hline OLU2015 & $20 \times 20$ & 15.2 & 223.0 & 181.0 & 30.0 & 1.86 & $\begin{array}{l}\text { Expansive CIP } \\
\text { w/opening/Epoxy }\end{array}$ & 78.0 \\
\hline
\end{tabular}

bxD: Column Width $x$ Depth

$A_{g}$ : Gross Area of Column Flexural Reinforcement

$\mathrm{P}_{\mathrm{x}} / \mathrm{A}_{\mathrm{cg}}$ : Column Axial Stress

$\mathrm{L}_{\mathrm{b}} / \mathrm{H}_{\mathrm{c}}$ : Ratio of Beam Length vs. Column Height

\subsubsection{Kahn ${ }^{1}$}

Four half-scale specimens were selected from this test program. The selected specimens consisted of a monolithic frame-wall system (specimen 1), a bare frame (specimen 2), a frame strengthened by CIP infilled wall (specimen 3), and a frame strengthened by multiple precast panel walls (specimen 5). Like those of Aoyama, Kahn's specimens were also designed to represent construction of the 50's and 60's. Three typical characteristics of Kahn's specimens which are representative of past building codes are: 
- There is no transverse reinforcement within the beam-column joint region.

- Column ties are widely spaced which provide little confinement to the concrete core.

- Negative and positive beam reinforcement are discontinuous with approximately 150 $\mathrm{mm}$ (6 inches) embedment length into the column.

No axial load was applied to the column. The principal variables of this study were the type of construction of the infilled wall (CIP wall vs. precast panel wall) and the frameto-wall connection. Table 4.2 lists the typical parameters and properties of the selected specimens. Figure 4.3 shows the geometry, dimensions, and reinforcement pattern of a specimen. Figure 4.4 shows the hysteresis behavior of specimens SP3 and SP5, as digitized from the published report ${ }^{1}$, for quasi-static cyclic loading. It was concluded from this study that frames strengthened by CIP infilled wall can achieve almost the same maximum strength as an equivalent monolithic wall-frame system but with less ductility, and that multiple precast infilled walls provide reasonable increase in shear strength and ductility.

Table 4.2 SUMMARY OF KAHN'S TEST SPECIMENS

\begin{tabular}{|c|c|c|c|c|c|c|c|}
\hline Specimen & 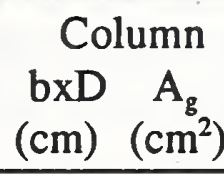 & $\begin{array}{l}\text { Concr } \\
(\mathrm{kgf} / \mathrm{c} \\
\text { Frame }\end{array}$ & $\begin{array}{l}\text { ete } f_{c} \\
\left.m^{2}\right) \\
\text { Wall }\end{array}$ & $\mathrm{P}_{\mathrm{x}} / \mathrm{A}_{\mathrm{c}}$ & $\mathrm{L}_{\mathrm{b}} / \mathrm{H}_{\mathrm{c}}$ & $\begin{array}{c}\text { Construction } \\
\text { and Anchor } \\
\text { Type }\end{array}$ & $\begin{array}{l}\text { Max. } \\
\text { Load } \\
\text { (ton) }\end{array}$ \\
\hline SP1 & $15 \times 158.0$ & 351.0 & 351.0 & 0.0 & 1.63 & Monolithic & 74.9 \\
\hline SP2 & $15 \times 158.0$ & 317.0 & ---- & 0.0 & 1.63 & Bare Frame & 4.7 \\
\hline SP3 & $15 \times 158.0$ & 251.6 & 198.2 & 0.0 & 1.63 & CIP Infill/Epoxy & 56.5 \\
\hline SP5 & $15 \times 158.0$ & 247.4 & 204.5 & 0.0 & 1.63 & \multicolumn{2}{|c|}{ Panel/Welded Connectors } \\
\hline
\end{tabular}




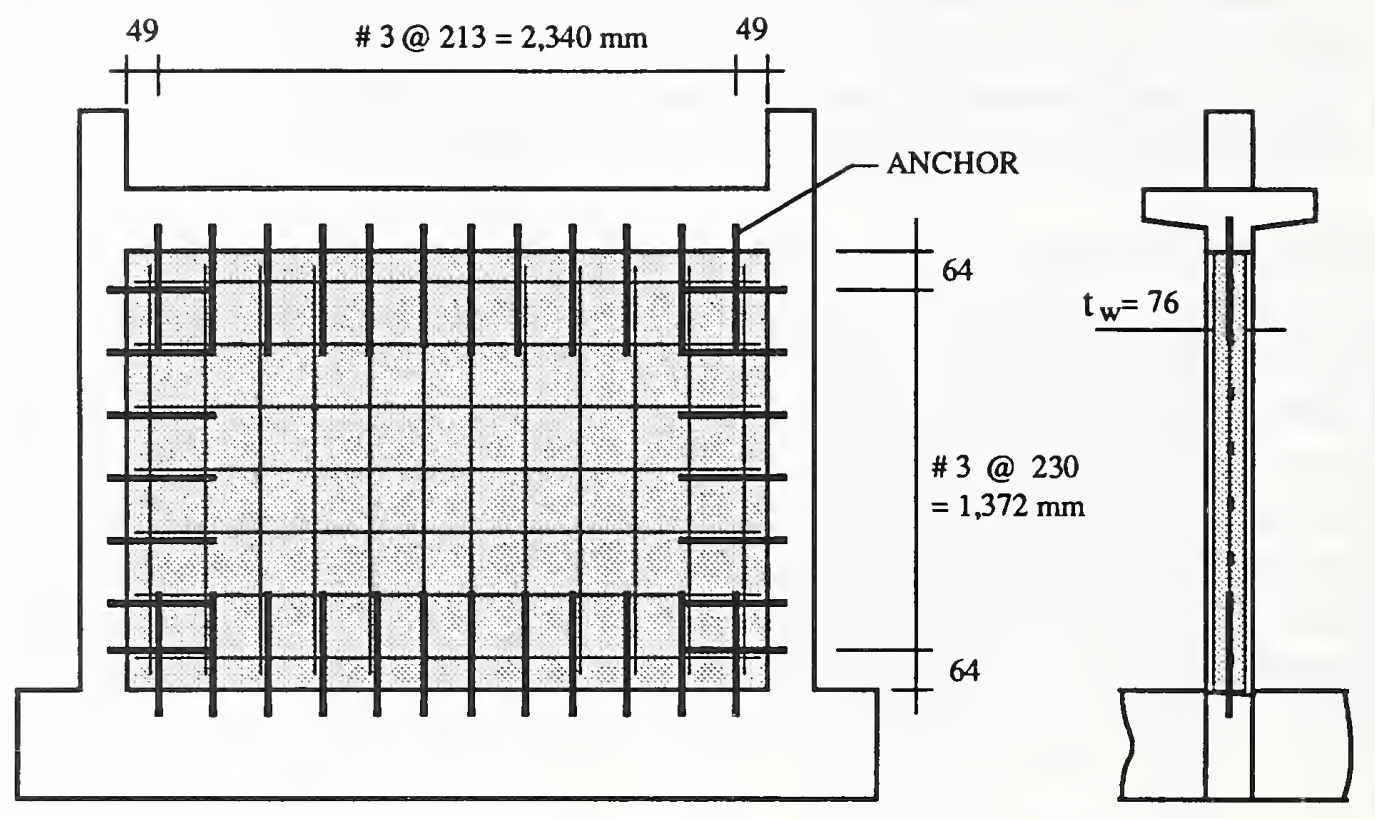

Figure 4.3 Geometry, Dimensions and Reinforcement Pattern of Kahn's Test Specimen

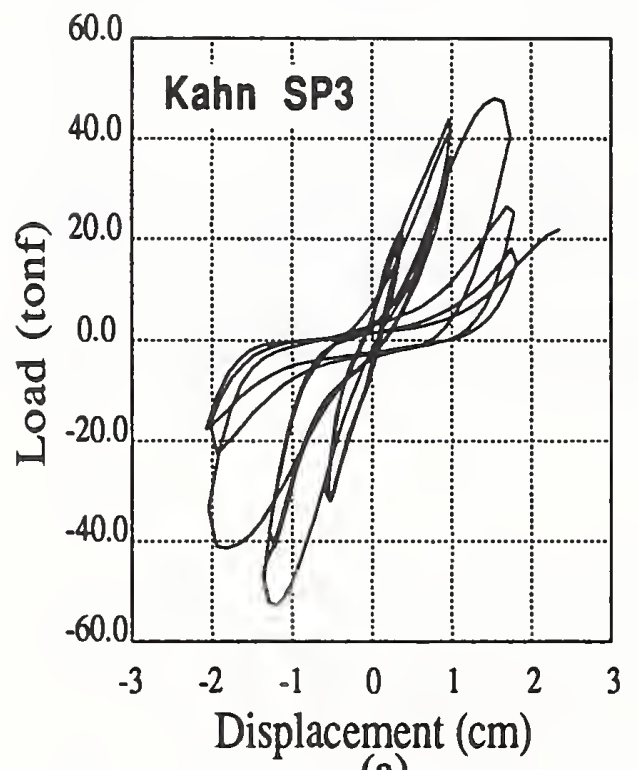

(a)

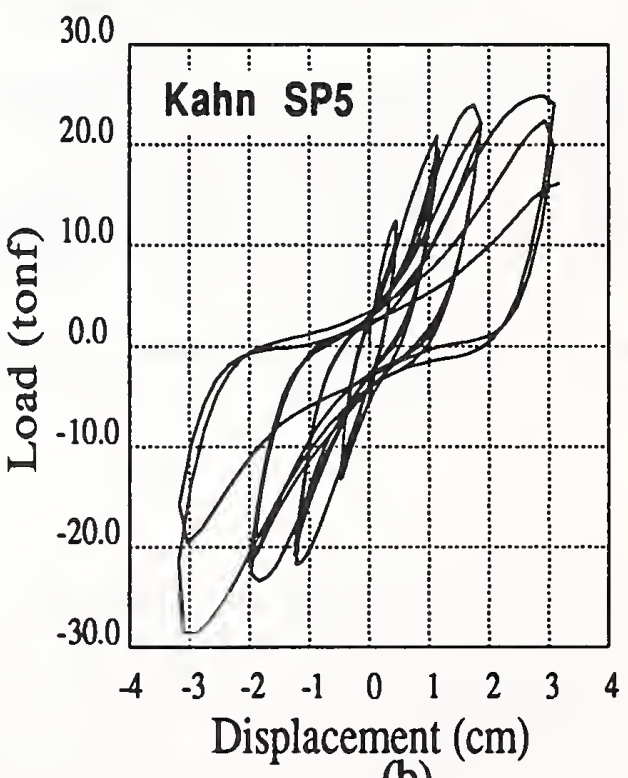

(b)

Figure 4.4 Hysteresis Behavior of Kahn's Test Specimens

(a) CIP Infilled Frame SP3

(b) Frame Infilled by Precast Panels SP5 


\subsubsection{Hayashi ${ }^{3}$}

Five specimens, labeled $\mathrm{W}-1, \mathrm{~W}-2, \mathrm{~W}-4, \mathrm{~W}-5, \mathrm{~W}-6$, were selected from this experimental program. The specimens were one-bay, one-story frames which were designed in accordance with the 1950 and 60's Japanese building code provisions. Specimen W-1 was a bare frame. Specimen W-2 was a monolithic wall-frame. Specimens W-4 to 6 were frames infilled with a reinforced concrete wall. The differences between specimens W-4, 5 , and 6 were in the methods of connecting CIP infilled walls to the frames. In specimen W-4, mechanical wedge anchors were used only at the bottom of the upper beam of the frame, and the remaining inner sides of the frame were roughened. In specimen W-5, wedge anchors were used on all four sides of the frame. In specimen W-6, wedge anchors were used on all inner sides of the frame, and roughening was done for all inner sides except for the top beam. There was a specimen W-3 which was also an infilled wall. However, this specimen was not used here since the method of connecting the infilled wall to the frame was by means of concrete shear keys, which is considered nonconventional and not compatible with other tests. Table 4.3 shows typical parameters and properties of these specimens. Figure 4.5 shows specimen's geometry, dimensions, and reinforcement pattern. Figure 4.6 shows the hysteresis curves of specimens W-5 and W-6 under quasi-static cyclic loading. This study concluded that an increase in lateral load capacity, by a factor of 3.5 to 5.0 times, can be achieved by strengthening a bare frame with infilled wall, and a frame strengthened by infilled wall may achieve a lateral strength of 55 to 75 percent of that for a corresponding monolithic wall-frame.

\section{Table 4.3 SUMMARY OF HAYASHI'S TEST SPECIMENS}

\begin{tabular}{|c|c|c|c|c|c|c|c|}
\hline Specimen & $\begin{array}{l}\text { Column } \\
\text { bxD } A_{\mathrm{g}} \\
(\mathrm{cm})\left(\mathrm{cm}^{2}\right)\end{array}$ & $\begin{array}{l}\text { Concre } \\
(\mathrm{kgf} / \mathrm{cr} \\
\text { Frame }\end{array}$ & $\begin{array}{l}\mathrm{m}^{2} \text { ) } \\
\text { Wall }\end{array}$ & $\begin{array}{l}\mathrm{P}_{\mathrm{x}} / \mathrm{A}_{\mathrm{cg}} \\
(\mathrm{kgf} / \mathrm{cm}\end{array}$ & $\begin{array}{l}\mathrm{L}_{\mathrm{b}} / \mathrm{H}_{\mathrm{c}} \\
\left.\mathrm{l}^{2}\right)\end{array}$ & $\begin{array}{c}\text { Construction } \\
\text { and Anchor } \\
\text { Type }\end{array}$ & $\begin{array}{l}\text { Max. } \\
\text { Load } \\
\text { (ton) }\end{array}$ \\
\hline W-1 & $20 \times 20$ & 183.0 & -.-- & 30.0 & 1.78 & Bare Frame & 11.2 \\
\hline W-2 & $20 \times 20 \quad 5.07$ & 183.0 & 183.0 & 30.0 & 1.78 & Monolithic & 77.5 \\
\hline W-4 & $20 \times 20 \quad 5.07$ & 183.0 & 272.0 & 30.0 & 1.78 & CIP Infill/Wedge & 55.0 \\
\hline W-5 & $20 \times 20 \quad 5.07$ & 185.0 & 306.0 & 30.0 & 1.78 & CIP Infill/Wedge & 48.0 \\
\hline W-6 & $20 \times 20 \quad 5.07$ & 185.0 & 306.0 & 30.0 & 1.78 & CIP Infill/Wedge & e 55.0 \\
\hline
\end{tabular}




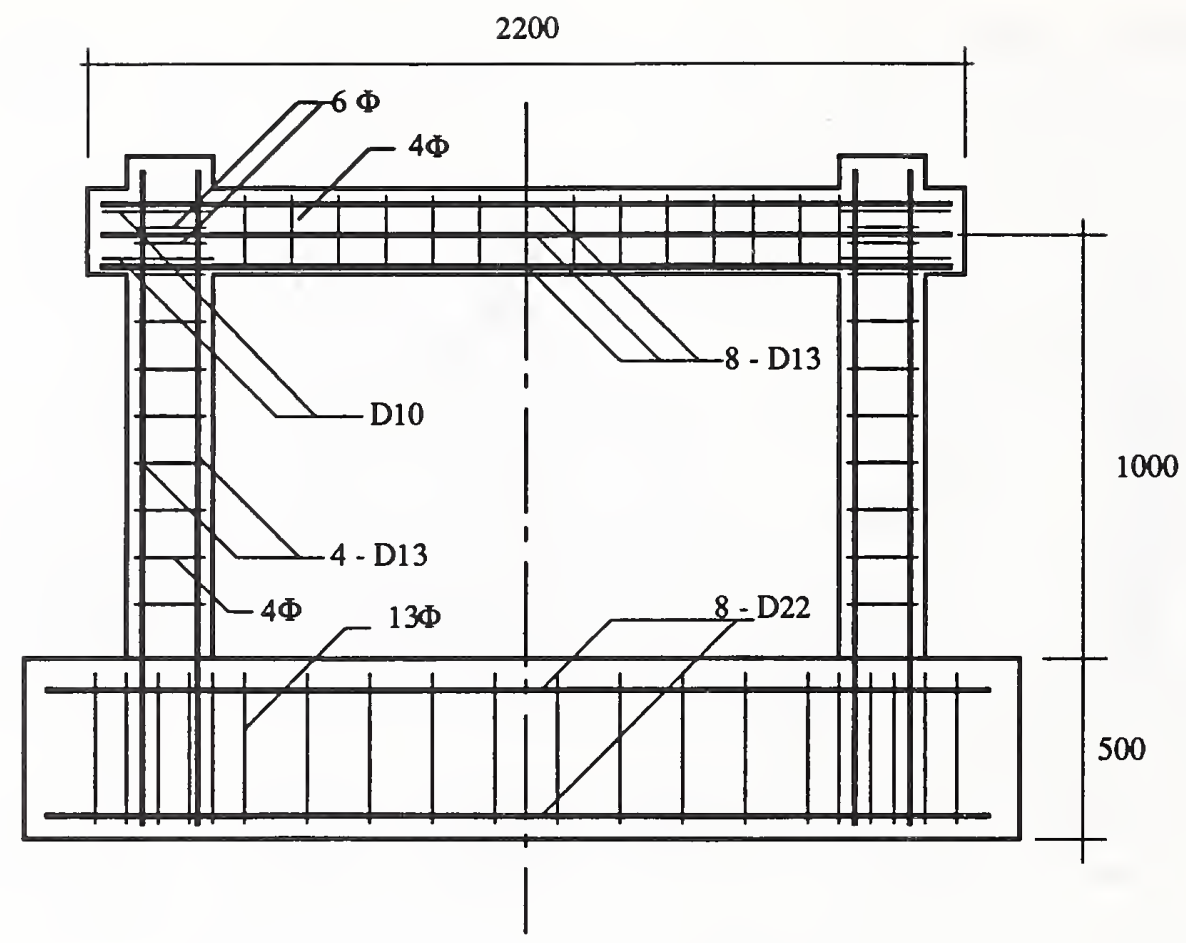

Figure 4.5 Geometry, Dimensions, and Reinforcement Patterns of Hayashi's Test Specimen
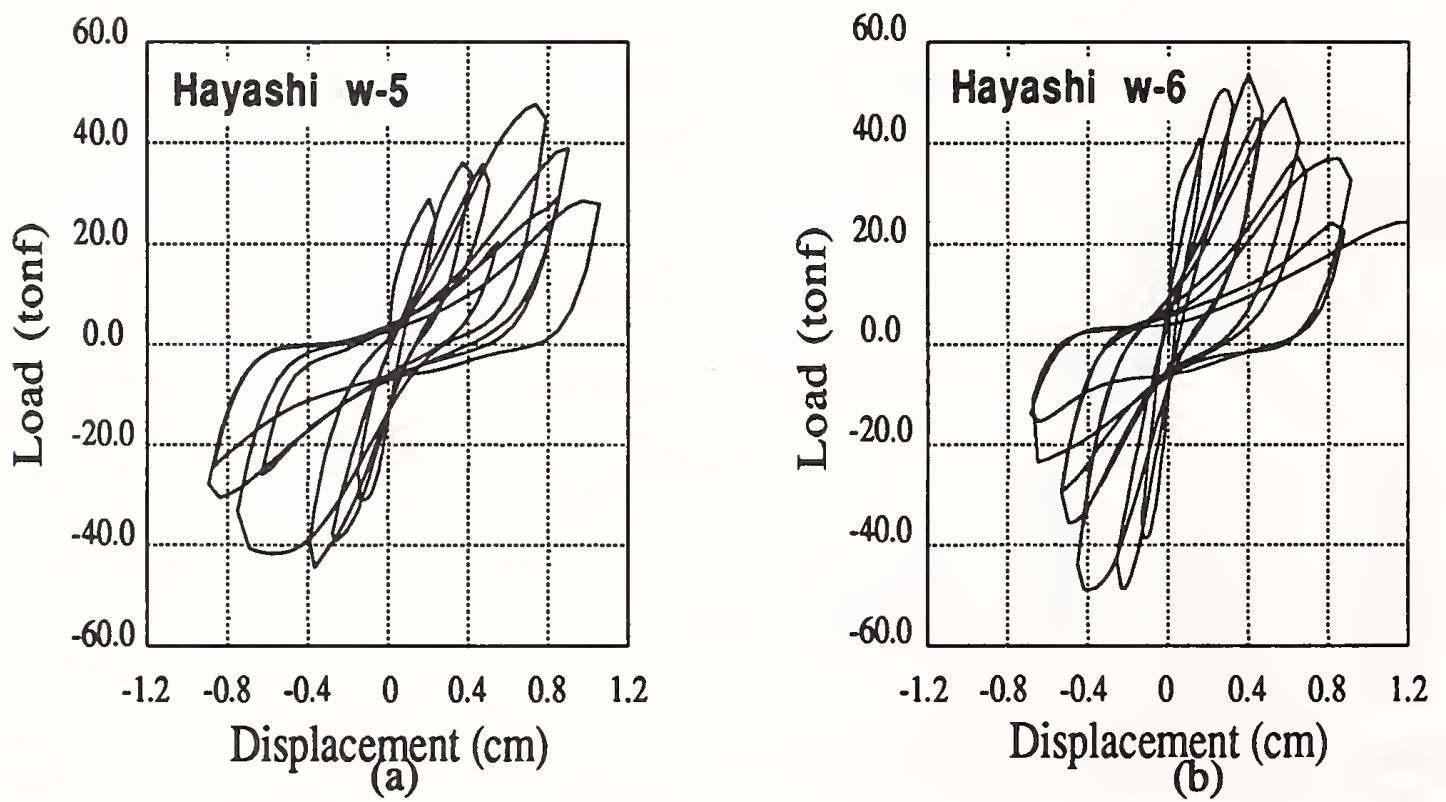

Figure 4.6 Hysteresis Behavior of Hayashi's Test Specimens

(a) CIP Infilled Frame W-5

(b) CIP Infilled Frame W-6 


\subsubsection{Sugano et $\mathrm{al}^{2}$}

Seven one-bay one-story specimens were selected from this study. Specimen F was a bare frame. Specimens W-80S and W-40S were monolithic wall-frames with wall thicknesses of $8.0 \mathrm{~cm}$ and $4.0 \mathrm{~cm}$, respectively. Specimen $\mathrm{W}-40 \mathrm{~W}$ was also a monolithic wall-frame similar to specimen W-40S except that the wall was thickened by new layers of concrete to $8 \mathrm{~cm}$ thick. Specimen W-HA was a frame strengthened by $8-\mathrm{cm}$ thick CIP infilled wall. The infilled wall was connected to the frame using wedge anchors. Specimen W-BL was a frame strengthened by precast concrete block wall. Specimen W$\mathrm{CO}$ was a frame strengthened by $8-\mathrm{cm}$ thick CIP infilled wall, but with mortar shear keys as connectors. Other specimens, W-S, B-C, and B-T, which were frames strengthened by a steel panel, a compression steel brace, and a tension steel brace, were not selected for use in this study. The variables studied included thicknesses of infilled wall, methods of wall-frame connection, and wall types. The study concluded that infilled wall may produce a lateral strength increase of at least 3.5 times that of a bare frame, and an infilled frame may achieve at least 60 percent of the lateral strength of a corresponding monolithic wall-frame system. Table 4.4 lists typical parameters and material properties of the selected specimens in Sugano's test program. Figure 4.7 shows geometry, dimension, and reinforcement pattern of a typical specimen. Figure 4.8 show the hysteresis behavior observed when the CIP infilled frame specimen W-HA and the monolithic wall-frame specimen W-40W were subjected to quasi-static cyclic loading.

\section{Table 4.4 SUMMARY OF SUGANO'S TEST SPECIMENS}

\begin{tabular}{|c|c|c|c|c|c|c|c|c|}
\hline Specimen & $\begin{array}{l}\text { Col } \\
\text { bxD } \\
(\mathrm{cm})\end{array}$ & $\begin{array}{r}\text { lumn } \\
A_{\mathrm{g}} \\
\left(\mathrm{cm}^{2}\right)\end{array}$ & $\begin{array}{l}\text { Concre } \\
(\mathrm{kgf} / \mathrm{cr} \\
\text { Frame }\end{array}$ & $\begin{array}{l}\text { te }^{\prime} f_{c} \\
\left.n^{2}\right)^{(1} \\
\text { Wall }\end{array}$ & $\begin{array}{l}P_{x} / A_{c g} \\
\left.\mathrm{kgf} / \mathrm{cm}^{2}\right)\end{array}$ & $\begin{array}{l}\mathrm{L}_{\mathrm{b}} / \mathrm{H}_{\mathrm{c}} \\
\text { Ratio }\end{array}$ & $\begin{array}{l}\text { Construction } \\
\text { and Anchor } \\
\text { Type }\end{array}$ & $\begin{array}{l}\text { Max. } \\
\text { Load } \\
\text { (ton) }\end{array}$ \\
\hline $\mathrm{F}$ & $20 \times 20$ & 5.16 & $240.0^{\circ}$ & -..- & 31.2 & 1.88 & Bare Frame & 12.9 \\
\hline W-80S & $20 \times 20$ & 5.16 & $240.0^{*}$ & $380.0^{\circ}$ & 31.2 & 1.88 & Monolithic & 72.2 \\
\hline W-40S & $20 \times 20$ & 5.16 & $240.0^{*}$ & $380.0^{\circ}$ & 31.2 & 1.88 & Monolithic & 52.9 \\
\hline W-40W & $20 \times 20$ & 5.16 & $240.0^{*}$ & $380.0^{\circ}$ & 31.2 & 1.88 & $\begin{array}{l}\text { Monolithic } \\
\text { w/thickened wa }\end{array}$ & $\begin{array}{l}63.2 \\
\text { all }\end{array}$ \\
\hline W-HA & $20 \times 20$ & 5.16 & $240.0^{*}$ & $380.0^{\circ}$ & 31.2 & 1.88 & CIP Infill/Wed & Ige 71.0 \\
\hline W-BL & $20 \times 20$ & 5.16 & $240.0^{*}$ & $300.0^{\circ}$ & 31.2 & 1.88 & $\begin{array}{l}\text { Precast block } \\
\text { Infill }\end{array}$ & 45.2 \\
\hline $\mathrm{W}-\mathrm{CO}$ & $20 \times 20$ & 5.16 & $240.0^{*}$ & $380.0^{\circ}$ & 31.2 & 1.88 & $\begin{array}{l}\text { CIP Infill/ } \\
\text { Mortar shear k }\end{array}$ & $\begin{array}{l}63.2 \\
\text { reys }\end{array}$ \\
\hline
\end{tabular}

- Design Compressive Strength 


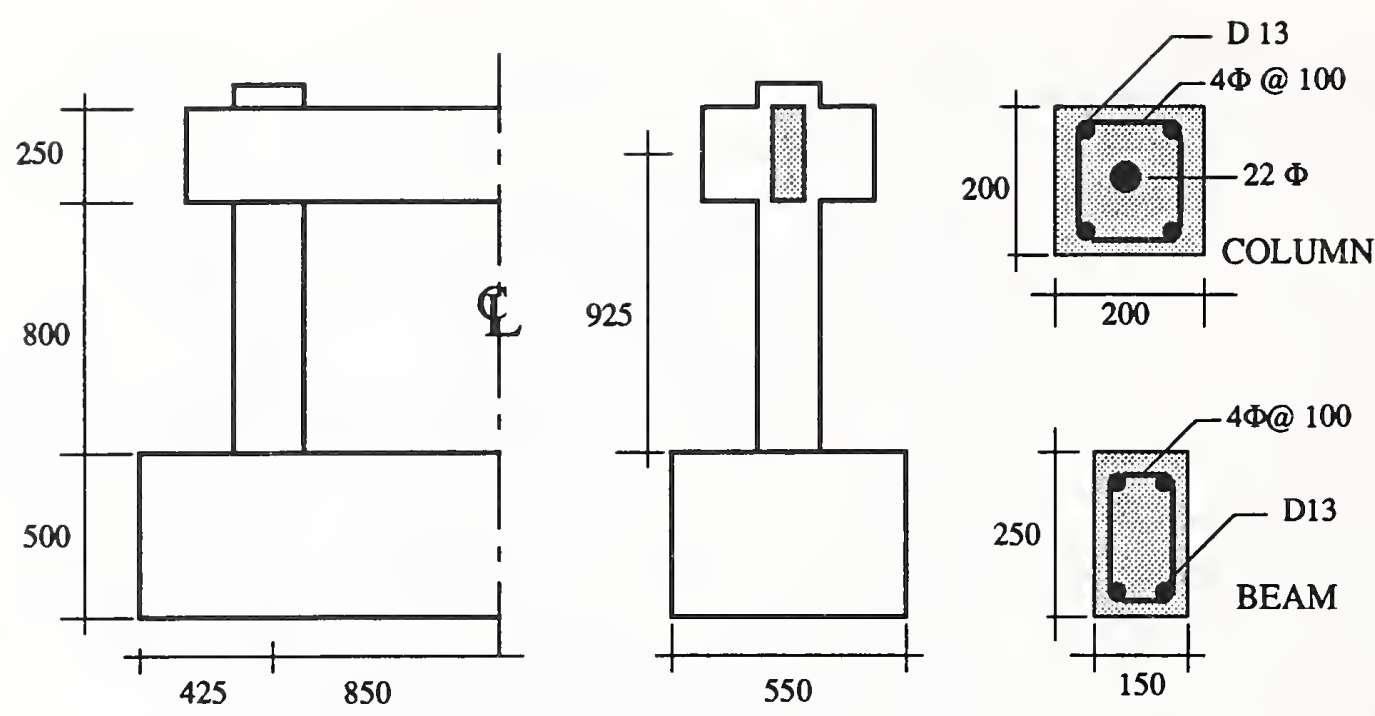

Figure 4.7 Geometry, Dimensions, and Reinforcement Patterns of Sugano's Test Specimen

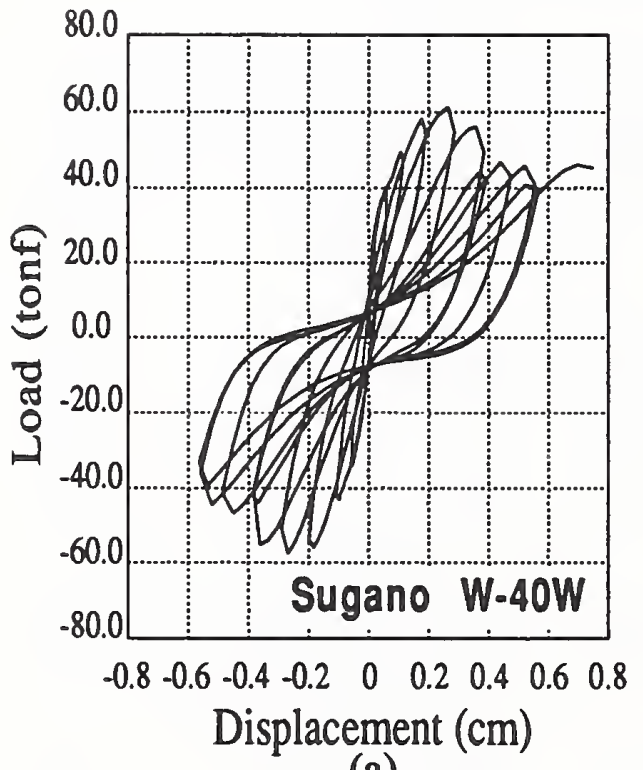

(a)

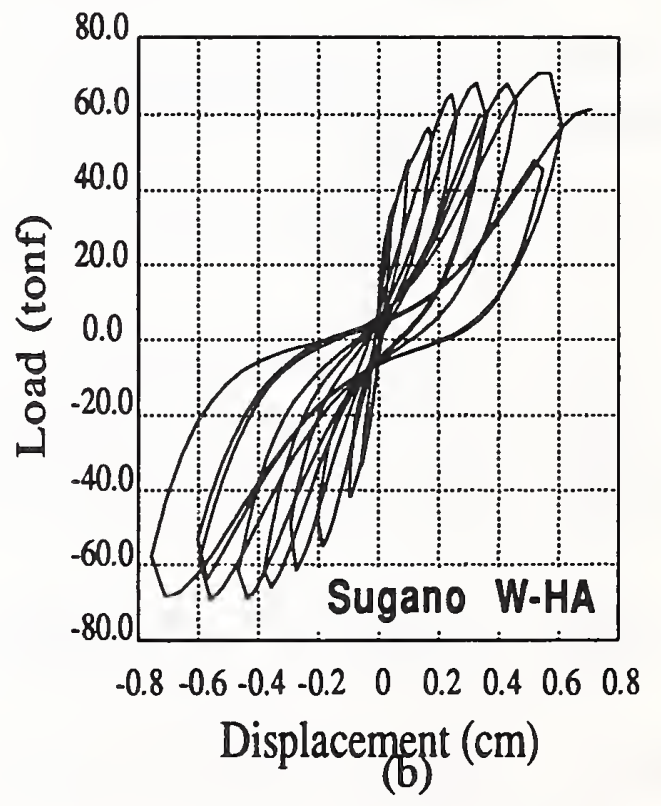

Figure 4.8 Hysteresis Behavior of Sugano's Test Specimens

(a) Monolithic Wall-Frame Construction W-40W

(b) CIP Infilled Frame W-HA 


\subsubsection{Higashi et $\mathrm{al}^{4}$}

Ten one-third scale, one-bay, one-story frames with low column shear reinforcement ratio were selected from Higashi's test program. The selected specimens included two bare frames (specimens 1-F1 and 5-F2), one monolithic wall-frame system (13-FW), one frame strengthened by CIP infilled wall (2-PW), and six frames strengthened by multiple precast concrete wall panels. The differences in these multiple precast panel infilled walls were in the methods of connecting the walls to the frames and the existence of wall openings. A uniform axial stress of $30 \mathrm{kgf} / \mathrm{cm}^{2}$ was applied to each column, and the frames were tested under quasi-static cyclic lateral load. This experimental program's main objective was to study the effectiveness of using multiple precast panels for strengthening lightly reinforced concrete frames. Table 4.5 lists the typical parameters and properties of the selected specimens. Figure 4.9 shows the geometry, dimensions, and reinforcement pattern of a typical specimen. Figure 4.10 shows the hysteresis behavior of the CIP infilled specimen 2-PW and the multiple precast panels infilled specimen 4-C3C due to quasi-static cyclic loading.

Table 4.5 SUMMARY OF HIGASHI'S TEST SPECIMENS

\begin{tabular}{|c|c|c|c|c|c|c|c|c|}
\hline Specimen & $\begin{array}{l}\text { Colt } \\
\text { bxD } \\
(\mathrm{cm})\end{array}$ & $\begin{array}{r}\mathrm{umn} \\
\mathrm{A}_{\mathrm{g}} \\
\left(\mathrm{cm}^{2}\right)\end{array}$ & \multicolumn{3}{|c|}{$\begin{array}{l}\text { Concrete } \mathrm{f}^{\prime} \mathrm{P}_{\mathrm{x}} / \mathrm{A}_{\mathrm{cg}} \\
\left(\mathrm{kgf} / \mathrm{cm}^{2}\right) \quad\left(\mathrm{kgf} / \mathrm{cm}^{2}\right) \\
\text { Frame Wall }\end{array}$} & $\begin{array}{l}\mathrm{L}_{b} / \mathrm{H}_{\mathrm{c}} \\
\text { Ratio }\end{array}$ & $\begin{array}{l}\text { Construction } \\
\text { and Anchor } \\
\text { Type }\end{array}$ & $\begin{array}{l}\text { Lax. } \\
\text { Load } \\
\text { ton) }\end{array}$ \\
\hline $1-\mathrm{F} 1$ & $20 \times 20$ & 5.16 & 176.0 & --.- & 30.0 & 1.78 & Bare Frame & 10.7 \\
\hline 2-PW & $20 \times 20$ & 5.16 & 176.0 & 219.0 & 30.0 & 1.78 & CIP Infill/Wedge & 40.0 \\
\hline $5-\mathrm{F} 2$ & $20 \times 20$ & 5.16 & 210.0 & ---- & 30.0 & 1.78 & Bare Frame & 11.1 \\
\hline 13-FW & $20 \times 20$ & 5.16 & 210.0 & 210.0 & 30.0 & 1.78 & Monolithic & 58.0 \\
\hline $4-C 3 C$ & $20 \times 20$ & 5.16 & 176.0 & 242.0 & 30.0 & 1.78 & Precast Panels & 46.0 \\
\hline $6-\mathrm{C} 2 \mathrm{~A}$ & $20 \times 20$ & 5.16 & 210.0 & 228.0 & 30.0 & 1.78 & $\begin{array}{l}\text { Precast Panels } \\
\text { w/Center Openin }\end{array}$ & 15.7 \\
\hline $7-\mathrm{C} 2 \mathrm{~B}$ & $20 \times 20$ & 5.16 & 210.0 & 228.0 & 30.0 & 1.78 & $\begin{array}{l}\text { Precast Panels } \\
\text { w/Side Opening }\end{array}$ & 14.5 \\
\hline $9-\mathrm{C} 40$ & $20 \times 20$ & 5.16 & 210.0 & 228.0 & 30.0 & 1.78 & Precast Panels & 16.0 \\
\hline $3-C 3$ & $20 \times 20$ & 5.16 & 176.0 & 242.0 & 30.0 & 1.78 & Precast Panels & 33.0 \\
\hline $8-C 4$ & $20 \times 20$ & 5.16 & 210.0 & 228.0 & 30.0 & 1.78 & Precast Panels & 40.0 \\
\hline
\end{tabular}




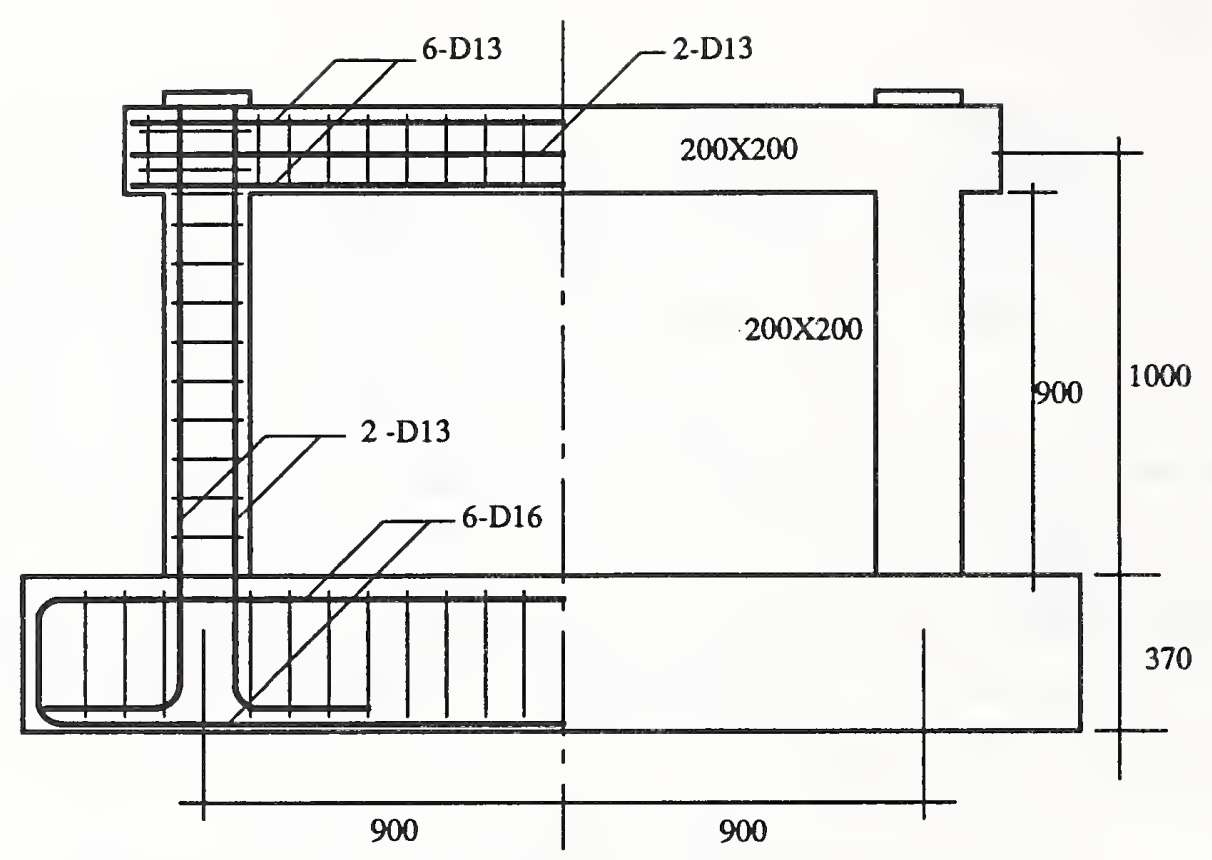

Figure 4.9 Geometry, Dimensions, and Reinforcement Patterns of Higashi's Test Specimen

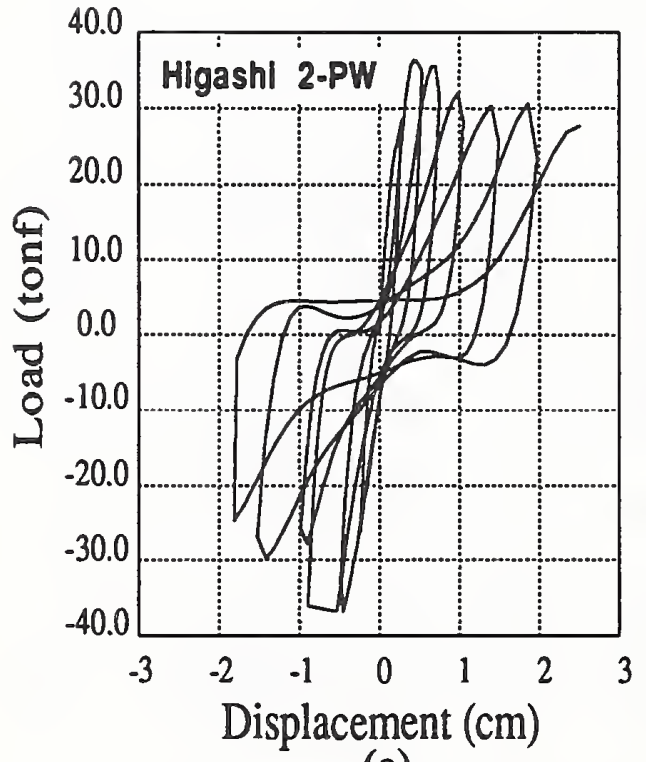

(a)

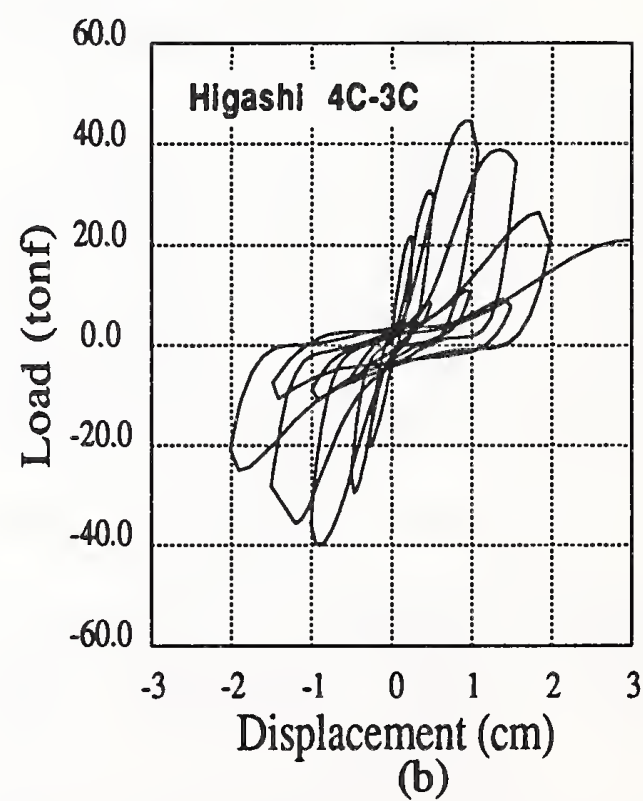

(b)

Figure 4.10 Hysteresis Behavior of Higashi's Test Specimens

(a) CIP Infilled Frame 2-PW

(b) Multiple Precast Panel Infilled Frame 4-C3C 


\subsubsection{Corley ${ }^{5,6,7}$}

Six monolithic Wall-Frame constructions, which represented high-rise structural walls $\left(\mathrm{L}_{\mathrm{b}} / \mathrm{H}_{\mathrm{c}}<1\right)$, were selected from the test program conducted by Corley et al. The specimens, named B5 to B9 and B11, were subjected to constant axial load in the column in combination with laterally-applied, quasi-static cyclic loading. Most of the specimens listed above were tested to complete failure and then repaired and retested. However, the results of the repaired specimens were not selected for this study since the focus here is on strengthening of existing, undamaged structures. The variables studied included the influence of axial load on the behavior of the walls, amount of column's flexural and shear reinforcement, and the effectiveness of the repair techniques employed in the test program. Table 4.6 lists some typical parameters and properties of the selected specimens. Figure 4.11 shows the geometry, dimensions, and reinforcement pattern of a typical specimen. Figure 4.12 shows the hysteresis behavior, as digitized from the published reports ${ }^{5,6,7}$, of a specimen without axial load (B5) and a specimen with axial load (B8) due to quasi-static cyclic lateral load.

Table 4.6 SUMMARY OF CORLEY'S SPECIMENS

\begin{tabular}{||c|cccccccc||}
\hline Specimen & \multicolumn{2}{|c|}{$\begin{array}{c}\text { Column } \\
\mathrm{bxD}\end{array}$} & $\begin{array}{c}\text { Concrete } \mathrm{f}_{\mathrm{g}}{ }_{\mathrm{c}} \\
(\mathrm{cm})\end{array}$ & $\begin{array}{c}\mathrm{P}_{\mathrm{x}} / \mathrm{A}_{\mathrm{cg}} \\
\left(\mathrm{kgf} / \mathrm{cm}^{2}\right)\end{array}$ & $\begin{array}{c}\left.\mathrm{L}^{2}\right) \\
\left(\mathrm{kgfame} / \mathrm{cm}^{2}\right)\end{array}$ & $\begin{array}{c}\mathrm{L}_{\mathrm{b}} / \mathrm{H}_{\mathrm{c}} \\
\text { Rall }\end{array}$ & $\begin{array}{c}\text { Construction } \\
\text { Rand Anchor } \\
\text { Type }\end{array}$ & $\begin{array}{c}\text { Max. } \\
\text { Load } \\
(\text { ton })\end{array}$ \\
\hline & & & & & & & & \\
B5 & $31 \times 31$ & 34.1 & 461.8 & 461.8 & 0.0 & 0.43 & Monolithic & 77.7 \\
B6 & $31 \times 31$ & 34.1 & 222.4 & 222.4 & 29.9 & 0.43 & Monolithic & 86.7 \\
B7 & $31 \times 31$ & 34.1 & 502.9 & 502.9 & 38.3 & 0.43 & Monolithic & 103.8 \\
B8 & $31 \times 31$ & 34.1 & 427.7 & 427.7 & 38.3 & 0.43 & Monolithic & 108.0 \\
B9 & $31 \times 31$ & 34.1 & 449.5 & 449.5 & 38.3 & 0.43 & Monolithic & 99.6 \\
B11 & $31 \times 31$ & 34.1 & 548.2 & 548.2 & 0.0 & 0.43 & Monolithic & 74.1 \\
\hline
\end{tabular}



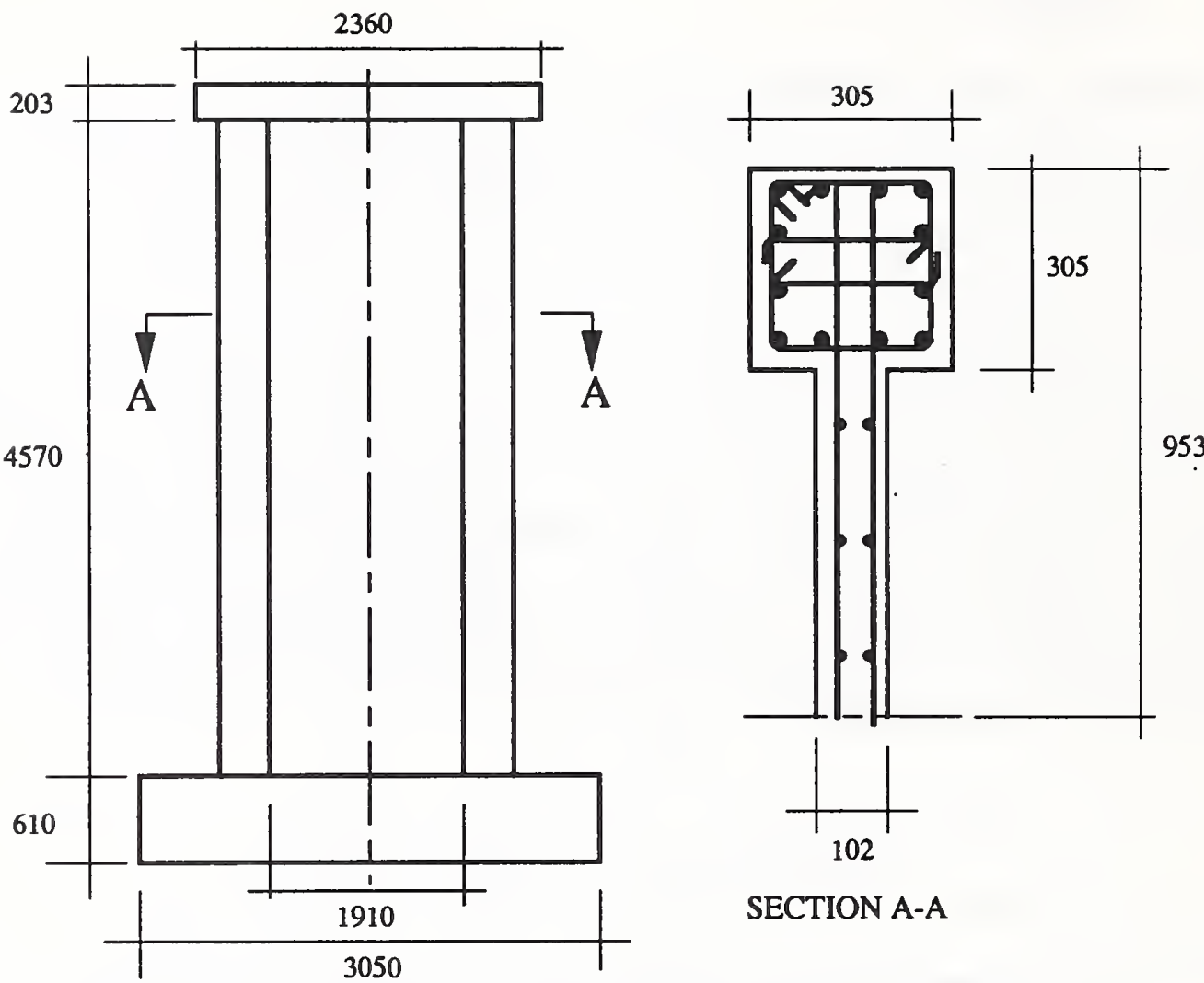

SECTION A-A

Figure 4.11 Geometry, Dimensions, and Reinforcement

Patterns of Corley's Test Specimen

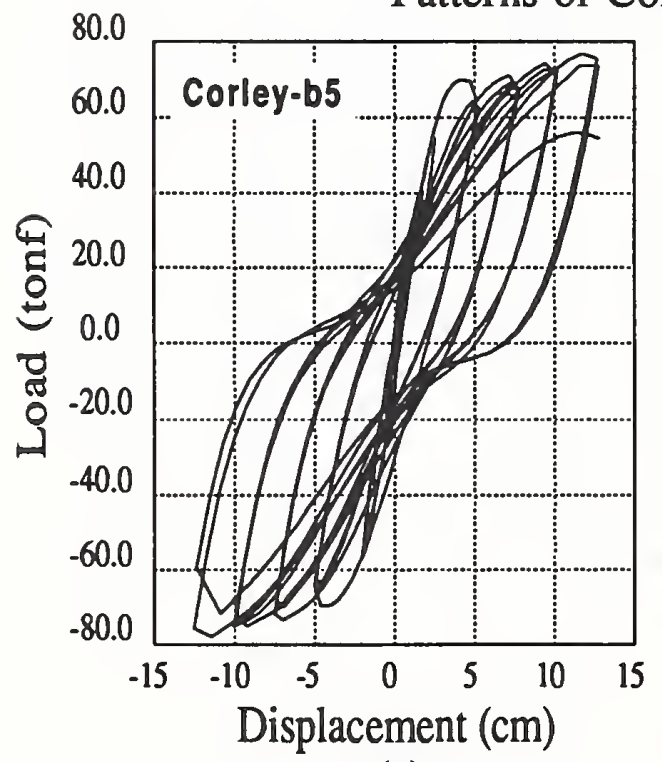

(a)

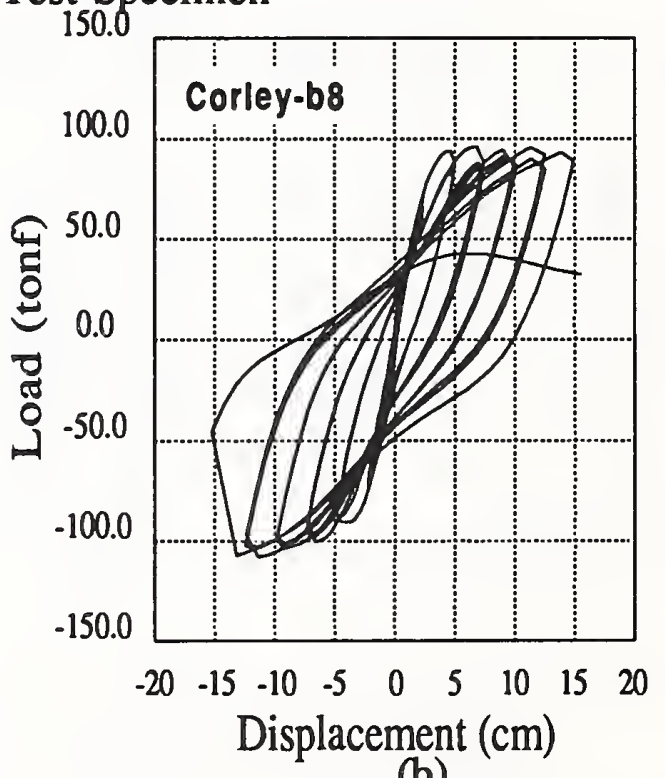

(b)

Figure 4.12 Hysteresis Behaviors of Corley's Test Specimens

(a) Monolithic Wall-Frame Specimen B5

(b) Monolithic Wall-Frame Specimen B8 


\subsubsection{Ogata et $\mathbf{a l}^{13}$}

All six monolithic wall-frame systems representing first-story, low-rise shear walls $\left(\mathrm{L}_{\mathrm{b}} / \mathrm{H}_{\mathrm{c}}\right.$ $\geq 1$ ) tested by Ogata et al. were included in this study. The specimens were designated K1 to K6. All six specimens have identical geometric dimensions. The variables investigated by Ogata et al. included the applied moment-to-shear ratios in the walls, the amount of flexural reinforcement in the columns and the walls, and the shear reinforcement in the columns. An axial load of 7.7 tons was applied to each column in combination with the quasi-static cyclic lateral load. Table 4.7 lists typical parameters of Ogata's specimens. Figure 4.13 shows the geometry, dimensions, and reinforcement pattern of the specimens. Figure 4.14 shows the hysteresis behavior of two typical specimens, $\mathrm{K} 2$ and $\mathrm{K} 5$, as digitized from the published report ${ }^{13}$.

Table 4.7 SUMMARY OF OGATA'S TEST SPECIMENS

\begin{tabular}{|c|c|c|c|c|c|c|c|}
\hline Specimen & \begin{tabular}{c}
\multicolumn{3}{c}{ Column } \\
bxD \\
$(\mathrm{cm})$ \\
$\left(\mathrm{cm}_{\mathrm{g}}^{2}\right)$
\end{tabular} & $\begin{array}{l}\text { Concre } \\
(\mathrm{kgf} / \mathrm{cr} \\
\text { Frame }\end{array}$ & $\begin{array}{l}\text { ete } \mathrm{f}_{\mathrm{c}} \\
\left.\mathrm{m}^{2}\right)( \\
\text { Wall }\end{array}$ & $\begin{array}{l}\mathrm{P}_{\mathrm{x}} / \mathrm{A}_{\mathrm{cg}} \\
\left.\mathrm{gf} / \mathrm{cm}^{2}\right)\end{array}$ & $\begin{array}{l}\mathrm{L}_{b} / \mathrm{H}_{c} \\
\text { Ratio }\end{array}$ & $\begin{array}{l}\text { Construction } \\
\text { and Anchor } \\
\text { Type }\end{array}$ & $\begin{array}{l}\text { Max. } \\
\text { Load } \\
\text { (ton) }\end{array}$ \\
\hline $\mathrm{K} 1$ & $20 \times 20 \quad 2.8$ & 196.0 & 196.0 & 19.2 & 1.07 & Monolithic & 45.0 \\
\hline $\mathrm{K} 2$ & $20 \times 20 \quad 5.7$ & 196.0 & 196.0 & 19.2 & 1.07 & Monolithic & 49.0 \\
\hline K3 & $20 \times 20 \quad 8.6$ & 196.0 & 196.0 & 19.2 & 1.07 & Monolithic & 55.2 \\
\hline K4 & $20 \times 20 \quad 5.7$ & 212.0 & 212.0 & 19.2 & 1.07 & Monolithic & 52.0 \\
\hline K5 & $20 \times 20 \quad 5.7$ & 212.0 & 212.0 & 19.2 & 1.07 & Monolithic & 59.9 \\
\hline K6 & $20 \times 208.6$ & 212.0 & 212.0 & 19.2 & 1.07 & Monolithic & 74.3 \\
\hline
\end{tabular}




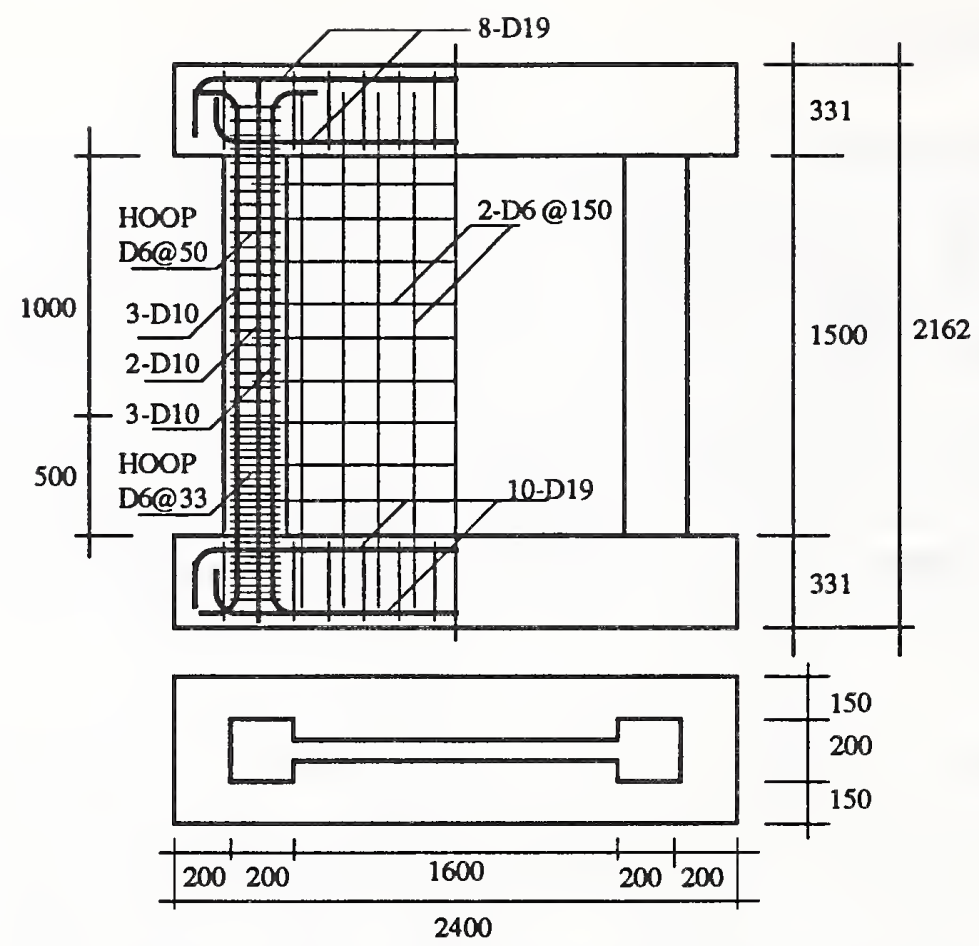

Figure 4.13 Geometry, Dimensions, and Reinforcement Patterns of Ogata's Test Specimen

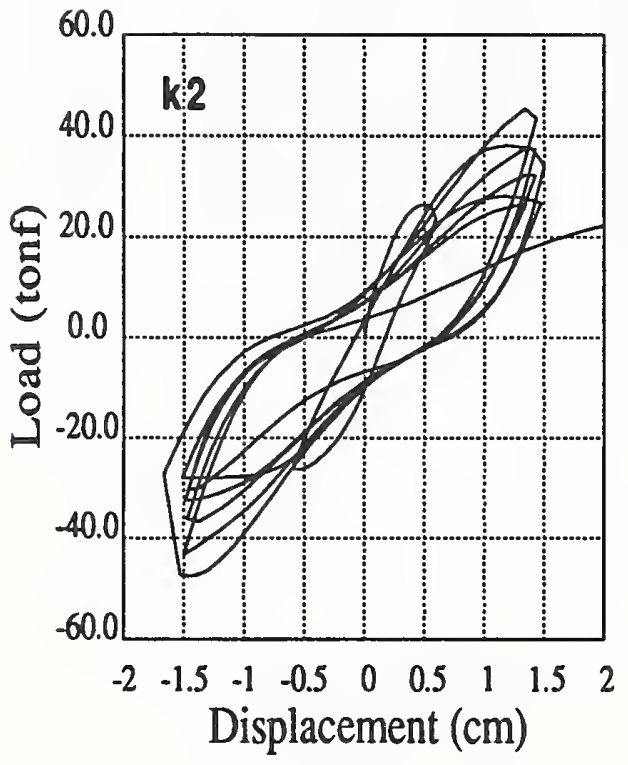

(a)

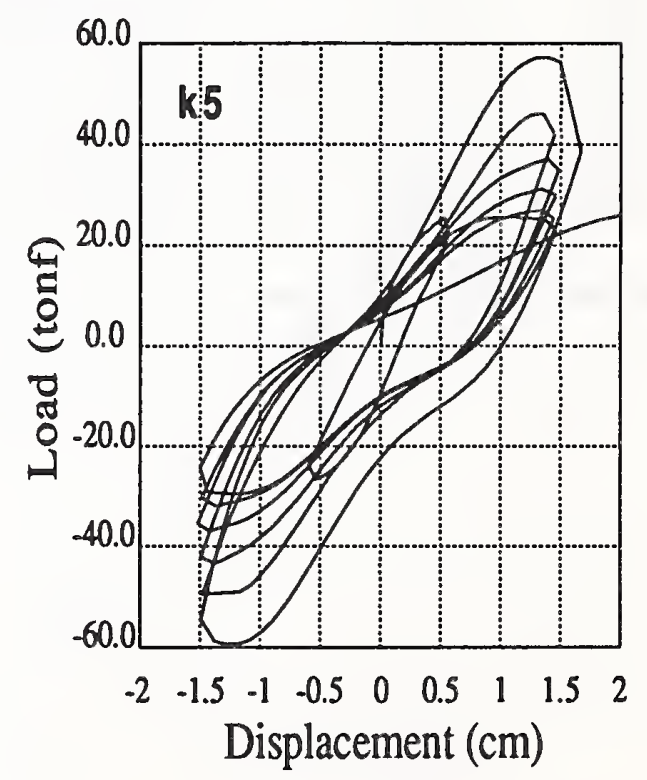

(b)

Figure 4.14 Hysteresis Behavior of Ogata's Test Specimens

(a) Monolithic Wall-Frame Specimen K2

(b) Monolithic Wall-Frame Specimen K5 


\subsubsection{Gaynor $^{18}$}

Three two-third scale, one-bay, one-story frames infilled by solid shotcrete wall, shotcrete wall with a window opening, and shotcrete wall with a door opening, were tested by Gaynor $^{18}$. The specimens were designed to be representative of non-ductile reinforced concrete frames of the 1950's (widely spaced column ties inadequate for the confinement of concrete core, compression splice at column base inadequate for developing tensile yield in the bars). The specimens were subjected to quasi-static cyclic loading. Typical parameters of the specimens in this test program are listed in Table 4.8. Figure 4.15 shows the geometry of the specimens tested in this program. The hysteresis behavior of two specimens, specimen W with window opening and specimen D with door opening, are shown in Figure 4.16.

Table 4.8 SUMMARY OF GAYNOR'S TEST SPECIMENS

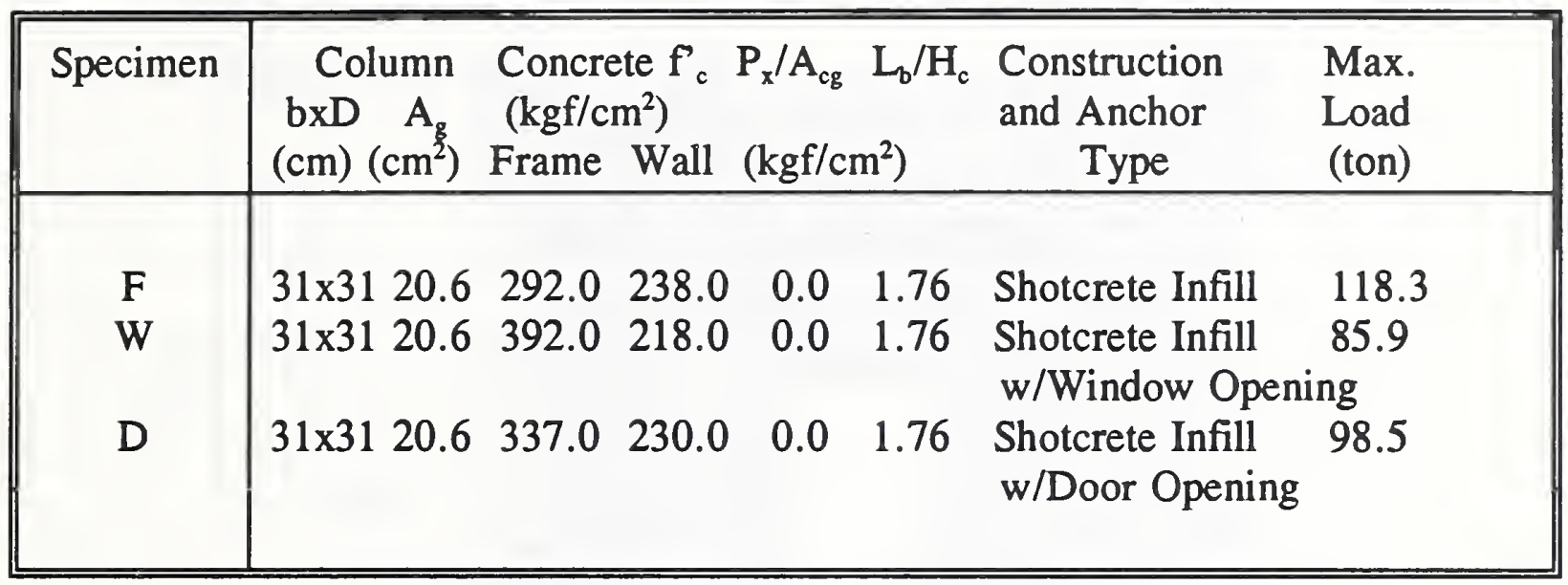

\subsubsection{Shah $^{16}$}

One of the specimens tested by Gaynor did not suffer major damage to the bounding frame. The specimen's shotcrete infilled wall was removed and the frame was restrengthened by a CIP infilled wall with a door opening and tested by Shah ${ }^{16}$. Typical parameters of this specimen, which was included in this study, are listed in Table 4.9. The hysteresis behavior of the tested specimen is shown in Figure 4.17. 
Table 4.9 SUMMARY OF SHAH'S TEST SPECIMEN

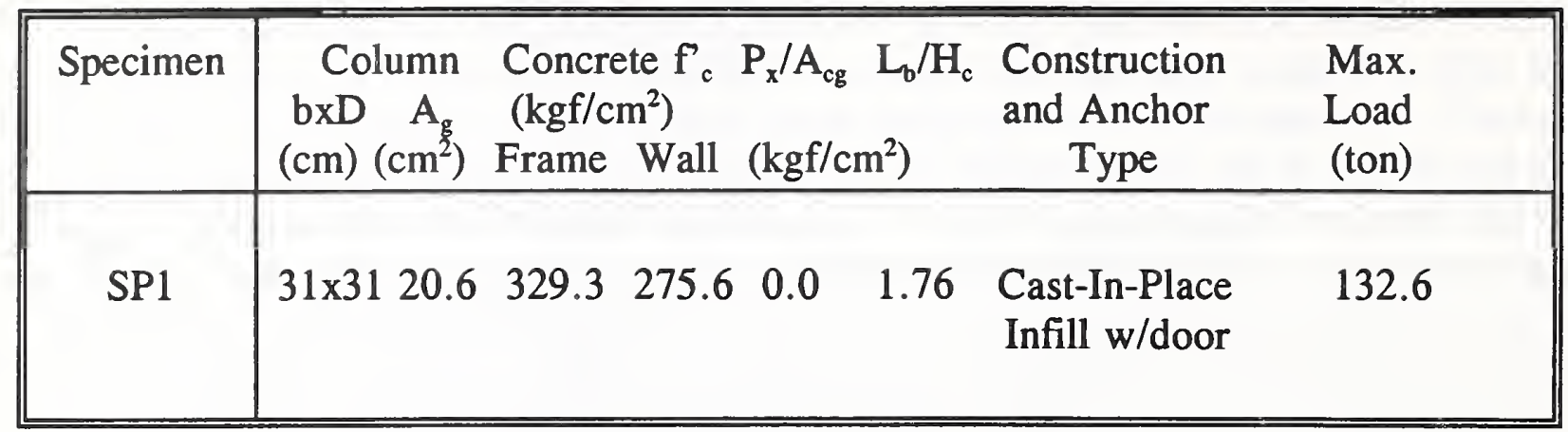

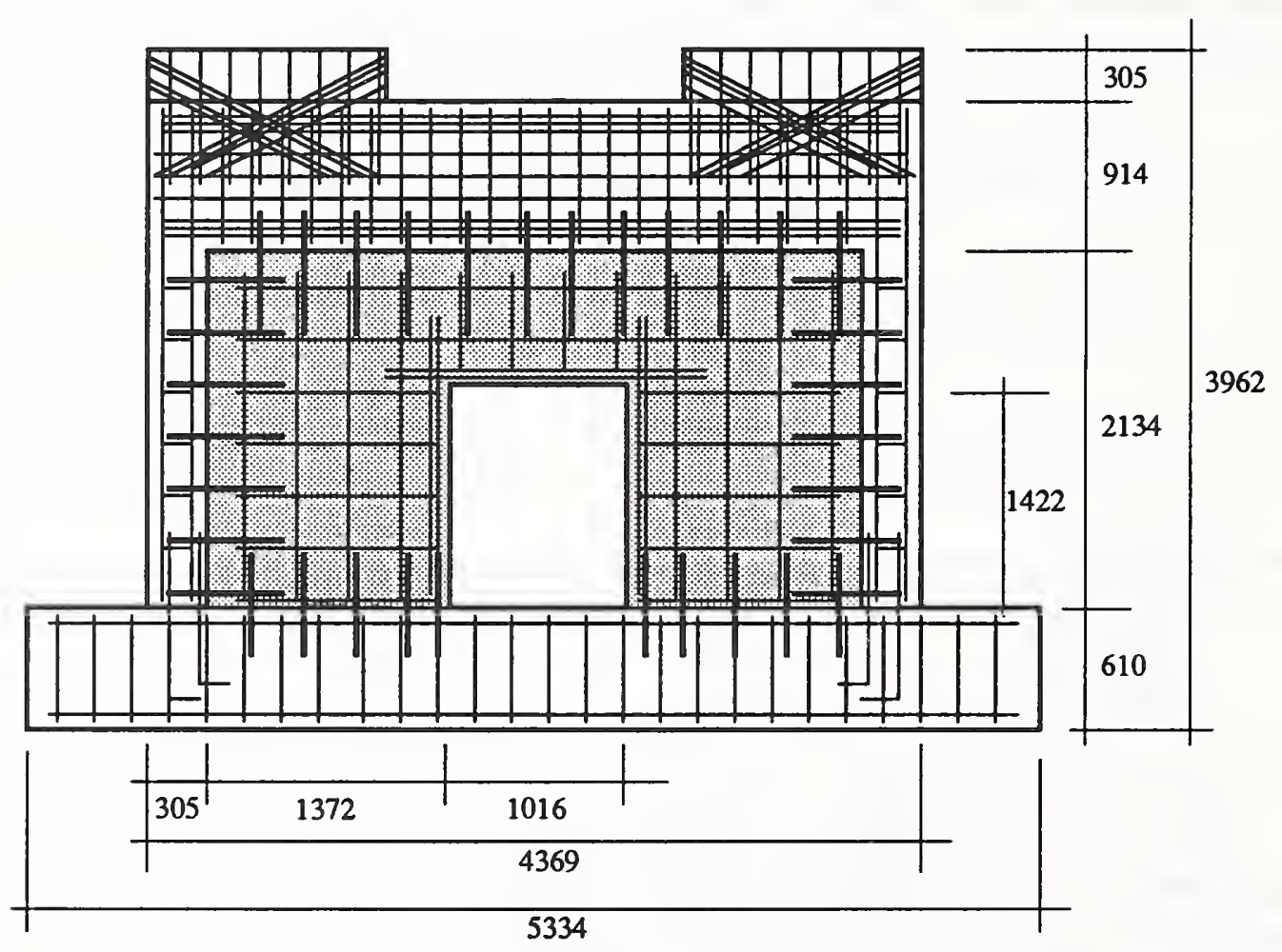

Figure 4.15 Geometry, Dimensions, and Reinforcement Patterns of Gaynor and Shah's Test Specimen 


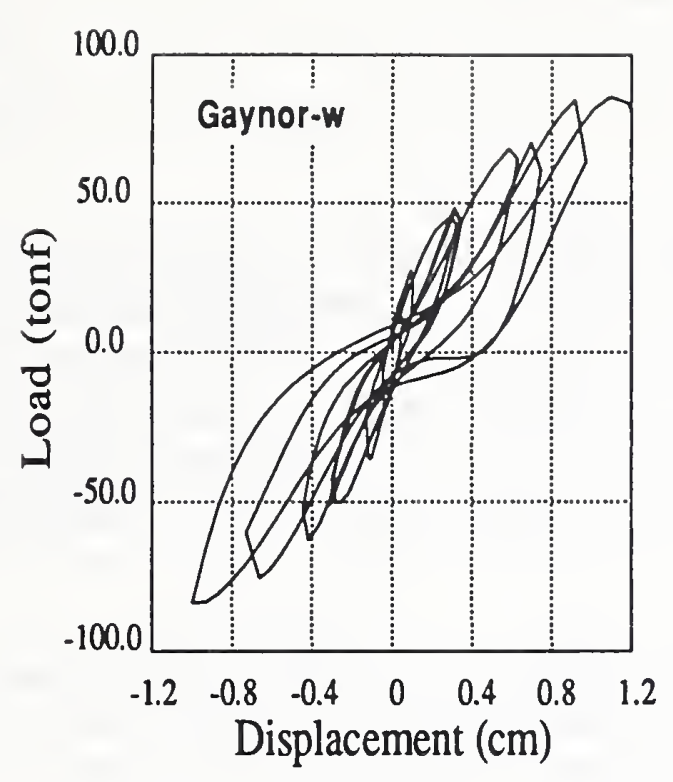

(a)

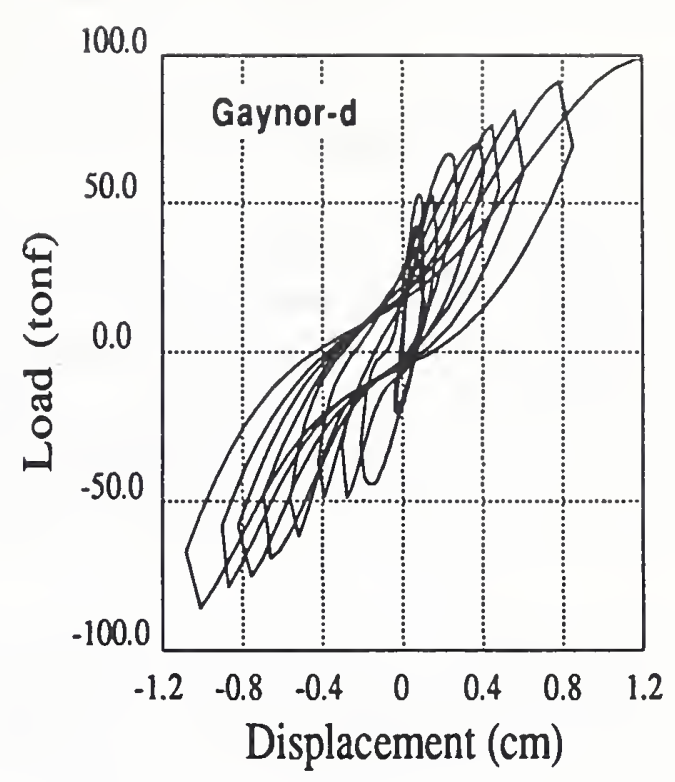

(b)

Figure 4.16 Hystereses Behavior of Gaynor's Test Specimens

(a) Shotcrete Infilled Frame with Window Opening W

(b) Shotcrete Infilled Frame with Door Opening D

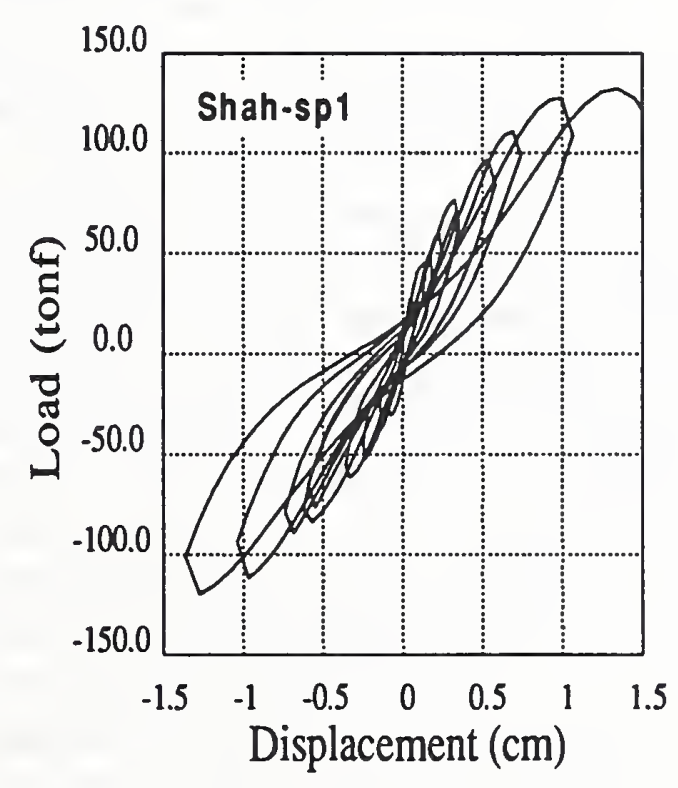

Figure 4.17 Hysteresis Behavior of Shah's Specimen SP1 


\subsection{Development of Three-Parameter Hysteresis Models}

The procedure used for the development of the empirical three-parameter hysteresis models in this study involved the following two main tasks:

1. Determine the values for three parameters $\alpha, \beta$, and $\gamma$ which best fit the experimental hysteresis loop of each of the fifty five tests selected in section 4.1. The method used for this process is referred to as the System Identification method (see $\mathrm{Yeh}^{38}, 1988$ and Kunnath and Reinhorn ${ }^{37}, 1989$ ). The corresponding fifty five sets of $\alpha, \beta, \gamma$, so determined are from here on referred to as the estimated parameters $\alpha, \beta, \gamma$. This task is further described in section 4.2.1 of this report.

2. Based on the fifty five sets of estimated parameters $\alpha, \beta$, and $\gamma$, perform multiplevariable regression to obtain empirical expressions for $\alpha, \beta$, and $\gamma$ in terms of the physical properties of the selected test specimens. These empirical expressions, referred to in this study as the hysteresis models, are then used to predict the three parameters for the analysis of bare frames, infilled frames, and monolithic wallframe constructions. This task is explained in detail in section 4.2.2.

\subsubsection{System Identification of Hysteresis Parameters}

The concept of identifying or estimating hysteresis parameters of concrete structures subjected to cyclic loading using actual test results has been tried by many researchers. The purpose is to derive a set of parameters which may be used to simulate as closely as possible the hysteresis behavior observed from experiment. Earlier research included the work by Yeh $^{38}$ (1988) at SUNY/Buffalo which utilized nonlinear search algorithms and optimization techniques to obtain the best possible set of hysteresis parameters based on the actual test results. Later modification of the optimization techniques used by $\mathrm{Yeh}^{38}$ (1988) were performed at NIST by Stone and Taylor ${ }^{40}$ (1992). The result is a graphicsbased system identification package, called NIDENT 3.0. Principally, the system identification procedure employed in NIDENT 3.0 performs a three dimensional trial and error search for a set of initial values of $\alpha, \beta, \gamma$ such that the cumulative error between the predicted and experimentally observed hysteretic energy is minimized. NIDENT 3.0 displays the hysteresis response corresponding to the initial parameters together with the experimentally-observed response. The users are then allowed to interactively adjust the values of $\alpha, \beta$, and $\gamma$ while continuously monitoring the fit between the predicted and the experimentally-observed responses in real time until a satisfactory match between the responses is observed. At any time during the fitting process, a check of cumulative error, in terms of the absorbed hysteretic energy, between the latest prediction and the experimentally-observed response can be performed. Generally, a reasonable visual match of the hysteretic responses and an absorbed energy cumulative error of within a few percent is considered satisfactory. The values of $\alpha, \beta$, and $\gamma$ so determined 
constitute the identified hysteresis parameters of the corresponding experiment. A more detailed discussion concerning NIDENT 3.0 is given in reference ${ }^{40}$.

The above system identification procedure was used to identify hysteresis parameters of the fifty-five test results selected for this study and described in section 4.1. In most cases, the cumulative errors between the predicted and measured total absorbed hysteretic energy were less than 3 percent. Table 4.10 lists the estimated hysteresis parameters and cumulative absorbed hysteresis energy error for each of the selected specimens. A negative difference in cumulative absorbed energy, as listed for a few cases in Table 4.10 , simply means that the total cumulative absorbed energy predicted by system identification exceeds that obtained from experiment. Examples of the match between the predicted and measured hysteresis responses of four specimens, Aoyama's specimen C2005-III, Ogata's specimen K3, Higashi's specimen 5-F2, and Gaynor's specimen W, are shown in Figures 4.18 a to $\mathrm{h}$. In these Figures ( $4.18 \mathrm{a}, \mathrm{c}, \mathrm{e}, \mathrm{g}$ ), the dashed lines represent the experimental results and the solid lines are the predicted hysteresis responses corresponding to the estimated hysteresis parameters $\alpha, \beta, \gamma$ obtained from system identification. Also plotted in Figures 4.18 (b, d, f, h) are histograms of the measured and predicted absorbed energy for the four specimens. As can be seen from Figures 4.18 , the three parameters $\alpha, \beta, \gamma$, identified for each test specimen were able to predict reasonably well the load-deformation hysteresis behavior of the test specimens. They also predict the absorbed energy of the specimen on a per cycle basis. A complete set of comparative plots for each of the fifty-five specimens, superposing the best-fit curve generated with NIDENT on the experimental load-displacement curve, are reproduced in Appendix B.

\subsubsection{Empirical Expressions for Hysteresis Parameters}

Empirical expressions for the hysteresis parameters were formulated by correlating the estimated hysteresis parameters, $\alpha_{\text {exp }}, \beta_{\text {exp }}$, and $\gamma_{\text {exp }}$, identified from the fifty five tests, with a set of variables relating to the geometric and material properties, dimensions, and reinforcement patterns of the specimens. These variables were selected to include all possible factors which were judged to have an influence on the hysteresis behavior of the lightly reinforced concrete frames. The variables are defined and listed in Appendix A. The numerical values corresponding to each of these variables for each of the fifty five test specimens are given in Appendix B. The correlation was performed using the linear regression procedure of a commercially available statistical analysis software package. There are several model-selection methods which can be selected for the regression analysis. The method which maximizes the $R^{2}$ values, was chosen for this study. $R^{2}$ is an indicator of how much variation in the data is explained by the empirical expressions obtained by the regression analysis and is defined as:

$$
\mathrm{R}^{2}=1-(\mathrm{SSE} / \mathrm{TSS})
$$


where SSE is the Sum of Square for Errors, and TSS is the Corrected Total Sum of Squares. As the Sum of Square for Errors approaches zero, $\mathrm{R}^{2}$ values approach one, indicating increasingly accurate models.

Four sets of empirical expressions for $\alpha, \beta$, and $\gamma$, constituting the hysteresis models for existing frames, frames strengthened by CIP infilled walls, frames strengthened by precast concrete wall panels, and monolithic wall-frame constructions, were derived from the regression analysis. It should be noted that, even though $\alpha, \beta, \gamma$ are non-dimensional parameters, the variables which are included in the hysteresis models are listed following specific units (see Appendix B). Therefore, to correctly compute $\alpha, \beta, \gamma$, units which are consistent with those listed in Appendix B must be used. The empirical expressions for each of those cases are given in the following sections. 


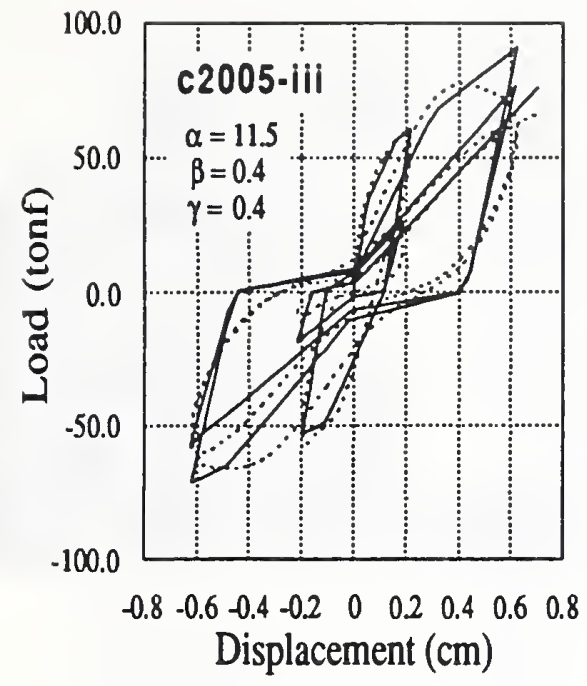

(a)

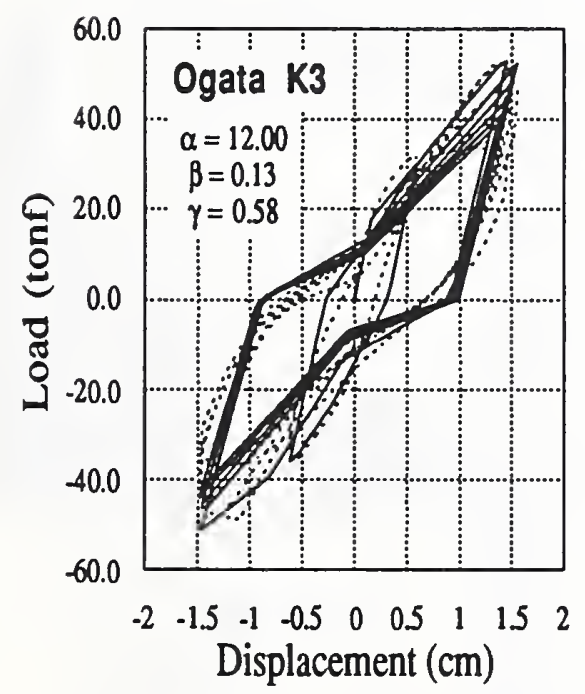

(c)

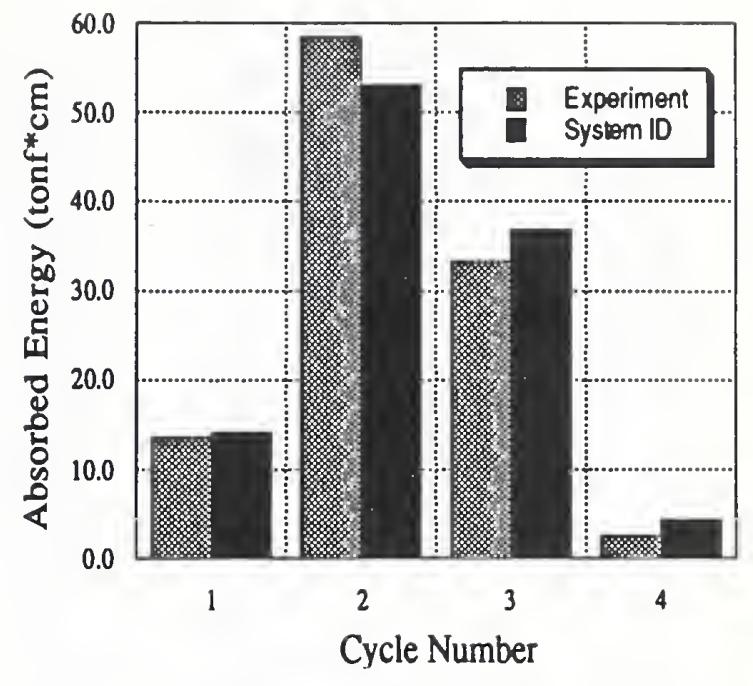

(b)

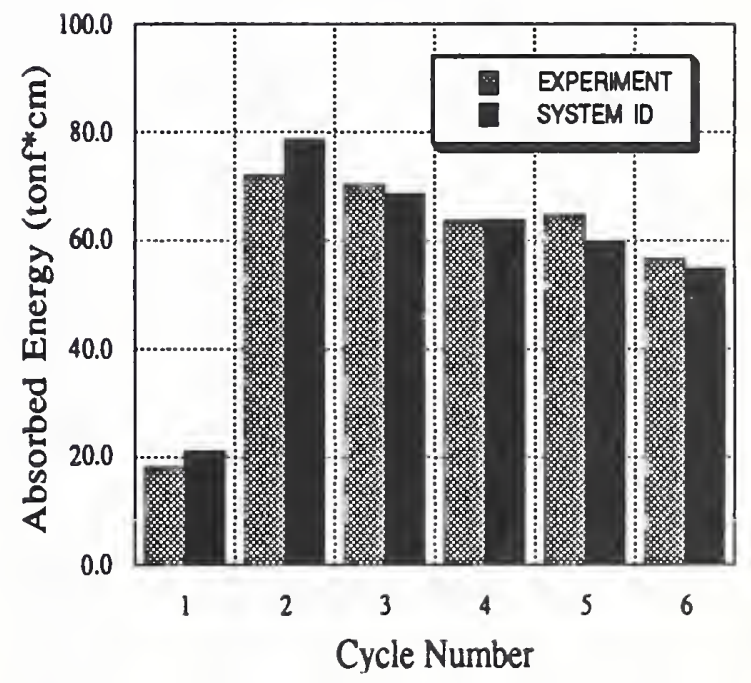

(d)

Figure 4.18 System Identification of Experimental Results
(a) Load-Deformation Characteristics of Specimen C2005-III
(b) Absorbed Energy Histograms of Specimen C2005-III
(c) Load-Deformation Characteristics of Specimen K3
(d) Absorbed Energy Histograms of Specimen K3 


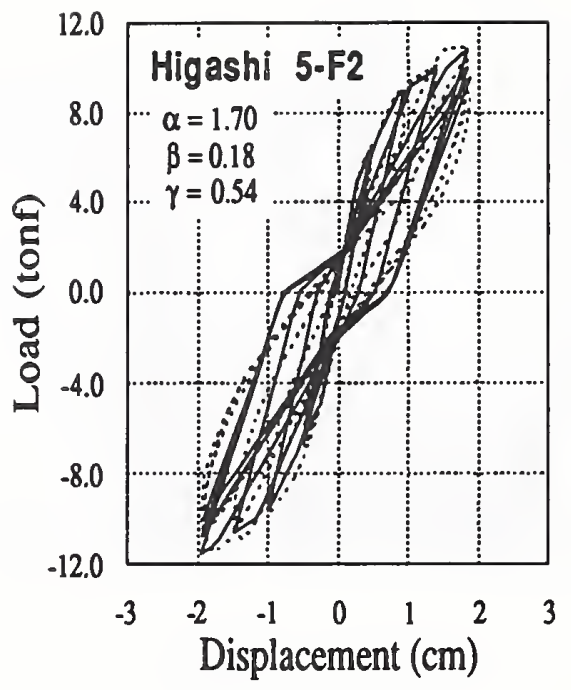

(e)

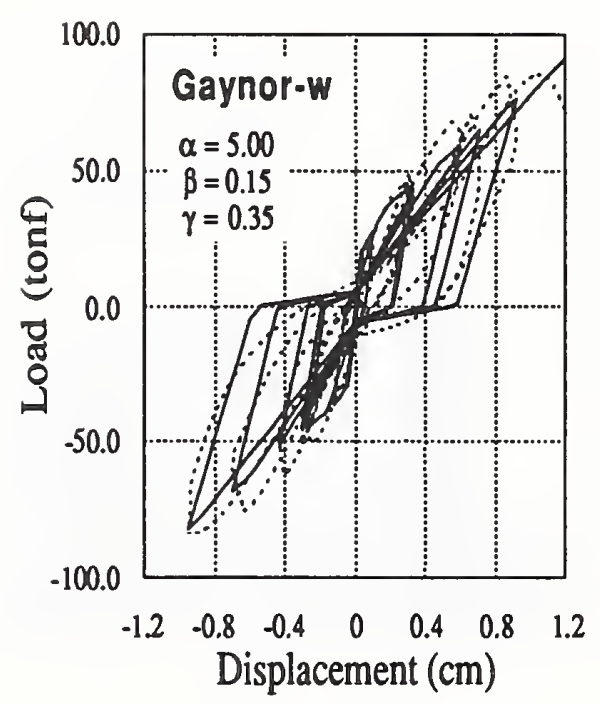

(g)

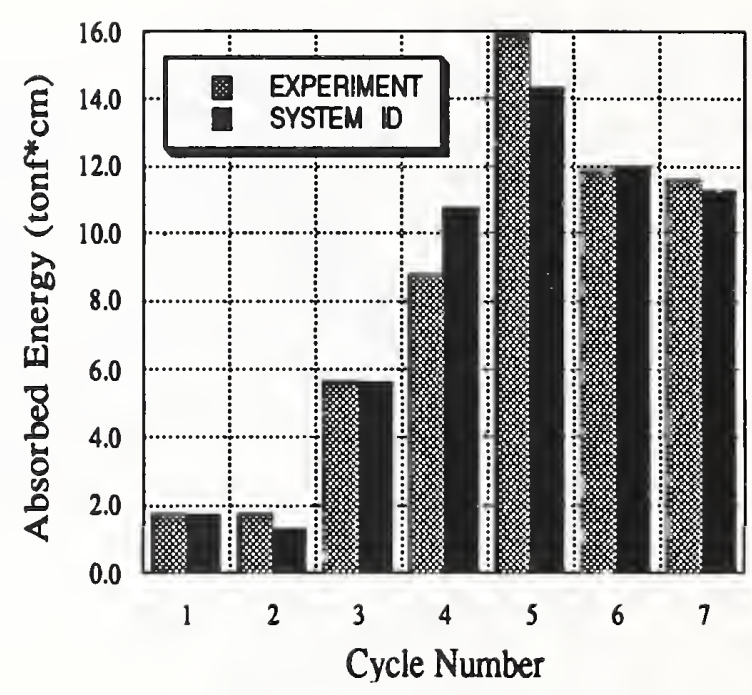

(f)

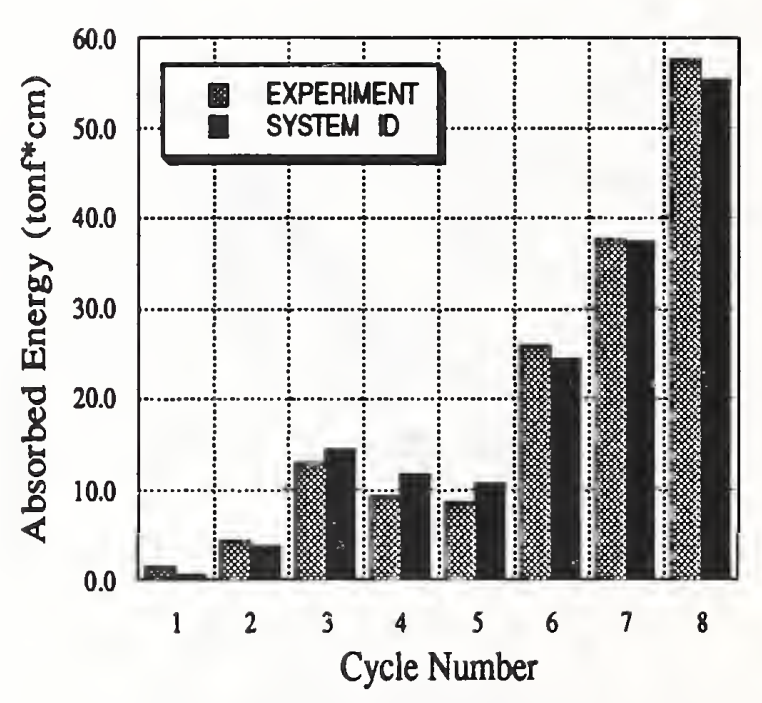

(h)

Figure 4.18 System Identification of Experimental Results (continued)

(e) Load-Deformation Characteristics of Specimen 5-F2

(f) Absorbed Energy Histograms of Specimen 5-F2

(g) Load-Deformation Characteristics of Specimen W

(h) Absorbed Energy Histograms of Specimen W 
Table 4.10 ESTIMATED HYSTERESIS PARAMETERS FROM SYSTEM IDENTIFICATION

\begin{tabular}{|c|c|c|c|c|}
\hline TEST NAME & $\alpha$ & $\beta$ & $\gamma$ & ENERGY DIFFERENCE (\%) \\
\hline AOYAMA C2005-I & 11.00 & 0.35 & 0.25 & -0.50 \\
\hline AOYAMA C2005-11 & 9.00 & 0.25 & 0.31 & 0.40 \\
\hline AOYAMA C2005-111 & 11.50 & 0.40 & 0.4 & 0.40 \\
\hline AOYAMA C2015-A & 9.00 & 0.88 & 0.5 & 0.10 \\
\hline AOYAMA C2015-B & 7.25 & 0.70 & 0.3 & 0.10 \\
\hline AOYAMA C2015-C & 2.50 & 0.02 & 0.2 & 0.20 \\
\hline AOYAMA P2005-A & 12.50 & 0.10 & 0.3 & -0.30 \\
\hline AOYAMA P2015-A & 2.00 & 0.10 & 0.3 & -0.30 \\
\hline AOYAMA C4015 & 4.00 & 0.01 & 0.32 & 0.00 \\
\hline AOYAMA P4015 & 3.50 & 0.01 & 0.4 & 0.70 \\
\hline AOYAMA M2005 & 12.50 & 0.45 & 0.94 & 0.10 \\
\hline AOYAMA CH2015 & 7.50 & 0.34 & 0.32 & 0.20 \\
\hline AOYAMA CH2018 & 12.50 & 0.96 & 0.63 & -0.30 \\
\hline AOYAMA OLUZO15 & 12.50 & 0.65 & 0.5 & -0.50 \\
\hline KAHN SP1 & 13.00 & 0.20 & 0.95 & -11.80 \\
\hline KAHN SP2 & 4.00 & 0.20 & 0.6 & 0.60 \\
\hline KAHN SP3 & 7.50 & 0.98 & 0.15 & 1.10 \\
\hline KAHN SP5 & 12.50 & 0.20 & 0.49 & 0.10 \\
\hline HAYASHI W1 & 5.00 & 0.39 & 0.8 & -0.40 \\
\hline HAYASHI W2 & 2.50 & 0.11 & 0.49 & 0.20 \\
\hline HAYASHI W4 & 11.50 & 0.44 & 0.75 & 0.00 \\
\hline HAYASHI W5 & 12.50 & 0.49 & 0.35 & -0.30 \\
\hline HAYASHI W6 & 12.50 & 0.75 & 0.5 & 0.40 \\
\hline SUGANO-WHA & 4.50 & 0.15 & 0.16 & 0.00 \\
\hline SUGANO-W4OS & 9.00 & 0.62 & 0.65 & -0.30 \\
\hline SUGANO-W4OW & 12.50 & 0.64 & 0.5 & 0.20 \\
\hline SUGANO-WBOS & 5.50 & 0.40 & 0.25 & 0.30 \\
\hline SUGANO-F & 3.50 & 0.45 & 0.7 & 0.20 \\
\hline SUGANO-WBL & 4.00 & 0.40 & 0.8 & -1.20 \\
\hline SUGANO-WCO & 12.50 & 0.39 & 0.5 & 0.30 \\
\hline HIGASHI 1-F1 & 10.50 & 0.75 & 0.94 & 3.00 \\
\hline HIGASHI 2-PW & 17.50 & 0.63 & 0.47 & 1.40 \\
\hline HIGASHI 5-F2 & 1.70 & 0.18 & 0.536 & -0.20 \\
\hline HIGASHI 13-FW & 10.00 & 0.45 & 0.9 & 0.30 \\
\hline HIGASHI 4-C3C & 12.50 & 1.00 & 0.2 & 9.60 \\
\hline HIGASHI 6-C2A & 12.50 & 0.48 & 0.6 & 0.40 \\
\hline HIGASHI 7-C2B & 6.00 & 0.49 & 0.5 & 7.00 \\
\hline HIGASHI $9-C_{40}$ & 10.50 & 0.31 & 0.98 & 3.10 \\
\hline HIGASHI 3-C3 & 12.50 & 0.85 & 0.25 & 0.20 \\
\hline HIGASHI 8-C4 & 12.50 & 1.35 & 0.45 & 0.50 \\
\hline CORLEY B5 & 3.00 & 0.02 & 0.7 & -3.00 \\
\hline CORLEY B6 & 2.00 & 0.10 & 0.5 & -0.50 \\
\hline CORLET B7 & 3.00 & 0.01 & 0.985 & -3.00 \\
\hline CORLEY B8 & 5.50 & 0.55 & 0.95 & -0.10 \\
\hline CORLEY B9 & 8.50 & 0.04 & 0.9 & -0.10 \\
\hline CORLEY B11 & 6.00 & 0.05 & 0.7 & 0.30 \\
\hline OGATA K1 & 7.50 & 0.49 & $0.7 \pi$ & 0.30 \\
\hline OGATA K2 & 12.50 & 0.02 & 0.99 & 0.20 \\
\hline OGATA K3 & 12.00 & 0.13 & 0.58 & 0.40 \\
\hline OGATA $\quad$ K4 & 12.50 & 0.08 & 0.98 & 0.20 \\
\hline OGATA K5 & 12.50 & 0.36 & 0.9 & 0.10 \\
\hline OGATA K6 & 10.50 & 0.42 & 1 & -0.50 \\
\hline GAYNOR F & 2.00 & 0.11 & 0.44 & 0.30 \\
\hline GAYNOR W & 5.00 & 0.15 & 0.35 & 0.50 \\
\hline GAYNOR D & 3.50 & 0.20 & 0.94 & 0.50 \\
\hline
\end{tabular}




\subsubsection{Hysteresis Model for Existing Frames}

Empirical expressions for $\alpha, \beta$, and $\gamma$ for existing reinforced concrete frames are given as follows:

$$
\begin{gathered}
\alpha=a_{0}+a_{1} d_{t b}+a_{2} \rho_{v b}+a_{3} b_{c}+a_{4} P_{x c}+a_{5}\left(\frac{P_{x c}}{A_{c} f_{c f}}\right)+a_{6}\left(\frac{h_{c}}{L_{b}}\right) \\
+a_{7} \rho_{v c}+a_{8} f_{c f}+a_{9} f_{y}+a_{10} E_{c f}+a_{11} I_{c}
\end{gathered}
$$

$$
\begin{gathered}
\beta=b_{0}+b_{1} b_{t b}+b_{2} \rho_{f b}+b_{3} \rho_{v b}+b_{4} A_{c}+b_{5}\left(\frac{h_{c}}{L_{b}}\right)+b_{6} \rho_{f c} \\
+b_{7} f_{y}+b_{8} E_{c f}+b_{9} E_{s}
\end{gathered}
$$

$$
\begin{gathered}
\gamma=g_{0}+g_{1} b_{t b}+g_{2} \rho_{f t b}+g_{3} d_{b b}+g_{4} b_{b b}+g_{5} \rho_{v b b}+g_{6} P_{x c} \\
+g_{7} \rho_{f c}+g_{8} f_{c f}+g_{g} f_{y}
\end{gathered}
$$

The $\mathrm{R}^{2}$ values for the above hysteresis models are $0.90,0.79$, and 0.74 for $\alpha, \beta$, and $\gamma$, respectively. The regression coefficients, $a_{i}, b_{i}$, and $g_{i}$, are listed in Table 4.11. Note that these coefficients and all others that follow are calibrated for use with SI units. The variable definitions are given in Appendix A. The ratio of the predicted hysteresis parameters (calculated using the above empirical expressions) and the estimated hysteresis parameters (obtained from the system identification procedure) are plotted in Figures 4.19 $\mathrm{a}, \mathrm{b}$ and $\mathrm{c}$ to facilitate an assessment of the adequacy of the empirical expressions in predicting the hysteresis parameters of the test specimens. A ratio of 1.0 means there is no deviation between the predicted and the estimated values. 
TABLE 4.11 REGRESSION COEFFICIENTS FOR HYSTERESIS MODEL FOR EXISTING FRAME

\begin{tabular}{||c|c|c|c||}
\hline $\mathrm{i}$ & $\mathrm{a}_{\mathrm{i}}$ & $\mathrm{b}_{\mathrm{i}}$ & $\mathrm{g}_{\mathrm{i}}$ \\
\hline 0 & -160.952 & 3.749 & -0.174 \\
\hline 1 & 1.525 & $-5.47 \times 10^{-3}$ & $-7.6 \times 10^{-3}$ \\
\hline 2 & -49.955 & -0.124 & $8.91 \times 10^{-2}$ \\
\hline 3 & -9.132 & 1.932 & $4.31 \times 10^{-3}$ \\
\hline 4 & -1.182 & $-8.61 \times 10^{-4}$ & -0.011 \\
\hline 5 & 539.596 & -1.720 & 0.597 \\
\hline 6 & 46.925 & 0.086 & $5.29 \times 10^{-3}$ \\
\hline 7 & 13.186 & 0.125 & -0.051 \\
\hline 8 & -463.459 & $-7.26 \times 10^{-3}$ & 1.685 \\
\hline 9 & 3.269 & $-5.69 \times 10^{-4}$ & 0.204 \\
\hline 10 & 1.381 & ---- & $-\cdots--$ \\
\hline 11 & $4.99 \times 10^{-6}$ & ---- & ---- \\
\hline
\end{tabular}




\subsubsection{Hysteresis Model for Frames with CIP Infilled Walls}

Similarly, empirical expressions for $\alpha, \beta$, and $\gamma$ for reinforced concrete frames strengthened by CIP infilled walls are given as follows:

$$
\begin{aligned}
\alpha=a_{0} & +a_{1} d_{z b}+a_{2} \rho_{v b}+a_{3} b_{c}+a_{4} P_{x c}+a_{5}\left(\frac{P_{x c}}{A_{c} f_{c f}}\right)+a_{6}\left(\frac{h_{c}}{L_{b}}\right)+a_{7} \rho_{v c} \\
& +a_{8} f_{c f}+a_{9} f_{y}+a_{10} E_{c f}+a_{11} I_{c}+a_{12} t_{w}+a_{13} I_{w}+a_{14} I_{0} \\
& +a_{15} \rho_{w v}+a_{16} f_{c w}+a_{17} f_{y w}+a_{18} f_{y a}+a_{19} A_{a c}+a_{20} d_{a c}
\end{aligned}
$$

$$
\begin{aligned}
\beta= & b_{0}+b_{1} b_{\imath b}+b_{2} \rho_{f b}+b_{3} \rho_{v b}+b_{4} A_{c}+b_{5}\left(\frac{h_{c}}{L_{b}}\right)+b_{6} \rho_{f c}+b_{7} f_{y} \\
+ & b_{8} E_{c f}+b_{9} E_{s}+b_{10} t_{w}+b_{11} I_{0}+b_{12} A_{w}+b_{13} \rho_{w h}+b_{14} \rho_{w v} \\
& +b_{15} f_{y w}+b_{16} A_{a b}+b_{17} d_{a b}+b_{18} s_{a c}+b_{19} A_{a c} f_{y a}
\end{aligned}
$$

$$
\begin{aligned}
\gamma= & g_{0}+g_{1} d_{\imath b}+g_{2} d_{c}+g_{3} P_{x c}+g_{4}\left(\frac{P_{x c}}{A_{c} f_{c f}}\right)+g_{5}\left(\frac{h_{c}}{L_{\imath b}}\right)+g_{6} \rho_{c f}+g_{7} f_{c f} \\
& +g_{g} f_{y}+g_{9} E_{c f}+g_{10} E_{s}+g_{11}\left(12 E_{c f} \frac{I_{c}}{h_{c}^{3}}\right)+g_{12} t_{w}+g_{13} I_{o}+g_{14} h_{3} \\
& +g_{15} f_{c w}+g_{16}\left(\frac{A_{o}}{L_{w} h_{c}}\right)+g_{17} f_{y a}+g_{18}\left(A_{a b} f_{y a}\right)+g_{19} s_{a c}+g_{20}\left(A_{a c} f_{y a}\right)
\end{aligned}
$$

The corresponding regression coefficients, $a_{i}, b_{i}$, and $g_{i}$, are listed in Table 4.12 as follows: 
TABLE 4.12 REGRESSION COEFFICIENTS FOR HYSTERESIS MODEL FOR CAST-IN-PLACE INFILLED FRAMES

\begin{tabular}{|c|c|c|c|}
\hline $\mathrm{i}$ & $a_{i}$ & $b_{i}$ & $g_{i}$ \\
\hline 0 & -160.952 & 3.749 & -14.224 \\
\hline 1 & 1.525 & $-5.47 \times 10^{-3}$ & 0.017 \\
\hline 2 & -49.955 & -0.124 & 0.130 \\
\hline 3 & -9.132 & 1.932 & -0.022 \\
\hline 4 & -1.182 & $-8.61 \times 10^{-4}$ & 12.049 \\
\hline 5 & 539.596 & -1.720 & -3.035 \\
\hline 6 & 46.925 & 0.086 & -0.044 \\
\hline 7 & 13.186 & 0.125 & -23.471 \\
\hline 8 & -463.459 & $-7.26 \times 10^{-3}$ & 0.285 \\
\hline 8 & 3.269 & $-5.69 \times 10^{-4}$ & 0.071 \\
\hline 10 & 1.381 & -0.09 & $1.441 \times 10^{-1}$ \\
\hline 11 & $4.99 \times 10^{-6}$ & $7 \times 10^{-8}$ & $-6.84 \times 10^{-5}$ \\
\hline 12 & -1.448 & $2.36 \times 10^{-4}$ & -0.055 \\
\hline 13 & $-2.29 \times 10^{-6}$ & 0.657 & ---- \\
\hline 14 & $-2.29 \times 10^{-6}$ & -0.550 & $-0.7 \times 10^{-7}$ \\
\hline 15 & -23.508 & 0.256 & -0.014 \\
\hline 18 & 26.881 & -0.027 & -0.735 \\
\hline 17 & 13.636 & -0.039 & 5.221 \\
\hline 18 & -2.285 & 0.015 & 0.109 \\
\hline 19 & -2.924 & $-6.81 \times 10^{-3}$ & $2.53 \times 10^{-3}$ \\
\hline 20 & 1.555 & ----- & -0.02 \\
\hline
\end{tabular}




\subsubsection{Hysteresis Model for Frame Infilled by Precast Panels}

The empirical expressions for hysteresis parameters $\alpha, \beta, \gamma$ for lightly reinforced concrete frames strengthened by adding precast concrete panels are given as follows:

$$
\begin{aligned}
\alpha= & a_{0}+a_{1} d_{b b}+a_{2} \rho_{v b}+a_{3} A_{c}+a_{4} h_{c}+a_{5} \rho_{v c}+a_{6} E_{s}+a_{7} I_{c} \\
& +a_{8}\left(12 E_{c f} \frac{I_{c}}{h_{c}^{3}}\right)+a_{9} \rho_{h p c}+a_{10} A_{a b}+a_{11} f_{y a}+a_{12}\left(A_{a c} f_{y a}\right)
\end{aligned}
$$

$$
\begin{aligned}
\beta=b_{0}+ & b_{1} b_{r b}+b_{2} d_{b b}+b_{3} b_{b b}+b_{4} b_{c}+b_{5} A_{c}+b_{6} \rho_{c f}+b_{7} f_{y}+b_{8}\left(12 E_{c f} \frac{I_{c}}{h_{c}^{3}}\right) \\
& +\frac{b_{9}}{n}\left(\frac{L_{b}}{L_{p c}}\right)+b_{10} \rho_{h p c}+b_{11}\left(A_{a b} f_{y a}\right)+b_{12} s_{a c}+b_{13} d_{a c}+b_{14}\left(\sqrt{f_{c w}}\right)
\end{aligned}
$$

$$
\begin{aligned}
\gamma=g_{0}+g_{1} b_{t b} & +g_{2} \rho_{f b}+g_{3} d_{b b}+g_{4} b_{b b}+g_{5} \rho_{v b b}+g_{6} P_{x c}+g_{7} \rho_{f c}+g_{g} f_{c f} \\
& +g_{9} f_{y}+g_{10} t_{p}+g_{11} L_{p c}+g_{12} f_{y a}+g_{13}\left(\sqrt{f_{c w}}\right)
\end{aligned}
$$

The corresponding regression coefficients are listed in Table 4.13. 
TABLE 4.13 REGRESSION COEFFICIENTS FOR HYSTERESIS MODEL FOR PRECAST PANEL INFILLED FRAME

\begin{tabular}{|c|c|c|c|}
\hline $\mathrm{i}$ & $\mathrm{a}_{\mathrm{i}}$ & $\mathrm{b}_{\mathrm{i}}$ & $\mathrm{g}_{\mathrm{i}}$ \\
\hline 0 & 148.92 & 0.641 & -0.174 \\
\hline 1 & 1.302 & -0.018 & $-7.6 \times 10^{-3}$ \\
\hline 2 & -38.426 & 0.034 & 0.089 \\
\hline 9 & 0.037 & 0.02 & $4.31 \times 10^{-3}$ \\
\hline 4 & -0.154 & -0.17 & -0.011 \\
\hline 5 & 2.577 & $2.24 \times 10^{-3}$ & 0.597 \\
\hline 6 & -0.093 & 0.072 & $5.29 \times 10^{-3}$ \\
\hline 7 & $1.02 \times 10^{-6}$ & 0.368 & -0.051 \\
\hline 8 & $6.22 \times 10^{-4}$ & $-4.57 \times 10^{-5}$ & 1.685 \\
\hline 9 & -6.819 & -0.429 & 0.204 \\
\hline 10 & 0.243 & 0.981 & 0.198 \\
\hline 11 & 2.694 & $-3.14 \times 10^{-3}$ & -0.034 \\
\hline 12 & -0.503 & 0.043 & 0.019 \\
\hline 13 & ---- & -0.06 & -0.034 \\
\hline 14 & --- & -0.019 & ---- \\
\hline
\end{tabular}




\subsubsection{Hysteresis Model for Monolithic Wall-Frame Construction}

Finally, the empirical expressions for $\alpha, \beta, \gamma$ for monolithic wall-frame constructions are given as follows:

$$
\begin{aligned}
\alpha=a_{0} & +a_{1} d_{\imath b}+a_{2} \rho_{v b b}+a_{3} b_{c}+a_{4} P_{x c}+a_{5}\left(\frac{P_{x c}}{A_{c} f_{c f}}\right)+a_{6}\left(\frac{h_{c}}{L_{b}}\right)+a_{7} \rho_{v c}+a_{8} f_{c f} \\
& +a_{9} f_{y}+a_{10} E_{c f}+a_{11} I_{c}+a_{12} t_{w}+a_{13} I_{w}+a_{14} I_{0}+a_{15} \rho_{v w}+a_{16} f_{c w} \\
& +a_{17} f_{y}+a_{18} f_{y t b}+a_{19}\left(A_{s t b} f_{y c b}\right)+a_{20} A_{s b b}+a_{21} A_{s c}+a_{22}\left(A_{s c} f_{y c}\right)
\end{aligned}
$$

$$
\begin{aligned}
\beta=b_{0} & +b_{1} b_{t b}+b_{2} \rho_{f b}+b_{3} \rho_{v b}+b_{4} A_{c}+b_{5}\left(\frac{h_{c}}{L_{b}}\right)+b_{6} \rho_{f c}+b_{7} f_{y}+b_{8} E_{c f} \\
& +b_{9} E_{s}+b_{10} t_{w}+b_{11} I_{o}+b_{12} A_{w}+b_{13} \rho_{w h}+b_{14} \rho_{w v}+b_{15} f_{y w} \\
& +b_{16}\left(t_{w} L_{b} \sqrt{f_{c w}}\right)+b_{17}\left(A_{s t b} f_{y t b}\right)+b_{18} A_{s b b}+b_{19} A_{s c}+b_{20} s_{s c}
\end{aligned}
$$

$$
\begin{aligned}
\gamma=g_{0}+g_{1} d_{t b} & +g_{2} d_{c}+g_{3} P_{x c}+g_{4}\left(\frac{P_{x c}}{A_{c} f_{c f}}\right)+g_{5}\left(\frac{h_{c}}{L_{b}}\right)+g_{6} \rho_{c f}+g_{7} f_{c f}+g_{8} f_{y} \\
& +g_{9} E_{c f}+g_{10} E_{s}+g_{11}\left(12 E_{c f} \frac{I_{c}}{h_{c}^{3}}\right)+g_{12} t_{w}+g_{13} I_{w}+g_{14} I_{o} \\
& +g_{15} h_{3}+g_{16} f_{c w}+g_{17}\left(\frac{A_{o}}{L_{w} h_{c}}\right)+g_{18} A_{s t b}+g_{19} s_{s b b}+g_{20} A_{s c}
\end{aligned}
$$

The regression coefficients are listed in Table 4.14 as follows: 
TABLE 4.14 REGRESSION COEFFICIENTS FOR HYSTERESIS MODEL FOR MONOLITHIC WALL-FRAME CONSTRUCTION

\begin{tabular}{|c|c|c|c||}
\hline $\mathrm{i}$ & $\mathrm{a}_{\mathrm{i}}$ & $\mathrm{b}_{\mathrm{i}}$ & $\mathrm{g}_{\mathrm{i}}$ \\
\hline 0 & -160.952 & 3.749 & -14.224 \\
\hline 1 & 1.525 & $-5.47 \times 10^{-3}$ & 0.017 \\
\hline 2 & -49.955 & -0.124 & 0.130 \\
\hline 3 & -9.132 & 1.932 & -0.022 \\
\hline 4 & -1.182 & $-8.61 \times 10^{-4}$ & 12.049 \\
\hline 5 & 539.596 & -1.720 & -3.035 \\
\hline 6 & 46.925 & 0.086 & -0.044 \\
\hline 7 & 13.186 & 0.125 & -23.471 \\
\hline 8 & -463.459 & $-7.26 \times 10^{-3}$ & 0.285 \\
\hline 9 & 3.269 & $-5.69 \times 10^{-4}$ & 0.071 \\
\hline 10 & 1.381 & -0.09 & $1.441 \times 10^{-1}$ \\
\hline 11 & $4.99 \times 10^{-6}$ & $7.46 \times 10^{-8}$ & $-6.84 \times 10^{-5}$ \\
\hline 12 & -1.448 & $2.36 \times 10^{-4}$ & -0.055 \\
\hline 13 & $-2.29 \times 10^{-6}$ & 0.657 & $-4.06 \times 10^{-9}$ \\
\hline 14 & $-2.29 \times 10^{-6}$ & -0.550 & $-6.64 \times 10^{-8}$ \\
\hline 15 & -23.508 & 0.256 & -0.014 \\
\hline 16 & 26.881 & $4.576 \times 10^{-5}$ & -0.735 \\
\hline 17 & 13.636 & -0.026 & 5.221 \\
\hline 18 & -7.576 & -0.0956 & -0.068 \\
\hline 19 & 1.629 & 0.107 & 0.049 \\
\hline 20 & -5.141 & -0.054 & 0.097 \\
\hline 21 & 3.872 & ---- & --- \\
\hline 22 & -1.133 & ---- & --- \\
\hline
\end{tabular}




\subsubsection{Comparison between the Predicted and Experimental Hysteresis Parameters}

From the four sets of empirical expressions for $\alpha, \beta, \gamma$ given above, the hysteresis parameters of the fifty-five specimens selected in this program were predicted using the material and geometric properties of the specimens. The ratios of the predicted vs. experimental hysteresis parameters (obtained by system identification) were then plotted against the predicted parameters (see Figures $4.19 \mathrm{a}, \mathrm{b}, \mathrm{c}$ ) to facilitate an assessment of the accuracy of the hysteresis models. A ratio of 1 means that the predicted parameter $\left(\alpha_{\text {pre }}\right.$, $\beta_{\text {pre }}$, or $\gamma_{\text {pre }}$ from the hysteresis models) is identical to the experimental $\alpha_{\text {exp }}, \beta_{\text {exp }}$, or $\gamma_{\text {exp }}$ (from system identification of test results). As can be seen from Figures 4.19a,b, and $\mathrm{c}$, the hysteresis models produce parameters that compare well with the hysteresis parameters determined from system identification of the given test specimens. It should be noted that, since the hysteresis models derived in the above sections are statistically based, the applicability of the models is limited to specimens with characteristics within the ranges of geometric and material properties of the selected fifty-five test specimens. Caution should be used when applying the derived hysteresis models to cases where material and geometric properties, reinforcement patterns, or reinforcement ratios fall outside the ranges of the selected specimens.

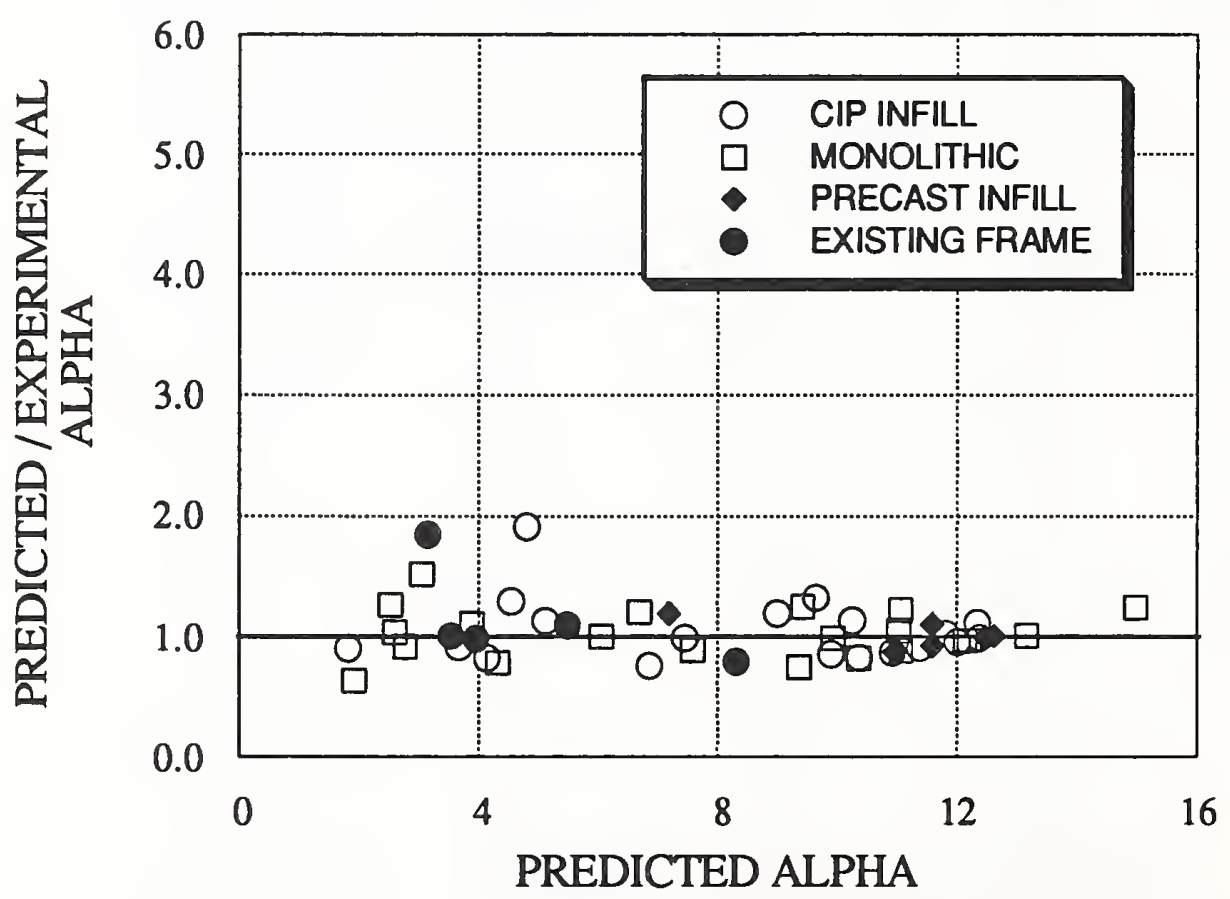

(a)

Figure 4.19 Comparisons of Predicted versus Experimental Hysteresis Parameters

(a) for Parameter $\alpha$

(b) for Parameter $\beta$

(c) for Parameter $\gamma$ 


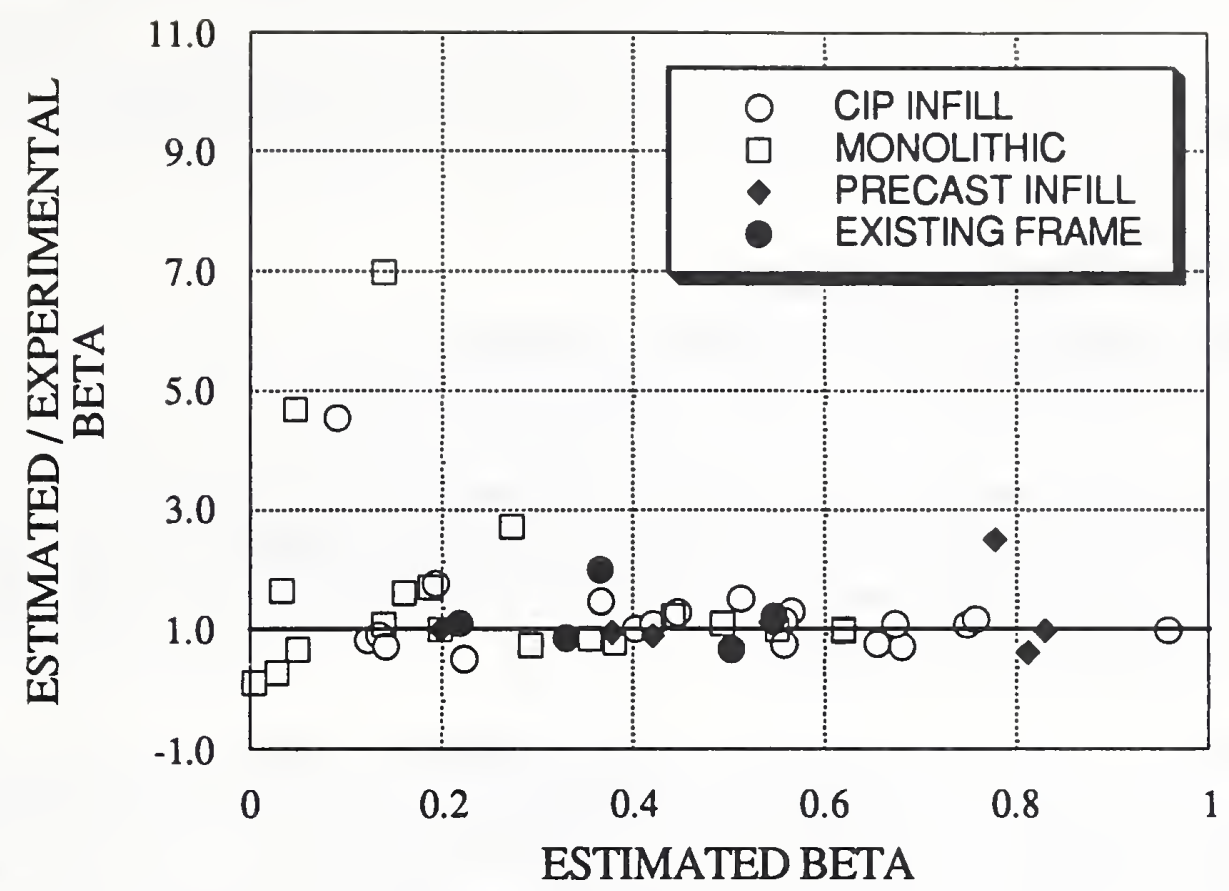

(b)

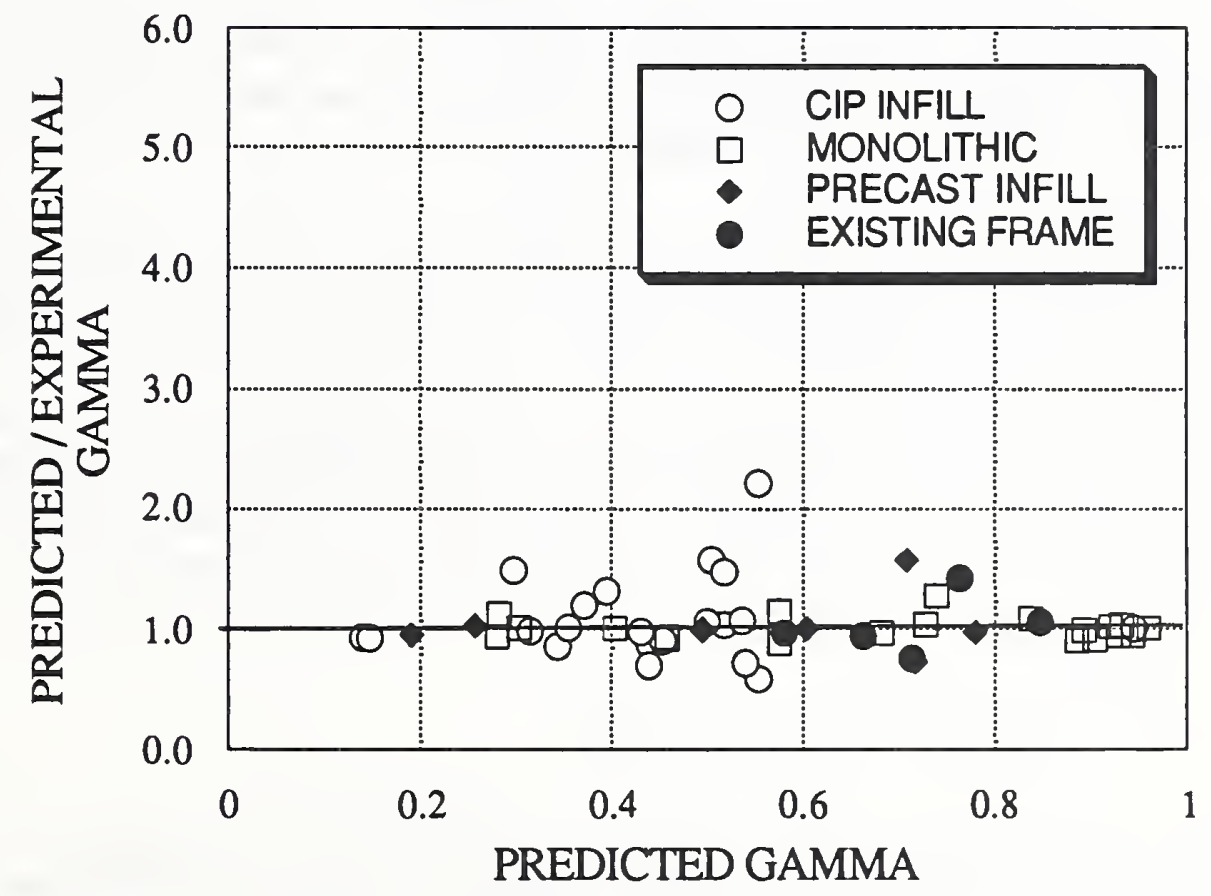

(c)

Figure 4.19 (Continued) 


\section{VALIDATION OF HYSTERETIC MODELS FOR USE WITH IDARC}

The hysteresis models developed above allow hysteresis parameters $\alpha, \beta, \gamma$ to be estimated for

- bare frames,

- monolithic wall-frame systems,

- frames strengthened by CIP infilled wall, and

- frames strengthened by multiple precast concrete panels.

The validity of the models for estimating hysteresis parameters for the ranges of geometric and material properties specified has been demonstrated in Section 4.2.2.5. The validity of using these models to predict the behavior of actual structures using IDARC is discussed in this chapter.

These parameters may be input into the program IDARC as rules for hysteresis behavior of RC frames for inelastic analysis. The validity of the hysteresis models may be examined by estimating, using the hysteresis models, the $\alpha, \beta, \gamma$ values for a variety of $\mathrm{RC}$ frames that have been experimentally tested, using IDARC to analyze the frames, and comparing the analytical to the experimental results.

The validation process answers two main questions. 1) Do the improved hysteresis models result in more accurate analysis by IDARC? 2) Can entire structures be analyzed using the limited array of improved hysteresis models now available, or is more work needed before actual buildings and proposed retrofit schemes can be evaluated?

Two frames were analyzed, a one-story one-bay frame tested by Aoyama et al..$^{8,9,10,11}$ (specimen C2005-I), and a three-story one-bay frame specimen tested by Higashi et $\mathrm{al}^{48}$ (specimen 78-3PW). For each frame, two IDARC analyses are performed, one using the IDARC recommended default values for hysteresis parameters $\alpha, \beta$, and $\gamma$, and the other using hysteresis parameters obtained from the hysteresis models developed in this study. Analytically-obtained load-deformation characteristics, per-cycle absorbed energy, and ultimate load capacity were compared to those obtained from test results.

\subsection{Analysis of One-Story One-Bay Frame}

A one-story one-bay frame strengthened with a CIP infilled wall tested by Aoyama et al..$^{8,9,10,11}$ (specimen C2005-I) was analyzed using IDARC. The one-third scale model test specimen was constructed using modern deformed bars and adequate transverse reinforcement rather than the smooth bars and minimal transverse reinforcement typical of Japanese construction prior to the 1960's. The cast in place infilled wall was connected to the frame using epoxied anchors. After placement of concrete, the gap left 
between the underside of the top beam and the top of the infilled wall was filled with expansive mortar. The specimen was subjected to five cycles of statically reversing lateral load. The measured ultimate strength of 84.2 tonf was attained in the second cycle. In the fifth cycle the specimen was loaded to failure. The experimental hysteresis behavior, measured at the center of the top beam and digitized in this study, is shown in Figure 5.1 a.

Two IDARC runs were performed, one using the default hysteresis parameters recommended by IDARC $(\alpha=2.0, \beta=0.02, \gamma=0.5)$, and one using the hysteresis parameters obtained from the hysteresis model developed in this study $(\alpha=11.0, \beta=0.35$, and $\gamma=0.25$ ). The analytical hysteresis behavior of the frame corresponding to these two analyses is shown in Figure $5.1 \mathrm{~b}$ and c. Further, the absorbed energy per cycle, calculated based on the experimental result and the two analytical results, are shown in Figure 5.2 for comparison.

As can be seen in Figure $5.1 \mathrm{a}, \mathrm{b}$, and $\mathrm{c}$, the experimental load-deformation characteristics of the frame was more closely matched by the analytical result which used the hysteresis parameters generated by the hysteresis models developed in this study. The default hysteresis parameters appear unable to correctly characterize the strength degradation characteristic (the decreasing load capacity with increasing number of cycle) and the pinching action of the frame. The ultimate load capacities, being 84.1 tonf for the experimental result, 84.3 tonf for the analytical result using hysteresis model developed in this study, and 95.5 tonf for the analytical result using the default hysteresis parameters, also show better comparison between the model developed in this study and the result of experiment. In terms of absorbed energy per cycle, the comparison between the result of this model and that of the experimental result is also more favorable than the comparison between the result using default parameters and the experiment, as illustrated in Figure 5.2. This is due to the ability of the model to characterize more accurately the pinching action that was observed in the experiment.

The results of these analyses show that the hysteresis model can be incorporated into IDARC, and that it does result in an improvement in the predictive ability of the analysis program. It also validates the idea of modeling an infilled frame as a single shear wall element, rather than as two beams, a column, and a wall. 


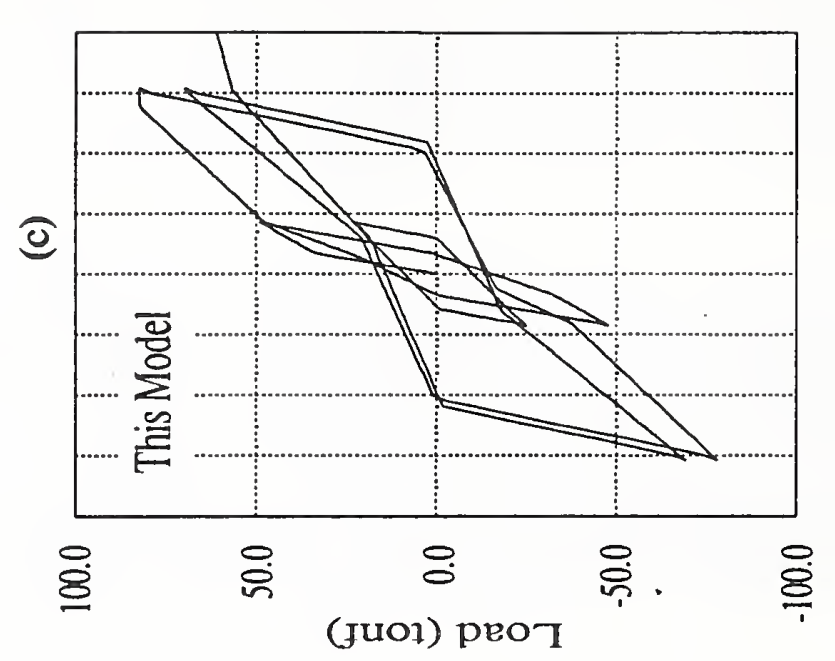

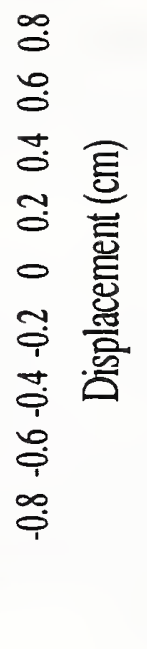

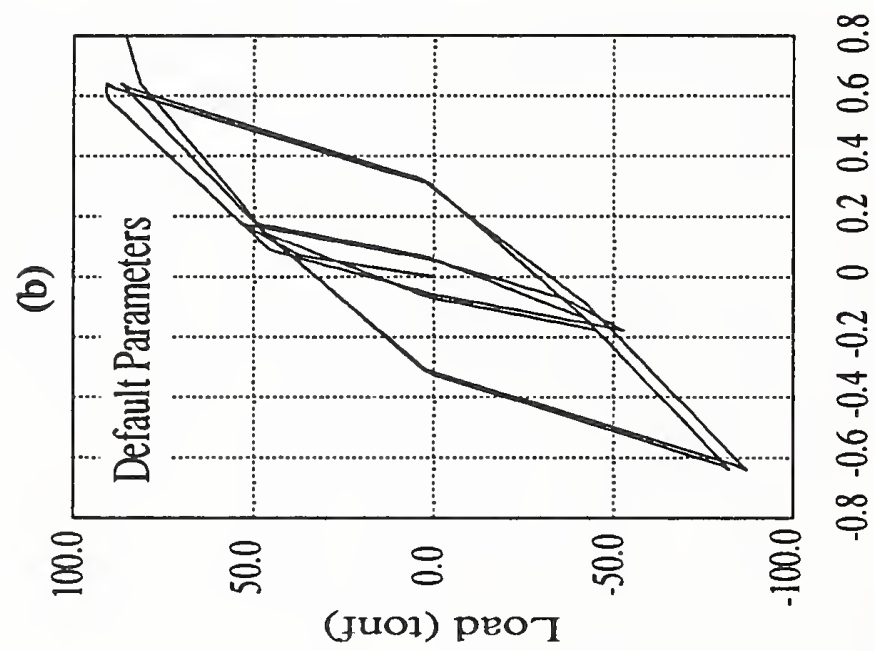

$\infty$

i
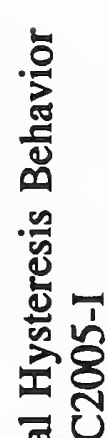

는 $\frac{0}{8}$

ป

为

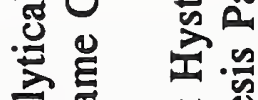

है

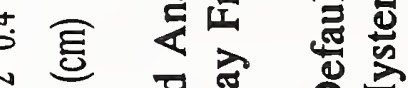

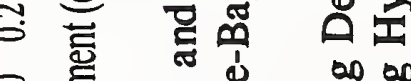

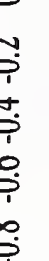

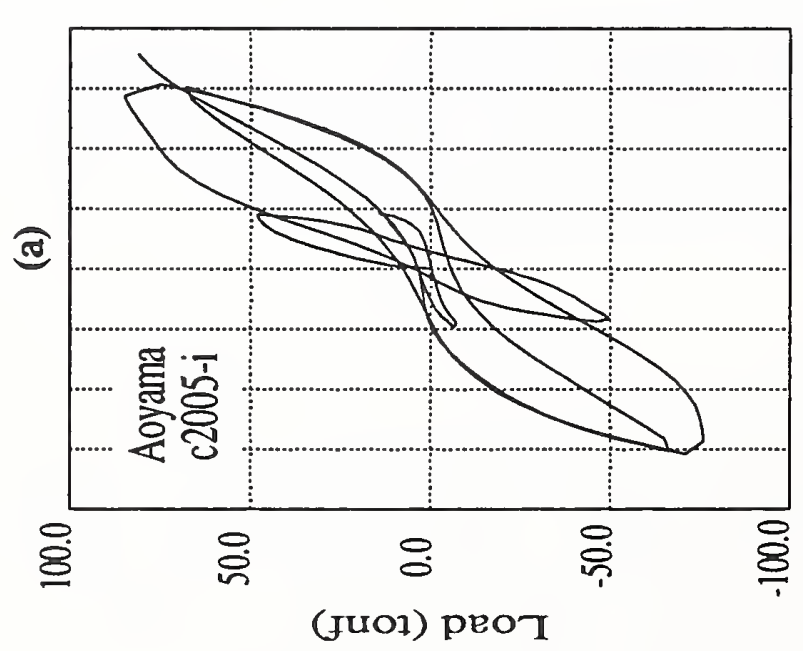

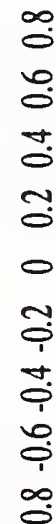

so 0

马्乛ి

可官

릉 등

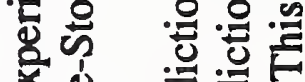

出

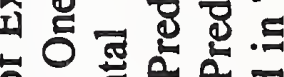

तु

is w is

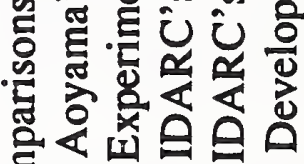

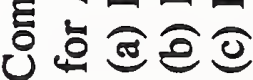

范

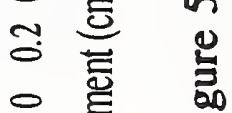

$\circ$ 总 


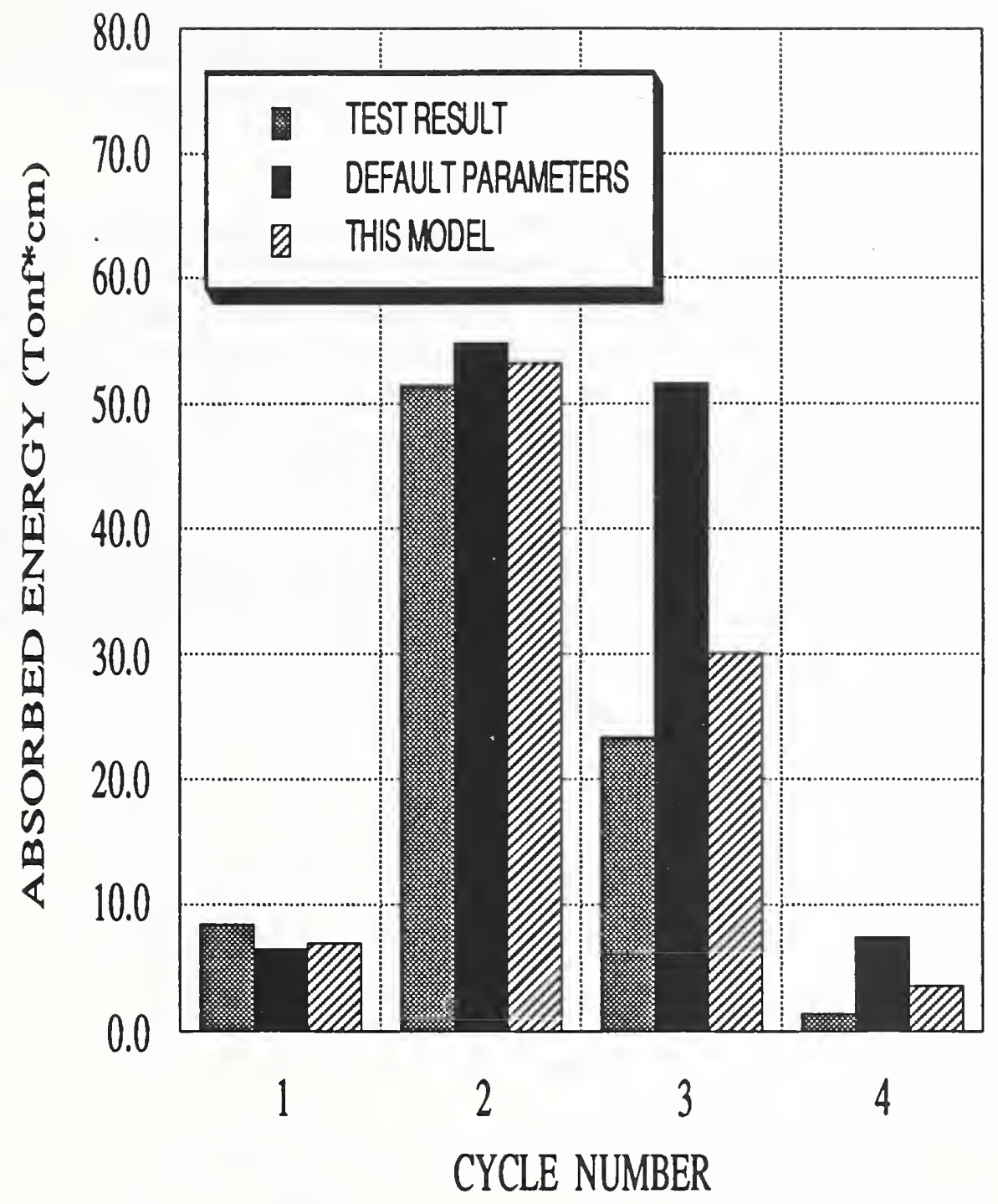

Figure 5.2 Comparisons of Experimental and Analytical Absorbed Energy on the Per Cycle Basis for Aoyama's Frame C2005-I 


\subsection{Analysis of a Three-Story One-Bay Frame}

A three-story one-bay frame tested by Higashi et al. ${ }^{48}$ (specimen $79-3 \mathrm{PW}$ ) was analyzed using IDARC. The one-eighth scale model was strengthened by filling all three openings with CIP concrete. The specimen was subjected to 6 cycles of displacement-controlled reversed cyclic loadings under constant axial load. Load-displacement curves were recorded at the top of the first story. The specimen achieved an ultimate load of 8.2 tonf before failing.

Two IDARC analyses were performed, one using default values and the other using hysteresis parameters obtained from the hysteresis models developed in this study. Similar to the case of the one-story one-bay frame described in 5.1, the load-deformation characteristics of the frame were more closely matched by using the hysteresis model developed in this study than by using the default hysteresis parameters, as can be seen in Figure $5.3 \mathrm{a}, \mathrm{b}$, and c. Ultimate strengths at the first story of 8.4 tonf and 9.5 tonf, respectively, were predicted for the two analytical cases where the hysteresis parameters obtained from this model and the default hysteresis parameters were used. Comparisons of absorbed energy per cycle, as shown in Figure 5.4, also show an improvement in predictive ability of the model developed in this study over the default hysteresis parameters. 


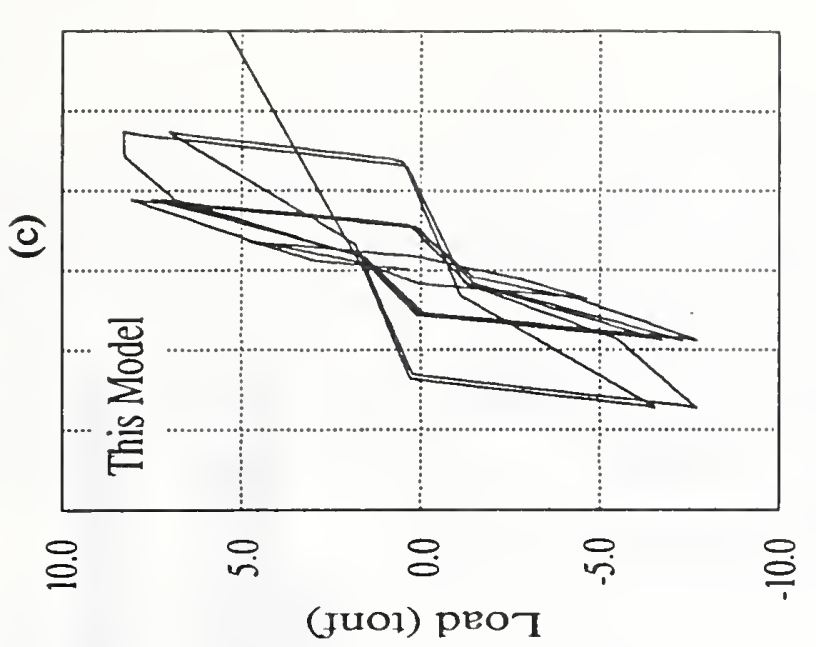

๖ㅇ.

t.

छิ

0 妾

$\circ$

仓ै.

宁

ำ

$\stackrel{\circ}{\circ}$

-

过

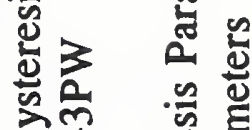
यक्त

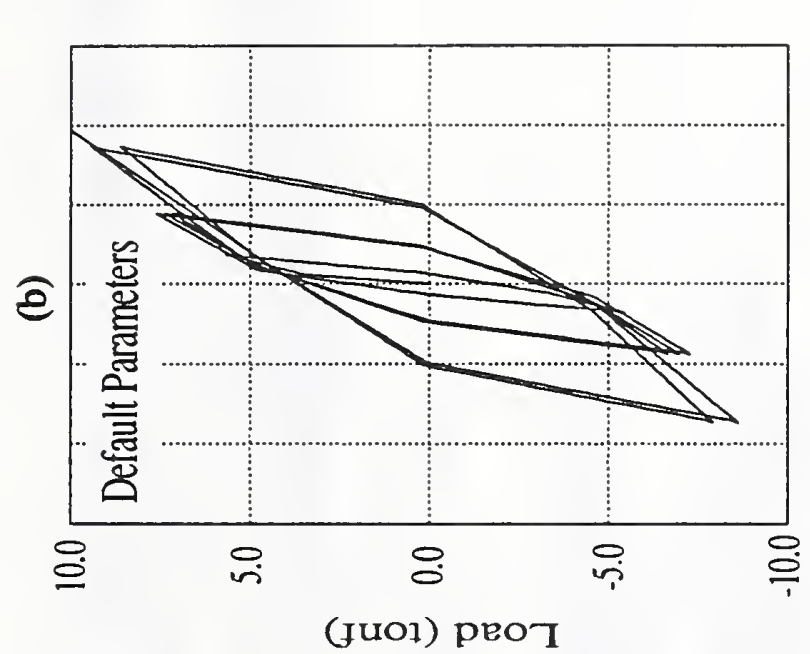

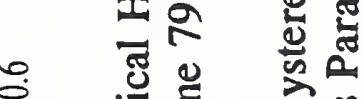

芫 톤 조.

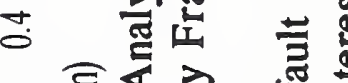

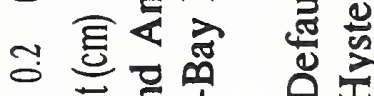

- 芯 它完 000

- 冚 퐁

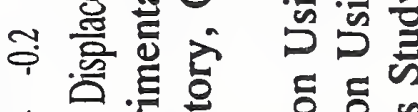

巳

@

के की

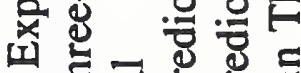

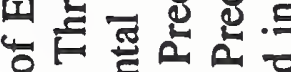

is 造的

¿ :

을

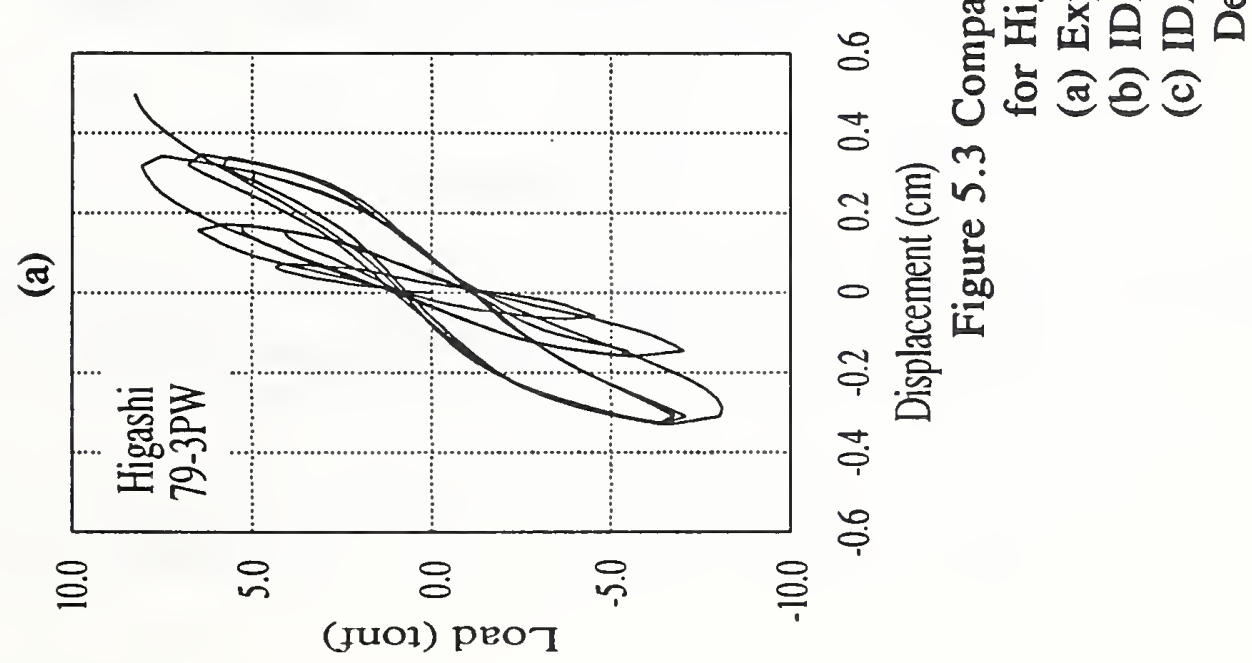




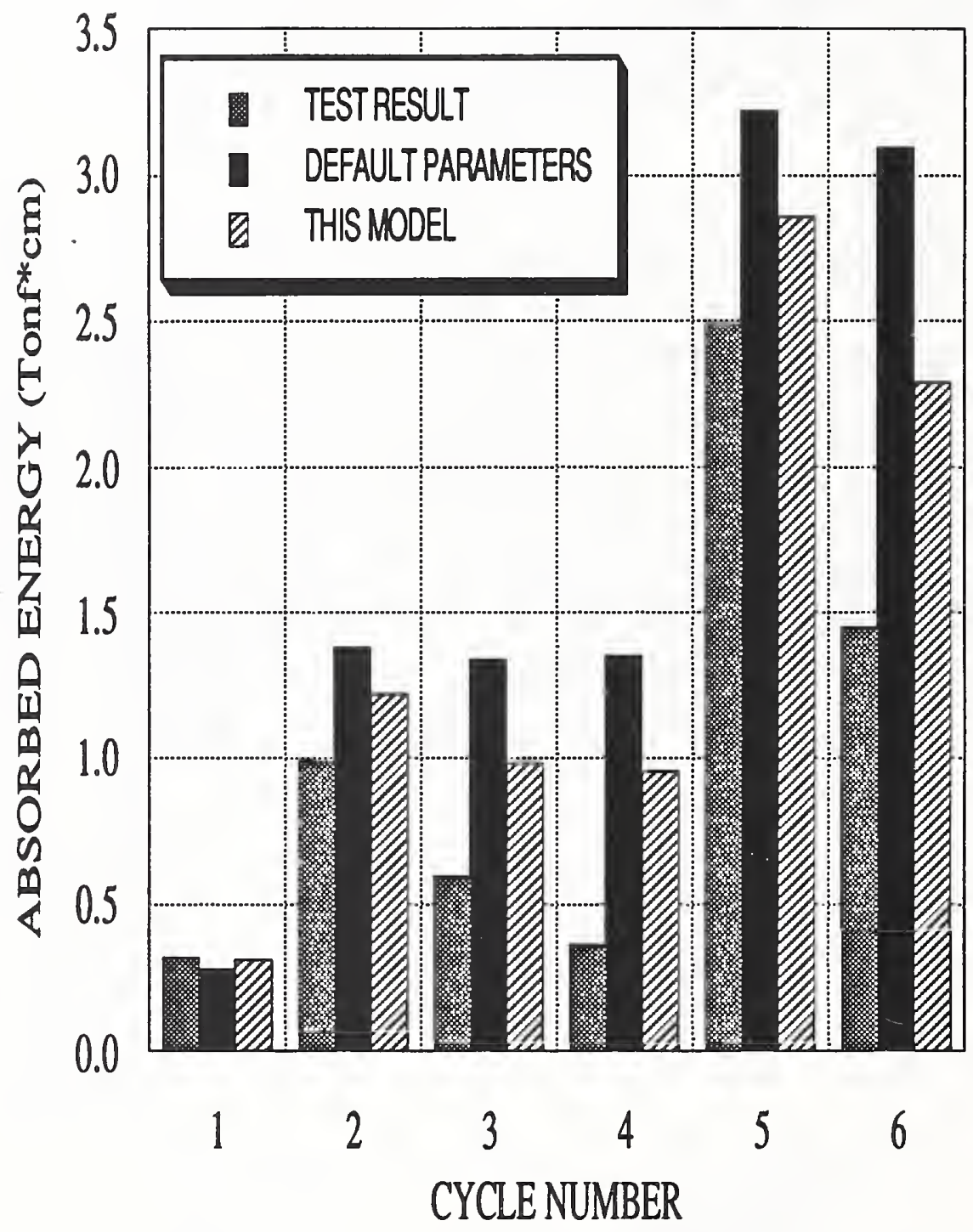

Figure 5.4 Comparisons of Experimental and Analytical Absorbed Energy on the Per Cycle Basis for Higashi's Frame 79-3PW 


\section{SUMMARY, CONCLUSIONS, AND RECOMMENDATION}

\subsection{Summary}

Experimental results of fifty five lightly reinforced concrete, one-story one-bay frame specimens, including bare frames, monolithic wall-frame constructions, frames infilled with CIP reinforced concrete walls, and frames infilled with precast reinforced concrete panels were systematically examined. The purpose is to develop empirical expressions, also called hysteresis models in this study, for predicting the three parameters $\alpha, \beta, \gamma$ which characterize the hysteresis behavior of reinforced concrete frames. The procedure used in developing the hysteresis models involved the following major tasks:

- Create a digital database for storage of load-deformation characteristics of lightly reinforced concrete one-story one-bay frames subjected to quasi-static reversed cyclic loading. This database, as of now, consists of fifty five tests.

Perform system identification of the digitized load-deformation records, using NIST System Identification program NIDENT 3.0, to obtain the estimated hysteresis parameters $\alpha, \beta, \gamma$, for each of the fifty five tests. The digitized load-deformation record of each of the fifty five specimens selected in this study are shown in Appendix C, superposed by the corresponding hysteresis behavior obtained from the system identification process.

- Correlate the estimated hysteresis parameters $\alpha, \beta, \gamma$, with the geometric and material properties, and reinforcement information using the commercially available Statistical Analysis package. The results are empirical expressions, or hysteresis models, for $\alpha, \beta, \gamma$ in terms of the physical properties of reinforced concrete frames.

The hysteresis models were then used to compute the hysteresis parameters of two strengthened frames. The first frame was a one-bay one-story infilled frame tested by Aoyama et al. (specimen C2005-I). The second frame was a three-story one-bay infilled frame tested by Higashi et al. (specimen 79-3PW). The computed hysteresis parameters were used in IDARC analyses of the frames and the results were compared with both the test results and the analytical results where the default values of $\alpha, \beta, \gamma$, recommended by IDARC, were used. Comparisons were made in terms of experimental and analytical load-deformation characteristics, absorbed energy per cycle, and ultimate load capacities. The comparisons show an improvement in predictive ability of the program IDARC when the hysteresis models developed in this study were used in providing hysteresis rules. 


\subsection{Conclusions}

The empirical hysteresis models developed in this study, as well as the program IDARC, are still research tools and admittedly cumbersome to use. These tools, however, are capable of providing reasonable estimates of the hysteresis performance of reinforced concrete frames. From the results of this phase of the study, the following conclusions are drawn:

The hysteresis performance (load-deformation histories) of one-bay one-story reinforced concrete bare frames, monolithic wall-frame constructions, frames infilled by CIP concrete walls, and frames infilled by precast concrete panels may be reasonably predicted using the hysteresis models developed in this study (see results in Appendix C).

- The hysteresis parameters obtained from the empirical hysteresis models developed in this study can be successfully incorporated into the program IDARC for use in the analysis of lightly reinforced concrete frames with more than one story in height.

- The database for load-deformation histories for one-bay, one-story frames created in this study enables a systematic examination of hysteresis performance of the unstrengthened and strengthened frames. These data currently are limited to two methods of frame strengthening, the CIP infilled wall and the multiple precast infilled wall methods. Future expansion of the existing database to include data concerning other frame strengthening techniques such as infilling with masonry walls, steel bracing, etc., will result in broader application and more statiscally significant hysteresis models.

- The hysteresis models presented in this study are developed based on the limited number of available frame tests. The complexity of the models may be reduced in the future by the increase in the number of available test data and by limiting the number of variables in the regression analysis to a few major variables.

- The same model development approach presented in this study can be used in developing hysteresis models for beam-column joints and column strengthening techniques to provide more analytical options for the selection of strengthening schemes for existing $\mathrm{RC}$ frames. 


\subsection{Recommendation}

Even though the hysteresis models developed in this study are cumbersome to use and might be judged impractical by practitioners, such models are needed to make use of computer programs (i.e. IDARC) to predict inelastic behavior of strengthened concrete frame structures. At the present time, these models are limited to CIP infilled walls and multiple precast infilled wall panels. Specifically, through the use of appropriate values of $\alpha, \beta, \gamma$ given by the empirical relationships developed in this report, one should be able to evaluate the structural responses of RC frames strengthened by CIP or precast infilled walls with different wall thicknesses, reinforcement ratios, or amounts of connecting anchors. Such evaluation process will provide an economical means for the selection of an optimal strengthening scheme.

In terms of model applicability, the hysteresis models developed in this study (which were based on one-bay, one-story frame test data) have been validated, as described in chapter 5, for two cases, i.e. one-bay, one-story frames; and one-bay, three-story frames. Thus, the application of the hysteresis models for the design and analysis of one-bay onestory, and one-bay multi-story frames is recommended. For the case of multi-bay onestory frames or multi-bay multi-story frames, the hysteresis models can be used for IDARC analysis in the same manner. At the present time, however, there is no experimental data currently exist for use in validating the analytical results for frames with more than one bay. It is suggested that the analytical results for the cases involving structures with more than one bay should be used with caution. 


\section{REFERENCES}

1. L.F. Kahn, "Reinforced Concrete Infilled Shear Walls for Aseismic Strengthening" UMEE 76R1, The University of Michigan, 01/1976.

2. S. Sugano: M. Fujimura, "Aseismic Strengthening of Existing Reinforced Concrete Buildings" Proceedings of the Seventh WCEE, Volume 4, p.449-456, Istanbul, Turkey, September 1980.

3. T. Hayashi; H. Niwa; M. Fukuhara, "The Strengthening Methods of the Existing Reinforced Concrete Buildings" Proceedings of the Seventh WCEE, Volume 4, p. 89-96, Istanbul, Turkey, September 1980.

4. Y. Higashi; T. Endo: M. Ohkubo: Y. Shimizu, "Experimental Study on Strengthening Reinforced Concrete Structure by Adding Shear Wall" Proceedings of the Seventh WCEE, Volume 7, p. 173-180, Istanbul, Turkey, September 1980.

5. R.G. Oesterle; A.E. Fiorato; L.S. Johal; J.E. Carpenter; H.G. Russel; W.G. Corley, "Earthquake Resistant Structural Walls - Tests of Isolated Walls", PCA R/D Series 1571, Construction Technology Laboratory, Portland Cement Association, Skokie, Illinois, November 1976.

6. R.G. Oesterle; J.D. Aristizabal-Ochoa; A.E. Fiorato; H.G. Russell; W.G. Corley, "Earthquake Resistant Structural Walls - Tests of Isolated Walls - Phase II", PCA R/D Series 1629, Construction Technology Laboratory, Portland Cement Association, Skokie, Illinois, October 1979.

7. W.G. Corley; A.E. Fiorato; R.G. Oesterle; A. Scanlon, "Evaluation, Repair, and Strengthening of Reinforced Concrete Buildings", Proceedings of the US/PRC Workshop on Seismic Analysis and Design of Reinforced Concrete Structures, p. 227-251, Ann Arbor, Michigan, May, 1981.

8. H. Aoyama: D. Kato: H. Katsumata: Y. Hosokawa, "Strength and Behavior of Postcast Shear Walls for Strengthening of Existing Reinforced Concrete Buildings" List of Manuscripts Submitted to Eighth WCEE in San Francisco 7/1984, Aoyama Laboratory, Department of Architecture, University of Tokyo, Hongo, Bunkyo-ku, Tokyo 113, Japan.

9. H. Aoyama, "Seismic Strengthening of Existing Reinforced Concrete Buildings in Japan", Department of Architecture, Faculty of Engineering, The University of Tokyo, Japan, September, 1986. 
10. H. Shiohara: Y. Hosokawa: T. Nakamura: H. Aoyama, "Earthquake Strengthening Method of Existing Reinforced Concrete Buildings", Transactions of the Japan Concrete Institute, Volume 6, p. 725-732, 1984.

11. H. Shiohara; Y. Hosokawa; T, Yamamoto; H, Aoyama, "Shear Stress Distribution in Earthquake Strengthening Post-Cast Reinforced Concrete Shear Wall", Transactions of the Japan Concrete Institute, Volume 7, 1985.

12. H. Aoyama: H. Shiohara, "Plastic Analysis for Ultimate Strength of Reinforced Concrete Shear Walls", Department of Architecture, Faculty of Engineering, The University of Tokyo, September, 1986.

13. K. Ogata; T. Kabeyasawa, "Experimental Study on the Hysteretic Behavior of Reinforced Concrete Shear Walls under the Loading of Different Moment-ToShear Ratios", Transactions of the Japan Concrete Institute, Volume 6, p. 717724, 1984.

14. G.L. Krause; J.K. Wight, "Strengthening of Reinforced Concrete Frame Structures", Proceedings of Fourth U.S. National Conference on Earthquake Engineering, EERI, Volume 3, p. 373-382, Palm Springs, California, May, 1990.

15. S.C. Goel; H. Lee, "Seismic Strengthening of RC Structures by Ductile Steel Bracing System", Proceedings of Fourth U.S. National Conference on Earthquake Engineering, EERI, Volume 3, p. 323-331, Palm Springs, California, May, 1990.

16. S.N. Shah, "Evaluation of Infill Wall Strengthening Schemes for Non-Ductile Reinforced Concrete Buildings", Master of Science Thesis, The University of Texas at Austin, May, 1989.

17. J.I. Estrada, "Use of Steel Elements to Strengthen a Reinforced Concrete Building", Master of Science Thesis, The University of Texas at Austin, December, 1990.

18. P.J. Gaynor, "The Effect of Openings on the Cyclic Behavior of Reinforced Concrete Infilled Shear Walls", Master of Science Thesis, The University of Texas at Austin, August, 1988.

19. R.R. Lopez, "A Numerical Model for Nonlinear Response of R/C Frame-Wall Structures", Doctoral Thesis, Civil Engineering Department, The University of Illinois at Urbana-Champaign, Urbana, Illinois, 1988. 
20. R.E. Klingner; V.V. Bertero, "Infilled Frames in Earthquake-Resistant Construction", Earthquake Engineering Research Center, Report No. EERC 76-32, University of California, Berkeley, California, December, 1976.

21. V.V. Bertero; E.P. Popov, "Seismic Behavior of Ductile Moment-Resisting Reinforced Concrete Frames", Symposium on Reinforced Concrete Structures in Seismic Zones, American Concrete Institute, SP-53, p.247-291, 1977.

22. E.A. Jones; J.O. Jirsa, "Seismic Strengthening of a Reinforced Concrete Frame Using Structural Steel Bracing", Phil M. Ferguson Structural Engineering Laboratory, PMFSEL Report No. 86-5, Department of Civil Engineering/Bureau of Engineering Research, The University of Texas at Austin, May 1986.

23. C.E. Roach: J.O. Jirsa, "Seismic Strengthening of a Reinforced Concrete Frame Using Reinforced Concrete Piers", Phil M. Ferguson Structural Engineering Laboratory, PMFSEL Report No. 86-4, Department of Civil Engineering/Bureau of Engineering Research, The University of Texas at Austin, May 1986.

24. B.J. Bett; R.E. Klingner; J.O. Jirsa, "Behavior of Strengthened and Repaired Reinforced Concrete Columns Under Cyclic Deformations", Phil M. Ferguson Structural Engineering Laboratory, PMFSEL Report No. 85-3, Department of Civil Engineering/Bureau of Engineering Research, The University of Texas at Austin, December 1985.

25. R.A. Bass: R.L. Carrasquillo: J.O. Jirsa, "Interface Shear Capacity of Concrete Surfaces Used in Strengthening Structures", Phil M. Ferguson Structural Engineering Laboratory, PMFSEL Report No. 85-4, Department of Civil Engineering/Bureau of Engineering Research, The University of Texas at Austin, December 1985.

26. M. Saiidi Movahhed, "Simple and Complex Models for Nonlinear Seismic Response of Reinforced Concrete Structures", Doctoral Thesis, Civil Engineering Department, The University of Illinois at Urbana-Champaign, Urbana, Illinois, 1979.

27. S.T. Brokken: V.V. Bertero, "Studies on Effects of Infills In Seismic Resistant R/C Construction", Report No. UCB/EERC-81/12, Earthquake Engineering Research Center, College of Engineering, The University of California, Berkeley, California, October, 1981.

28. A.O.Cifuentes, "System Identification of Hysteretic Structures", Doctoral Thesis, California Institute of Technology, Earthquake Engineering Research Laboratory, EERL 84-04, Pasadena, California, September 1984. 
29. S. Otani, "Hysteresis Models of Reinforced Concrete for Earthquake Response Analysis", Reprinted from Journal of The Faculty of Engineering, The University of Tokyo, Volume XXXVI, No. 2, 1981.

30. A.G, El-Attar, "A Study on the Seismic Behavior of Lightly Reinforced Concrete Buildings Using Small-Scale Models", Doctoral Thesis, Cornell University, Ithaca, New York, May 1991.

31. Applied Technology Council, "Seismic Resistance of Reinforced Concrete Shear Walls and Frame Joints: Implications of Recent Research for Design Engineers", ATC-11, 1983.

32. Building Seismic Safety Council, "NEHRP Handbook for the Seismic Evaluation of Existing Buildings", Building Seismic Safety Council of the National Institute of Building Sciences, Program on Improved Seismic Safety Provisions, Washington, D.C. 1992.

33. Building Seismic Safety Council, "NEHRP Handbook of Techniques for the Seismic Rehabilitation of Existing Buildings", Building Seismic Safety Council of the National Institute of Building Sciences, Program on Improved Seismic Safety Provisions, Washington D.C. 1992.

34. G.L. Krause; C.J. Lopez; J.K. Wight, "The Mexico City Research Program: Testing of a Two-Story Reinforced Concrete Frame", Department of Civil Engineering Report No. UMCE 88-10, The University of Michigan, Ann Arbor, MI, November 1988.

35. Y.J. Park: A.M. Reinhorn: S.K. Kunnath, "IDARC: Inelastic Damage Analysis of Reinforced Concrete Frame-Shear Wall Structures", National Center for Earthquake Engineering Research, Technical Report NCEER-87-0008, July 1987.

36. S. El-Borgi; R.N. White; P. Gergely, "Analytical Models for Seismic Retrofit of Lightly-Reinforced Concrete Frame Buildings", September, 1991.

37. S.K. Kunnath; A.M. Reinhorn, "Inelastic Three-Dimensional Response Analysis of Reinforced Concrete Building Structures (IDARC-3D) - Part I - Modeling", National Center for Earthquake Engineering Research, Technical Report NCEER89-0011, April 1989.

38. L-J, Yeh, "Identification of Nonlinear Cyclic Behavior of RC Frame Components Using Three Parameter Model", M.S. Project, State University of New York at Buffalo, 1987. 
39. W. Kim: A. El-Attar; R.N. White, "Small-Scale Modeling Techniques for Reinforced Concrete Structures Subjected to Seismic Loads", National Center for Earthquake Engineering Research, Technical Report NCEER-88-0041, November 1988.

40. W.C. Stone: A.W. Taylor, "A Predictive Model for Hysteretic Failure Parameters", Proceedings of the Tenth World Conference on Earthquake Engineering, Vol. 5, pp. 2575-2580, Spain, July, 1992.

41. L.A. Wyllie, Jr., "Strengthening Existing Concrete and Masonry Buildings for Seismic Resistance", Proceedings of the Second Seminar on Repair and Retrofit of Structures, pp. 322-333, University of Michigan, Ann Arbor, MI, May 1981.

42. S.M. Alcocer; J.O. Jirsa, "Assessment of the Response of Reinforced Concrete Frame Connections Redesigned by Jacketing", Proceedings of Fourth U.S. National Conference on Earthquake Engineering, EERI, Volume 3, pp. 295-304, Palm Springs, California, May, 1990.

43. A. Beres; S. El-Borgi; R.N. White; P. Gergely, "Full-Scale Tests of Retrofitted Beam-Column Joints in Lightly Reinforced Concrete Frame Buildings", Internal Report to NIST, School of Civil and Environmental Engineering, Cornell University, Ithica, New York, March 1992.

44. R. Zarnic; M. Tomazevic, "Behavior of Repaired Masonry Infilled R/C Frames, The 1st Year Report", US-Yugoslav Joint Board on Scientific and Technological Cooperation, Ljubljana, Yugoslavia, March 1989.

45. R. Zarnic: M. Tomazevic, "Behavior of Repaired Masonry Infilled R/C Frames, The 2nd Year Report", US-Yugoslav Joint Board on Scientific and Technological Cooperation, Ljubljana, Yugoslavia, March 1990.

46. L.F. Kahn, "Strengthening Existing RC Columns for Earthquake Resistance", Proceedings of the Seventh WCEE, Volume 4, p.327-334, Istanbul, Turkey, September 1980.

47. R.L. Nene, "Repair and Restoration of Reinforced Concrete Columns", ACI SP85, Rehabilitation, Renovation, and Preservation of Concrete and Masonry Structures, 1985, pp. SP85-12 259-263.

48. Y. Higashi: T. Endo: Y. Shimizu, "Experimental Studies on Retrofitting of Reinforced Concrete Structural Members", Proceedings of the Second Seminar on Repair and Retrofit of Structures, pp. 126-155, University of Michigan, Ann Arbor, MI, May 1981. 
49. Y. Higashi: T. Endo: Y. Shimizu, "Effects on Behaviors of Reinforced Concrete Frames by Adding Shear Walls", Third US/Japan Seminar on Repair and Retrofit of Structures, San Francisco, May 13-15 1982, pp. 265-290. 
APPENDIX A. Definitions of Variables Used in Regression Analysis
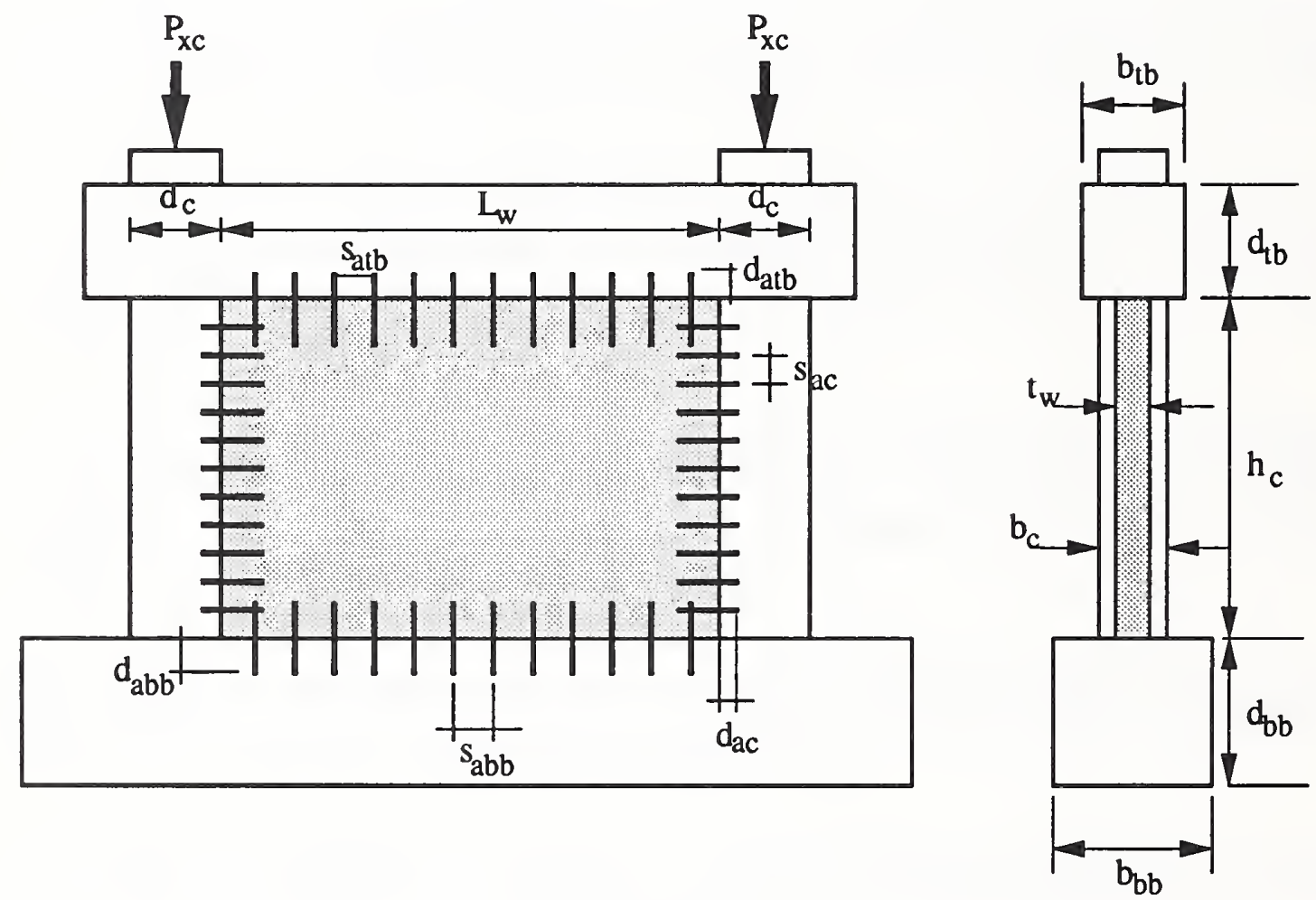
APPENDIX A. (Continued)

\begin{tabular}{|c|c|c|}
\hline Variable & Symbols & Descriptions \\
\hline \multicolumn{3}{|c|}{ VARIABLES RELATING TO EXISTING FRAME } \\
\hline $\mathrm{X} 1$ & $\mathrm{~d}_{\mathrm{tb}}$ & Top Beam Effective Depth \\
\hline $\mathrm{X} 2$ & $b_{\mathrm{tb}}$ & Top Beam Width \\
\hline $\mathrm{X} 3$ & $A_{s t} / d_{b b} b_{t b}$ & Total flexural Rein. Ratio of Top Beam \\
\hline $\mathrm{X} 1$ & $\rho_{\mathrm{tb}, \mathrm{sh}}$ & Shear Rein. Ratio of Top Beam \\
\hline $\mathrm{X} 5$ & $b_{b b}$ & Bottom Beam Effective Depth \\
\hline $\mathrm{X} 6$ & $b_{b b}$ & Bottom Beam Width \\
\hline $\mathrm{X} 8$ & $\mathrm{~A}_{\mathrm{sb}} / \mathrm{d}_{\mathrm{bb}} \mathrm{b}_{\mathrm{bb}}$ & Total Flexural Rein. Ratio of Bottom Beam \\
\hline $\mathrm{X} 8$ & $\rho_{\mathrm{bb}, \mathrm{sh}}$ & Shear Rein. Ratio of Bottom Beam \\
\hline $\mathrm{X} 8$ & $d_{c}$ & Column Effective Depth \\
\hline $\mathrm{X} 10$ & $b_{c}$ & Column Width \\
\hline $\mathrm{X} 11$ & $\mathbf{A}_{c}$ & Column Effective Area $\left(d_{c} \cdot b_{c}\right)$ \\
\hline $\mathrm{X} 18$ & $A_{c g}$ & Column Gross Cross Section Area \\
\hline $\mathrm{X} 13$ & $\mathrm{P}_{\mathrm{xc}}$ & Axial Force in Each Column \\
\hline $\mathrm{X} 14$ & $\mathrm{P}_{\mathrm{xc}} / \mathrm{A}_{\mathrm{cg} \cdot} \cdot \mathrm{f}_{\mathrm{c}, \mathrm{f}}$ & Normalized Column Axial Stress \\
\hline $\mathrm{X} 18$ & $\mathbf{b}_{\mathbf{c}}$ & Column Height \\
\hline $\mathrm{X} 16$ & $h_{c} / L_{t b}$ & $\begin{array}{l}\text { Ratio of Column Height to Top Beam Clear } \\
\text { Span }\end{array}$ \\
\hline $\mathrm{X} 17$ & $\rho_{\mathrm{f}, \mathrm{cl}}$ & Total Flex. Rein. Ratio of Left Column \\
\hline $\mathrm{X} 18$ & $\rho_{\mathrm{sh}, \mathrm{cl}}$ & Shear Rein. Ratio of Left Column \\
\hline $\mathrm{X} 19$ & $\rho_{\mathrm{f}, \mathrm{cr}}$ & Total Flex. Rein. Ratio of Right Column \\
\hline $\mathrm{X} 20$ & $\rho_{\text {sh }, \mathrm{cr}}$ & Shear Rein. Ratio of Right Column \\
\hline $\mathrm{X} 21$ & $\mathbf{f}_{\mathrm{c}, \mathrm{f}}$ & Concrete Compressive Strength of Frame \\
\hline $\mathrm{X} 22$ & $f_{y}$ & Reinforcement Yield Strength \\
\hline
\end{tabular}


APPENDIX A. (Continued)

\begin{tabular}{|c|c|c|}
\hline Variable & Symbols & Descriptions \\
\hline $\mathrm{X} 23$ & $\left.\mathrm{E}_{\mathrm{c}, \mathrm{f}}=15,100 \mathrm{f}_{\mathrm{c}, \mathrm{f}}\right)$ & Young's Modulus of Concrete \\
\hline $\mathrm{X} 24$ & $\mathrm{E}_{8}$ & Young's Modulus of Steel Reinforcement \\
\hline $\mathrm{X} 25$ & $I_{c}$ & $\begin{array}{l}\text { Moment of Inertia of Frame's Horizontal } \\
\text { Cross-Section (Two Columns Cross-Sections) }\end{array}$ \\
\hline $\mathrm{X} 26$ & 12. $\mathrm{E}_{\mathrm{c}, \mathrm{f}} \cdot \mathrm{I}_{\mathrm{c}} / \mathrm{h}_{\mathrm{c}}{ }^{3}$ & Lateral Stiffness of Frame \\
\hline \multicolumn{3}{|c|}{ VARIABLES RELATING TO CAST-IN-PLACE INFILL WALLS } \\
\hline $\mathrm{X} 27$ & $t_{w}$ & Thickness of Infill Wall \\
\hline $\mathrm{X} 28$ & $\mathbf{I}_{\mathrm{w}}$ & $\begin{array}{l}\text { Moment of Inertia of Horizontal Cross Section } \\
\text { of Infill Wall-Column System w/o Opening }\end{array}$ \\
\hline X29 & $I_{e}$ & $\begin{array}{l}\text { Moment of Inertia of Horizontal Cross Section } \\
\text { of Opening }\end{array}$ \\
\hline $\mathrm{X} 30$ & $h_{1}$ & $\begin{array}{l}\text { Height From Column Base to Bottom of } \\
\text { Opening }\end{array}$ \\
\hline $\mathrm{X} 31$ & $h_{2}$ & Height From Bottom to Top of Opening \\
\hline $\mathrm{X} 32$ & $h_{3}$ & $\begin{array}{l}\text { Height From Top of Opening to Bottom of } \\
\text { Top Beam }\end{array}$ \\
\hline $\mathrm{X} 33$ & $A_{w}$ & $\begin{array}{l}\text { Horizontal Cross Sectional Area of the Infill } \\
\text { Wall-Column System }\end{array}$ \\
\hline $\mathrm{X} 33$ & $A_{0}$ & $\begin{array}{l}\text { Horizontal Cross Sectional Area of the } \\
\text { Opening }\end{array}$ \\
\hline $\mathrm{X} 35$ & $\begin{array}{l}{\left[\mathrm{h}_{3}{ }^{3} / 3 \cdot \mathrm{E}_{\mathrm{c}} \cdot \mathrm{I}_{\mathrm{w}}\right]+} \\
{\left[\mathrm{h}_{3} / \mathrm{A}_{\mathrm{w}} \cdot \mathrm{G}_{\mathrm{w}}\right]}\end{array}$ & $\begin{array}{l}\text { Lateral Stiffness of Portion of Wall Above } \\
\text { Opening }\left(G_{w}=E_{c} / 2(1+\nu)\right)\end{array}$ \\
\hline $\mathrm{X} 36$ & $\begin{array}{r}{\left[\mathrm{h}^{3}{ }^{3} / 12 \cdot \mathrm{E}_{\mathrm{c}} \cdot\left(\mathrm{I}_{\mathrm{w}}-\mathrm{I}_{\mathrm{o}}\right)\right]} \\
+\left[\mathrm{h}_{2} /\left(\mathrm{A}_{\mathrm{w}}-\mathrm{A}_{\mathrm{o}} \mathrm{o}\right) \cdot \mathrm{G}_{\mathrm{w}}\right] \\
\end{array}$ & $\begin{array}{l}\text { Lateral Stiffness of Portion of Wall Below } \\
\text { Opening }\end{array}$ \\
\hline
\end{tabular}


APPENDIX A. (Continued)

\begin{tabular}{|c|c|c|}
\hline Variable & Symbols & Descriptions \\
\hline $\mathrm{X} 37$ & $\rho_{\mathrm{w}, \mathrm{b}}$ & Horizontal Rein. Ratio for Infill Wall \\
\hline $\mathrm{X} 38$ & $\rho_{\mathrm{w}, \mathrm{v}}$ & Vertical Rein. Ratio for Infill Wall \\
\hline $\mathrm{X} 39$ & $\rho_{\mathrm{w}, \mathrm{sh}}$ & Shear Rein. Ratio for Infill Wall \\
\hline $\mathrm{X} 40$ & $\mathbf{f}_{c, w}$ & Concrete Compressive Strength for Infill Wall \\
\hline $\mathrm{X} 41$ & $f_{y, w}$ & Yield Strength of Infill Wall's Reinforcements \\
\hline $\mathrm{X} 42$ & $A_{\text {ov }}$ & Vertical Area of Wall Opening \\
\hline $\mathrm{X} 43$ & $\mathrm{~A}_{\mathrm{ov1}} /\left(\mathrm{L}_{\mathrm{w}} \cdot \mathrm{h}_{\mathrm{c}}\right)_{1}$ & $\begin{array}{l}\text { Ratio of Area of Opening in the First } \\
\text { Quardrant (Top Left) and Area of the First } \\
\text { Quardrant of Infill Wall }\end{array}$ \\
\hline $\mathrm{X} 44$ & $\mathrm{~A}_{\mathrm{ov} 2} /\left(\mathrm{L}_{\mathrm{w}} \cdot \mathrm{h}_{\mathrm{c}}\right)_{2}$ & $\begin{array}{l}\text { Ratio....................... Second Quardrant } \\
\text { (Bottom Left) ........... }\end{array}$ \\
\hline $\mathrm{X} 45$ & $\mathrm{~A}_{\mathrm{ov} 3} /\left(\mathrm{L}_{\mathrm{w}} \cdot \mathrm{h}_{\mathrm{c}}\right)_{3}$ & $\begin{array}{l}\text { Ratio......................... Third Quardrant } \\
\text { (Top Right)............... }\end{array}$ \\
\hline $\mathrm{X} 46$ & $\mathrm{~A}_{\mathrm{ov} 4} /\left(\mathrm{L}_{\mathrm{w}} \cdot \mathrm{h}_{\mathrm{c}}\right)_{4}$ & $\begin{array}{l}\text { Ratio......................... Fourth Quadrant } \\
\text { (Bottom Right).................. }\end{array}$ \\
\hline \multicolumn{3}{|c|}{ VARIABLES RELATING TO PRECAST PANEL INFILL WALLS } \\
\hline $\mathrm{X} 47$ & $t_{p}$ & Thickness of Precast Panel \\
\hline $\mathrm{X} 48$ & $\mathrm{~L}_{\mathrm{pe}}$ & Length of Each Precast Panel \\
\hline $\mathrm{X} 49$ & $\mathrm{~L}_{\mathrm{tb}} / \mathrm{n} \cdot \mathrm{L}_{\mathrm{pe}}$ & $\begin{array}{l}\text { Ratio of Top Beam Length and Length of } \\
\text { Precast Panel, } \mathrm{n} \text { is the Number of Panels } \\
\text { Used. }\end{array}$ \\
\hline $\mathrm{X} 50$ & $\rho_{\mathrm{h}, \mathrm{pe}}$ & Horizontal Rein. Ratio of Each Precast Panel \\
\hline $\mathrm{X} 51$ & $\rho_{\mathrm{v}, \mathrm{pe}}$ & Vertical Rein. Ratio of Each Precast Panel \\
\hline $\mathrm{X} 52$ & $\rho_{\mathrm{sh}, \mathrm{pe}}$ & Shear Rein. Ratio of Each Precast Panel \\
\hline
\end{tabular}




\section{APPENDIX A. (Continued)}

\begin{tabular}{|c|c|c|}
\hline Variable & Symbols & Descriptions \\
\hline $\mathrm{X} 53$ & $A_{o v 1} /\left(L_{c b} \cdot h_{c}\right)_{1}$ & $\begin{array}{l}\text { Ratio of Area of Opening in the First } \\
\text { Quardrant (Top Left) and Area of the First } \\
\text { Quardrant of Infill Wall }\end{array}$ \\
\hline $\mathrm{X} 54$ & $A_{o v 2} /\left(L_{t b} \cdot h_{c}\right)_{2}$ & $\begin{array}{l}\text { Ratio........................ second Quardrant } \\
\text { (Bottom Left) ........... }\end{array}$ \\
\hline $\mathrm{X} 55$ & $A_{o v 3} /\left(L_{\imath b} \cdot h_{c}\right)_{3}$ & $\begin{array}{l}\text { Ratio........................ third Quardrant } \\
\text { (Top Right)................ }\end{array}$ \\
\hline $\mathrm{X} 56$ & $A_{o v 4} /\left(L_{c b} \cdot h_{c}\right)_{4}$ & $\begin{array}{l}\text { Ratio........................ Fourth Quadrant } \\
\text { (Bottom Right)................... }\end{array}$ \\
\hline \multicolumn{3}{|c|}{$\begin{array}{l}\text { VARIABLES RELATING TO CONNECTING ANCHORS } \\
\text { (For Cast-in-Place Infill Walls) }\end{array}$} \\
\hline $\mathrm{X} 57$ & $A_{a, c b}$ & $\begin{array}{l}\text { Total Area of Anchors Crossing the Interface } \\
\text { Between the Infill Wall \& Top Beam }\end{array}$ \\
\hline $\mathrm{X} 58$ & $\mathrm{~s}_{\mathrm{a}, \mathrm{b}}$ & Anchor Spacing at Top Beam \\
\hline $\mathbf{X} 59$ & $d_{a, b}$ & Anchor Embedment Depth at Top Beam \\
\hline $\mathrm{X} 60$ & $\mathrm{f}_{\mathrm{y}, \mathrm{a}, \mathrm{bb}}$ & Material Yield Stress of Anchors on Top Beam \\
\hline $\mathrm{X} 61$ & $A_{a, b b} \cdot f_{y, a, b b}$ & Tensile Strength of Anchors on Top Beam \\
\hline $\mathrm{X} 62$ & $A_{a, b b}$ & $\begin{array}{l}\text { Total Area of Anchors and Rebars Crossing } \\
\text { the Interface Between the Infill Wall \& Bottom } \\
\text { Beam }\end{array}$ \\
\hline $\mathrm{X} 63$ & $s_{a, b b}$ & Anchor Spacing at Bottom Beam \\
\hline $\mathrm{X} 64$ & $d_{a, b b}$ & Anchor Embedment Depth at Bottom Beam \\
\hline $\mathrm{X} 65$ & $f_{y, a, b b}$ & $\begin{array}{l}\text { Material Yield Stress of Anchors on Bottom } \\
\text { Beam }\end{array}$ \\
\hline
\end{tabular}


APPENDIX A. (Continued)

\begin{tabular}{|c|c|c|}
\hline Variable & Symbols & Descriptions \\
\hline X66 & $A_{a, b b} \cdot f_{y, a, b b}$ & Tensile Strength of Anchors on Bottom Beam \\
\hline $\mathrm{X} 67$ & $\mathrm{~A}_{\mathrm{a}, \mathrm{cl}}$ & $\begin{array}{l}\text { Total Area of Anchors and Rebars Crossing } \\
\text { the Interface Between the Infill Wall \& Left } \\
\text { Column }\end{array}$ \\
\hline $\mathrm{X} 66$ & $\mathrm{~s}_{\mathrm{a}, \mathrm{cl}}$ & Anchor Spacing in Left Column \\
\hline $\mathrm{X} 69$ & $d_{a, c l}$ & Anchor Embedment Depth in Left Column \\
\hline $\mathrm{X} 70$ & $\mathrm{f}_{\mathrm{y}, \mathrm{a}, \mathrm{cl}}$ & $\begin{array}{l}\text { Material Yield Stress of Anchors on Left } \\
\text { Column }\end{array}$ \\
\hline $\mathrm{X} 71$ & $A_{a, c l} \cdot f_{y, a, c l}$ & Tensile Strength of Anchors on Left Column \\
\hline $\mathrm{X} 72$ & $\mathrm{~A}_{\mathrm{a}, \mathrm{cl}}$ & $\begin{array}{l}\text { Total Area of Anchors and Rebars Crossing } \\
\text { the Interface Between the Infill Wall \& Right } \\
\text { Column }\end{array}$ \\
\hline $\mathrm{X} 73$ & $\mathrm{~s}_{\mathrm{a}, \mathrm{cr}}$ & Anchor Spacing in Right Column \\
\hline $\mathrm{X} 74$ & $\mathrm{~d}_{\mathrm{a}, \mathrm{cr}}$ & Anchor Embedment Depth in Right Column \\
\hline $\mathrm{X} 75$ & $f_{y, a, c r}$ & $\begin{array}{l}\text { Material Yield Stress of Anchors on Right } \\
\text { Column }\end{array}$ \\
\hline $\mathrm{X} 76$ & $A_{a, c r} \cdot f_{y, a, c r}$ & Tensile Strength of Anchors on Right Column \\
\hline \multicolumn{3}{|c|}{$\begin{array}{l}\text { VARIABLES RELATING TO CONNECTING ANCHORS } \\
\text { (For Monolithically-cast Wall-Frame Systems) }\end{array}$} \\
\hline $\mathrm{X} 77$ & $t_{w} \cdot L_{b b} \cdot J f_{c, w}$ & $\begin{array}{l}\text { (For Monolithically-Cast Wall-Frame System } \\
\text { only, = } 0 \text { for all other cases) }\end{array}$ \\
\hline $\mathrm{X} 78$ & $A_{s, c b}$ & $\begin{array}{l}\text { Total Area of Rebars Crossing the Interface } \\
\text { Between Wall \& Top Beam of Frame }\end{array}$ \\
\hline X79 & $S_{s, t b}$ & Rebar Spacing at Top Beam \\
\hline
\end{tabular}




\section{APPENDIX A. (Continued)}

\begin{tabular}{|c|c|c|}
\hline Variable & Symbols & Descriptions \\
\hline $\mathrm{X} 80$ & $f_{y, s, b}$ & Material Yield Stress of Rebar on Top Beam \\
\hline $\mathrm{X} 81$ & $A_{s, t b} \cdot f_{y, s, b}$ & Tensile Strength of Rebars on Top Beam \\
\hline $\mathrm{X} 82$ & $A_{s, b b}$ & $\begin{array}{l}\text { Total Area of Rebars Crossing the Interface } \\
\text { Between Wall \& Bottom Beam of Frame }\end{array}$ \\
\hline $\mathrm{X} 83$ & $s_{s, b b}$ & Rebar Spacing at Bottom Beam \\
\hline $\mathrm{X} 84$ & $f_{y, s, b b}$ & $\begin{array}{l}\text { Material Yield Stress of Anchors on Bottom } \\
\text { Beam }\end{array}$ \\
\hline $\mathrm{X} 85$ & $A_{s, b b} \cdot f_{y, s, b b}$ & Tensile Strength of Anchors on Bottom Beam \\
\hline $\mathrm{X} 86$ & $A_{s, c l}$ & $\begin{array}{l}\text { Total Area of Rebars Crossing the Interface } \\
\text { Between Wall \& Left Column of Frame }\end{array}$ \\
\hline $\mathrm{X} 87$ & $s_{s, c l}$ & Rebar Spacing at Left Column \\
\hline $\mathrm{X} 88$ & $\mathrm{f}_{\mathrm{y}, \mathrm{s}, \mathrm{cl}}$ & $\begin{array}{l}\text { Material Yield Stress of Rebars on Left } \\
\text { Column }\end{array}$ \\
\hline $\mathrm{X} 89$ & $A_{s, c l} \cdot f_{y, s, c l}$ & Tensile Strength of Rebars in Left Column \\
\hline $\mathrm{X} 90$ & $A_{s, c r}$ & $\begin{array}{l}\text { Total Area of Rebars Crossing the Interface } \\
\text { Between Wall \& Right Column of Frame }\end{array}$ \\
\hline $\mathrm{X} 91$ & $s_{s, c r}$ & Rebar Spacing in Right Column \\
\hline $\mathrm{X} 92$ & $f_{y, s, c r}$ & $\begin{array}{l}\text { Material Yield Stress of Rebars on Right } \\
\text { Column }\end{array}$ \\
\hline $\mathrm{X} 93$ & $A_{s, r r} f_{y, s, r r}$ & Tensile Strength of Rebars in Right Column \\
\hline
\end{tabular}


APPENDIX B. Test Specimen's Parameters

\begin{tabular}{|c|c|c|c|c|c|c|}
\hline TEST NAME & $\begin{array}{ll}X 1 & (\mathrm{CM}) \\
\end{array}$ & $\times 2 \quad(\mathrm{CM})$ & $(\%)$ & $(\%)$ & $(\mathrm{CM})$ & $X_{6} \quad(\mathrm{CM})$ \\
\hline AOYAMA C2005-I & 35.00 & 30.00 & 4.86 & 0.48 & 45.00 & 65.00 \\
\hline AOYAMA C2005-1I & 35.00 & 30.00 & 4.86 & 0.48 & 45.00 & 65.00 \\
\hline AOYAMA C2005-111 & 35.00 & 30.00 & 4.86 & 0.48 & 45.00 & 65.00 \\
\hline AOYAMA C2015-A & 35.00 & 30.00 & 4.86 & 0.48 & 45.00 & 65.00 \\
\hline AOYAMA C2015-B & 35.00 & 30.00 & 4.86 & 0.48 & 45.00 & 65.00 \\
\hline AOYAMA C2015-C & 35.00 & 30.00 & 4.86 & 0.48 & 45.00 & 65.00 \\
\hline AOYAMA P2005-A & 35.00 & 30.00 & 4.86 & 0.48 & 45.00 & 65.00 \\
\hline AOYAMA P2015-A & 35.00 & 30.00 & 4.86 & 0.48 & 45.00 & 65.00 \\
\hline AOYAMA C4015 & 35.00 & 30.00 & 4.86 & 0.48 & 45.00 & 65.00 \\
\hline AOYAMA P4015 & 35.00 & 30.00 & 4.86 & 0.48 & 45.00 & 65.00 \\
\hline AOYAMA MZO05 & 35.00 & 30.00 & 4.86 & 0.48 & 45.00 & 65.00 \\
\hline AOYAMA CH2O15 & 35.00 & 30.00 & 4.86 & 0.48 & 45.00 & 65.00 \\
\hline AOYAMA CH2018 & 35.00 & 30.00 & 4.86 & 0.48 & 45.00 & 65.00 \\
\hline AOYAMA OLU2015 & 35.00 & 30.00 & 4.86 & 0.48 & 45.00 & 65.00 \\
\hline KAHN SP1 & 15.88 & 60.96 & 1.10 & 0.14 & 34.93 & 15.24 \\
\hline KAHN SP2 & 15.88 & 60.96 & 1.10 & 0.14 & 34.93 & 15.24 \\
\hline KAHN SP3 & 15.88 & 60.96 & 1.10 & 0.14 & 34.93 & 15.24 \\
\hline KAHN SP5 & 15.88 & 60.96 & 1.10 & 0.14 & 34.93 & 15.24 \\
\hline HAYASHI-W1 & 17.00 & 20.00 & 2.98 & 0.11 & 47.00 & 30.00 \\
\hline HAYASHI-W2 & 17.00 & 20.00 & 2.98 & 0.11 & 47.00 & 30.00 \\
\hline HAYASHI-W4 & 17.00 & 20.00 & 2.98 & 0.11 & 47.00 & 30.00 \\
\hline HAYASHI-W5 & 17.00 & 20.00 & 2.98 & 0.11 & 47.00 & 30.00 \\
\hline HAYASHI-W6 & 17.00 & 20.00 & 2.98 & 0.11 & 47.00 & 30.00 \\
\hline SUGANO-WHA & 22.00 & 15.00 & 1.54 & 0.17 & 47.00 & 55.00 \\
\hline SUGANO-W4OS & 22.00 & 15.00 & 1.54 & 0.17 & 47.00 & 55.00 \\
\hline SUGANO-W4OW & 22.00 & 15.00 & 1.54 & 0.17 & 47.00 & 55.00 \\
\hline SUGANO-WBOS & 22.00 & 15.00 & 1.54 & 0.17 & 47.00 & 55.00 \\
\hline SUGANO-F & 22.00 & 15.00 & 1.54 & 0.17 & 47.00 & 55.00 \\
\hline SUGANO-WBL & 22.00 & 15.00 & 1.54 & 0.17 & 47.00 & 55.00 \\
\hline SUGANO-WCO & 22.00 & 15.00 & 1.54 & 0.17 & 47.00 & 55.00 \\
\hline HIGASHI 1-F1 & 17.00 & 20.00 & 2.98 & 0.11 & 37.00 & 50.00 \\
\hline HIGASHI 2-PW & 17.00 & 20.00 & 2.98 & 0.11 & 37.00 & 50.00 \\
\hline HIGASHI 5-F2 & 17.00 & 20.00 & 2.98 & 0.11 & 34.00 & 50.00 \\
\hline HIGASHI13-FW & 17.00 & 20.00 & 2.98 & 0.11 & 34.00 & 50.00 \\
\hline HIGASHI 4-C3C & 17.00 & 20.00 & 2.98 & 0.11 & 37.00 & 50.00 \\
\hline HIGASHI 6-C2A & 17.00 & 20.00 & 2.98 & 0.11 & 34.00 & 50.00 \\
\hline HIGASHI 7-C2B & 17.00 & 20.00 & 2.98 & 0.11 & 34.00 & 50.00 \\
\hline HIGASHI 9-C40 & 17.00 & 20.00 & 2.98 & 0.11 & 34.00 & 50.00 \\
\hline HIGASHI 3-C3 & 17.00 & 20.00 & 2.98 & 0.11 & 37.00 & 50.00 \\
\hline HIGASHI 8-C4 & 17.00 & 20.00 & 2.98 & 0.11 & 34.00 & 50.00 \\
\hline CORLEY B5 & 15.24 & 121.92 & 1.00 & 0.10 & 54.61 & 121.92 \\
\hline CORLEY 86 & 15.24 & 121.92 & 1.00 & 0.10 & 54.61 & 121.92 \\
\hline CORLEY B7 & 15.24 & 121.92 & 1.00 & 0.10 & 54.61 & 121.92 \\
\hline CORLEY B8 & 15.24 & 121.92 & 1.00 & 0.10 & 54.61 & 121.92 \\
\hline CORLEY B9 & 15.24 & 121.92 & 1.00 & 0.10 & 54.61 & 121.92 \\
\hline CORLEY B11 & 15.24 & 121.92 & 1.00 & 0.10 & 54.61 & 121.92 \\
\hline OGATA K1 & 27.00 & 50.00 & 1.68 & 0.57 & 27.00 & 50.00 \\
\hline OGATA K2 & 27.00 & 50.00 & 1.68 & 0.57 & 27.00 & 50.00 \\
\hline OGATA K3 & 27.00 & 50.00 & 1.68 & 0.57 & 27.00 & 50.00 \\
\hline OGATA K4 & 27.00 & 50.00 & 1.68 & 0.57 & 27.00 & 50.00 \\
\hline OGATA K5 & 27.00 & 50.00 & 1.68 & 0.57 & 27.00 & 50.00 \\
\hline OGATA K6 & 27.00 & 50.00 & 1.68 & 0.57 & 27.00 & 50.00 \\
\hline GAYNOR F & 83.82 & 30.48 & 0.91 & 0.56 & 53.34 & 45.72 \\
\hline GAYNOR W & 83.82 & 30.48 & 0.91 & 0.56 & 53.34 & 45.72 \\
\hline GAYNOR D & 83.82 & 30.48 & 0.91 & 0.56 & 53.34 & 45.72 \\
\hline
\end{tabular}




\section{APPENDIX B. (Continued)}

\begin{tabular}{|c|c|c|c|c|c|c|}
\hline TEST NAME & $\begin{array}{ll}x 7 & (\%) \\
\end{array}$ & 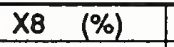 & $\begin{array}{ll}X 9 & \text { (CM) } \\
\end{array}$ & $\begin{array}{ll}X 10 & (\mathrm{CM}) \\
\end{array}$ & $\begin{array}{ll}\mathrm{X} 11 & \text { (CM2) } \\
\end{array}$ & X12 (CM2) \\
\hline AOYAMA C2005-1 & 1.82 & 0.22 & 17.00 & 20.00 & 340.00 & 400.00 \\
\hline AOYAMA C2005-11 & 1.82 & 0.22 & 17.00 & 20.00 & 340.00 & 400.00 \\
\hline AOYAMA C2005-III & 1.82 & 0.22 & 17.00 & 20.00 & 340.00 & 400.00 \\
\hline AOYAMA C2015-A & 1.82 & 0.22 & 17.00 & 20.00 & 340.00 & 400.00 \\
\hline AOYAMA C2015-B & 1.82 & 0.22 & 17.00 & 20.00 & 340.00 & 400.00 \\
\hline AOYAMA C2015-C & 1.82 & 0.22 & 17.00 & 20.00 & 340.00 & 400.00 \\
\hline AOYAMA P2005-A & 1.82 & 0.22 & 17.00 & 20.00 & 340.00 & 400.00 \\
\hline AOYAMA P2015-A & 1.82 & 0.22 & 17.00 & 20.00 & 340.00 & 400.00 \\
\hline AOYAMA C4015 & 1.82 & 0.22 & 37.00 & 20.00 & 740.00 & 800.00 \\
\hline AOYAMA P4015 & 1.82 & 0.22 & 37.00 & 20.00 & 740.00 & 800.00 \\
\hline AOYAMA M2005 & 1.82 & 0.22 & 17.00 & 20.00 & 340.00 & 400.00 \\
\hline AOYAMA CH2015 & 1.82 & 0.22 & 17.00 & 20.00 & 340.00 & 400.00 \\
\hline AOYAMA CH2018 & 1.82 & 0.22 & 17.00 & 20.00 & 340.00 & 400.00 \\
\hline AOYAMA OLU2015 & 1.82 & 0.22 & 17.00 & 20.00 & 340.00 & 400.00 \\
\hline KAHN SP1 & 0.38 & 0.14 & 13.34 & 15.24 & 203.30 & 232.26 \\
\hline KAHN SP2 & 0.38 & 0.14 & 13.34 & 15.24 & 203.30 & 232.26 \\
\hline KAHN SP3 & 0.38 & 0.14 & 13.34 & 15.24 & 203.30 & 232.26 \\
\hline KAHN SP5 & 0.38 & 0.14 & 13.34 & 15.24 & 203.30 & 232.26 \\
\hline HAYASHI-W1 & 2.16 & 0.11 & 17.00 & 20.00 & 340.00 & 400.00 \\
\hline HAYASHI-W2 & 2.16 & 0.11 & 17.00 & 20.00 & 340.00 & 400.00 \\
\hline HAYASHI-W4 & 2.16 & 0.11 & 17.00 & 20.00 & 340.00 & 400.00 \\
\hline HAYASHI-W5 & 2.16 & 0.11 & 17.00 & 20.00 & 340.00 & 400.00 \\
\hline HAYASHI-W6 & 2.16 & 0.11 & 17.00 & 20.00 & 340.00 & 400.00 \\
\hline SUGANO-WHA & 2.00 & 0.17 & 17.00 & 20.00 & 340.00 & 400.00 \\
\hline SUGANO-W4OS & 2.00 & 0.17 & 17.00 & 20.00 & 340.00 & 400.00 \\
\hline SUGANO-W4OW & 2.00 & 0.17 & 17.00 & 20.00 & 340.00 & 400.00 \\
\hline SUGANO-WBOS & 2.00 & 0.17 & 17.00 & 20.00 & 340.00 & 400.00 \\
\hline SUGANO-F & 2.00 & 0.17 & 17.00 & 20.00 & 340.00 & 400.00 \\
\hline SUGANO-WBL & 2.00 & 0.17 & 17.00 & 20.00 & 340.00 & 400.00 \\
\hline SUGANO-WCO & 2.00 & 0.17 & 17.00 & 20.00 & 340.00 & 400.00 \\
\hline HIGASHI 1-F1 & 0.54 & 0.04 & 17.00 & 20.00 & 340.00 & 400.00 \\
\hline HIGASHI 2-PW & 0.54 & 0.04 & 17.00 & 20.00 & 340.00 & 400.00 \\
\hline HIGASHI 5-F2 & 0.59 & 0.04 & 17.00 & 20.00 & 340.00 & 400.00 \\
\hline HIGASHI13-FW & 0.59 & 0.04 & 17.00 & 20.00 & 340.00 & 400.00 \\
\hline HIGASHI 4-C3C & 0.54 & 0.04 & 17.00 & 20.00 & 340.00 & 400.00 \\
\hline HIGASHI 6-C2A & 0.59 & 0.04 & 17.00 & 20.00 & 340.00 & 400.00 \\
\hline HIGASHI 7-C2B & 0.59 & 0.04 & 17.00 & 20.00 & 340.00 & 400.00 \\
\hline HIGASHI 9-C40 & 0.59 & 0.04 & 17.00 & 20.00 & 340.00 & 400.00 \\
\hline HIGASHI 3-C3 & 0.54 & 0.04 & 17.00 & 20.00 & 340.00 & 400.00 \\
\hline HIGASHI 8-C4 & 0.59 & 0.04 & 17.00 & 20.00 & 340.00 & 400.00 \\
\hline CORLEY B5 & 1.00 & 0.10 & 27.94 & 30.48 & 851.61 & 929.03 \\
\hline CORLEY B6 & 1.00 & 0.10 & 27.94 & 30.48 & 851.61 & 929.03 \\
\hline CORLEY B7 & 1.00 & 0.10 & 27.94 & 30.48 & 851.61 & 929.03 \\
\hline CORLEY 88 & 1.00 & 0.10 & 27.94 & 30.48 & 851.61 & 929.03 \\
\hline CORLEY B9 & 1.00 & 0.10 & 27.94 & 30.48 & 851.61 & 929.03 \\
\hline CORLEY B11 & 1.00 & 0.10 & 27.94 & 30.48 & 851.61 & 929.03 \\
\hline OGATA K1 & 2.10 & 0.57 & 17.00 & 20.00 & 340.00 & 400.00 \\
\hline OGATA K2 & 2.10 & 0.57 & 17.00 & 20.00 & 340.00 & 400.00 \\
\hline OGATA K3 & 2.10 & 0.57 & 17.00 & 20.00 & 340.00 & 400.00 \\
\hline OGATA K4 & 2.10 & 0.57 & 17.00 & 20.00 & 340.00 & 400.00 \\
\hline OGATA K5 & 2.10 & 0.57 & 17.00 & 20.00 & 340.00 & 400.00 \\
\hline OGATA KG & 2.10 & 0.57 & 17.00 & 20.00 & 340.00 & 400.00 \\
\hline GAYNOR F & 1.59 & 0.25 & 22.86 & 30.48 & 696.77 & 929.03 \\
\hline GAYNOR W & 1.59 & 0.25 & 22.86 & 30.48 & 696.77 & 929.03 \\
\hline GAYNOR D & 1.59 & 0.25 & 22.86 & 30.48 & 696.77 & 929.03 \\
\hline
\end{tabular}




\section{APPENDIX B. (Continued)}

\begin{tabular}{|c|c|c|c|c|c|c|}
\hline TEST NAME & $\mathrm{X} 13$ (TONF) & $\times 14$ & $(\mathrm{CM})$ & $\times 16$ & $\times 17$ & $\times 18 \quad(\%)$ \\
\hline AOYAMA C2005-I & 12.00 & 0.12712 & 97.00 & 0.539 & 1.49 & 0.21 \\
\hline AOYAMA C2005-II & 12.00 & 0.12712 & 97.00 & 0.539 & 1.49 & 0.21 \\
\hline AOYAMA C2005-III & 12.00 & 0.13274 & 97.00 & 0.539 & 1.49 & 0.21 \\
\hline AOYAMA C2015-A & 12.00 & 0.13453 & 97.00 & 0.539 & 4.47 & 0.21 \\
\hline AOYAMA C2015-B & 12.00 & 0.15152 & 97.00 & 0.539 & 4.47 & 0.21 \\
\hline AOYAMA C2015-C & 12.00 & 0.074442 & 97.00 & 0.539 & 4.47 & 0.21 \\
\hline AOYAMA P2005-A & 12.00 & 0.13636 & 97.00 & 0.539 & 1.49 & 0.21 \\
\hline AOYAMA P2015-A & 12.00 & 0.076142 & 97.00 & 0.539 & 4.47 & 0.21 \\
\hline AOYAMA C4015 & 12.00 & 0.064103 & 97.00 & 0.606 & 2.06 & 0.21 \\
\hline AOYAMA P4015 & 12.00 & 0.050505 & 97.00 & 0.606 & 2.06 & 0.21 \\
\hline AOYAMA MZOO5 & 12.00 & 0.099668 & 97.00 & 0.539 & 1.49 & 0.21 \\
\hline AOYAMA CH2O15 & 12.00 & 0.10381 & 97.00 & 0.539 & 4.47 & 0.21 \\
\hline AOYAMA CH2018 & 12.00 & 0.11494 & 97.00 & 0.539 & 5.35 & 0.21 \\
\hline AOYAMA OLU2015 & 12.00 & 0.13453 & 97.00 & 0.539 & 4.47 & 0.21 \\
\hline KAHN SP1 & 0.00 & 0 & 149.86 & 0.615 & 3.94 & 0.07 \\
\hline KAHN SP2 & 0.00 & 0 & 149.86 & 0.615 & 3.94 & 0.07 \\
\hline KAHN SP3 & 0.00 & 0 & 149.86 & 0.615 & 3.94 & 0.07 \\
\hline KAHN SP5 & 0.00 & 0 & 149.86 & 0.615 & 3.94 & 0.07 \\
\hline HAYASHI-W1 & 12.00 & 0.16393 & 90.00 & 0.5625 & 1.49 & 0.11 \\
\hline HAYASHI-W2 & 12.00 & 0.16393 & 90.00 & 0.5625 & 1.49 & 0.11 \\
\hline HAYASHI-W4 & 12.00 & 0.16393 & 90.00 & 0.5625 & 1.49 & 0.11 \\
\hline HAYASHI-W5 & 12.00 & 0.16216 & 90.00 & 0.5625 & 1.49 & 0.11 \\
\hline HAYASHI-W6 & 12.00 & 0.16216 & 90.00 & 0.5625 & 1.49 & 0.11 \\
\hline SUGANO-WHA & 12.48 & 0.13 & 80.00 & 0.53333 & 1.49 & 0.13 \\
\hline SUGANO-W4OS & 12.48 & 0.13 & 80.00 & 0.53333 & 1.49 & 0.13 \\
\hline SUGANO-W4OW & 12.48 & 0.13 & 80.00 & 0.53333 & 1.49 & 0.13 \\
\hline SUGANO-WBOS & 12.48 & 0.13 & 80.00 & 0.53333 & 1.49 & 0.13 \\
\hline SUGANO-F & 12.48 & 0.13 & 80.00 & 0.53333 & 1.49 & 0.13 \\
\hline SUGANO-WBL & 12.48 & 0.13 & 80.00 & 0.53333 & 1.49 & 0.13 \\
\hline SUGANOWCO & 12.48 & 0.13 & 80.00 & 0.53333 & 1.49 & 0.13 \\
\hline HIGASHI 1-F1 & 12.00 & 0.17045 & 90.00 & 0.5625 & 1.49 & 0.11 \\
\hline HIGASHI 2-PW & 12.00 & 0.17045 & 90.00 & 0.5625 & 1.49 & 0.11 \\
\hline HIGASHI 5-F2 & 12.00 & 0.14286 & 90.00 & 0.5625 & 1.49 & 0.11 \\
\hline HIGASHI13-FW & 12.00 & 0.14286 & 90.00 & 0.5625 & 1.49 & 0.11 \\
\hline HIGASHI 4-C3C & 12.00 & 0.17045 & 90.00 & 0.5625 & 1.49 & 0.11 \\
\hline HIGASHI 6-C2A & 12.00 & 0.14286 & 90.00 & 0.5625 & 1.49 & 0.11 \\
\hline HIGASHI 7.C2B & 12.00 & 0.14286 & 90.00 & 0.5625 & 1.49 & 0.11 \\
\hline HIGASHI $2-\mathrm{C} 40$ & 12.00 & 0.14286 & 90.00 & 0.5625 & 1.49 & 0.11 \\
\hline HIGASHI 3-C3 & 12.00 & 0.17045 & 90.00 & 0.5625 & 1.49 & 0.11 \\
\hline HIGASHI 8-C4 & 12.00 & 0.14286 & 90.00 & 0.5625 & 1.49 & 0.11 \\
\hline CORLEY BS & 0.00 & 0 & 447.04 & 2.3467 & 3.67 & 1.35 \\
\hline CORLEY B6 & 27.75 & 0.13432 & 447.04 & 2.3467 & 3.67 & 0.81 \\
\hline CORLEY B7 & 35.59 & 0.076172 & 447.04 & 2.3467 & 3.67 & 1.35 \\
\hline CORLEY B8 & 35.59 & 0.089565 & 447.04 & 2.3467 & 3.67 & 1.35 \\
\hline CORLEY B9 & 35.59 & 0.08521 & 447.04 & 2.3467 & 3.67 & 1.35 \\
\hline CORLEY B11 & 0.00 & 0 & 447.04 & 2.3467 & 3.67 & 1.35 \\
\hline OGATA K1 & 7.68 & 0.097959 & 150.00 & 0.9375 & 0.71 & 0.96 \\
\hline OGATA K2 & 7.68 & 0.097959 & 150.00 & 0.9375 & 1.43 & 1.44 \\
\hline OGATA K3 & 7.68 & 0.097959 & 150.00 & 0.9375 & 2.14 & 1.92 \\
\hline OGATA K4 & 7.68 & 0.090566 & 150.00 & 0.9375 & 1.43 & 1.44 \\
\hline OGATA K5 & 7.68 & 0.090566 & 150.00 & 0.9375 & 1.43 & 1.44 \\
\hline OGATA K6 & 7.68 & 0.090566 & 150.00 & 0.9375 & 214 & 1.92 \\
\hline GAYNOR F & 0.00 & 0 & 213.36 & 0.5676 & 2.22 & 0.15 \\
\hline GAYNOR W & 0.00 & 0 & 213.36 & 0.5676 & 2.22 & 0.15 \\
\hline GAYNOR D & 0.00 & 0 & 213.36 & 0.5676 & 2.22 & 0.15 \\
\hline
\end{tabular}




\section{APPENDIX B. (Continued)}

\begin{tabular}{|c|c|c|c|c|c|}
\hline TEST NAME & $\begin{array}{ll}X 19 & (\%) \\
\end{array}$ & $\begin{array}{ll}\times 20 & (\%) \\
\end{array}$ & $\mathrm{X} 21$ (TONF/CM2) & X22 (TONF/CM2) & $\mathrm{X} 23$ (TONF/CM2) \\
\hline AOYAMA C2005-I & 1.49 & $\begin{array}{r}0.21 \\
\end{array}$ & $\begin{array}{r}0.236 \\
\end{array}$ & 3.72 & 231.97 \\
\hline AOYAMA C2005-II & 1.49 & 0.21 & 0.236 & 3.08 & 231.97 \\
\hline AOYAMA C2005-III & 1.49 & 0.21 & 0.226 & 3.08 & 227.00 \\
\hline AOYAMA C2015-A & 4.47 & 0.21 & 0.223 & 3.71 & 225.49 \\
\hline AOYAMA C2015-B & 4.47 & 0.21 & 0.198 & 3.71 & 212.48 \\
\hline AOYAMA C2015-C & 4.47 & 0.21 & 0.403 & 3.71 & 303.13 \\
\hline AOYAMA P2005-A & 1.49 & 0.21 & 0.22 & 3.08 & 223.97 \\
\hline AOYAMA P2015-A & 4.47 & 0.21 & 0.394 & 3.71 & 299.73 \\
\hline AOYAMA C4015 & 2.06 & 0.21 & 0.234 & 3.62 & 230.99 \\
\hline AOYAMA P4015 & 2.06 & 0.21 & 0.297 & 3.62 & 260.23 \\
\hline AOYAMA M2005 & 1.49 & 0.21 & 0.301 & 3.68 & 261.98 \\
\hline AOYAMA CH2O15 & 4.47 & 0.21 & 0.289 & 3.84 & 256.70 \\
\hline AOYAMA CH2018 & 5.35 & 0.21 & 0.261 & 3.84 & 243.95 \\
\hline AOYAMA OLU2015 & 4.47 & 0.21 & 0.223 & 3.84 & 225.49 \\
\hline KAHN SP1 & 3.94 & 0.07 & 0.35085 & 3.5844 & 282.84 \\
\hline KAHN SP2 & 3.94 & 0.07 & 0.31698 & 3.5844 & 268.84 \\
\hline KAHN SP3 & 3.94 & 0.07 & 0.25161 & 3.5844 & 239.52 \\
\hline KAHN SP5 & 3.94 & 0.07 & 0.2474 & 3.5844 & 237.51 \\
\hline HAYASHI-W1 & 1.49 & 0.11 & 0.183 & 3.55 & 204.27 \\
\hline HAYASHI-W2 & 1.49 & 0.11 & 0.183 & 3.55 & 204.27 \\
\hline HAYASHI-W4 & 1.49 & 0.11 & 0.183 & 3.55 & 204.27 \\
\hline HAYASHI-W5 & 1.49 & 0.11 & 0.185 & 3.55 & 205.38 \\
\hline HAYASHI-W6 & 1.49 & 0.11 & 0.185 & 3.55 & 205.38 \\
\hline SUGANO-WHA & 1.49 & 0.13 & 0.24 & 3.76 & 233.93 \\
\hline SUGANO-W4OS & 1.49 & 0.13 & 0.24 & 3.76 & 233.93 \\
\hline SUGANO-W4OW & 1.49 & 0.13 & 0.24 & 3.76 & 233.93 \\
\hline SUGANO-WBOS & 1.49 & 0.13 & 0.24 & 3.76 & 233.93 \\
\hline SUGANO-F & 1.49 & 0.13 & 0.24 & 3.76 & 233.93 \\
\hline SUGANO-WBL & 1.49 & 0.13 & 0.24 & 3.76 & 233.93 \\
\hline SUGANO-WCO & 1.49 & 0.13 & 0.24 & 3.76 & 233.93 \\
\hline HIGASHI 1-F1 & 1.49 & 0.11 & 0.176 & 3.98 & 200.32 \\
\hline HIGASHI 2-PW & 1.49 & 0.11 & 0.176 & 3.98 & 200.32 \\
\hline HIGASHI 5-F2 & 1.49 & 0.11 & 0.21 & 3.96 & 218.82 \\
\hline HIGASHI13-FW & 1.49 & 0.11 & 0.21 & 3.96 & 218.82 \\
\hline HIGASHI 4-C3C & 1.49 & 0.11 & 0.176 & 3.98 & 200.32 \\
\hline HIGASHI 6-C2A & 1.49 & 0.11 & 0.21 & 3.96 & 218.82 \\
\hline HIGASHI 7-C2B & 1.49 & 0.11 & 0.21 & 3.96 & 218.82 \\
\hline HIGASHI 9-C40 & 1.49 & 0.11 & 0.21 & 3.96 & 218.82 \\
\hline HIGASHI 3-C3 & 1.49 & 0.11 & 0.176 & 3.98 & 200.32 \\
\hline HIGASHI 8-C4 & 1.49 & 0.11 & 0.21 & 3.96 & 218.82 \\
\hline CORLEY B5 & 3.67 & 1.35 & 0.46176 & 4.5262 & 324.48 \\
\hline CORLEY B6 & 3.67 & 0.81 & 0.22238 & 4.4911 & 225.18 \\
\hline CORLEY B7 & 3.67 & 1.35 & 0.50287 & 4.6668 & 338.61 \\
\hline CORLEY B8 & 3.67 & 1.35 & 0.42767 & 4.5614 & 312.27 \\
\hline CORLEY B9 & 3.67 & 1.35 & 0.44953 & 4.3786 & 320.15 \\
\hline CORLEY B11 & 3.67 & 1.35 & 0.54821 & 4.4419 & 353.55 \\
\hline OGATA K1 & 0.71 & 0.96 & 0.196 & 3.995 & 211.40 \\
\hline OGATA K2 & 1.43 & 1.44 & 0.196 & 3.995 & 211.40 \\
\hline OGATA K3 & 2.14 & 1.92 & 0.196 & 3.995 & 211.40 \\
\hline OGATA K4 & 1.43 & 1.44 & 0.212 & 3.995 & 219.86 \\
\hline OGATA K5 & 1.43 & 1.44 & 0.212 & 3.995 & 219.86 \\
\hline OGATA K6 & 2.14 & 1.92 & 0.212 & 3.995 & 219.86 \\
\hline GAYNOR F & 2.22 & 0.15 & 0.292 & 4.217 & 258.03 \\
\hline GAYNOR W & 2.22 & 0.15 & 0.392 & 4.217 & 298.96 \\
\hline GAYNOR D & 2.22 & 0.15 & 0.337 & 4.217 & 277.20 \\
\hline
\end{tabular}




\section{APPENDIX B. (Continued)}

\begin{tabular}{|c|c|c|c|c|c|c|}
\hline TEST NAME & X24 (TONF/CM2) & $\times 25$ (CM4) & $\times 26$ (TONF/CM) & $\times 27 \quad(\mathrm{CM})$ & $\times 28 \quad(\mathrm{CM} 4)$ & $\times 29$ (CM4) \\
\hline AOYAMA C2005-I & 1800.00 & $8.02 E+06$ & 24472.00 & 10.00 & 1.29E+07 & 0 \\
\hline AOYAMA C2005-11 & 1800.00 & $8.02 E+06$ & 24472.00 & 10.00 & $1.29 E+07$ & 0 \\
\hline AOYAMA C2005-III & 1800.00 & $8.02 E+06$ & 23948.00 & 10.00 & $1.29 E+07$ & 0 \\
\hline AOYAMA C2015-A & 1800.00 & $8.02 E+06$ & 23788.00 & 10.00 & $1.29 E+07$ & 0 \\
\hline AOYAMA C2015-B & 1800.00 & $8.02 E+06$ & 22416.00 & 10.00 & $1.29 E+07$ & 0 \\
\hline AOYAMA C2015-C & 1800.00 & $8.02 E+06$ & 31979.00 & 10.00 & 1.29E+07 & 0 \\
\hline AOYAMA P2005-A & 1800.00 & $8.02 E+06$ & 23628.00 & 10.00 & $1.29 E+07$ & 0 \\
\hline AOYAMA P2015-A & 1800.00 & $8.02 E+06$ & 31620.00 & 10.00 & $1.29 E+07$ & 0 \\
\hline AOYAMA C4015 & 1800.00 & $1.62 \mathrm{E}+07$ & 49273.00 & 10.00 & $1.96 E+07$ & 0 \\
\hline AOYAMA P4015 & 1800.00 & $1.62 E+07$ & 55511.00 & 10.00 & $1.96 \mathrm{E}+07$ & 0 \\
\hline AOYAMA M2005 & 1800.00 & $8.02 E+06$ & 27638.00 & 10.00 & $1.29 E+07$ & 0 \\
\hline AOYAMA CH2O15 & 1800.00 & $8.02 E+06$ & 27081.00 & 10.00 & $1.29 E+07$ & 0 \\
\hline AOYAMA CH2018 & 1800.00 & $8.02 E+06$ & 25736.00 & 10.00 & $1.29 E+07$ & 0 \\
\hline AOYAMA OLU2015 & 1800.00 & $8.02 E+06$ & 23789.00 & 10.00 & $1.29 E+07$ & $2.51 E+05$ \\
\hline KAHN SP1 & 1800.00 & $7.79 E+06$ & 7860.00 & 7.62 & $1.70 E+07$ & 0 \\
\hline KAHN SP2 & 1800.00 & $7.79 E+06$ & 7471.00 & 0.00 & $7.79 E+06$ & 0 \\
\hline KAHN SP3 & 1800.00 & $7.79 E+06$ & 6656.20 & 7.62 & $1.70 E+07$ & 0 \\
\hline KAHN SP5 & 1800.00 & $7.79 E+06$ & 6600.30 & 7.62 & $1.70 E+07$ & 0 \\
\hline HAYASHI-W1 & 1970.00 & $6.51 E+06$ & 21878.00 & 0.00 & $6.51 E+06$ & 0 \\
\hline HAYASHI-W2 & 1970.00 & $6.51 E+06$ & 21878.00 & 7.50 & 9.07E+06 & 0 \\
\hline HAYASHI-W4 & 1970.00 & $6.51 E+06$ & 21878.00 & 7.50 & $9.07 E+\infty 6$ & 0 \\
\hline HAYASHI-W5 & 1970.00 & $6.51 E+06$ & 21998.00 & 7.50 & 9.07E+06 & 0 \\
\hline HAYASHI-W6 & 1970.00 & $6.51 E+06$ & 21998.00 & 7.50 & $9.07 E+06$ & 0 \\
\hline SUGANO-WHA & 1900.00 & $5.81 E+06$ & 31837.00 & 8.00 & $8.06 E+06$ & 0 \\
\hline SUGANO-W4OS & 1900.00 & $5.81 E+06$ & 31837.00 & 4.00 & $6.93 E+\infty 6$ & 0 \\
\hline SUGANO-W4OW & 1900.00 & $5.81 E+06$ & 31837.00 & 4.00 & $6.93 E+\infty 6$ & 0 \\
\hline SUGANO-WBOS & 1900.00 & $5.81 E+06$ & 31837.00 & 8.00 & $8.06 E+\infty 6$ & 0 \\
\hline SUGANO-F & 1900.00 & $5.81 E+06$ & 31837.00 & 0.00 & $5.81 E+06$ & 0 \\
\hline SUGANO-WBL & 1900.00 & $5.81 E+06$ & 31837.00 & 10.00 & $8.62 E+\infty 6$ & 0 \\
\hline SUGANO-WCO & 1900.00 & $5.81 E+06$ & 31837.00 & 8.00 & $8.06 E+06$ & 0 \\
\hline HIGASHI 1-F1 & 1800.00 & $6.51 E+06$ & 21456.00 & 0.00 & $6.51 E+06$ & 0 \\
\hline HIGASHI 2-PW & 1800.00 & $6.51 E+06$ & 21456.00 & 7.50 & 9.07E+06 & 0 \\
\hline HIGASHI 5-F2 & 1800.00 & $6.51 E+06$ & 23437.00 & 0.00 & $6.51 E+\infty 6$ & 0 \\
\hline HIGASHI13-FW & 1800.00 & $6.51 E+06$ & 23437.00 & 7.50 & $9.07 E+06$ & 0 \\
\hline HIGASHI 4-C3C & 1800.00 & $6.51 E+06$ & 21456.00 & 7.50 & 9.07E+06 & 의 \\
\hline HIGASHI 6-C2A & 1800.00 & $6.51 E+06$ & 23437.00 & 7.50 & $9.0 \pi E+06$ & $2.74 E+05$ \\
\hline HIGASHI 7-C2B & 1800.00 & $6.51 E+06$ & 23437.00 & 7.50 & $9.07 E+06$ & $1.92 E+06$ \\
\hline HIGASHI 9-C40 & 1800.00 & $6.51 E+06$ & 23437.00 & 7.50 & $9.0 \pi E+\infty 6$ & 0 \\
\hline HIGASHI 3-C3 & 1800.00 & $6.51 E+06$ & 21456.00 & 7.50 & $9.07 E+06$ & 0 \\
\hline HIGASHI 8-C4 & 1800.00 & $6.51 E+06$ & 23437.00 & 7.50 & $9.07 E+06$ & 0 \\
\hline CORLEY B5 & 1900.00 & $2.28 E+07$ & 994.87 & 10.20 & 2.87E+07 & 0 \\
\hline CORLEY B6 & 1900.00 & $2.28 E+07$ & 690.41 & 10.20 & $2.87 E+07$ & 0 \\
\hline CORLEY B7 & 1900.00 & $2.28 E+07$ & 1038.20 & 10.20 & 2.87E+07 & 0 \\
\hline CORLEY B8 & 1900.00 & $2.28 E+07$ & 957.45 & 10.20 & $2.87 E+07$ & 0 \\
\hline CORLEY B9 & 1900.00 & $2.28 E+07$ & 981.61 & 10.20 & 2.87E+07 & 0 \\
\hline CORLEY B11 & 1900.00 & $2.28 E+07$ & 1084.00 & 10.20 & $2.87 E+07$ & 0 \\
\hline OGATA K1 & 1900.00 & $6.51 E+06$ & 4890.70 & 8.00 & $9.24 E+06$ & 0 \\
\hline OGATA K2 & 1900.00 & $6.51 E+06$ & 4890.70 & 8.00 & $9.24 E+06$ & 0 \\
\hline OGATA K3 & 1900.00 & $6.51 \mathrm{E}+06$ & 4890.70 & 8.00 & $9.24 E+06$ & 0 \\
\hline OGATA K4 & 1900.00 & $6.51 E+06$ & 5086.40 & 8.00 & $9.24 E+06$ & 0 \\
\hline OGATA K5 & 1900.00 & $6.51 E+06$ & 5086.40 & 8.00 & $9.24 E+06$ & 0 \\
\hline OGATA K6 & 1900.00 & $6.51 E+06$ & 5086.40 & 8.00 & $9.24 E+06$ & 0 \\
\hline GAYNOR F & 1800.00 & $7.69 E+07$ & 24501.00 & 13.34 & $1.36 E+08$ & 0 \\
\hline GAYNOR W & 1800.00 & $7.69 E+07$ & 28388.00 & 13.34 & $1.36 \mathrm{E}+08$ & $3.20 E+\infty 6$ \\
\hline GAYNOR D & 1800.00 & $7.69 E+07$ & 26321.00 & 13.34 & $1.36 \mathrm{E}+08$ & 1.17E+06 \\
\hline
\end{tabular}




\section{APPENDIX B. (Continued)}

\begin{tabular}{|c|c|c|c|c|c|c|}
\hline TEST NAME & \begin{tabular}{ll|}
$\times 30$ & $(\mathrm{CM})$ \\
\end{tabular} & $\begin{array}{ll}X 31 & (\mathrm{CM})\end{array}$ & $\begin{array}{ll}32 & (\mathrm{CM}) \\
\end{array}$ & $\mathrm{X33} \quad$ (CM2) & $\begin{array}{ll}34 & \text { (CM2) } \\
\end{array}$ & $\times 35$ \\
\hline AOYAMA C2005-I & 0.00 & 0.00 & 0.00 & 2599.60 & 0.00 & 0 \\
\hline AOYAMA C2005-11 & 0.00 & 0.00 & 0.00 & 2599.60 & 0.00 & 0 \\
\hline AOYAMA C2005-III & 0.00 & 0.00 & 0.00 & 2599.60 & 0.00 & 0 \\
\hline AOYAMA C2015-A & 0.00 & 0.00 & 0.00 & 2599.60 & 0.00 & 0 \\
\hline AOYAMA C2015-B & 0.00 & 0.00 & 0.00 & 2599.60 & 0.00 & 0 \\
\hline AOYAMA C2015-C & 0.00 & 0.00 & 0.00 & 2599.60 & 0.00 & 0 \\
\hline AOYAMA P2005-A & 0.00 & 0.00 & 0.00 & 2599.60 & 0.00 & 0 \\
\hline AOYAMA P2015-A & 0.00 & 0.00 & 0.00 & 2599.60 & 0.00 & 0 \\
\hline AOYAMA C4015 & 0.00 & 0.00 & 0.00 & 3200.70 & 0.00 & 0 \\
\hline AOYAMA P4015 & 0.00 & 0.00 & 0.00 & 3200.70 & 0.00 & 0 \\
\hline AOYAMA M2005 & 0.00 & 0.00 & 0.00 & 2599.60 & 0.00 & 0 \\
\hline AOYAMA CH2O15 & 0.00 & 0.00 & 0.00 & 2599.60 & 0.00 & 0 \\
\hline AOYAMA CH2O18 & 0.00 & 0.00 & 0.00 & 2599.60 & 0.00 & 0 \\
\hline AOYAMA OLU2015 & 43.00 & 40.00 & 14.00 & 2599.60 & 670.00 & $6.93 E-08$ \\
\hline KAHN SP1 & 0.00 & 0.00 & 0.00 & 2321.30 & 0.00 & 0 \\
\hline KAHN SP2 & 0.00 & 0.00 & 0.00 & 464.52 & 0.00 & 0 \\
\hline KAHN SP 3 & 0.00 & 0.00 & 0.00 & 2321.30 & 0.00 & 0 \\
\hline KAHN SP5 & 0.00 & 0.00 & 0.00 & 2321.30 & 0.00 & 0 \\
\hline HAYASHI-W1 & 0.00 & 0.00 & 0.00 & 800.00 & 0.00 & 0 \\
\hline HAYASHI-W2 & 0.00 & 0.00 & 0.00 & 2000.00 & 0.00 & 0 \\
\hline HAYASHI-W4 & 0.00 & 0.00 & 0.00 & 2000.00 & 0.00 & 0 \\
\hline HAYASHI-W5 & 0.00 & 0.00 & 0.00 & 2000.00 & 0.00 & 0 \\
\hline HAYASHI-W6 & 0.00 & 0.00 & 0.00 & 2000.00 & 0.00 & 0 \\
\hline SUGANO-WHA & 0.00 & 0.00 & 0.00 & 2000.00 & 0.00 & 0 \\
\hline SUGANO-W4OS & 0.00 & 0.00 & 0.00 & 1400.00 & 0.00 & 0 \\
\hline SUGANO-W4OW & 0.00 & 0.00 & 0.00 & 1400.00 & 0.00 & 0 \\
\hline SUGANO-WBOS & 0.00 & 0.00 & 0.00 & 2000.00 & 0.00 & 0 \\
\hline SUGANO-F & 0.00 & 0.00 & 0.00 & 800.00 & 0.00 & 0 \\
\hline SUGANO-WBL & 0.00 & 0.00 & 0.00 & 2300.00 & 0.00 & 0 \\
\hline SUGANO-WCO & 0.00 & 0.00 & 0.00 & 2000.00 & 0.00 & 0 \\
\hline HIGASHI 1-F1 & 0.00 & 0.00 & 0.00 & 800.00 & 0.00 & 0 \\
\hline HIGASHI 2-PW & 0.00 & 0.00 & 0.00 & 2000.00 & 0.00 & 0 \\
\hline HIGASHI 5-F2 & 0.00 & 0.00 & 0.00 & 800.00 & 0.00 & 0 \\
\hline HIGASHI13-FW & 0.00 & 0.00 & 0.00 & 2000.00 & 0.00 & 0 \\
\hline HIGASHI 4-C3C & 0.00 & 0.00 & 0.00 & 2000.00 & 0.00 & 0 \\
\hline HIGASHI 6-C2A & 0.00 & 90.00 & 0.00 & 2000.00 & 570.00 & 0 \\
\hline HIGASHI 7-C2B & 0.00 & 90.00 & 0.00 & 2000.00 & 570.00 & 0 \\
\hline HIGASHI 9-C40 & 0.00 & 0.00 & 0.00 & 2000.00 & 0.00 & 0 \\
\hline HIGASHI 3-C3 & 0.00 & 0.00 & 0.00 & 2000.00 & 0.00 & 0 \\
\hline HIGASHI \&-C4 & 0.00 & 0.00 & 0.00 & 2000.00 & 0.00 & 0 \\
\hline CORLEY B5 & 0.00 & 0.00 & 0.00 & 3801.10 & 0.00 & 0 \\
\hline CORLEY B6 & 0.00 & 0.00 & 0.00 & 3801.10 & 0.00 & 0 \\
\hline CORLEY B7 & 0.00 & 0.00 & 0.00 & 3801.10 & 0.00 & 0 \\
\hline CORLEY B8 & 0.00 & 0.00 & 0.00 & 3801.10 & 0.00 & 0 \\
\hline CORLEY B9 & 0.00 & 0.00 & 0.00 & 3801.10 & 0.00 & 0 \\
\hline CORLEY B11 & 0.00 & 0.00 & 0.00 & 3801.10 & 0.00 & 0 \\
\hline OGATA K1 & 0.00 & 0.00 & 0.00 & 0.00 & 0.00 & 0 \\
\hline OGATA K2 & 0.00 & 0.00 & 0.00 & 0.00 & 0.00 & 0 \\
\hline OGATA K3 & 0.00 & 0.00 & 0.00 & 0.00 & 0.00 & 0 \\
\hline OGATA K4 & 0.00 & 0.00 & 0.00 & 0.00 & 0.00 & 0 \\
\hline OGATA K5 & 0.00 & 0.00 & 0.00 & 0.00 & 0.00 & 0 \\
\hline OGATA KG & 0.00 & 0.00 & 0.00 & 0.00 & 0.00 & 0 \\
\hline GAYNOR F & 0.00 & 0.00 & 0.00 & 6872.80 & 0.00 & 0 \\
\hline GAYNOR W & 66.04 & 81.28 & 66.04 & 6872.80 & 1897.50 & $1.15 E-07$ \\
\hline GAYNOR D & 0.00 & 142.24 & 71.12 & 6872.80 & 1355.30 & $1.21 \mathrm{E}-07$ \\
\hline
\end{tabular}




\section{APPENDIX B. (Continued)}

\begin{tabular}{|c|c|c|c|c|c|c|}
\hline TEST NAME & $\times 36$ & $\times 37(\%)$ & $\times 38(\%)$ & $\begin{array}{ll}\times 39 & (\%) \\
\end{array}$ & X40 (TONF/CM2) & $X_{41}$ (TONF/CM2) \\
\hline AOYAMA C2005-I & 0 & 0.85 & 0.85 & 0 & 0.21 & 3.99 \\
\hline AOYAMA C2005-11 & 0 & 0.85 & 0.85 & 0 & 0.21 & 3.99 \\
\hline AOYAMA C2005-1II & 0 & 0.85 & 0.85 & 0 & 0.22 & 3.99 \\
\hline AOYAMA C2015-A & 0 & 0.85 & 0.85 & 0 & 0.15 & 3.62 \\
\hline AOYAMA C2015-B & 0 & 0.85 & 0.85 & 0 & 0.15 & 3.62 \\
\hline AOYAMA C2015-C & 0 & 0.85 & 0.85 & 0 & 0.39 & 3.62 \\
\hline AOYAMA P2005-A & 0 & 0.85 & 0.85 & 0 & 0.22 & 3.99 \\
\hline AOYAMA P2015-A & 0 & 0.85 & 0.85 & 0 & 0.39 & 3.62 \\
\hline AOYAMA C4015 & 0 & 0.85 & 0.85 & 0 & 0.30 & 3.62 \\
\hline AOYAMA P4015 & 0 & 0.85 & 0.85 & 0 & 0.30 & 3.62 \\
\hline AOYAMA M2005 & 0 & 0.85 & 0.85 & 0 & 0.29 & 3.99 \\
\hline AOYAMA CH2O15 & 0 & 0.85 & 0.85 & 0 & 0.22 & 3.96 \\
\hline AOYAMA CH2018 & 0 & 0.85 & 0.85 & 0 & 0.22 & 3.96 \\
\hline AOYAMA OLU2015 & 2.67E-07 & 0.85 & 0.85 & 0 & 0.18 & 3.96 \\
\hline KAHN SP1 & 0 & 0.44 & 0.46 & 0 & 0.35 & 4.49 \\
\hline KAHN SP2 & 0 & 0.00 & 0.00 & 0 & 0.00 & 0.00 \\
\hline KAHN SP3 & 0 & 0.44 & 0.46 & 0 & 0.20 & 4.49 \\
\hline KAHN SP5 & 0 & 0.00 & 0.00 & 0 & 0.20 & 4.49 \\
\hline HAYASHI-W1 & 0 & 0.00 & 0.00 & 0 & 0.00 & 0.00 \\
\hline HAYASHI-W2 & 0 & 0.75 & 0.75 & 0 & 0.18 & 3.55 \\
\hline HAYASHI-W4 & 0 & 0.75 & 0.75 & 0 & 0.27 & 3.55 \\
\hline HAYASHI-W5 & 0 & 0.75 & 0.75 & 0 & 0.31 & 3.55 \\
\hline HAYASHI-W6 & 0 & 0.75 & 0.75 & 0 & 0.31 & 3.55 \\
\hline SUGANO-WHA & 0 & 0.70 & 0.70 & 0 & 0.38 & 3.38 \\
\hline SUGANO-W4OS & 0 & 0.70 & 0.70 & 0 & 0.38 & 3.38 \\
\hline SUGANO-W4OW & 0 & 0.70 & 0.70 & of & 0.38 & 3.38 \\
\hline SUGANO-W8OS & 0 & 0.70 & 0.70 & 0 & 0.38 & 3.38 \\
\hline SUGANO-F & 0 & 0.00 & 0.00 & 0 & 0.00 & 0.00 \\
\hline SUGANO-WBL & 0 & 0.70 & 0.70 & ㅇ․ & 0.30 & 3.38 \\
\hline SUGANO-WCO & 0 & 0.70 & 0.70 & 0 & 0.38 & 3.38 \\
\hline HIGASHI 1-F1 & 0 & 0.00 & 0.00 & 0 & 0.00 & 0.00 \\
\hline HIGASHI 2-PW & 0 & 0.85 & 0.85 & 0 & 0.22 & 3.43 \\
\hline HIGASHI 5-F2 & 0 & 0.00 & 0.00 & 0 & 0.00 & 0.00 \\
\hline HIGASHI13-FW & 0 & 0.28 & 0.28 & 0 & 0.21 & 3.76 \\
\hline HIGASHI 4-C3C & 0 & 0.85 & 0.85 & 0 & 0.24 & 3.43 \\
\hline HIGASHI 6-C2A & $7.48 \mathrm{E}-07$ & 0.85 & 0.85 & 0 & 0.23 & 3.76 \\
\hline HIGASHI 7-C2B & $7.55 \mathrm{E}-07$ & 0.85 & 0.85 & 0 & 0.23 & 3.76 \\
\hline HIGASHI $9-\mathrm{C} 40$ & 0 & 0.85 & 0.85 & 0 & 0.23 & 3.76 \\
\hline HIGASHI 3-C3 & 0 & 0.85 & 0.85 & 0 & 0.24 & 3.43 \\
\hline HIGASHI 8-C4 & 0 & 0.85 & 0.85 & 0 & 0.23 & 3.76 \\
\hline CORLEY B5 & 0 & 0.63 & 0.29 & 0 & 0.46 & 4.53 \\
\hline CORLEY BG & 0 & 0.63 & 0.29 & 0 & 0.22 & 4.49 \\
\hline CORLEY B7 & 0 & 0.63 & 0.29 & 0 & 0.50 & 4.67 \\
\hline CORLEY B8 & 0 & 1.38 & 0.29 & 0 & 0.43 & 4.56 \\
\hline CORLEY B9 & 0 & 0.63 & 0.29 & 0 & 0.45 & 4.38 \\
\hline CORLEY B11 & 0 & 0.63 & 0.29 & 0 & 0.55 & 4.44 \\
\hline OGATA K1 & 0 & 0.27 & 0.27 & 0 & 0.20 & 4.03 \\
\hline OGATA K2 & 0 & 0.53 & 0.53 & 0 & 0.20 & 4.03 \\
\hline OGATA K3 & 0 & 0.80 & 0.80 & 0 & 0.20 & 4.03 \\
\hline OGATA K4 & 0 & 0.80 & 0.80 & 0 & 0.21 & 4.03 \\
\hline OGATA K5 & 0 & 0.53 & 0.53 & 0 & 0.21 & 4.03 \\
\hline OGATA K6 & 0 & 0.83 & 0.83 & 0 & 0.21 & 4.03 \\
\hline GAYNOR F & 0 & 0.32 & 0.32 & 0 & 0.24 & 4.22 \\
\hline GAYNOR W & $1.92 E-07$ & 0.32 & 0.32 & 0 & 0.22 & 4.22 \\
\hline GAYNOR D & $3.00 \mathrm{E}-07$ & 0.32 & 0.32 & 0 & 0.23 & 4.22 \\
\hline
\end{tabular}




\section{APPENDIX B. (Continued)}

\begin{tabular}{|c|c|c|c|c|c|c|}
\hline TEST NAME & $\mathrm{X} 42$ (CM2) & $x 43$ & $\mathrm{X} 44$ & $\mathrm{X} 45$ & $\times 46$ & $\mathrm{X} 47(\mathrm{CM})$ \\
\hline AOYAMA C2005-1 & 0.00 & 0.00 & 0.00 & 0.00 & 0.00 & 0.00 \\
\hline AOYAMA C2005-11 & 0.00 & 0.00 & 0.00 & 0.00 & 0.00 & 0.00 \\
\hline AOYAMA C2005-111 & 0.00 & 0.00 & 0.00 & 0.00 & 0.00 & 0.00 \\
\hline AOYAMA C2015-A & 0.00 & 0.00 & 0.00 & 0.00 & 0.00 & 0.00 \\
\hline AOYAMA C2015-B & 0.00 & 0.00 & 0.00 & 0.00 & 0.00 & 0.00 \\
\hline AOYAMA C2015-C & 0.00 & 0.00 & 0.00 & 0.00 & 0.00 & 0.00 \\
\hline AOYAMA P2005-A & 0.00 & 0.00 & 0.00 & 0.00 & 0.00 & 0.00 \\
\hline AOYAMA P2015-A & 0.00 & 0.00 & 0.00 & 0.00 & 0.00 & 0.00 \\
\hline AOYAMA C4015 & 0.00 & 0.00 & 0.00 & 0.00 & 0.00 & 0.00 \\
\hline AOYAMA P4015 & 0.00 & 0.00 & 0.00 & 0.00 & 0.00 & 0.00 \\
\hline AOYAMA M2005 & 0.00 & 0.00 & 0.00 & 0.00 & 0.00 & 0.00 \\
\hline AOYAMA CH2015 & 0.00 & 0.00 & 0.00 & 0.00 & 0.00 & 0.00 \\
\hline AOYAMA CH2O18 & 0.00 & 0.00 & 0.00 & 0.00 & 0.00 & 0.00 \\
\hline AOYAMA OLU2015 & 2680.00 & 0.26 & 0.04 & 0.26 & 0.04 & 0.00 \\
\hline KAHN SP1 & 0.00 & 0.00 & 0.00 & 0.00 & 0.00 & 0.00 \\
\hline KAHN SP2 & 0.00 & 0.00 & 0.00 & 0.00 & 0.00 & 0.00 \\
\hline KAHN SP3 & 0.00 & 0.00 & 0.00 & 0.00 & 0.00 & 0.00 \\
\hline KAHN SP5 & 0.00 & 0.00 & 0.00 & 0.00 & 0.00 & 7.62 \\
\hline HAYASHI-W1 & 0.00 & 0.00 & 0.00 & 0.00 & 0.00 & 0.00 \\
\hline HAYASHI-W2 & 0.00 & 0.00 & 0.00 & 0.00 & 0.00 & 0.00 \\
\hline HAYASHI-W4 & 0.00 & 0.00 & 0.00 & 0.00 & 0.00 & 0.00 \\
\hline HAYASHI-W5 & 0.00 & 0.00 & 0.00 & 0.00 & 0.00 & 0.00 \\
\hline HAYASHI-W6 & 0.00 & 0.00 & 0.00 & 0.00 & 0.00 & 0.00 \\
\hline SUGANO-WHA & 0.00 & 0.00 & 0.00 & 0.00 & 0.00 & 0.00 \\
\hline SUGANO-W4OS & 0.00 & 0.00 & 0.00 & 0.00 & 0.00 & 0.00 \\
\hline SUGANO-W $40 W$ & 0.00 & 0.00 & 0.00 & 0.00 & 0.00 & 0.00 \\
\hline SUGANO-WBOS & 0.00 & 0.00 & 0.00 & 0.00 & 0.00 & 0.00 \\
\hline SUGANO-F & 0.00 & 0.00 & 0.00 & 0.00 & 0.00 & 0.00 \\
\hline SUGANO-WBL & 0.00 & 0.00 & 0.00 & 0.00 & 0.00 & 0.00 \\
\hline SUGANO-WCO & 0.00 & 0.00 & 0.00 & 0.00 & 0.00 & 0.00 \\
\hline HIGASHI 1-F1 & 0.00 & 0.00 & 0.00 & 0.00 & 0.00 & 0.00 \\
\hline HIGASHI 2-PW & 0.00 & 0.00 & 0.00 & 0.00 & 0.00 & 0.00 \\
\hline HIGASHI 5-F2 & 0.00 & 0.00 & 0.00 & 0.00 & 0.00 & 0.00 \\
\hline HIGASHI13-FW & 0.00 & 0.00 & 0.00 & 0.00 & 0.00 & 0.00 \\
\hline HIGASHI 4-C3C & 0.00 & 0.00 & 0.00 & 0.00 & 0.00 & 7.50 \\
\hline MIGASHI 6-C2A & 6612.00 & 0.00 & 0.00 & 0.00 & 0.00 & 7.50 \\
\hline HIGASHI 7-C2B & 6612.00 & 0.00 & 0.00 & 0.00 & 0.00 & 7.50 \\
\hline HIGASHI 9-C40 & 0.00 & 0.00 & 0.00 & 0.00 & 0.00 & 7.50 \\
\hline HIGASHI 3-C3 & 0.00 & 0.00 & 0.00 & 0.00 & 0.00 & 7.50 \\
\hline HIGASHI 8-C4 & 0.00 & 0.00 & 0.00 & 0.00 & 0.00 & 7.50 \\
\hline CORLEY B5 & 0.00 & 0.00 & 0.00 & 0.00 & 0.00 & 0.00 \\
\hline CORLEY B6 & 0.00 & 0.00 & 0.00 & 0.00 & 0.00 & 0.00 \\
\hline CORLEY B7 & 0.00 & 0.00 & 0.00 & 0.00 & 0.00 & 0.00 \\
\hline CORLEY B8 & 0.00 & 0.00 & 0.00 & 0.00 & 0.00 & 0.00 \\
\hline CORLEY B9 & 0.00 & 0.00 & 0.00 & 0.00 & 0.00 & 0.00 \\
\hline CORLEY B11 & 0.00 & 0.00 & 0.00 & 0.00 & 0.00 & 0.00 \\
\hline OGATA K1 & 0.00 & 0.00 & 0.00 & 0.00 & 0.00 & 0.00 \\
\hline OGATA K2 & 0.00 & 0.00 & 0.00 & 0.00 & 0.00 & 0.00 \\
\hline OGATA K3 & 0.00 & 0.00 & 0.00 & 0.00 & 0.00 & 0.00 \\
\hline OGATA K4 & 0.00 & 0.00 & 0.00 & 0.00 & 0.00 & 0.00 \\
\hline OGATA K5 & 0.00 & 0.00 & 0.00 & 0.00 & 0.00 & 0.00 \\
\hline OGATA K6 & 0.00 & 0.00 & 0.00 & 0.00 & 0.00 & 0.00 \\
\hline GAYNOR F & 0.00 & 0.00 & 0.00 & 0.00 & 0.00 & 0.00 \\
\hline GAYNOR W & 11561.00 & 0.14 & 0.14 & 0.14 & 0.14 & 0.00 \\
\hline GAYNOA D & 14452.00 & 0.09 & 0.27 & 0.09 & 0.27 & 0.00 \\
\hline
\end{tabular}




\section{APPENDIX B. (Continued)}

\begin{tabular}{|c|c|c|c|c|c|c|}
\hline TEST NAME & $\mathrm{X} 48$ (CM) & $x 49$ & $\times 50(\%)$ & $\times 51(\%)$ & $\times 52(\%)$ & $\times 53$ \\
\hline AOYAMA C2005-I & 0.00 & 0.00 & 0 & 0 & 0 & 0 \\
\hline AOYAMA C2005-11 & 0.00 & 0.00 & 0 & 0 & 0 & 0 \\
\hline AOYAMA C2005-III & 0.00 & 0.00 & 0 & 0 & 0 & 0 \\
\hline AOYAMA C2015-A & 0.00 & 0.00 & 0 & 0 & 0 & 0 \\
\hline AOYAMA C2015-B & 0.00 & 0.00 & 0 & 0 & 0 & 0 \\
\hline AOYAMA C2015-C & 0.00 & 0.00 & 0 & 0 & 0 & 0 \\
\hline AOYAMA P2005-A & 0.00 & 0.00 & 0 & 0 & 0 & 0 \\
\hline AOYAMA P2015-A & 0.00 & 0.00 & 0 & 0 & 0 & 0 \\
\hline AOYAMA C4015 & 0.00 & 0.00 & 0 & 0 & 0 & 0 \\
\hline AOYAMA P4015 & 0.00 & 0.00 & 0 & 0 & 0 & 0 \\
\hline AOYAMA MZOOS & 0.00 & 0.00 & 0 & 0 & 0 & 0 \\
\hline AOYAMA CH2O15 & 0.00 & 0.00 & 0 & 0 & 0 & 0 \\
\hline AOYAMA CH2018 & 0.00 & 0.00 & 0 & 0 & 0 & 0 \\
\hline AOYAMA OLU2015 & 0.00 & 0.00 & 0 & 0 & 0 & 0 \\
\hline KAHN SPI & 0.00 & 0.00 & 0 & 0 & 0 & 0 \\
\hline KAHN SP2 & 0.00 & 0.00 & 0 & 0 & 0 & 0 \\
\hline KAHN SP3 & 0.00 & 0.00 & 0 & 0 & 0 & 0 \\
\hline KAHN SP5 & 40.32 & 1.00 & 0.678 & 0.458 & 0 & 0 \\
\hline HAYASHI-W1 & 0.00 & 0.00 & 0 & 0 & 0 & 0 \\
\hline HAYASHI-W2 & 0.00 & 0.00 & 0 & 0 & 0 & 0 \\
\hline HAYASHI-W4 & 0.00 & 0.00 & 0 & 0 & 0 & 0 \\
\hline HAYASHI-W5 & 0.00 & 0.00 & 0 & 0 & 0 & 0 \\
\hline HAYASHI-W6 & 0.00 & 0.00 & 0 & 0 & 0 & 0 \\
\hline SUGANO-WHA & 0.00 & 0.00 & 0 & 0 & 0 & 0 \\
\hline SUGANO-W4OS & 0.00 & 0.00 & 0 & 0 & 0 & 0 \\
\hline SUGANO-W4OW & 0.00 & 0.00 & 0 & 0 & 0 & 0 \\
\hline SUGANO-WBOS & 0.00 & 000 & 0 & 0 & 0 & 0 \\
\hline SUGANO-F & 0.00 & 0.00 & 0 & 0 & 0 & 0 \\
\hline SUGANO-WBL & 0.00 & 0.00 & 0 & 0 & 0 & 0 \\
\hline SUGANO-WCO & 0.00 & 0.00 & 0 & 0 & 0 & 0 \\
\hline HIGASHI 1-F1 & 0.00 & 0.00 & 0 & 0 & 0 & $\underline{0}$ \\
\hline HIGASHI 2-PW & 0.00 & 0.00 & 0 & 0 & 0 & 0 \\
\hline HIGASHI 5-F2 & 0.00 & 0.00 & 0 & 0 & 0 & 0 \\
\hline HIGASHI13-FW & 0.00 & 0.00 & 0 & 0 & 0 & 0 \\
\hline HIGASHI 4-C3C & 51.00 & 1.00 & 0.8453 & 0.8453 & 0 & 0 \\
\hline HIGASHI 6-C2A & 38.00 & 2.00 & 0.8453 & 0.8453 & 0 & 0.475 \\
\hline HIGASHI 7-C2B & 38.00 & 2.00 & 0.8453 & 0.8453 & 0 & 0.475 \\
\hline HIGASHI 9-C40 & 38.00 & 1.00 & 0.8453 & 0.8453 & 0 & 0 \\
\hline HIGASHI 3-C3 & 51.00 & 1.00 & 0.8453 & 0.8453 & 0 & 0 \\
\hline HIGASHI 8-C4 & 38.00 & 1.00 & 0.8453 & 0.8453 & 0 & 0 \\
\hline CORLEY B5 & 0.00 & 0.00 & 0 & 0 & 0 & 0 \\
\hline CORLEY B6 & 0.00 & 0.00 & 0 & 0 & 0 & 0 \\
\hline CORLEY B7 & 0.00 & 0.00 & 0 & 0 & 0 & 0 \\
\hline CORLEY B8 & 0.00 & 0.00 & 0 & 0 & 0 & 0 \\
\hline CORLEY B9 & 0.00 & 0.00 & 0 & 0 & 0 & 0 \\
\hline CORLEY B11 & 0.00 & 0.00 & 0 & 0 & 0 & 0 \\
\hline OGATA K1 & 0.00 & 0.00 & 0 & 0 & 0 & 0 \\
\hline OGATA K2 & 0.00 & 0.00 & 0 & 0 & 0 & 0 \\
\hline OGATA K3 & 0.00 & 0.00 & 0 & 0 & 0 & 0 \\
\hline OGATA K4 & 0.00 & 0.00 & 0 & 0 & 0 & 0 \\
\hline OGATA K5 & 0.00 & 0.00 & 0 & 0 & 0 & 0 \\
\hline OGATA K6 & 0.00 & 0.00 & 0 & 0 & 0 & 0 \\
\hline GAYNOR F & 0.00 & 0.00 & 0 & 0 & 0 & 0 \\
\hline GAYNOR W & $0 . \infty$ & $0 . \infty$ & 0 & 0 & 0 & 0 \\
\hline GAYNOR D & 0.00 & 0.00 & 0 & 0 & 0 & 0 \\
\hline
\end{tabular}




\section{APPENDIX B. (Continued)}

\begin{tabular}{|c|c|c|c|c|c|c|}
\hline TEST NAME & $\times 54$ & $\times 55$ & $\times 56$ & $\mathrm{X} 57$ (CM2) & $\times 58(\mathrm{CM})$ & $\times 59(\mathrm{CM})$ \\
\hline AOYAMA C2005-I & 0 & 0 & 0 & 15.69 & 7.50 & 10.00 \\
\hline AOYAMA C2005-II & 0 & 0 & 0 & 15.69 & 7.50 & 10.00 \\
\hline AOYAMA C2005-1II & 0 & 0 & 0 & 15.69 & 7.50 & 10.00 \\
\hline AOYAMA C2015-A & 0 & 0 & 0 & 15.69 & 7.50 & 10.00 \\
\hline AOYAMA C2015-B & 0 & 0 & 0 & 15.69 & 7.50 & 10.00 \\
\hline AOYAMA C2015-C & 0 & 0 & 0 & 15.69 & 7.50 & 10.00 \\
\hline AOYAMA P2005-A & 0 & 0 & 0 & 0.00 & 0.00 & 0.00 \\
\hline AOYAMA P2015-A & 0 & 0 & 0 & 0.00 & 0.00 & 0.00 \\
\hline AOYAMA C4015 & 0 & 0 & 0 & 14.26 & 7.50 & 10.00 \\
\hline AOYAMA P4015 & 0 & 0 & 0 & 0.00 & 0.00 & 0.00 \\
\hline AOYAMA M2005 & 0 & 0 & 0 & 15.69 & 7.50 & 10.00 \\
\hline AOYAMA CH2015 & 0 & 0 & 0 & 15.69 & 7.50 & 10.00 \\
\hline AOYAMA CH2018 & 0 & 0 & 0 & 15.69 & 7.50 & 10.00 \\
\hline AOYAMA OLU2015 & 0 & 0 & 0 & 15.69 & 7.50 & 10.00 \\
\hline KAHN SP1 & 0 & 0 & 0 & 0.00 & 0.00 & 0.00 \\
\hline KAHN SP2 & 0 & 0 & 0 & 0.00 & 0.00 & 0.00 \\
\hline KAHN SP3 & 0 & 0 & 0 & 8.52 & 21.27 & 9.53 \\
\hline KAHN SP5 & 0 & 0 & 0 & 47.50 & 9.84 & 9.53 \\
\hline HAYASHI-W1 & 0 & 0 & 0 & 0.00 & 0.00 & 0.00 \\
\hline HAYASHI-W2 & 0 & 0 & 0 & 0.00 & 0.00 & 0.00 \\
\hline HAYASHI-W4 & 0 & 0 & 0 & 9.54 & 10.00 & 4.00 \\
\hline HAYASHI-W5 & 0 & 0 & 0 & 9.54 & 10.00 & 4.00 \\
\hline HAYASHI-W6 & 0 & 0 & 0 & 9.54 & 10.00 & 4.00 \\
\hline SUGANO-WHA & 0 & 0 & 0 & 12.57 & 10.00 & 10.00 \\
\hline SUGANO-W4OS & 0 & 0 & 0 & 0.00 & 0.00 & 0.00 \\
\hline SUGANO-W4OW & 0 & 0 & 0 & 0.00 & 0.00 & 0.00 \\
\hline SUGANO-W8OS & 0 & 0 & 0 & 0.00 & 0.00 & 0.00 \\
\hline SUGANO-F & 0 & 0 & 0 & 0.00 & 0.00 & 0.00 \\
\hline SUGANO-WBL & 0 & 0 & 0 & 6.28 & 20.00 & 10.00 \\
\hline SUGANO-WCO & 0 & 0 & 0 & 8.64 & 15.00 & 10.00 \\
\hline HIGASHI 1-F1 & 0 & 0 & 0 & 0.00 & 0.00 & 0.00 \\
\hline HIGASHI 2-PW & 0 & 0 & 0 & 9.12 & 12.00 & 4.00 \\
\hline HIGASHI 5-F2 & 0 & 0 & 0 & 0.00 & 0.00 & 0.00 \\
\hline HIGASHI13-FW & 0 & 0 & 0 & 0.00 & 0.00 & 0.00 \\
\hline HIGASHI 4-C3C & 0 & 0 & 0 & 12.06 & 14.00 & 4.00 \\
\hline HIGASHI 6-C2A & 0.475 & 0.475 & 0.475 & 8.04 & 14.00 & 4.00 \\
\hline HIGASHI 7-C2B & 0.475 & 0.475 & 0.475 & 8.04 & 14.00 & 4.00 \\
\hline HIGASHI 9-C40 & 0 & 0 & 0 & 21.63 & 10.00 & 4.00 \\
\hline HIGASHI 3-C3 & 0 & 0 & 0 & 21.63 & 10.00 & 4.00 \\
\hline HIGASHI 8-C4 & 0 & 0 & 0 & 20.36 & 10.00 & 4.00 \\
\hline CORLEY B5 & 0 & 0 & 0 & 0.00 & 0.00 & 0.00 \\
\hline CORLEY B6 & 0 & 0 & 0 & 0.00 & 0.00 & 0.00 \\
\hline CORLEY B7 & 0 & 0 & 0 & 0.00 & 0.00 & 0.00 \\
\hline CORLEY B8 & 0 & 0 & 0 & 0.00 & 0.00 & 0.00 \\
\hline CORLEY B9 & 0 & 0 & 0 & 0.00 & 0.00 & 0.00 \\
\hline CORLEY B11 & 0 & 0 & 0 & 0.00 & 0.00 & 0.00 \\
\hline OGATA K1 & 0 & 0 & 0 & 0.00 & 0.00 & 0.00 \\
\hline OGATA K2 & 0 & 0 & 0 & 0.00 & 0.00 & 0.00 \\
\hline OGATA K3 & 0 & 0 & 0 & 0.00 & 0.00 & 0.00 \\
\hline OGATA K4 & 0 & 0 & 0 & 0.00 & 0.00 & 0.00 \\
\hline OGATA K5 & 의 & 0 & 0 & 0.00 & 0.00 & 0.00 \\
\hline OGATA K6 & 0 & 0 & 0 & 0.00 & 0.00 & 0.00 \\
\hline GAYNOR F & 0 & 0 & 0 & 34.06 & 30.48 & 22.86 \\
\hline GAYNOR W & 0 & 0 & 0 & 34.06 & 30.48 & 22.86 \\
\hline GAYNOR D & 0 & 0 & 0 & 34.06 & 30.48 & 22.86 \\
\hline
\end{tabular}




\section{APPENDIX B. (Continued)}

\begin{tabular}{|c|c|c|c|c|c|c|}
\hline TEST NAME & X60 (TONF/CM2) & $\mathrm{X} 61$ (TONF) & $\mathrm{X} 62 \quad(\mathrm{CM} 2)$ & $\mathrm{X63}(\mathrm{CM})$ & $\times 64(\mathrm{CM})$ & X65 (TONF/CM2) \\
\hline AOYAMA C2005-1 & 3.53 & 55.37 & 15.69 & 7.50 & 10.00 & 3.53 \\
\hline AOYAMA C2005-11 & 3.53 & 55.37 & 15.69 & 7.50 & 10.00 & 3.53 \\
\hline AOYAMA C2005-1II & 3.53 & 55.37 & 15.69 & 7.50 & 9.00 & 3.53 \\
\hline AOYAMA C2015-A & 3.53 & 55.37 & 15.69 & 7.50 & 10.00 & 3.53 \\
\hline AOYAMA C2015-B & 3.53 & 55.37 & 15.69 & 7.50 & 10.00 & 3.53 \\
\hline AOYAMA C2015-C & 3.53 & 55.37 & 15.69 & 7.50 & 10.00 & 3.53 \\
\hline AOYAMA P2005-A & 0.00 & 0.00 & 0.00 & 0.00 & 0.00 & 0.00 \\
\hline AOYAMA P2015-A & 0.00 & 0.00 & 0.00 & 0.00 & 0.00 & 0.00 \\
\hline AOYAMA C4015 & 3.53 & 50.34 & 14.26 & 7.50 & 10.00 & 3.53 \\
\hline AOYAMA P4015 & 0.00 & 0.00 & 0.00 & 0.00 & 0.00 & 0.00 \\
\hline AOYAMA M2005 & 3.53 & 55.37 & 15.69 & 7.50 & 10.00 & 3.53 \\
\hline AOYAMA CHZO15 & 3.88 & 60.86 & 15.69 & 7.50 & 10.00 & 3.88 \\
\hline AOYAMA CH2018 & 3.88 & 60.86 & 15.69 & 7.50 & 10.00 & 3.88 \\
\hline AOYAMA OLU2015 & 3.88 & 60.86 & 15.69 & 7.50 & 10.00 & 3.88 \\
\hline KAHN SP1 & 0.00 & 0.00 & 0.00 & 0.00 & 0.00 & 0.00 \\
\hline KAHN SP2 & 0.00 & 0.00 & 0.00 & 0.00 & 0.00 & 0.00 \\
\hline KAHN SP3 & 4.49 & 38.25 & 8.52 & 21.27 & 9.53 & 4.49 \\
\hline KAHN SP5 & 4.49 & 213.35 & 47.50 & 9.84 & 9.53 & 4.49 \\
\hline HAYASHI-W1 & 0.00 & 0.00 & 0.00 & 0.00 & 0.00 & 0.00 \\
\hline HAYASHI-W2 & 0.00 & 0.00 & 0.00 & 0.00 & 0.00 & 0.00 \\
\hline HAYASHI-W4 & 2.79 & 26.62 & 9.54 & 10.00 & 4.00 & 2.79 \\
\hline HAYASHI-W5 & 2.79 & 26.62 & 9.54 & 10.00 & 4.00 & 2.79 \\
\hline HAYASHI-W6 & 2.79 & 26.62 & 9.54 & 10.00 & 4.00 & 2.79 \\
\hline SUGANO-WHA & 7.18 & 90.22 & 12.57 & 10.00 & 10.00 & 7.18 \\
\hline SUGANO-W4OS & 0.00 & 0.00 & 0.00 & 0.00 & 0.00 & 0.00 \\
\hline SUGANO-W4OW & 0.00 & 0.00 & 0.00 & 0.00 & 0.00 & 0.00 \\
\hline SUGANO-W8OS & 0.00 & 0.00 & 0.00 & 0.00 & 0.00 & 0.00 \\
\hline SUGANO-F & 0.00 & 0.00 & 0.00 & 0.00 & 0.00 & 0.00 \\
\hline SUGANO-WBL & 7.18 & 45.11 & 6.28 & 20.00 & 10.00 & 7.18 \\
\hline SUGANO-WCO & 7.18 & 62.03 & 8.64 & 15.00 & 10.00 & 7.18 \\
\hline HIGASHI 1-F1 & 0.00 & 0.00 & 0.00 & 0.00 & 0.00 & 0.00 \\
\hline HIGASHI 2-PW & 2.79 & 25.44 & 9.12 & 12.00 & 4.00 & 2.79 \\
\hline HIGASHI 5-F2 & 0.00 & 0.00 & 0.00 & 0.00 & 0.00 & 0.00 \\
\hline HIGASHI13-FW & 0.00 & 0.00 & 0.00 & 0.00 & 0.00 & 0.00 \\
\hline HIGASHI 4-C3C & 2.79 & 33.66 & 12.06 & 14.00 & 4.00 & 2.79 \\
\hline HIGASHI 6-C2A & 2.79 & 22.44 & 8.04 & 14.00 & 4.00 & 2.79 \\
\hline HIGASHI 7-C2B & 2.79 & 22.44 & 8.04 & 14.00 & 4.00 & 2.79 \\
\hline HIGASHI 9-C40 & 279 & 60.35 & 21.63 & 10.00 & 4.00 & 2.79 \\
\hline HIGASHI 3-C3 & 2.79 & 60.35 & 21.63 & 10.00 & 4.00 & 2.79 \\
\hline HIGASHI 8-C4 & 2.79 & 56.80 & 20.36 & 10.00 & 4.00 & 2.79 \\
\hline CORLEY B5 & 0.00 & 0.00 & 0.00 & 0.00 & 0.00 & 0.00 \\
\hline CORLEY B6 & 0.00 & 0.00 & 0.00 & 0.00 & 0.00 & 0.00 \\
\hline CORLEY B7 & 0.00 & 0.00 & 0.00 & 0.00 & 0.00 & 0.00 \\
\hline CORLEY B8 & 0.00 & 0.00 & 0.00 & 0.00 & 0.00 & 0.00 \\
\hline CORLEY 89 & 0.00 & 0.00 & 0.00 & 0.00 & 0.00 & 0.00 \\
\hline CORLEY B11 & 0.00 & 0.00 & 0.00 & 0.00 & 0.00 & 0.00 \\
\hline OGATA K1 & 0.00 & 0.00 & 0.00 & 0.00 & 0.00 & 0.00 \\
\hline OGATA K2 & 0.00 & 0.00 & 0.00 & 0.00 & 0.00 & 0.00 \\
\hline OGATA K3 & 0.00 & 0.00 & 0.00 & 0.00 & 0.00 & 0.00 \\
\hline OGATA K4 & 0.00 & 0.00 & 0.00 & 0.00 & 0.00 & 0.00 \\
\hline OGATA K5 & 0.00 & 0.00 & 0.00 & 0.00 & 0.00 & 0.00 \\
\hline OGATA K6 & 0.00 & 0.00 & 0.00 & 0.00 & 0.00 & 0.00 \\
\hline GAYNOR F & 4.22 & 143.65 & 34.06 & 30.48 & 22.86 & 4.22 \\
\hline GAYNOR W & 4.22 & 143.65 & 34.06 & 30.48 & 22.86 & 4.22 \\
\hline GAYNOR D & 4.22 & 143.65 & 34.06 & 30.48 & 22.86 & 4.22 \\
\hline
\end{tabular}


APPENDIX B. (Continued)

\begin{tabular}{|c|c|c|c|c|c|c|}
\hline TEST NAME & $\mathrm{X66}$ (TONF) & $\mathrm{X67}(\mathrm{CM} 2)$ & $X 68$ (CM) & X69 (CM) & X70 (TONF/CM2) & X71 (TONF) \\
\hline AOYAMA C2005-1 & 55.37 & 7.84 & 7.50 & 10.00 & 3.53 & 27.69 \\
\hline AOYAMA C2005-1I & 55.37 & 7.84 & 7.50 & 10.00 & 3.53 & 27.69 \\
\hline AOYAMA C2005-III & 55.37 & 7.84 & 7.50 & 9.00 & 3.53 & 27.69 \\
\hline AOYAMA C2015-A & 55.37 & 7.84 & 7.50 & 10.00 & 3.53 & 27.69 \\
\hline AOYAMA C2015-B & 55.37 & 7.84 & 7.50 & 10.00 & 3.53 & 27.69 \\
\hline AOYAMA C2015-C & 55.37 & 7.84 & 7.50 & 10.00 & 3.53 & 27.69 \\
\hline AOYAMA P2005-A & 0.00 & 0.00 & 0.00 & 0.00 & 0.00 & 0.00 \\
\hline AOYAMA P2015-A & 0.00 & 0.00 & 0.00 & 0.00 & 0.00 & 0.00 \\
\hline AOYAMA C4015 & 50.34 & 7.84 & 7.50 & 10.00 & 3.53 & 27.69 \\
\hline AOYAMA P4015 & 0.00 & 0.00 & 0.00 & 0.00 & 0.00 & 0.00 \\
\hline AOYAMA M2005 & 55.37 & 7.84 & 7.50 & 10.00 & 3.53 & 27.69 \\
\hline AOYAMA CH2015 & 60.86 & 7.84 & 7.50 & 10.00 & 3.88 & 30.43 \\
\hline AOYAMA CH2O18 & 60.86 & 7.84 & 7.50 & 10.00 & 3.88 & 30.43 \\
\hline AOYAMA OLU2015 & 60.86 & 7.84 & 7.50 & 10.00 & 3.88 & 30.43 \\
\hline KAHN SP1 & 0.00 & 0.00 & 0.00 & 0.00 & 0.00 & 0.00 \\
\hline KAHN SP2 & 0.00 & 0.00 & 0.00 & 0.00 & 0.00 & 0.00 \\
\hline KAHN SP3 & 38.25 & 4.97 & 22.86 & 9.53 & 4.49 & 22.31 \\
\hline KAHN SP5 & 213.35 & 0.00 & 0.00 & 0.00 & 0.00 & 0.00 \\
\hline HAYASHI-W1 & 0.00 & 0.00 & 0.00 & 0.00 & 0.00 & 0.00 \\
\hline HAYASHI-W2 & 0.00 & 0.00 & 0.00 & 0.00 & 0.00 & 0.00 \\
\hline HAYASHI-W4 & 26.62 & 5.09 & 10.00 & 4.00 & 2.79 & 14.20 \\
\hline HAYASHI-W5 & 26.62 & 5.09 & 10.00 & 4.00 & 2.79 & 14.20 \\
\hline HAYASHI-W6 & 26.62 & 5.09 & 10.00 & 4.00 & 2.79 & 14.20 \\
\hline SUGANO-WHA & 90.22 & 7.07 & 10.00 & 10.00 & 7.18 & 50.75 \\
\hline SUGANO-W4OS & 0.00 & 0.00 & 0.00 & 0.00 & 0.00 & 0.00 \\
\hline SUGANO-W4OW & 0.00 & 0.00 & 0.00 & 0.00 & 0.00 & 0.00 \\
\hline SUGANO-WBOS & 0.00 & 0.00 & 0.00 & 0.00 & 0.00 & 0.00 \\
\hline SUGANO-F & 0.00 & 0.00 & 0.00 & 0.00 & 0.00 & 0.00 \\
\hline SUGANO-WBL & 45.11 & 0.00 & 0.00 & 0.00 & 0.00 & 0.00 \\
\hline SUGANO-WCO & 62.03 & 4.71 & 15.00 & 10.00 & 7.18 & 33.84 \\
\hline HIGASHI 1-FY & 0.00 & 0.00 & 0.00 & 0.00 & 0.00 & 0.00 \\
\hline HIGASHI 2-PW & 25.44 & 0.00 & 0.00 & 0.00 & 0.00 & 0.00 \\
\hline HIGASHI 5-F2 & 0.00 & 0.00 & 0.00 & 0.00 & 0.00 & 0.00 \\
\hline HIGASHI13-FW & 0.00 & 0.00 & 0.00 & 0.00 & 0.00 & 0.00 \\
\hline HIGASHI 4-C3C & 33.66 & 0.00 & 0.00 & 0.00 & 0.00 & 0.00 \\
\hline HIGASHI 6-C2A & 22.44 & 0.00 & 0.00 & 0.00 & 0.00 & 0.00 \\
\hline HIGASHI 7-C2B & 22.44 & 0.00 & 0.00 & 0.00 & 0.00 & 0.00 \\
\hline HIGASHI 9-C40 & 60.35 & 0.00 & 0.00 & 0.00 & 0.00 & 0.00 \\
\hline HIGASHI 3-C3 & 60.35 & 0.00 & 0.00 & 0.00 & 0.00 & 0.00 \\
\hline HIGASHI \&-C4 & 56.80 & 0.00 & 0.00 & 0.00 & 0.00 & 0.00 \\
\hline CORLEY B5 & 0.00 & 0.00 & 0.00 & 0.00 & 0.00 & 0.00 \\
\hline CORLEY B6 & 0.00 & 0.00 & 0.00 & 0.00 & 0.00 & 0.00 \\
\hline CORLEY B7 & 0.00 & 0.00 & 0.00 & 0.00 & 0.00 & 0.00 \\
\hline CORLEY B8 & 0.00 & 0.00 & 0.00 & 0.00 & 0.00 & 0.00 \\
\hline CORLEY B9 & 0.00 & 0.00 & 0.00 & 0.00 & 0.00 & 0.00 \\
\hline CORLEY B11 & 0.00 & 0.00 & 0.00 & 0.00 & 0.00 & 0.00 \\
\hline OGATA K1 & 0.00 & 0.00 & 0.00 & 0.00 & 0.00 & 0.00 \\
\hline OGATA K2 & 0.00 & 0.00 & 0.00 & 0.00 & 0.00 & 0.00 \\
\hline OGATA K3 & 0.00 & 0.00 & 0.00 & 0.00 & 0.00 & 0.00 \\
\hline OGATA K4 & 0.00 & 0.00 & 0.00 & 0.00 & 0.00 & 0.00 \\
\hline OGATA K5 & 0.00 & 0.00 & 0.00 & 0.00 & 0.00 & 0.00 \\
\hline OGATA KG & 0.00 & 0.00 & 0.00 & 0.00 & 0.00 & 0.00 \\
\hline GAYNOR F & 143.65 & 19.87 & 30.48 & 22.86 & 4.22 & 83.80 \\
\hline GAYNOR W & 143.65 & 19.87 & 30.48 & 22.86 & 4.22 & 83.80 \\
\hline GAYNOF D & 143.65 & 19.87 & 30.48 & 22.86 & 4.22 & 83.80 \\
\hline
\end{tabular}


APPENDIX B. (Continued)

\begin{tabular}{|c|c|c|c|c|c|c|}
\hline TEST NAME & $\mathrm{X} 72$ (CM2) & $\mathrm{X} 73(\mathrm{CM})$ & X74 (CM) & X75 (TONF/CM2) & X76 (TONF) & $\times 77$ \\
\hline AOYAMA C2005-I & 7.84 & 7.50 & 10.00 & 3.53 & 27.69 & 0.00 \\
\hline AOYAMA C2005-1I & 7.84 & 7.50 & 10.00 & 3.53 & 27.69 & 0.00 \\
\hline AOYAMA C2005-III & 7.84 & 7.50 & 9.00 & 3.53 & 27.69 & 0.00 \\
\hline AOYAMA C2015-A & 7.84 & 7.50 & 10.00 & 3.53 & 27.69 & 0.00 \\
\hline AOYAMA C2015-B & 7.84 & 7.50 & 10.00 & 3.53 & 27.69 & 0.00 \\
\hline AOYAMA C2015-C & 7.84 & 7.50 & 10.00 & 3.53 & 27.69 & 0.00 \\
\hline AOYAMA P2005-A & 0.00 & 0.00 & 0.00 & 0.00 & $0 . \infty$ & 26693.00 \\
\hline AOYAMA P2015-A & 0.00 & 0.00 & 0.00 & 0.00 & $0 . \infty$ & 35722.00 \\
\hline AOYAMA C4015 & 7.84 & 7.50 & 10.00 & 3.53 & 27.69 & 0.00 \\
\hline AOYAMA P4015 & 0.00 & 0.00 & 0.00 & 0.00 & 0.00 & 27585.00 \\
\hline AOYAMA M2005 & 7.84 & 7.50 & 10.00 & 3.53 & 27.69 & 0.00 \\
\hline AOYAMA CH2O15 & 7.84 & 7.50 & 10.00 & 3.88 & 30.43 & 0.00 \\
\hline AOYAMA CH2O18 & 7.84 & 7.50 & 10.00 & 3.88 & 30.43 & 0.00 \\
\hline AOYAMA OLU2015 & 7.84 & 7.50 & 10.00 & 3.88 & 30.43 & 0.00 \\
\hline KAHN SP1 & 0.00 & 0.00 & 0.00 & 0.00 & 0.00 & 34780.00 \\
\hline KAHN SP2 & 0.00 & 0.00 & 0.00 & 0.00 & 0.00 & 0.00 \\
\hline KAHN SP3 & 4.97 & 22.86 & 9.53 & 4.49 & 22.31 & 0.00 \\
\hline KAHN SP5 & 0.00 & 0.00 & 0.00 & 0.00 & 0.00 & 0.00 \\
\hline HAYASHI-W1 & 0.00 & 0.00 & 0.00 & 0.00 & 0.00 & 0.00 \\
\hline HAYASHI-W2 & 0.00 & 0.00 & 0.00 & 0.00 & 0.00 & 16233.00 \\
\hline HAYASHI-W4 & 5.09 & 10.00 & 4.00 & 2.79 & 14.20 & 0.00 \\
\hline HAYASHI-W5 & 5.09 & 10.00 & 4.00 & 2.79 & 14.20 & 0.00 \\
\hline HAYASHI-W6 & 5.09 & 10.00 & 4.00 & 2.79 & 14.20 & 0.00 \\
\hline SUGANO-WHA & 7.07 & 10.00 & 10.00 & 7.18 & 50.75 & 0.00 \\
\hline SUGANO-W4OS & 0.00 & 0.00 & 0.00 & 0.00 & 0.00 & 9295.20 \\
\hline SUGANO-W4OW & 0.00 & 0.00 & 0.00 & 0.00 & 0.00 & 9295.20 \\
\hline SUGANO-WBOS & 0.00 & 0.00 & 0.00 & 0.00 & $0 . \infty$ & 18590.00 \\
\hline SUGANO-F & 0.00 & 0.00 & 0.00 & 0.00 & 0.00 & 0.00 \\
\hline SUGANO-WBL & 0.00 & 0.00 & 0.00 & 0.00 & 0.00 & 0.00 \\
\hline SUGANO-WCO & 4.71 & 15.00 & 10.00 & 7.18 & 33.84 & 0.00 \\
\hline HIGASHI 1-F1 & 0.00 & 0.00 & 0.00 & 0.00 & 0.00 & 0.00 \\
\hline HIGASHI 2-PW & 0.00 & $0 . \infty$ & 0.00 & 0.00 & 0.00 & 0.00 \\
\hline HIGASHI 5-F2 & 0.00 & 0.00 & 0.00 & 0.00 & 0.00 & 0.00 \\
\hline HIGASHI13-FW & 0.00 & 0.00 & 0.00 & 0.00 & 0.00 & 17389.00 \\
\hline HIGASHI 4-C3C & 0.00 & 0.00 & 0.00 & 0.00 & 0.00 & 0.00 \\
\hline HIGASHI 6-C2A & 0.00 & 0.00 & 0.00 & 0.00 & 0.00 & 0.00 \\
\hline HIGASHI 7-C2B & 0.00 & $0 . \infty$ & 0.00 & 0.00 & $0 . \infty$ & 0.00 \\
\hline HIGASHI 9-C40 & 0.00 & $0 . \infty$ & 0.00 & 0.00 & 0.00 & 0.00 \\
\hline HIGASHI 3-C3 & 0.00 & $0 . \infty$ & 0.00 & 0.00 & 0.00 & 0.00 \\
\hline HIGASHI 8-C4 & 0.00 & 0.00 & 0.00 & 0.00 & 0.00 & 0.00 \\
\hline CORLEY B5 & 0.00 & $0 . \infty$ & 0.00 & 0.00 & 0.00 & 41754.00 \\
\hline CORLEY B6 & 0.00 & $0 . \infty$ & 0.00 & 0.00 & 0.00 & 28976.00 \\
\hline CORLEY B7 & 0.00 & 0.00 & 0.00 & 0.00 & 0.00 & 43573.00 \\
\hline CORLEY B8 & 0.00 & 0.00 & 0.00 & 0.00 & 0.00 & 40183.00 \\
\hline CORLEY B9 & 0.00 & $0 . \infty$ & 0.00 & 0.00 & 0.00 & 41197.00 \\
\hline CORLEY B11 & 0.00 & $0 . \infty$ & 0.00 & 0.00 & 0.00 & 45495.00 \\
\hline OGATA K1 & 0.00 & 0.00 & 0.00 & 0.00 & 0.00 & 17920.00 \\
\hline OGATA K2 & 0.00 & 0.00 & 0.00 & 0.00 & 0.00 & 17920.00 \\
\hline OGATA K3 & 0.00 & 0.00 & 0.00 & 0.00 & 0.00 & 17920.00 \\
\hline OGATA K4 & 0.00 & 0.00 & 0.00 & 0.00 & 0.00 & 18637.00 \\
\hline OGATA K5 & 0.00 & $0 . \infty$ & 0.00 & 0.00 & 0.00 & 18637.00 \\
\hline OGATA K6 & 0.00 & 0.00 & 0.00 & 0.00 & 0.00 & 18637.00 \\
\hline GAYNOR F & 19.87 & 30.48 & 22.86 & 4.22 & 83.80 & 0.00 \\
\hline GAYNOR W & 19.87 & 30.48 & 22.86 & 4.22 & 83.80 & 0.00 \\
\hline GAYNOR D & 19.87 & 30.48 & 22.86 & 4.22 & 83.80 & 0.00 \\
\hline
\end{tabular}




\section{APPENDIX B. (Continued)}

\begin{tabular}{|c|c|c|c|c|c|c|}
\hline TEST NAME & X78 (CM2) & $X 79$ (CM) & X80 (TONF/CM2) & X81 (TONF) & X82 (CM2) & $\mathrm{X83}(\mathrm{CM})$ \\
\hline AOYAMA C2005-I & 0.00 & 0.00 & 0.00 & 0.00 & 0.00 & 0.00 \\
\hline AOYAMA C2005-1I & 0.00 & 0.00 & 0.00 & 0.00 & 0.00 & 0.00 \\
\hline AOYAMA C2005-III & 0.00 & 0.00 & 0.00 & 0.00 & 0.00 & 0.00 \\
\hline AOYAMA C2015-A & 0.00 & 0.00 & 0.00 & 0.00 & 0.00 & 0.00 \\
\hline AOYAMA C2015-B & 0.00 & 0.00 & 0.00 & 0.00 & 0.00 & 0.00 \\
\hline AOYAMA C2015-C & 0.00 & 0.00 & 0.00 & 0.00 & 0.00 & 0.00 \\
\hline AOYAMA P2005-A & 14.58 & 7.50 & 3.99 & 58.18 & 14.58 & 7.50 \\
\hline AOYAMA P2015-A & 14.58 & 7.50 & 3.62 & 52.79 & 14.58 & 7.50 \\
\hline AOYAMA C4015 & 0.00 & 0.00 & 0.00 & 0.00 & 0.00 & 0.00 \\
\hline AOYAMA P4015 & 13.31 & 7.50 & 3.62 & 48.20 & 13.31 & 7.50 \\
\hline AOYAMA M2005 & 0.00 & 0.00 & 0.00 & 0.00 & 0.00 & 0.00 \\
\hline AOYAMA CH2015 & 0.00 & 0.00 & 0.00 & 0.00 & 0.00 & 0.00 \\
\hline AOYAMA CH2018 & 0.00 & 0.00 & 0.00 & 0.00 & 0.00 & 0.00 \\
\hline AOYAMA OLU2015 & 0.00 & 0.00 & 0.00 & 0.00 & 0.00 & 0.00 \\
\hline KAHN SP1 & 7.81 & 21.27 & 4.49 & 35.06 & 7.81 & 21.27 \\
\hline KAHN SP2 & 0.00 & 0.00 & 0.00 & 0.00 & 0.00 & 0.00 \\
\hline KAHN SP3 & 0.00 & 0.00 & 0.00 & 0.00 & 0.00 & 0.00 \\
\hline KAHN SP5 & 0.00 & 0.00 & 0.00 & 0.00 & 0.00 & 0.00 \\
\hline HAYASHI-W1 & 0.00 & 0.00 & 0.00 & 0.00 & 0.00 & 0.00 \\
\hline HAYASHI-W2 & 9.00 & 6.00 & 3.55 & 31.95 & 9.00 & 6.00 \\
\hline HAYASHI-W4 & 0.00 & 0.00 & 0.00 & 0.00 & 0.00 & 0.00 \\
\hline HAYASHI-W5 & 0.00 & 0.00 & 0.00 & 0.00 & 0.00 & 0.00 \\
\hline HAYASHI-W6 & 0.00 & 0.00 & 0.00 & 0.00 & 0.00 & 0.00 \\
\hline SUGANO-WHA & 0.00 & 0.00 & 0.00 & 0.00 & 0.00 & 0.00 \\
\hline SUGANO-W4OS & 4.20 & 10.00 & 3.38 & 14.20 & 4.20 & 10.00 \\
\hline SUGANO-W4OW & 4.20 & 10.00 & 3.38 & 14.20 & 4.20 & 10.00 \\
\hline SUGANO-W8OS & 8.40 & 10.00 & 3.38 & 28.39 & 8.40 & 10.00 \\
\hline SUGANO-F & 0.00 & 0.00 & 0.00 & 0.00 & 0.00 & 0.00 \\
\hline SUGANO-WBL & 0.00 & 0.00 & 0.00 & 0.00 & 0.00 & 0.00 \\
\hline SUGANO-WCO & 0.00 & 0.00 & 0.00 & 0.00 & 0.00 & 0.00 \\
\hline HIGASHI 1-F1 & 0.00 & 0.00 & 0.00 & 0.00 & 0.00 & 0.00 \\
\hline HIGASHI 2-PW & 0.00 & 0.00 & 0.00 & 0.00 & 0.00 & 0.00 \\
\hline HIGASHI 5-F2 & 0.00 & 0.00 & 0.00 & 0.00 & 0.00 & 0.00 \\
\hline HIGASHI13-FW & 3.49 & 15.00 & 3.96 & 13.81 & 3.49 & 15.00 \\
\hline HIGASHI 4-C3C & 0.00 & 0.00 & 0.00 & 0.00 & 0.00 & 0.00 \\
\hline HIGASHI 6-C2A & 0.00 & 0.00 & 0.00 & 0.00 & 0.00 & 0.00 \\
\hline HIGASHI 7-C2B & 0.00 & 0.00 & 0.00 & 0.00 & 0.00 & 0.00 \\
\hline HIGASHI 9-C4O & 0.00 & 0.00 & 0.00 & 0.00 & 0.00 & 0.00 \\
\hline HIGASHI 3-C3 & 0.00 & 0.00 & 0.00 & 0.00 & 0.00 & 0.00 \\
\hline HIGASHI 8-C4 & 0.00 & 0.00 & 0.00 & 0.00 & 0.00 & 0.00 \\
\hline CORLEY B5 & 5.60 & 20.00 & 4.53 & 25.35 & 5.60 & 20.00 \\
\hline CORLEY B6 & 5.60 & 20.00 & 4.49 & 25.15 & 5.60 & 20.00 \\
\hline CORLEY B7 & 5.60 & 20.00 & 4.67 & 26.13 & 5.60 & 20.00 \\
\hline CORLEY B8 & 5.60 & 20.00 & 4.56 & 25.54 & 5.60 & 20.00 \\
\hline CORLEY B9 & 5.60 & 20.00 & 4.38 & 24.52 & 5.60 & 20.00 \\
\hline CORLEY B11 & 5.60 & 20.00 & 4.44 & 24.88 & 5.60 & 20.00 \\
\hline OGATA K1 & 3.49 & 15.00 & 4.03 & 14.06 & 3.49 & 15.00 \\
\hline OGATA K2 & 6.97 & 15.00 & 4.03 & 28.12 & 6.97 & 15.00 \\
\hline OGATA K3 & 10.78 & 10.00 & 4.03 & 43.46 & 10.78 & 10.00 \\
\hline OGATA K4 & 10.78 & 10.00 & 4.03 & 43.46 & 10.78 & 10.00 \\
\hline OGATA K5 & 3.49 & 15.00 & 4.03 & 14.06 & 3.49 & 15.00 \\
\hline OGATA KG & 5.39 & 15.00 & 4.03 & 21.73 & 5.39 & 15.00 \\
\hline GAYNOR F & 0.00 & 0.00 & 0.00 & 0.00 & 0.00 & 0.00 \\
\hline GAYNOR W & 0.00 & 0.00 & 0.00 & 0.00 & 0.00 & 0.00 \\
\hline GAYNOR D & 0.00 & 0.00 & 0.00 & 0.00 & 0.00 & 0.00 \\
\hline
\end{tabular}


APPENDIX B. (Continued)

\begin{tabular}{|c|c|c|c|c|c|c|}
\hline TEST NAME & X84 (TONF/CM2) & X85 (TONF) & $\mathrm{X86}$ (CM2) & $\mathrm{X87}(\mathrm{CM})$ & X88 (TONF/CM2) & X89 (TONF) \\
\hline AOYAMA C2005-I & 0.00 & 0.00 & 0.00 & 0.00 & 0.00 & 0.00 \\
\hline AOYAMA C2005-II & 0.00 & 0.00 & 0.00 & 0.00 & 0.00 & 0.00 \\
\hline AOYAMA C2005-1II & 0.00 & 0.00 & 0.00 & 0.00 & 0.00 & 0.00 \\
\hline AOYAMA C2015-A & 0.00 & 0.00 & 0.00 & 0.00 & 0.00 & 0.00 \\
\hline AOYAMA C2015-B & 0.00 & 0.00 & 0.00 & 0.00 & 0.00 & 0.00 \\
\hline AOYAMA C2015-C & 0.00 & 0.00 & 0.00 & 0.00 & 0.00 & 0.00 \\
\hline AOYAMA P2005-A & 3.99 & 58.18 & 7.61 & 7.50 & 3.99 & 30.36 \\
\hline AOYAMA P2015-A & 3.62 & 52.79 & 7.61 & 7.50 & 3.62 & 27.54 \\
\hline AOYAMA C4015 & 0.00 & 0.00 & 0.00 & 0.00 & 0.00 & 0.00 \\
\hline AOYAMA P4015 & 3.62 & 48.20 & 7.61 & 7.50 & 3.62 & 27.54 \\
\hline AOYAMA M2005 & 0.00 & 0.00 & 0.00 & 0.00 & 0.00 & 0.00 \\
\hline AOYAMA CH 2015 & 0.00 & 0.00 & 0.00 & 0.00 & 0.00 & 0.00 \\
\hline AOYAMA CH2O18 & 0.00 & $0 . \infty$ & 0.00 & 0.00 & 0.00 & 0.00 \\
\hline AOYAMA OLU2015 & 0.00 & 0.00 & 0.00 & 0.00 & 0.00 & 0.00 \\
\hline KAHN SP1 & 4.49 & 35.06 & 4.26 & 22.86 & 4.49 & 19.12 \\
\hline KAHN SP2 & 0.00 & 0.00 & 0.00 & 0.00 & 0.00 & 0.00 \\
\hline KAHN SP3 & 0.00 & 0.00 & 0.00 & 0.00 & 0.00 & 0.00 \\
\hline KAHN SP5 & 0.00 & 0.00 & 0.00 & 0.00 & 0.00 & 0.00 \\
\hline HAYASHI-W1 & 0.00 & 0.00 & 0.00 & 0.00 & 0.00 & 0.00 \\
\hline HAYASHI-W2 & 3.55 & 31.95 & 5.06 & 6.00 & 3.55 & 17.97 \\
\hline HAYASHI-W4 & 0.00 & 0.00 & 0.00 & 0.00 & 0.00 & 0.00 \\
\hline HAYASHI-W5 & 0.00 & 0.00 & 0.00 & 0.00 & 0.00 & 0.00 \\
\hline HAYASHI-W6 & 0.00 & 0.00 & 0.00 & 0.00 & 0.00 & 0.00 \\
\hline SUGANO-WHA & 0.00 & 0.00 & 0.00 & 0.00 & 0.00 & 0.00 \\
\hline SUGANO-W4OS & 3.38 & 14.20 & 2.24 & 10.00 & 3.38 & 7.57 \\
\hline SUGANO-W4OW & 3.38 & 14.20 & 2.24 & 10.00 & 3.38 & 7.57 \\
\hline SUGANO-WBOS & 3.38 & 28.39 & 4.48 & 10.00 & 3.38 & 15.14 \\
\hline SUGANO-F & 0.00 & 0.00 & 0.00 & 0.00 & 0.00 & 0.00 \\
\hline SUGANO-WBL & 0.00 & 0.00 & 0.00 & 0.00 & 0.00 & 0.00 \\
\hline SUGANOWCO & 0.00 & 0.00 & 0.00 & 0.00 & 0.00 & 0.00 \\
\hline HIGASHI 1-F1 & 0.00 & 0.00 & 0.00 & 0.00 & 0.00 & 0.00 \\
\hline HIGASHI 2-PW & 0.00 & 0.00 & 0.00 & 0.00 & 0.00 & 0.00 \\
\hline HIGASHI 5-F2 & 0.00 & 0.00 & 0.00 & 0.00 & 0.00 & 0.00 \\
\hline HIGASHI13-FW & 3.96 & 13.81 & 2.22 & 15.00 & 3.96 & 8.79 \\
\hline HIGASHI 4-C3C & 0.00 & 0.00 & 0.00 & 0.00 & 0.00 & 0.00 \\
\hline HIGASHI 6-C2A & 0.00 & 0.00 & 0.00 & 0.00 & 0.00 & 0.00 \\
\hline HIGASHI 7-C2B & 0.00 & 0.00 & 0.00 & 0.00 & 0.00 & 0.00 \\
\hline HIGASHI 9-C40 & 0.00 & 0.00 & 0.00 & 0.00 & 0.00 & 0.00 \\
\hline HIGASHI 3-C3 & 0.00 & 0.00 & 0.00 & 0.00 & 0.00 & 0.00 \\
\hline HIGASHI 8-C4 & 0.00 & 0.00 & 0.00 & 0.00 & 0.00 & 0.00 \\
\hline CORLEY B5 & 4.53 & 25.35 & 25.47 & 10.16 & 4.53 & 115.28 \\
\hline CORLEY B6 & 4.49 & 25.15 & 25.47 & 10.16 & 4.49 & 114.39 \\
\hline CORLEY B7 & 4.67 & 26.13 & 25.47 & 10.16 & 4.67 & 118.86 \\
\hline CORLEY B8 & 4.56 & 25.54 & 25.47 & 10.16 & 4.56 & 116.18 \\
\hline CORLEY B9 & 4.38 & 24.52 & 25.47 & 10.16 & 4.38 & 111.52 \\
\hline CORLEY B11 & 4.44 & 24.88 & 25.47 & 10.16 & 4.44 & 113.14 \\
\hline OGATA K1 & 4.03 & 14.06 & 3.49 & 15.00 & 4.03 & 14.06 \\
\hline OGATA K2 & 4.03 & 28.12 & 6.97 & 15.00 & 4.03 & 28.12 \\
\hline OGATA K3 & 4.03 & 43.46 & 10.78 & 10.00 & 4.03 & 43.46 \\
\hline OGATA K4 & 4.03 & 43.46 & 10.78 & 10.00 & 4.03 & 43.46 \\
\hline OGATA K5 & 4.03 & 14.06 & 3.49 & 15.00 & 4.03 & 14.06 \\
\hline OGATA K6 & 4.03 & 21.73 & 5.39 & 15.00 & 4.03 & 21.73 \\
\hline GAYNOR F & 0.00 & 0.00 & 0.00 & 0.00 & 0.00 & 0.00 \\
\hline GAYNOR W & 0.00 & 0.00 & 0.00 & 0.00 & 0.00 & 0.00 \\
\hline GAYNOR D & 0.00 & 0.00 & 0.00 & 0.00 & 0.00 & 0.00 \\
\hline
\end{tabular}


APPENDIX B. (Continued)

\begin{tabular}{|c|c|c|c|c|}
\hline TEST NAME & $\mathrm{X} 90$ (CM2) & $\mathrm{X91}(\mathrm{CM})$ & X92 (TONF/CM2) & X93 (TONF) \\
\hline AOYAMA C2005-I & 0.00 & 0.00 & $\begin{array}{r}0.00 \\
\end{array}$ & 0.00 \\
\hline AOYAMA C2005-1I & 0.00 & 0.00 & 0.00 & 0.00 \\
\hline AOYAMA C2005-III & 0.00 & 0.00 & 0.00 & 0.00 \\
\hline AOYAMA C2015-A & 0.00 & 0.00 & 0.00 & 0.00 \\
\hline AOYAMA C2015-B & 0.00 & 0.00 & 0.00 & 0.00 \\
\hline AOYAMA C2015-C & 0.00 & 0.00 & 0.00 & 0.00 \\
\hline AOYAMA P2005-A & 7.61 & 7.50 & 3.99 & 30.36 \\
\hline AOYAMA P2015-A & 7.61 & 7.50 & 3.62 & 27.54 \\
\hline AOYAMA C4015 & 0.00 & 0.00 & 0.00 & 0.00 \\
\hline AOYAMA P4015 & 7.61 & 7.50 & 3.62 & 27.54 \\
\hline AOYAMA M2005 & 0.00 & 0.00 & 0.00 & 0.00 \\
\hline AOYAMA CH2O15 & 0.00 & 0.00 & 0.00 & 0.00 \\
\hline AOYAMA CH2018 & 0.00 & 0.00 & 0.00 & 0.00 \\
\hline AOYAMA OLU2015 & 0.00 & $=0.00$ & 0.00 & 0.00 \\
\hline KAHN SP1 & 4.26 & 22.86 & 4.49 & 19.12 \\
\hline KAHN SP2 & 0.00 & 0.00 & 0.00 & 0.00 \\
\hline KAHN SP3 & 0.00 & 0.00 & 0.00 & 0.00 \\
\hline KAHN SP5 & 0.00 & 0.00 & 0.00 & 0.00 \\
\hline HAYASHI-W1 & 0.00 & 0.00 & 0.00 & 0.00 \\
\hline HAYASHI-W2 & 5.06 & 6.00 & 3.55 & 17.97 \\
\hline HAYASHI-W4 & 0.00 & 0.00 & 0.00 & 0.00 \\
\hline HAYASHI-W5 & 0.00 & 0.00 & 0.00 & 0.00 \\
\hline HAYASHI-W6 & 0.00 & 0.00 & 0.00 & 0.00 \\
\hline SUGANO-WHA & 0.00 & 0.00 & 0.00 & 0.00 \\
\hline SUGANO-W4OS & 2.24 & 10.00 & 3.38 & 7.57 \\
\hline SUGANO-W4OW & 2.24 & 10.00 & 3.38 & 7.57 \\
\hline SUGANO-W8OS & 4.48 & 10.00 & 3.38 & 15.14 \\
\hline SUGANO-F & 0.00 & 0.00 & 0.00 & 0.00 \\
\hline SUGANO-WBL & 0.00 & 0.00 & 0.00 & 0.00 \\
\hline SUGANO-WCO & 0.00 & 0.00 & 0.00 & 0.00 \\
\hline HIGASHI 1-F1 & 0.00 & 0.00 & 0.00 & 0.00 \\
\hline HIGASHI 2-PW & 0.00 & 0.00 & 0.00 & 0.00 \\
\hline HIGASHI 5-F2 & 0.00 & 0.00 & 0.00 & 0.00 \\
\hline HIGASHI13-FW & 2.22 & 15.00 & 3.96 & 8.79 \\
\hline HIGASHI 4-C3C & 0.00 & 0.00 & 0.00 & 0.00 \\
\hline HIGASHI 6-C2A & 0.00 & 0.00 & 0.00 & 0.00 \\
\hline HIGASHI 7-C2B & 0.00 & 0.00 & 0.00 & 0.00 \\
\hline HIGASHI 9-C40 & 0.00 & 0.00 & 0.00 & 0.00 \\
\hline HIGASHI 3-C3 & 0.00 & 0.00 & 0.00 & 0.00 \\
\hline HIGASHI 8-C4 & 0.00 & 0.00 & 0.00 & 0.00 \\
\hline CORLEY B5 & 25.47 & 10.16 & 4.53 & 115.28 \\
\hline CORLEY B6 & 25.47 & 10.16 & 4.49 & 114.39 \\
\hline CORLEY B7 & 25.47 & 10.16 & 4.67 & 118.86 \\
\hline CORLEY B8 & 25.47 & 10.16 & 4.56 & 116.18 \\
\hline CORLEY B9 & 25.47 & 10.16 & 4.38 & 111.52 \\
\hline CORLEY B11 & 25.47 & 10.16 & 4.44 & 113.14 \\
\hline OGATA K1 & 3.49 & 15.00 & 4.03 & 14.06 \\
\hline OGATA K2 & 6.97 & 15.00 & 4.03 & 28.12 \\
\hline OGATA $\mathrm{K} 3$ & 10.78 & 10.00 & 4.03 & 43.46 \\
\hline OGATA K4 & 10.78 & 10.00 & 4.03 & 43.46 \\
\hline OGATA K5 & 3.49 & 15.00 & 4.03 & 14.06 \\
\hline OGATA K6 & 5.39 & 15.00 & 4.03 & 21.73 \\
\hline GAYNOR F & 0.00 & 0.00 & 0.00 & 0.00 \\
\hline GAYNOR W & 0.00 & 0.00 & 0.00 & 0.00 \\
\hline GAYNOR D & 0.00 & 0.00 & 0.00 & 0.00 \\
\hline
\end{tabular}




\section{APPENDIX C. Test Results and System Identification}
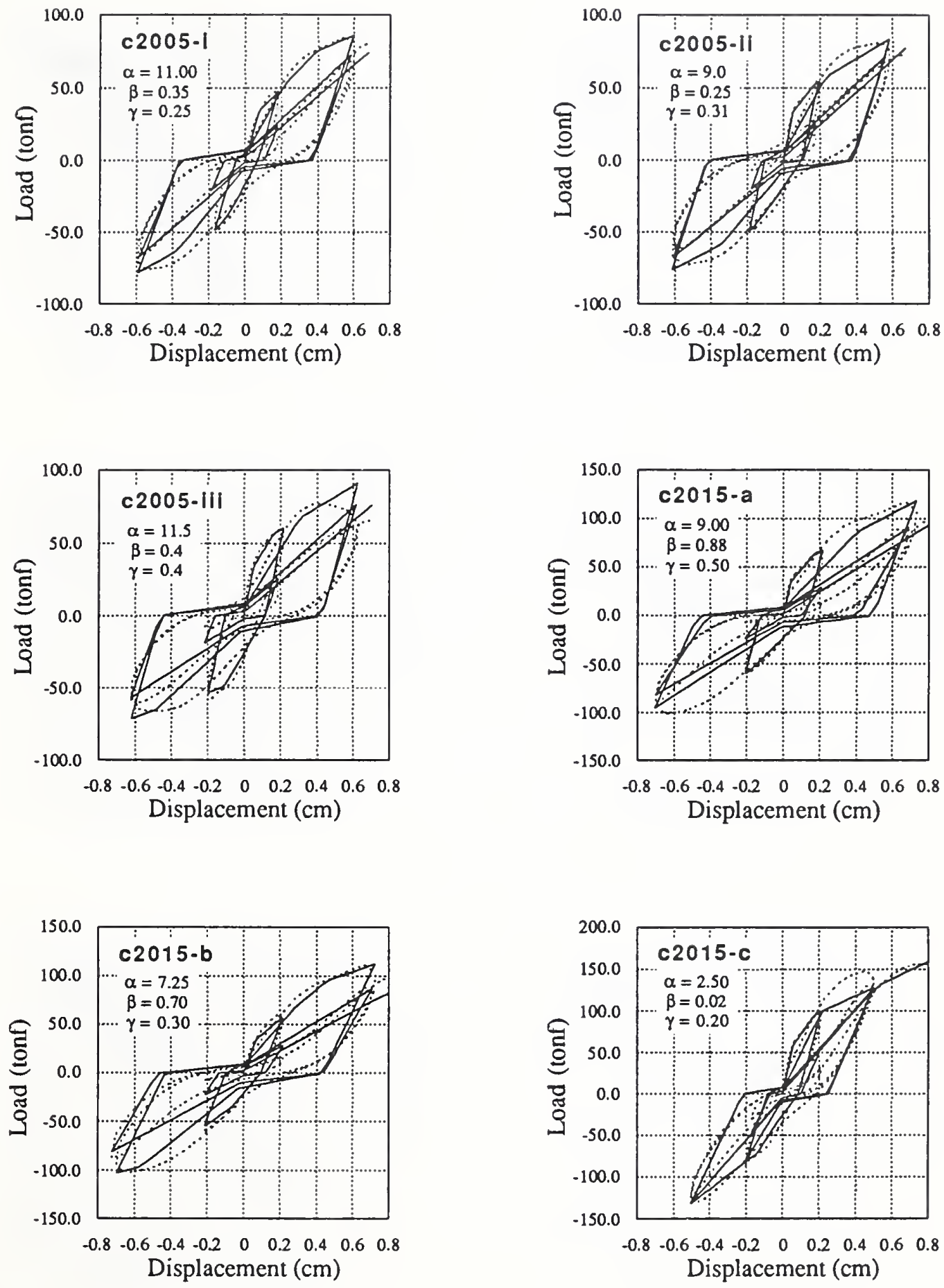


\section{APPENDIX C. (Continued)}
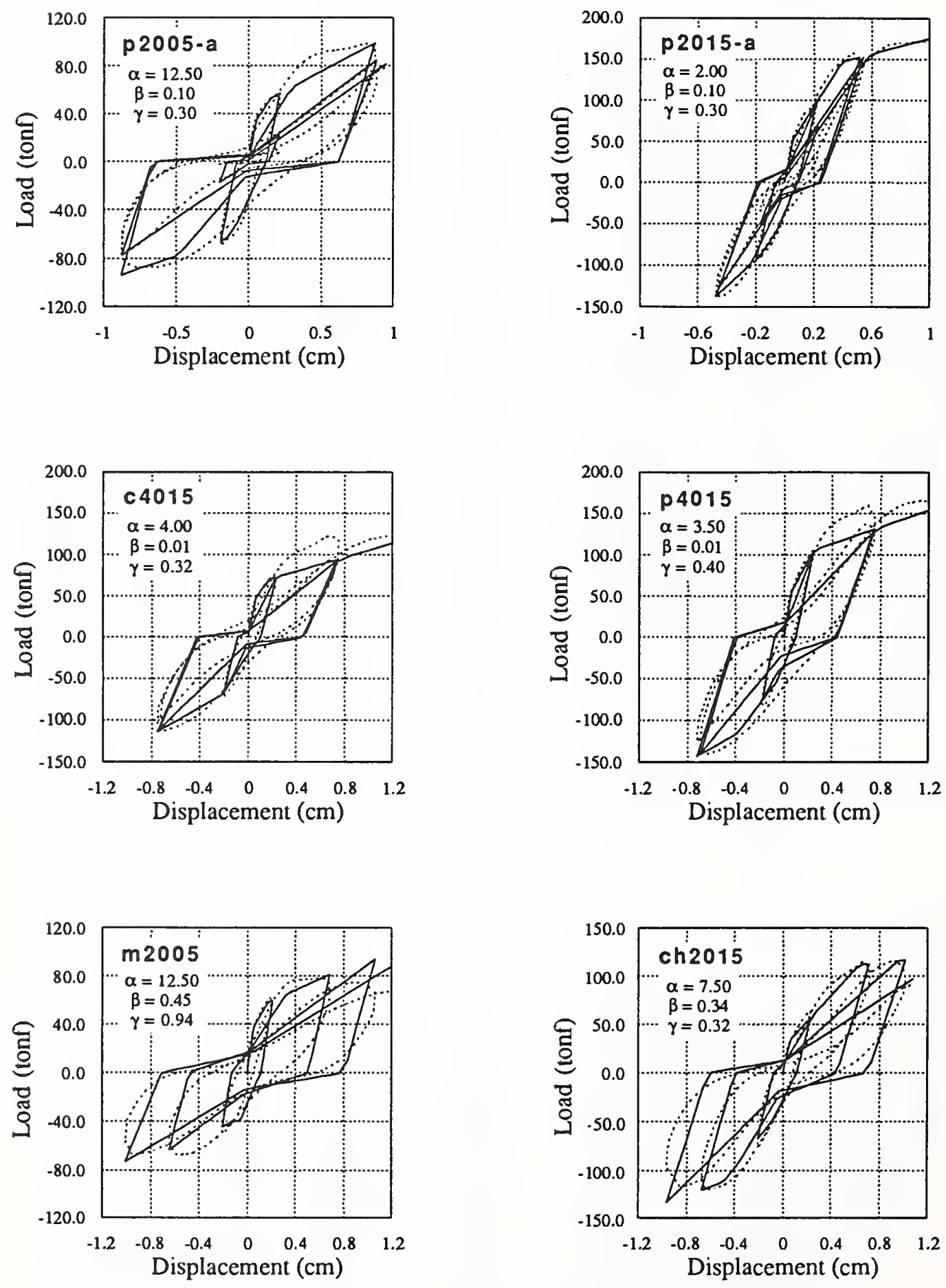

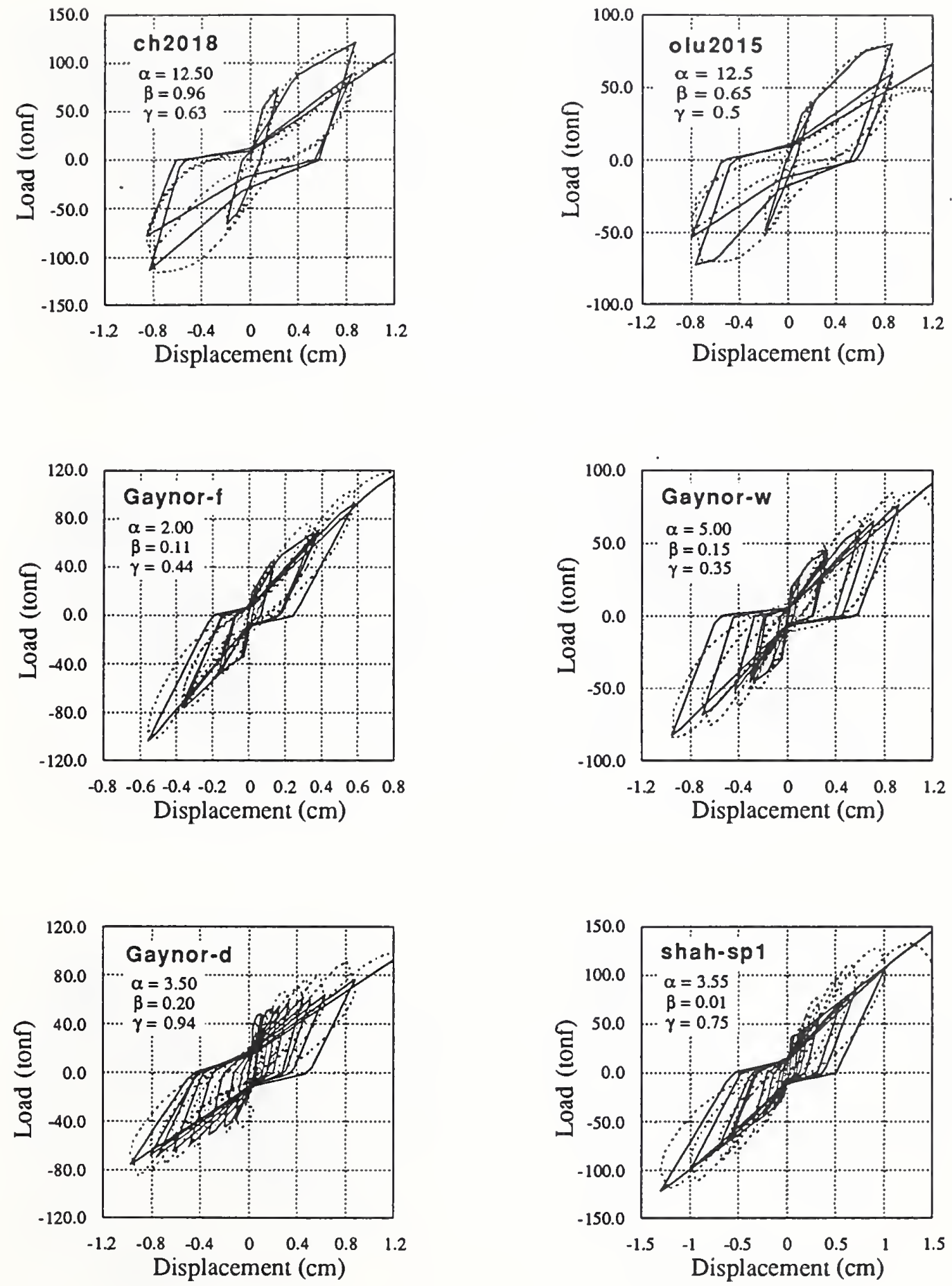


\section{APPENDIX C. (Continued)}
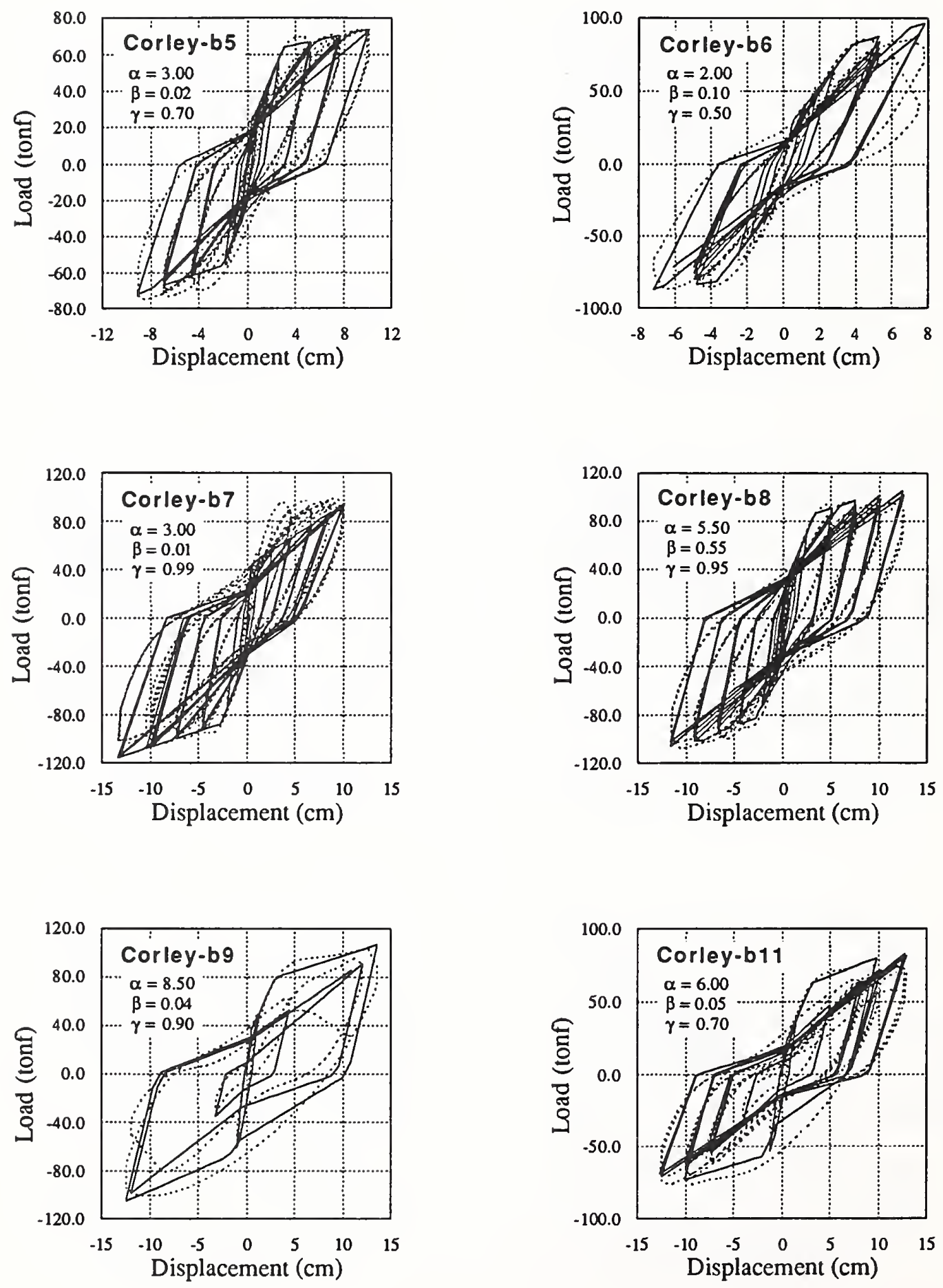


\section{APPENDIX C. (Continued)}
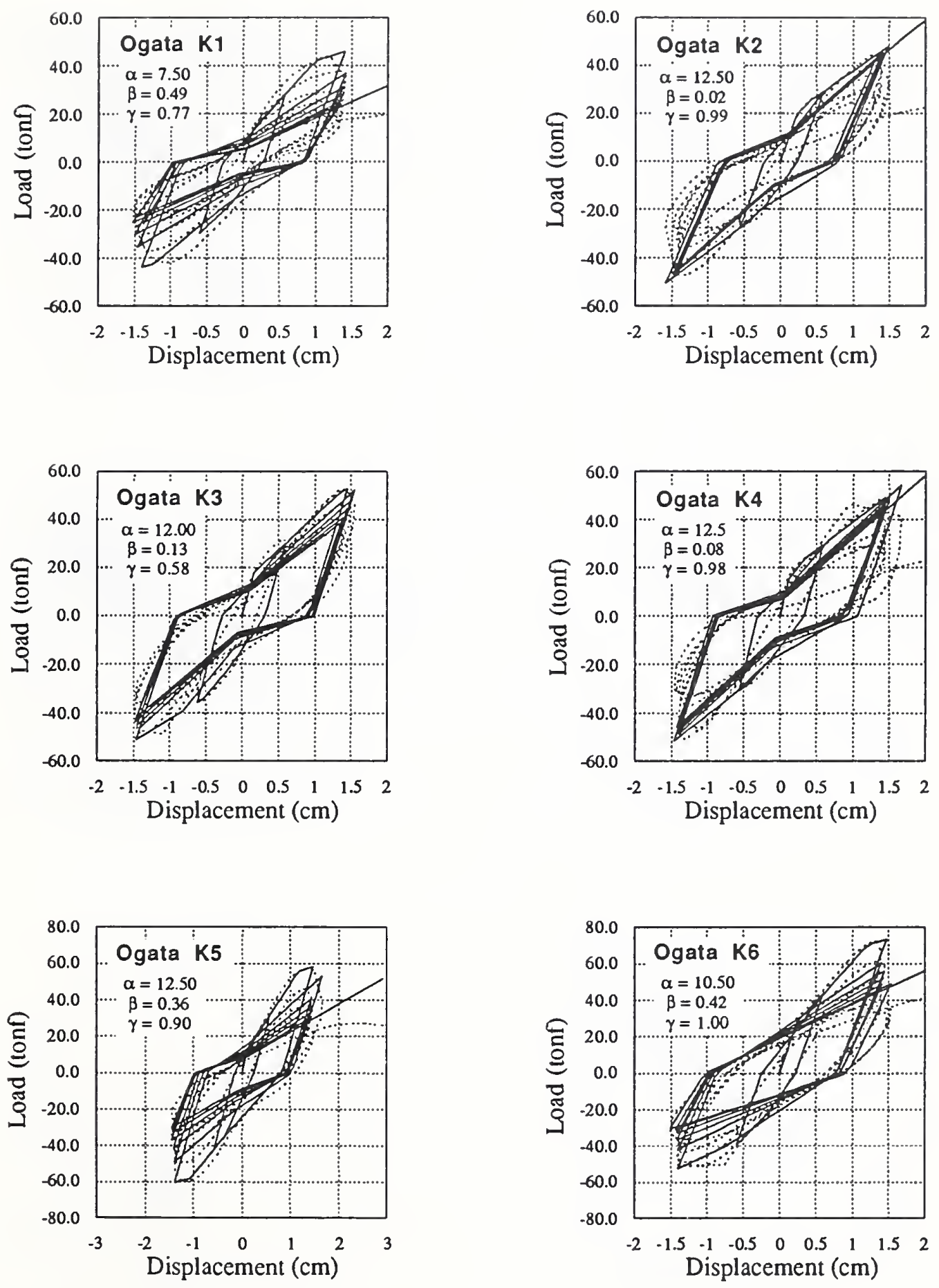


\section{APPENDIX C. (Continued)}
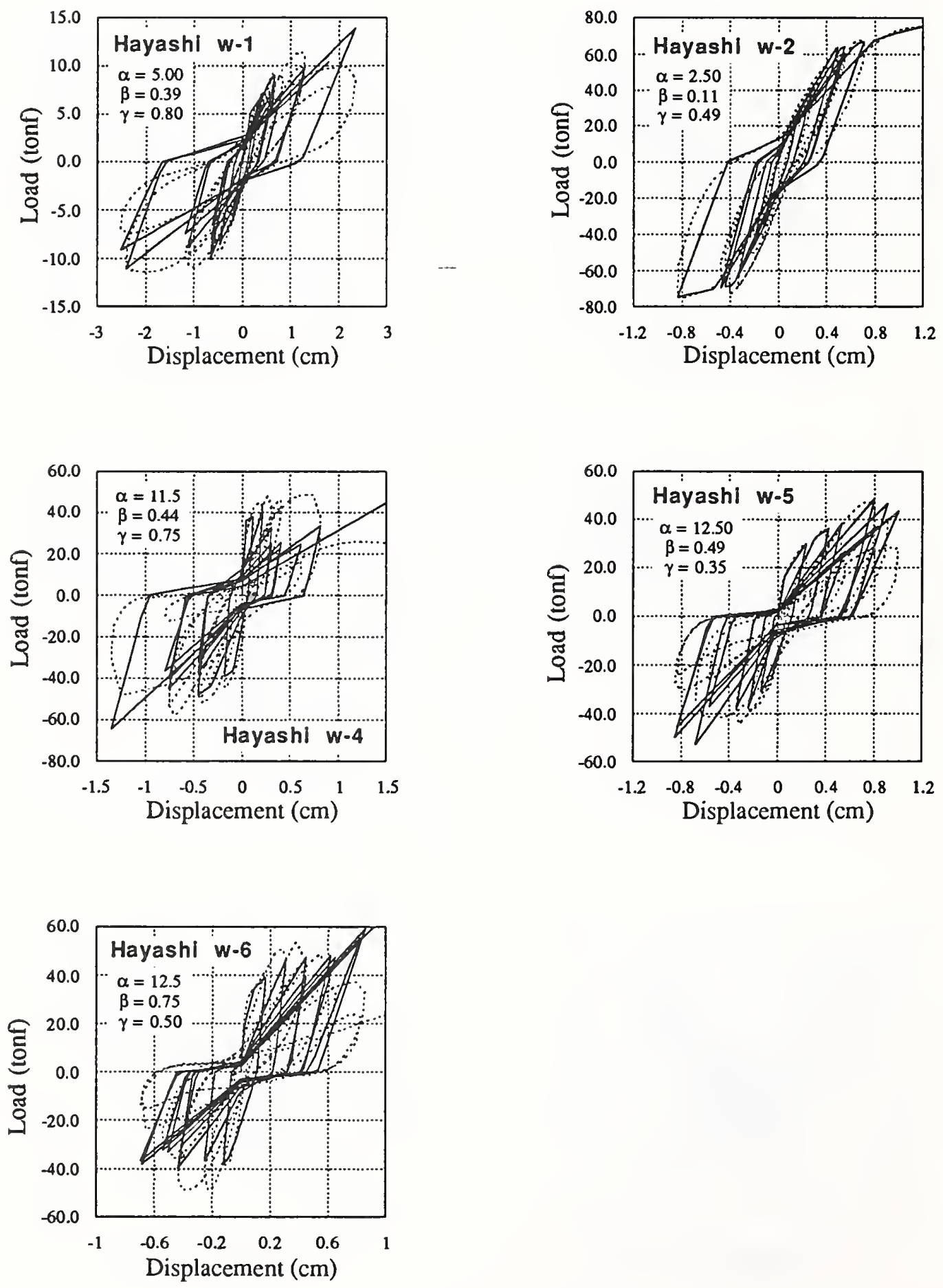


\section{APPENDIX C. (Continued)}
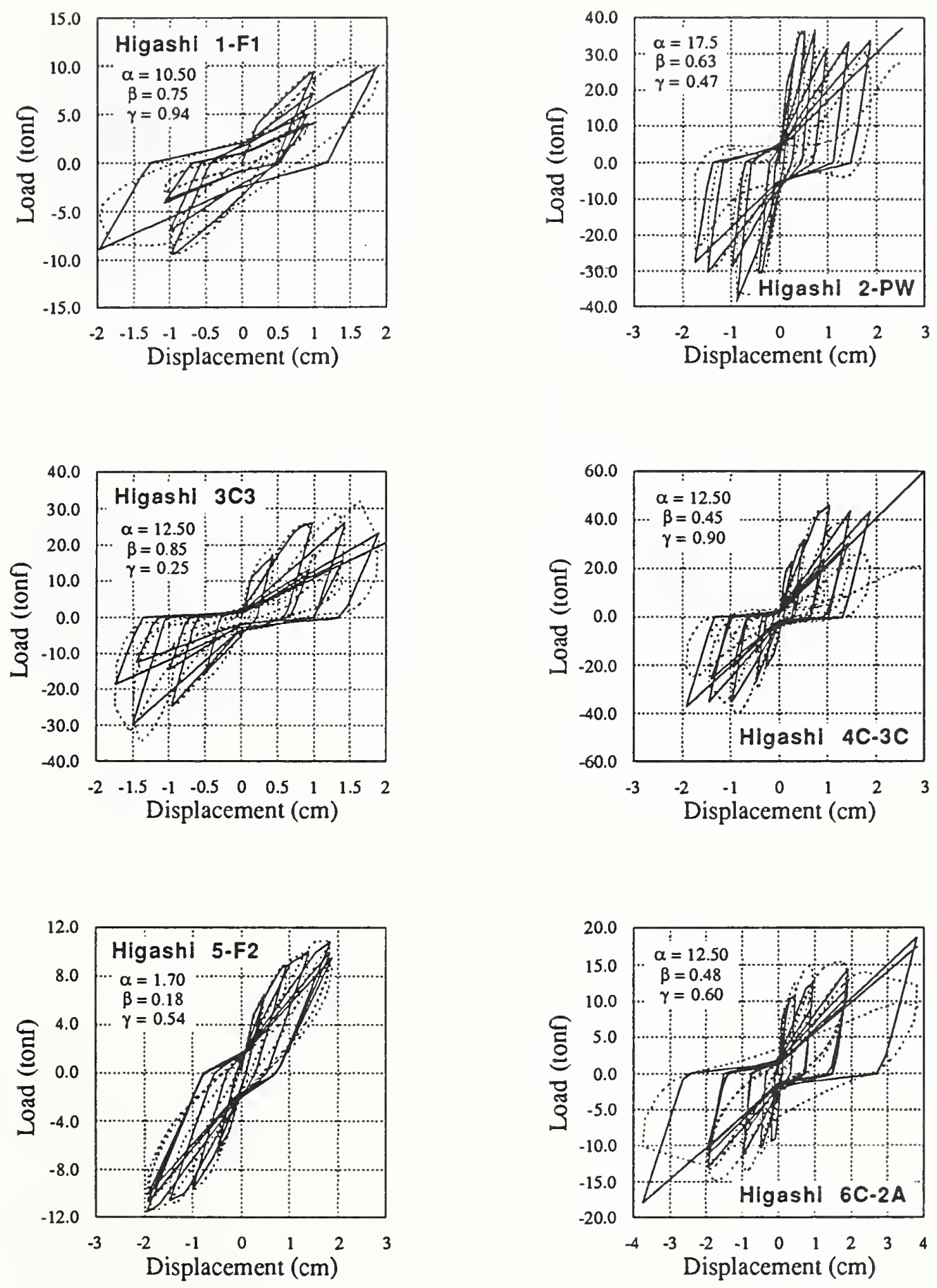


\section{APPENDIX C. (Continued)}
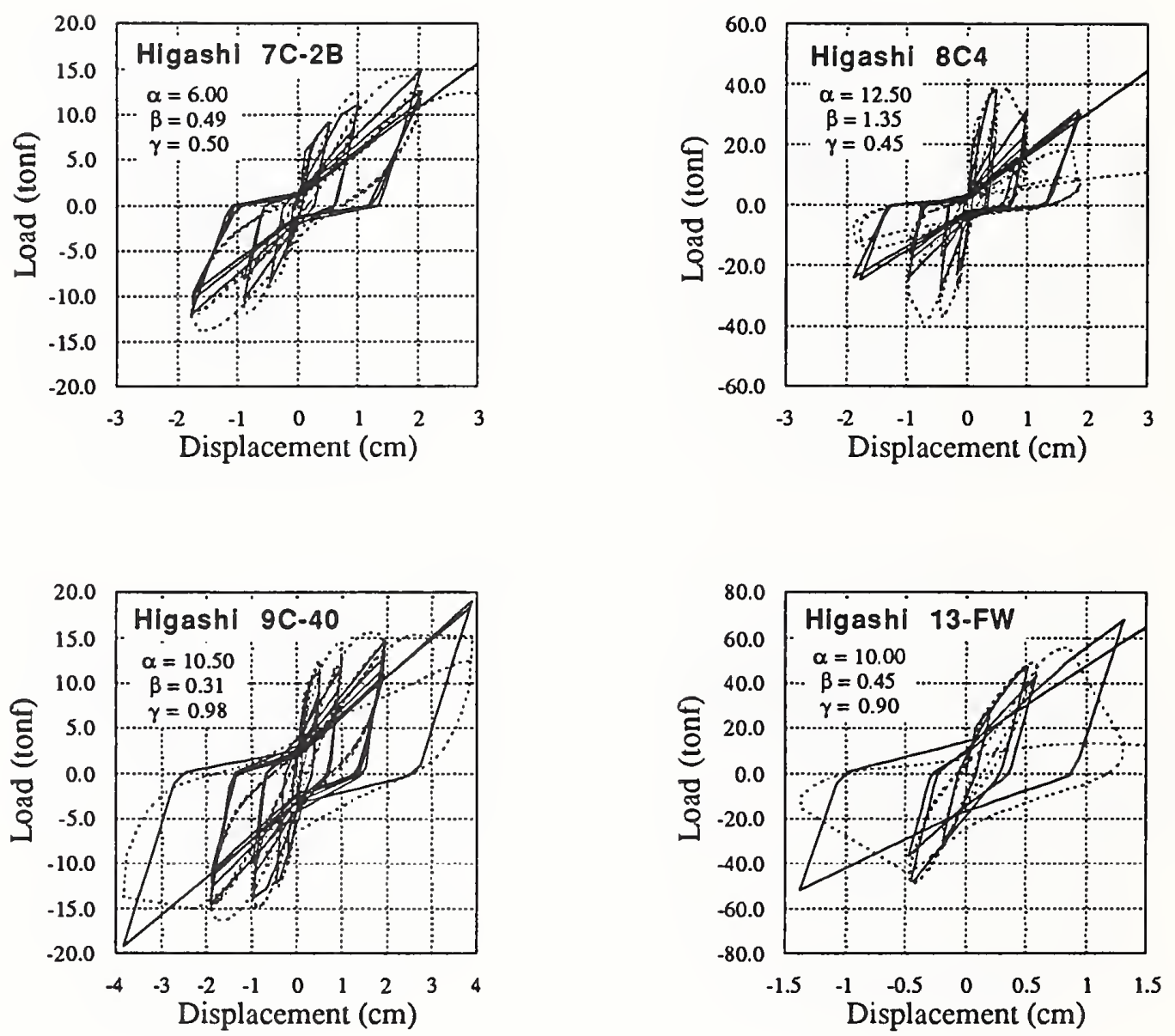


\section{APPENDIX C. (Continued)}
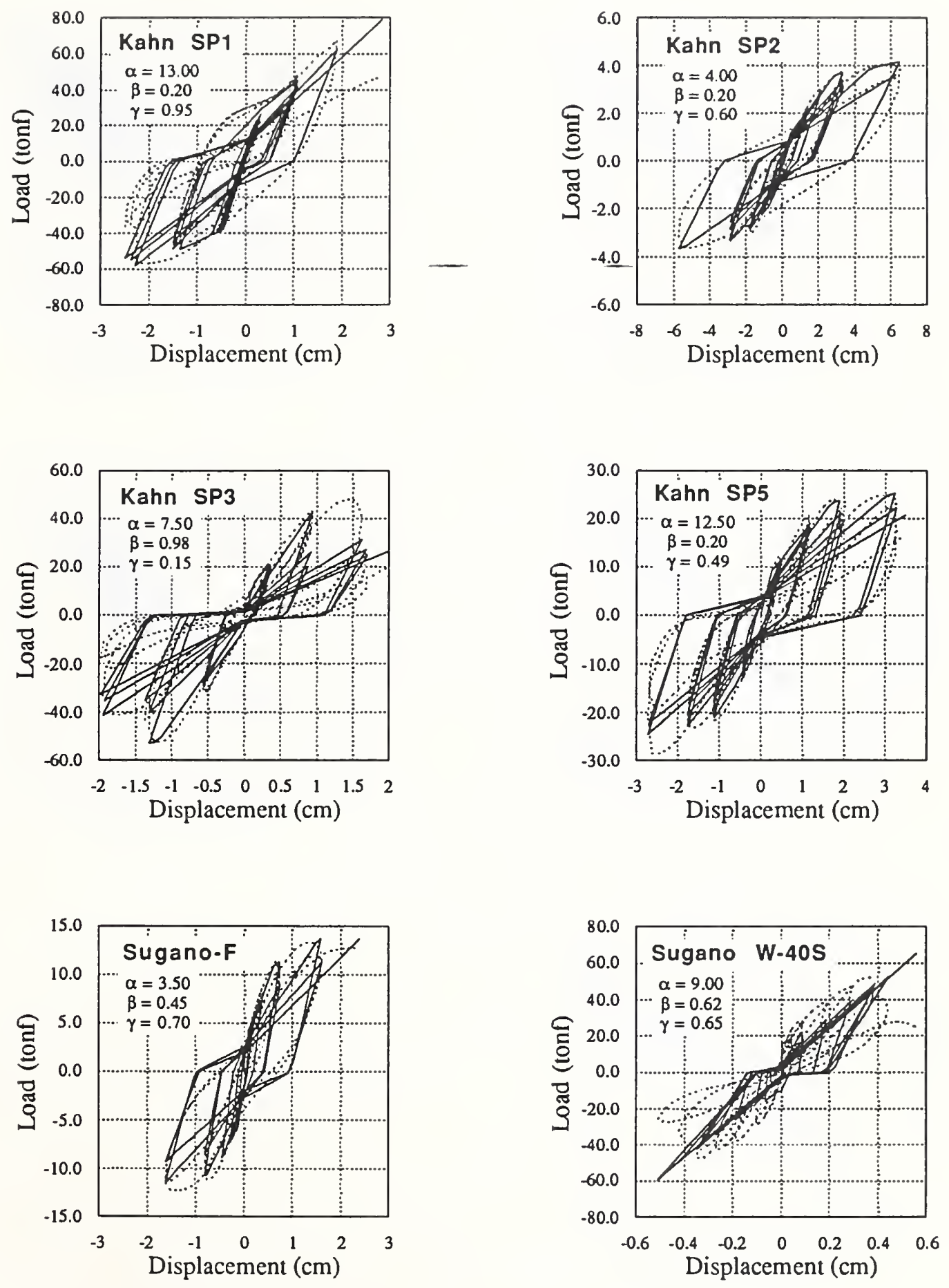


\section{APPENDIX C. (Continued)}
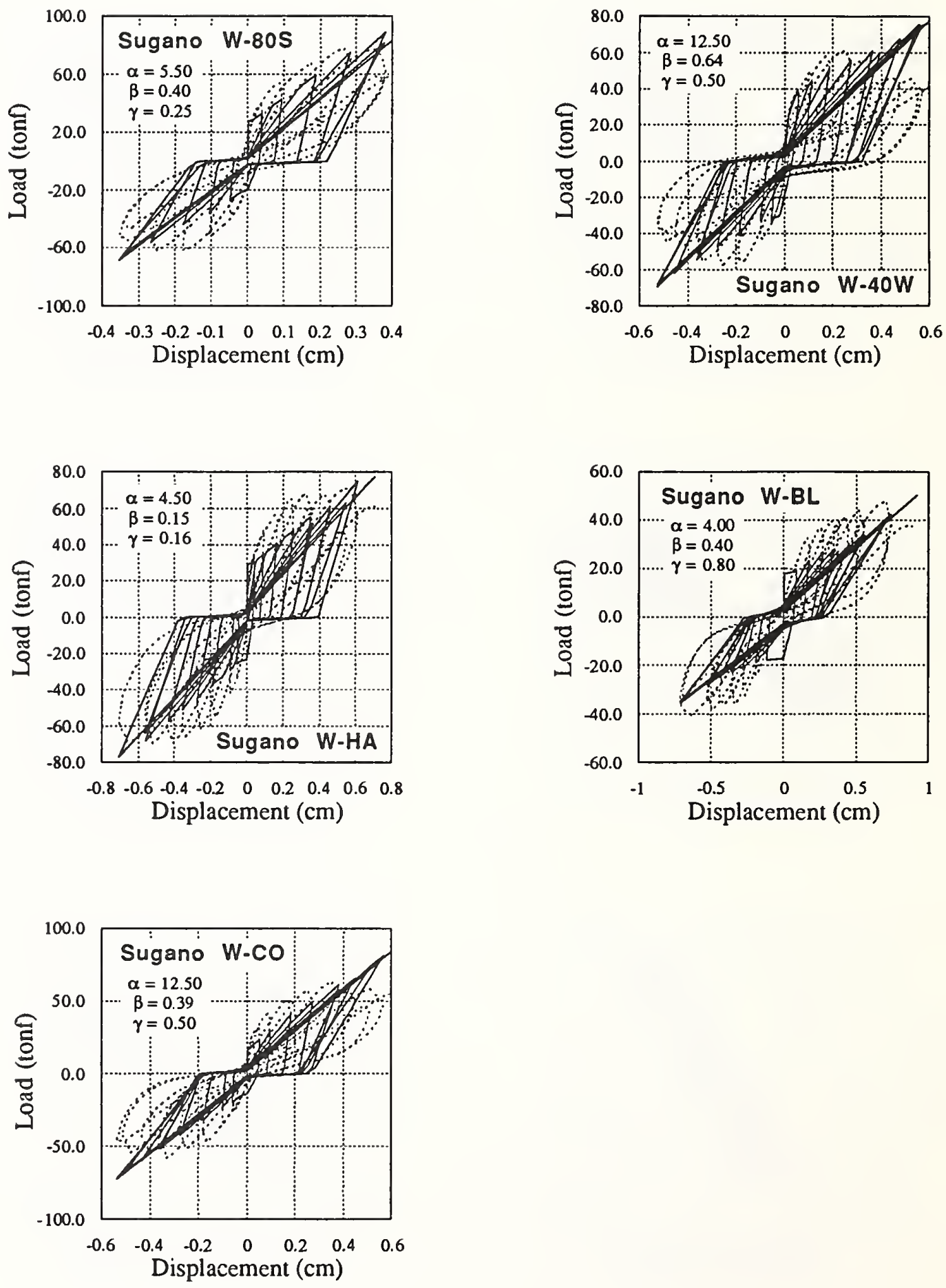

